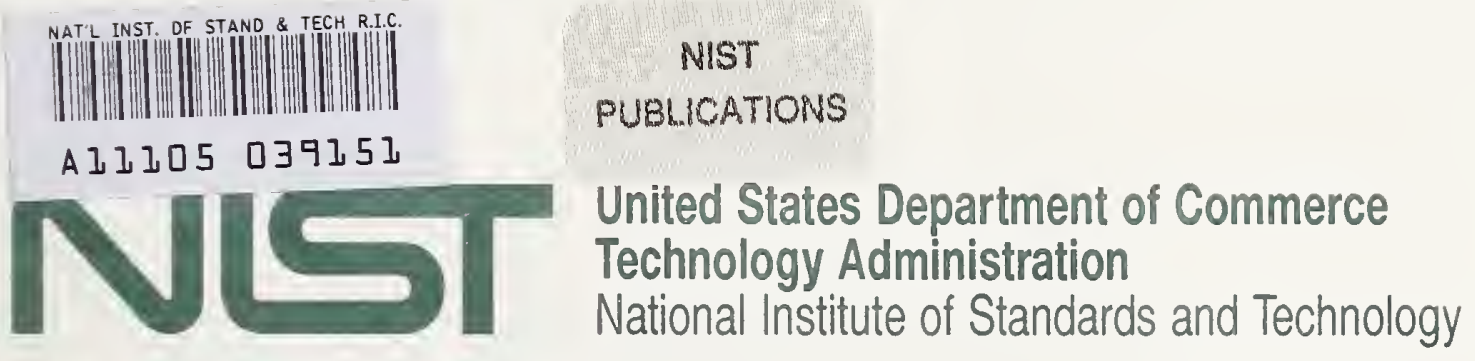

NIST Special Publication 908

\title{
Third International Green Building Conference and Exposition-1996
}

A. H. Fanney, P. R. Svincek, Editors 
4 


\section{NIST Special Publication 908}

\section{Third International Green Building Conference and Exposition-1996}

A. H. Fanney, P. R. Svincek, Editors

Building and Fire Research Laboratory

National Institute of Standards and Technology

Gaithersburg, MD 20899-0001

November 1996

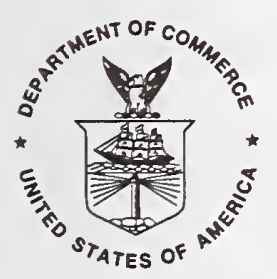

U.S. Department of Commerce

Michael Kantor, Secretary

Technology Administration

Mary L. Good, Under Secretary for Technology

National Institute of Standards and Technology

Arati Prabhakar, Director 
National Institute of Standards

and Technology

Special Publication 908

Natl. Inst. Stand. Technol.

Spec. Publ. 908

228 pages (Nov. 1996)

CODEN: NSPUE2
U.S. Government Printing Office

Washington: 1996

For sale by the Superintendent of Documents U.S. Government Printing Office Washington, DC 20402 


\section{PREFACE}

In 1993 , building construction and renovation activity exceeded $\$ 800$ billion, representing 13 percent of the United States' gross domestic product. The resources required to create, operate, and renovate buildings within the United States is enormous. As a means of reducing the impact that buildings have on the environment, the building industry is developing and marketing products and processes that are both environmentally and economically viable.

The primary objective of the Third Annual Green Building Conference and Trade Show is to provide a forum in which the latest information on sustainable practices, materials, and technologies can be presented. The conference was sponsored by the U.S. Green Building Council (USGBC), the National Institute of Standards and Technology, the American Institute of Architects, and the San Diego Gas and Electric Company. Cosponsors of this event were the American Society of Landscape Architects and the American Society of Interior Designers.

Sessions within the conference and corresponding papers within these proceedings focused on the following topics:

- The role of chief executive officers in bringing green products and services to market.

- A review of the U.S. Green Building Council's Leadership in Energy and Environmental Design Building Rating System.

- A review of the latest international green building projects including examples of commercial, industrial, historical, retail, office, academic, and residential projects.

- The selection of sustainable building materials.

- An overview of the latest practices in energy conservation.

- A world overview of solar photovoltaic components and systems.

- Commercial, residential, and legal indoor air quality issues.

- Design tools and resources that are applicable to green buildings including the Internet, 3D design visualization, computer simulations, and the Department of Energy's energy simulation programs.

- The implications of green buildings on the real estate, financial, and insurance industries.

Keynote addresses were presented by Richard Fedrizzi, USGBC Chairman and Director North American Operations (NAO) Environmental Marketing for United Technologies/Carrier Corporation, Thomas A. Page, Chairman of Enova Corporation and San Diego Gas \& Electric Company, Gail A. Lindsey, 1997 Chair of the American Institute of Architects Committee on the Environment, David A. Gottfried, Co-Founder and Vice Chairman of the USGBC and President of Gottfried Technology, Inc., and Ray C. Anderson, Chairman and CEO of Interface Inc. 


\begin{abstract}
This report constitutes the proceedings of the Green Building Conference held in San Diego, CA, November 17-19, 1996. The primary objective of the Third Annual Green Building Conference and Trade Show is to provide a forum in which the latest information on sustainable practices, materials, and technologies can be presented. The conference was sponsored by the U.S. Green Building Council, the National Institute of Standards and Technology, the American Society of Landscape Architects and the San Diego Gas and Electric Company. Cosponsors of this event were the American Institute of Architects and the American Society of Interior Designers.
\end{abstract}

Keywords: Building Technology; conference; green buildings; photovoltaics; sustainable material; 


\section{TABLE OF CONTENTS}

\section{PAPERS}

New Sustainable Mindset Needed

Diane R. Morrison .............................. 1

The Environment Studies Center at Oberlin College

William McDonough, Christopher Hays, Kevin Burke, Charles Rosenblum,

Michael Shaw, David Orr, John Lyle and Brad Masi .............. 5

Patagonia Distribution Center: Valuing Direct and Indirect Benefits

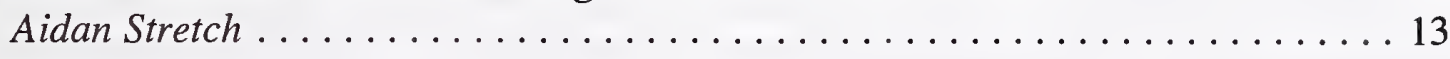

How Rather Than What: Environmentally Responsible Building Design

Raymond J. Cole ................................. 15

The Queens Building at de Montfort University, Leicester, UK

C. Alan Short ............................... 23

Environmental Responsibility at the Jean-Michel Cousteau Fiji Islands Resort

Richard C. Murphy ................................ 37

Ridgehaven Green Building Demonstration Project

Charles Angyal

Building Duracell's New Corporate Headquarters-An Environmental Success Story Glenn R. Machemer . . . . . . . . . . . . . . . . . . . . . . . . . . . 49

Protocol Development for Assessing the Ancillary Benefits of Green Buildings:

A Case Study Using the MSQA Building

James A. Wise, Judith Heerwagen, David B. Lantrip and Michael Ivanovich . . . 63

Greening the Presidio: A Case Study of the Thoreau Center for Sustainability

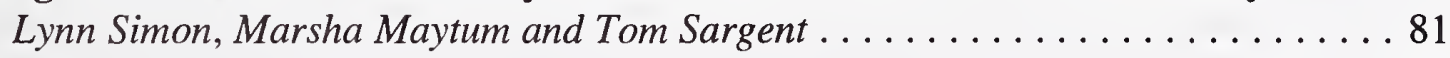

Civano Village

John Laswick . . . . . . . . . . . . . . . . . . . . . . . . . . . . 99

A Simplified Environmental Screening Method for Building Materials

Alex Wilson and Nadav Malin ........................... 101 
An Overview of Worldwide Development Activity in Building-Integrated Photovoltaics

Steven Strong . . . . . . . . . . . . . . . . . . . . . . . . 109

Best Sustainable Indoor Air Quality Practices in Commercial Buildings

Hal Levin ................................. 135

Improving Indoor Air Quality in Residences - A Systems Approach

Subrato Chandra, David Beal and Andrew Downing ................ 159

Interoperable, Life Cycle Tools for Assuring Building Performance:

An Overview of a New Commercial Building Initiative

Stephen Selkowitz............................ 173

Digital Perspectives in Architecture

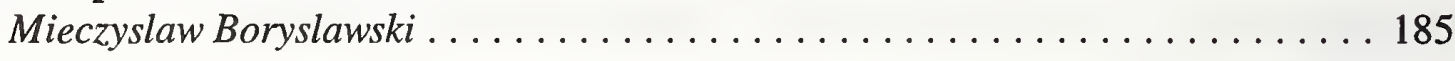

The NARM Sustainability Model: Dynamic Aids for Ecological Design and

Sustainable Communities

David A. Tice . . . . . . . . . . . . . . . . . . . . . . . . . . . . 189

Vertical Integration - The Key to Creating Optimum Real Estate Environments

Kevork M. Derderian ................................ 201

The Science and Art of "Daylighting" - Bringing Natures Light Inside

Phillipe C. Dordai .................................... 213 


\title{
NEW SUSTAINABLE MINDSET NEEDED
}

\author{
Diane R. Morrison \\ Energy Resource Center Manager \\ Southern California Gas Company \\ 9240 E. Firestone Blvd. \\ Downey, CA 90241-5388
}

Abstract. Southern California Gas Company's Energy Resource Center (ERC) is designed with the dual purpose of being a living model of advanced, energy-efficient and environmentally sensitive building technology, showcasing innovations in resource-efficient designs, materials and equipment, and in addition, providing a resource for thousands of businesses throughout southern California to help them make informed choices about their energy use. The 45,000square-foot structure includes an 10,000-square-foot exhibit hall that can accommodate groups of up to 500 people, along with numerous specialty rooms, each of which highlights a different energy and environmental theme, such as air quality, combustion, clean fuel transportation, etc. The center also provides technical assistance, computerized equipment simulations, state-of-theart audio-visual facilities and air quality and environmental permitting assistance.

\section{Shattering Paradigms}

Forget everything you ever thought was true or untrue about constructing and operating buildings, particularly the large ones where we work. In other words, please read the rest of this essay with an open mind.

The motivator is twofold: money and piece of mind.

What our society needs to do is begin to view buildings as changeable, and not static, structures on our landscape. Next, we need to really believe that it's possible to improve profits, the environment and employee productivity. If we can turn that mental corner, we will be well on our way to understanding and beginning to apply some aspect of "sustainable design."

Our social commentators have coined a phrase for it: "green" building. That was originally meant to capture the environmental acceptability of certain projects. But in sustainable design it goes further to mean "green," as in money saved from various energy-saving features and efficiency gains. From the business or facility operator's perspective, sustainable design offers a means of leveraging a firm's resources.

With competitiveness and operating efficiencies being critical elements in all parts of society today, sustainable design is a tool with potential interest and use for literally everyone-consumers, businesses, communities and governments. The reason: it provides some meaningful hope that society will be able to do something about the historic conflict between economic progress and environmental safeguards. 
Simply described, to design and build in a sustainable manner means to carefully recycle and reuse as much of existing buildings as possible, and in the new and remodeled mixture build in energy-savings and environmental sensitivity, so that with proper maintenance a structure can cost less in terms of both money and finite resources. The key is recognizing and maximizing the complex interconnectedness of building materials, techniques, design, natural daylighting and artificial light, heating, cooling and ventilation systems and the computerized controls linking all of these elements.

Buildings in this context become complex and powerful. They are not just inanimate objects; they can be shaped and changed on an ongoing basis.

- For consumers, that means buildings can add value in several ways:

(a) adapting to customer and employee needs, (b) stimulating a healthy economy and (c) building a healthier environment for present and future generations.

- For businesses, who must increasingly squeeze new savings and efficiencies out of their operations, the techniques of sustainable design can help drive down one of the biggest portions of their operating costs: energy and staffing to manage its use.

- For communities, if planning and political leaders can get in back of sustainable design as a socio-economic tool, it offers the possibility of creating jobs, rejuvenating neighborhoods and husbanding resources.

- Finally, for governmental leaders, here is a tool waiting to be tried. We have had "enterprise zones" and other model areas over the past decades, offering hope in renewing areas that had been written-off as hopeless. Now, there is a realistic way to rebuild aging building stock and do it responsibly.

Recycling already is one of the fastest growing business segments in the U. S. and other parts of the industrial world. Good business sense drives it. Technology in terms of lighting and mechanical systems in buildings continues to improve. It is like a dream come true for both the builders and the environmentalists.

Architects and builders are getting increasingly more interested in sustainable design because it takes advantage of existing resources and techniques. It also brings together everyone connected with the building construction process and adds a couple of new people: environmentalists and so-called "commissioning agents" to make sure buildings operate as efficiently as they are designed to do.

In southern California, a recent example of this comprehensive approach to energy and environmental concerns is found in the new Energy Resource Center (ERC), Downey, CA, a 45,000-square-foot energy/environmental education/convocation/demonstration center. The structure was created from an original, 1950s-vintage utility office structure that was single story and 35,000 square feet. A middle one-third of the old building was replaced by a two-story section that contains a main hall and lobby areas, with operating office space placed above it. Everything from the finishes to the glazing to the mechanical equipment is carefully coordinated to save energy and be environmentally sensitive. 
The center's architect, Larry Wolff, founder and principal of WLC Architects, Inc., Rancho Cucamonga, CA, calls it "a premium case study of the adaptive reuse of an existing, underutilized facility. It confirms the feasibility of converting existing building and land developments into valuable and efficient facilities that begin to solve critical issues for global sustainability." (Note: Wolff's 1996 master's thesis at California Polytechnic State University, San Luis Obispo, "An Executive Design Process for Transforming a Client Strategy into a Building Design," used the ERC as a major case study. It also was selected as Cal Poly, SLO's outstanding thesis for 1996.)

As part of the lessons for energy decision-makers who use the center to follow the ERC's approach included "source reduction," eliminating the need to use resources or have to recycle them, in addition to the recycling and re-use of materials.

In its total planning and collaborative approach, the systems and materials applied in the ERC were aimed at optimizing indoor environmental quality. Detailed efforts were made to minimize the use of products containing toxics and to make the best use of the fresh air available in energy efficient ventilation systems. Gases given off by traditional carpet and construction adhesives were kept to absolute minimums. 



\section{THE ENVIRONMENTAL STUDIES CENTER AT OBERLIN COLLEGE}

\section{Oberlin College}

David Orr, Program Chair of Environmental Studies Program

Brad Masi, Oberlin Project Coordinator

William McDonough + Partners

William McDonough, Partner-in-Charge

Christopher Hays, Design Partner

Kevin Burke, Project Manager

Charles Rosenblum, Public Relations Coordinator

California State Polytechnic University, Pomona

John Lyle, Professor and Landscape Architect

Living Technologies

Michael Shaw, Ecological Engineer

Abstract. The Environmental Studies Center will be a highly visible model of ecological design in a 14,000 square foot, zero emissions facility that meets advanced criteria for energy and materials efficiency, use of recycled materials, biological and wastewater treatment systems, solar and wind energy, and ecological landscaping. The Center will promote the development of collaborative, integrative research projects between different departments on campus and parallel efforts in the community. This calls for a series of spaces where groups of various sizes and functions can meet both privately and publicly, a resource center, and display and presentation space.

\section{The Challenge: Ecological Design and the Environmental Studies Center}

"We must create a facility that takes less from the environment, gives more to the people, reveals the qualities of our place and empowers us as a community to address proactively today's environmental challenge."

David W. Orr

"Living in sustainable architecture is nothing less than an appeal to accept our place in the world, mediated between human and natural purposes."

The Hannover Principles-Design for Sustainability. William McDonough Architects, 1992, p. 11.

As the architects selected to lead the design of the new Environmental Studies Center ("ESC"), William McDonough + Partners have been challenged by Oberlin College to develop nothing less than the most inspirational campus building of its time. The ESC, through its synthesis of building and landscape, serves as a signal of hope for the future of intelligent ecological design. 
The design for the ESC is both "restorative" and "regenerative". It seeks to move beyond "ecoefficiency" and its emphasis upon minimizing waste and inefficiency. Instead, the project addresses how fundamental design assumptions must be considered in the future, to begin to restore the environmental stresses brought on by the industrial revolution. To this end, we have considered how the building can be fecund, like a tree, accruing solar income to the benefit of living systems. Or how the entire project can act like healthy soil, absorbing water quickly and releasing it slowly in a healthy state.

We seek to eliminate the concept of waste in the ESC, following nature's fundamental principle that "waste equals food". ${ }^{1}$ This principle is applied to all of the ESC's building systems, incorporating the material typologies of "products of consumption" ${ }^{\mathrm{TM}}$ and "products of service $^{\text {"TM }}$ ?

As part of the biological "consumable" nutrient cycle, the overall building fabric is designed to return to the soil safely. The "technical" nutrient cycle includes interior fittings, mechanical systems, and photovoltaic panels. These "products of service,"TM are continuously owned and recycled by the manufacturer, and leased to Oberlin College. This typology enhances the building's flexibility over time, allowing technical systems to be updated and replaced as technologies change. ${ }^{3}$

The Environmental Studies Center is an urbane addition to the architectural heritage of Oberlin College, linking environmental conscience with enduring architectural design principles. The building's form, scale, and proportion make direct reference to the built legacy of the Oberlin campus. Its response to local climate builds upon the traditions of regional architecture in northern Ohio.

At its most fundamental level, the Center is a place of wonder and beauty which celebrates the interaction of human and natural environments. Because we believe that people would rather spend their day outdoors, the design of the ESC blurs the distinction between indoors and outdoors. Spaces are filled with daylight and are naturally ventilated. And the light-filled, twostory atrium provides the campus with a winter garden, an interior meeting place warmed by the sun for formal and informal gatherings throughout the year.

The design of the Environmental Studies Center represents a collaborative and cooperative effort on the part of the leading thinkers of the ecological design community, working closely with Oberlin College. This paper outlines the process of giving form to the highest ideals of ecological design.

\section{Education and Ecological Literacy}

From a variety of indicators measuring emission of greenhouse gases, soil loss, rates of species extinction, human appropriation of photosynthesis, release of toxins and heavy metals, and population growth, it is increasingly clear that the quality of the human future is directly related to our ability to reduce the fossil energy, water, materials, land, and waste absorptive capacity 
believed to be necessary to a good life. By one estimate, extension of current U.S. lifestyles to all of the 5.7 billion persons now living on the earth would require the land and resources of two more earths.

Fortunately, the knowledge necessary to reduce the environmental impacts of development is growing rapidly in areas such as energy technology, automotive design, industrial ecology, sustainable agriculture, restoration ecology, ecological engineering, and architectural design. In other words, we have the tools to develop the ecological design competence necessary to make things that fit in a world of trees, microbes, rivers, animals, bugs, and small children. Ecological design is the careful meshing of human purposes with the larger patterns and flows of the natural world and the study of those patterns and flows to inform human purposes. Ecological design competence means maximizing resource and energy efficiency, taking advantage of the free services of nature, recycling wastes, making ecologically smarter things, and educating ecologically smarter people.

Ecological design requires the ability to comprehend patterns that connect, which means getting beyond the boxes that we call disciplines to see things in their ecological context. It requires, in other words, a liberal education, but nearly everywhere the liberal arts have tended to become more specialized and narrow. Design competence requires the integration of first-hand experience and practical competence with theoretical knowledge, but the liberal arts have become more abstract, fragmented, and remote from lived reality. Design competence requires us to be students of the natural world, but the study of nature is being displaced by the effort to engineer nature to fit the economy instead of the other way around.

It is essential that we educate a citizen constituency that supports change and is competent to do the local work of rebuilding households, farms, institutions, communities, corporations, and economies that 1) do not emit carbon dioxide or other heat-trapping gases; 2) do not reduce biological diversity; 3) use energy, materials, and water with high efficiency; and 4) recycle wastes. In other words, a constituency that is capable of building economies that can be sustained without further reducing the earth's potential to sustain life. At a minimum this will require a modification of the skills, aptitudes, abilities, and curriculum by which we have learned how to industrialize the earth.

This project aims to equip the Environmental Studies Program with resources and capabilities essential to meet growing student interests and to fulfill our own obligations to equip students with the know-how and know-why necessary to:

- use energy and materials with great efficiency

- $\quad$ prevent pollution and eliminate waste

- $\quad$ power civilization on sunshine

- manage forests and soils sustainably

- $\quad$ restore degraded ecologies

- $\quad$ preserve species and entire ecosystems

- stabilize and then reduce population

- develop economies that can be sustained and regenerated within the limits of nature 
to do all of these things while preserving cultural diversity and enabling the poor and disadvantaged to improve their lives

To do so requires understanding how to integrate knowledge from different disciplines and different cultural traditions, comprehend the way complex systems work, and master the emerging field of ecological design.

The crisis of the biosphere is symptomatic of a prior crisis of the mind, perception, and heart. It is not so much a problem in education, but a problem of education.

\section{Building Design and the Oberlin Campus}

The Environmental Studies Center (ESC) building design combines the architectural traditions of the Oberlin campus with a fundamental understanding of natural energy systems. Oberlin's architectural character stems from the consistent qualities of many of its buildings: moderatelyscaled rectangular pavilions which share similar proportions, cornice-lines, and materials. They are also carefully sited in deference to the campus as a whole. By adhering to these precedents, the ESC will establish itself architecturally as a member of the Oberlin community. It will extend the college's architectural fabric of human scale and accessibility.

The building's disposition of spaces comes from an analysis of natural energy flows and the building's energy needs. The atrium will be the primary organizing feature of the building because it optimizes the possibilities for air circulation, insulation, and daylighting. The floors will form a modified U-shape around a central, multi-story space. This basic building form is almost as old as architecture itself. Placement of specific rooms will be related to solar orientation. The Living Machine, the natural wastewater treatment facility, will have both southern and eastern exposures to light. Workspaces and classrooms will face south and west also to take advantage of daylight and heat gain. In the absence of direct sunlight, the northern face of the building will be shielded from prevailing winds by an amphitheater and earth berm. The north-facing auditorium will be well-insulated by the amphitheater and berm overhead.

The roof shape, with a strong projecting cornice similar to many buildings on the Oberlin campus, will also have active and passive solar attributes. The three hip roofs will maximize south-facing surfaces for photovoltaic panels which will be used as a primary energy source. Skylights designed into much of the north-facing slopes will take advantage of the consistency and lack of glare of northern light.

These variations and innovations in the roof and wall treatments will acknowledge the emerging technologies and values of sustainable architecture, while making a place for them at Oberlin College. 


\section{Building Systems}

"Eliminate the concept of waste. Evaluate and optimize the full life-cycle of products and processes, to approach the state of natural systems, in which there is no waste."

William McDonough, The Hannover Principles, p.5.

Buildings must eliminate waste by adopting the principle that waste equals food and by optimizing the use of current solar income. Most buildings are designed with no thought of what becomes of their materials if they require replacement or if the building's useful life ever ends. In the ESC, all building components and systems are designed to be biodegradable, recyclable or reusable. Instead of becoming waste, they become raw materials for ecological systems or manufacturing processes. Similarly, the building makes maximum use of current solar income and natural energy flows, rather than relying upon inefficient mechanical systems. In both cases, the results are ecological and economic savings. Furthermore, these transformations are crucial in the ultimate development of a net energy surplus and the ability to inhabit buildings sustainably.

To eliminate material waste, the ESC is being designed as a hybrid of natural and man-made systems, categorized as either consumables or products of service. Consumables are goods or materials that can be decomposed after their use, becoming nutrients for other living organisms. At the ESC, the wooden post and beam frame and straw bale insulation will return to the earth if the building's useful life ever ends. Other building systems, as products of service, are removable, able to be sent back to their manufacturers for refurbishing or recycling. The exterior wall system is a rain screen of terra cotta panels in aluminum frames which are demountable for repair or replacement, as are both interior and exterior light shelves and shades. An underfloor system for displacement air delivery and electrical wiring accommodates changes in these components without requiring wholesale replacement. Flooring consists of carpet squares that can be removed individually and returned directly to the manufacturer for recycling. All material, finishes, and systems for the building are being carefully considered, particularly in terms of embodied energy, life-cycle costs, and toxicity.

Toward the goal of being a net energy exporter, the ESC design maximizes the use of current solar income through the use of massive walls, a glass membrane, and a thermal storage system. The building's southern orientation along the east-west axis and its organization around a central atrium take advantage of passive solar design principles. Extensive southern and eastern glazing in the atrium promotes maximum radiant thermal gains during the winter. Heat energy collects in the thermal mass of the atrium's masonry floor and flows through radiant coils to a gravel and water storage cistern below. This cistern acts as the building's thermal battery, retaining heat or exchanging it with the building's water-source heat pumps. On cloudy winter days, the cistern serves as a heat source to the atrium, reversing the heat flow back to the radiant coils in the atrium floor.

During the summer, heat gain is minimized by an exterior brise soleil calibrated to block the high summer sun angles. Any thermal energy that does accrue drives a desiccant dehumidification 
system, reducing the cooling loads of the building. The atrium also promotes summer cooling by expelling warm air through operable louvers at its top while bringing in cool air at a lower level.

Energy considerations continue through the design of the roof, which maximizes south-facing slopes at an optimum angle for photovoltaics. PV's use the sun's energy to produce electricity without the need for moving parts, extensive depletion of resources, or pollution. They are also silent. Sunlight on the silicon cell produces electrons, which flow through conducting strips to an inverter, where they are converted from direct to alternating current. The energy flow can be stored in batteries, used directly to power equipment, or directed onto the grid where it is often purchased by a local utility.

Applying these concepts to building design, construction and operation insures not only that the building will be economically effective through its own lifecycle, but also that it will not impose deferred costs upon future generations.

\section{Landscape}

The landscape of the Environmental Studies Center will be a working and learning landscape: a place where students and others learn how nature works and how humans interact with nature.

Although many people think of landscape only as decoration, it is, in fact, the medium for all ecological processes. The landscape converts solar energy into useful forms. It processes and guides water, recycles materials, and provides for the whole array of living creatures. If these essential but non-decorative functions have been forgotten, it is because they have been relinquished to industrially-based processes. Fossil-fuels now provide our energy, and concrete pipes and containers supply our water. Even our food relies upon petro-chemical and fossil-fuel sources. We emphasize the landscape as the medium of life and communicate this idea visually and experientially. We aim for a deeper beauty that replicates fundamental processes.

The ESC landscape incorporates basic ecological processes in four basic components.

The indigenous landscape. This component is a microcosm of the expansive hardwood forest that once existed on this land and which remains in places nearby. Through renewal of both understory and canopy tree species landscape students, faculty, and community members will be brought in closer contact with their historical and regional landscape.

The aquatic landscape. Many problems with water are caused by the desire to get it quickly into a lake or river or an ocean basin to prevent flooding. Instead, the ESC landscape reverses that course and uses its own rainwater on site. A small wetland will be a visible feature of this process, one that will also receive water from the building's "Living Machine," the internal firststage sewage treatment system. Through these elements sewage treatment becomes not a hidden process that is out of sight somewhere but a visible process that reminds us of nature's cycles and the need to build biological processes into our human environment. 
The social landscape. Present use patterns are an important element of the existing landscape; the ESC landscape design will respect and enhance them. Pedestrian circulation as well as a prominent range of student play and leisure activities give the current landscape its rich social character. The ESC landscape will reinforce those activities by providing a place that really fits all of them, in a way that the current site does not.

Food growing. Part of the ESC landscape will be devoted to growing food, including vegetables, herbs, and fruit. It will include a compost area and perhaps a small greenhouse or cold frames for winter use to extend the season. Growing food in small areas without the use of chemicals, using only organic fertilizers, will particularly suit the ESC Landscape Project. It will be close to an urban community garden with an emphasis on active participation and education. Our goal is to develop a working landscape where students learn about growing food and fundamental ecological processes.

By making these various ecological processes visible and social in character, the ESC landscape will show how nature's workings give form to our environment even as it invites them to participate in these processes. People, whether students or members of the larger community, will want to walk through this landscape and spend time in such a diverse range of life. They will feel connected with the earth.

\section{Living Machine}

Living Machines are natural wastewater treatment systems which replicate and accelerate the natural purification processes of ponds and marshes. Diverse communities of bacteria, algae, microorganisms, numerous species of plants and trees, snails, fish and other living creatures interact as whole ecologies in tanks and living bio-filters. With the help of sunlight and a managed environment, these organisms thrive on wastewater from which they break down and digest the organic material.

Living Machines offer several exceptional features. Unlike their conventional transportationbased or chemical counterparts, Living Machines are energy efficient and use few if any chemicals. Yet they produce advanced quality water which is recyclable for non-potable purposes. Sludge handling and disposal expenses are also significantly lower than for conventional technologies. In Living Machines, organisms use sludge as food, so most solids are consumed rather than requiring removal. Because Living Machines are mechanically simple and biologically complex, they are resistant to "shock loads" in the waste stream.

At Oberlin, the Living Machine will process all sewage waste generated from the building while also acting as a significant pedagogical tool. Students will set-up, monitor and maintain the Living Machine system. Its accessibility may allow eventual expansion of the technology throughout the campus, the City of Oberlin Public Works Department, and the Lorain County Health Department. 
The Living Machine is seen as a bridge between the architecture and the landscape of the Environmental Studies Center. The Living Machine is an integral piece of the building as the third bay of the atrium separated only by a layer of glass. It is also linked physically to the landscape supplying water to the wetlands. The wetland acts as the last stage of purification for the wastewater system. As stated previously, the design of the project is derived from an observation of natural energy flows.

\section{Conclusion}

The challenge of the Environmental Studies Center arises from the recognition that we live in a profound historical moment. We have created a culture of waste which cannot be sustained. Our situation is daunting and alarming, but we view it above all as an opportunity to develop models embodying higher goals and principles, including those of justice and ecological sustainability.

Our building is both a prototype and a pioneer. The process of giving form to the building program at Oberlin has coalesced and enhanced many of the constituencies and ideas necessary for the remaking of our relationship to the natural world. Upon completion this project will stimulate the thinking of those who learn within it and inspire others to use it as a model for their own institutions and communities.

\section{Endnotes}

1 This idea was first articulated by William McDonough in The Hannover Principles, which were developed as design principles for the World's Fair for the year 2000.

${ }^{2}$ Waste Equals Food, Product of Consumption, Product of Service: These terms have been defined by William McDonough and German ecological chemist Michael Braungart, and acknowledge that ownership of a great majority of manufactured objects is not beneficial when it is merely the use of those objects which we desire. Given appropriate economic incentives, we would prefer not to be responsible for the repair and disposal of these objects at the end of their useful lives.

${ }^{3}$ The "Products of Service" typology has already been incorporated by a number of industries, altering their method of production; in particular, Interface, Inc. has adopted this thinking in their "Evergreen Lease" for access floors and carpets. 


\author{
PATAGONIA DISTRIBUTION CENTER: \\ Valuing Direct and Indirect Benefits \\ USGBC Conference, Concurrent Case Studies \\ November 18, 1996, $2.00 \mathrm{pm}$ \\ Aidan Stretch, RIBA, Consultant
}

Abstract

Sustainable development solutions create both economic and environmental value. In this sense they are similar to the total quality movement, which proved that it is possible to improve quality and reduce costs, in other words achieve the seemingly impossible. Sustainable development solutions extend our definition of quality to include social and environmental value, as well as economic value, while capitalizing on increased efficiency and productivity.

Green buildings are a good example of sustainable development practices at work. Through the design of a buildings systems, material use, waste stream and energy consumption a green building minimizes its affects on the environment. Many green buildings cost significantly less to operate and maintain than conventional buildings, allowing financial resources to be reallocated. Businesses are fast realizing that this approach not only has environmental benefits but also improves their effectiveness and competitive advantage.

However, this is only half the story. Recent studies by the Rocky mountain Institute indicate that these operational savings are insignificant in comparison to the potential savings from increased productivity. Improving indoor air quality, occupant comfort, day lighting and energy efficiency has realized a 10-15 percent increase in productivity of employees and staff. Because on average, wages and salaries make up 70 percent of an organizations operating costs, providing a quality work environment through green buildings is an easy choice. These productivity gains could have a significant impact on a company's bottom line. A rule of thumb suggests a factor 5 relationship, that is a 1 percent increase in productivity translates into a 5 percent increase in operating income for a company. Similarly, a 5 percent increase in productivity translates into a 25 percent increase in operating income. Other studies show similar results for sales in retail outlets.

These facts explain why many nationally and internationally recognized businesses are embracing the concept of green buildings. AT\&T, WalMart, Sony, Herman Miller, Bank of America and the Gap are just a sample from an ever increasing list. The challenge then for the industry and professions is to capture the value from green developments in the design, planning, engineering, construction, assessment and financing aspects of real estate. Clearly, each profession requires new tools to realize a competitive advantage.

Two recently completed facilities illustrate how economic and environmental value is created through design, planning and engineering. These green buildings are also an example of how enlightened clients can practice environmental stewardship and good business at the same time. 
The NW Federal Credit Union Branch \& Office Headquarters is a 40,000 -square-foot building located in Seattle. The site planning and organization allows for most of the existing trees to be retained. The

building is narrow in plan in the north-south direction and elongated in the east-west direction. This maximizes the opportunity for natural ventilation and daylight harvesting through extensive shaded operable glazing and light shelves at the north and south elevations. Lighting equipment is dimmed by photo sensors to maximize the energy savings from day lighting. Ventilation also provides a night flushing cycle to cool the buildings exposed thermal mass, and improve indoor air quality by diluting pollutants that build up during the day. The night flush cycle is 100 percent outside air. This day lighting and lighting strategy combined with an energy efficient mechanical system and naturally ventilated areas reduce energy consumption by 30 percent below the already stringent Washington State Energy Code. Interior \& exterior material selections throughout were screened for environmental considerations, indoor air quality and life cycle costing considerations. The building was a market priced commercial building ( $\$ 4.6$ million), which costs less to operate and is a healthier more productive workplace. This project recently received a 1996 Architecture + Energy Award from the AIA and Bonneville Power Administration.

Patagonias Worldwide Distribution \& Office facility is a 184,000 -square-foot building in Reno. The site planning and organization orients the building to southern exposure focusing views towards the adjacent Truckee River. To the south of the building the river ecosystem is re-established up to the building edge and incorporates biofiltration swales which treat all site runoff before entering the river. The building envelope is designed to maximize daylight where appropriate in the warehouse and office areas. This is achieved through extensive shaded glazing, light shelves and skylighting provided by a combination of sun-tracking lights in the warehouse and north lights in the office areas. In combination with the building optimized daylight section, lighting systems were designed to be highly efficient. The combination of efficient lamps \& fixtures with motion \& daylight controls provided a 60 percent reduction in energy consumption below industry standard systems.

The building is superinsulated to optimize heating \& cooling loads and conditioned by hydronic radiant heating and cooling panels. This system provides an estimated 50 percent reduction in energy use over a conventional mechanical ventilation system. The system was complemented by a combination of displacement ventilation and mechanically assisted stack effect.

Again, interior \& exterior material selections throughout were screened for environmental considerations, indoor air quality and life cycle costing considerations. The project cost was $\$ 6$ million and the range of energy efficient systems, technologies and measures are expected to payback within 1-3 years.

These and many other projects show that green buildings really do make sense. They begin to bridge the gap between development and the environment that has existed for so long, by simultaneously creating both economic and environmental value in projects. This approach has implications for the real estate and development community, beyond the design and planning professions. Those in the industry that meet this challenge will be positioning themselves in the market through both cost and differentiation, providing a clear strategic competitive advantage. 


\title{
HOW RATHER THAN WHAT: ENVIRONMENTALLY RESPONSIBLE BUILDING DESIGN
}

\author{
Raymond J Cole \\ School of Architecture \\ University of British Columbia \\ Vancouver, BC V6T 1Z2
}

\begin{abstract}
Case-studies are important vehicles for communicating advances in environmentally responsible building design and construction. This paper uses the specific example of the recently completed C.K. Choi Buiilding for the Institute of Asian Research at the University of British Columbia to raise a series of general issues associated with our current progress toward improving the environmental performance of buildings. It argues that probably the most important lessons that can be gained from case-studies is not in their technical features but in the circumstances which led to their creation - the process, the conflicts and types of compromises that were met and overcome during the design.
\end{abstract}

\section{Introduction}

Addressing the environmental agenda requires an explicit restructuring of priorities and a questioning of a host of related assumptions which directly and indirectly shape buildings. It requires transcending professional boundaries between architects and engineering consultants and creating a more effective dialogue among all participants involved in the production of buildings. Innovative buildings reflect changes in both the process of their creation as well as their distinctively different design features and characteristics. As such it is first useful to differentiate between the notions of an 'environmentally responsive building' and 'environmentally responsible building design.'

An environmentally responsive building is one which satisfies the physical requirements for housing human activity using resources efficiently and effectively, and with minimum stress on natural systems -- offering the highest environmental performance within the site, program and cost constraints. Environmentally responsible design describes the process by which an environmentally responsive building emerges. It relates to the way in which the designers choose to place environmental issues as guiding notions within the full breadth and complexity of decision making -- wherever and whenever choosing to evaluate the potential of natural systems and emerging environmental options prior to conventional ones.

Environmentally responsible building design also involves challenging many existing design norms and promoting an attitudinal shift to embrace new ways of thinking about the processes of production, use and disposal of a building. An environmentally responsive building is recognized equally by the integration of the various environmental strategies as it is by the strategies themselves and, as such, requires a team approach throughout its execution. Since building design is holistic, there is no true way to separate out the architect's role from others in the design team - every member has, at some level, to be aware of all the significant design issues. [1] Moreover, since environmentally responsible design is process related, it extends beyond the physical design and embraces the subsequent responsibilities and roles of the contractor and user. 
Many aspects of a building design are a function of, and shaped by, the cultural, physical, and economic context in which it occurs. Moreover, architecture does not typically change until the context in which it occurs, changes. [2] The context in which the design of buildings occurs does not currently support environmental responsibility and, despite the considerable advances in awareness of environmental concerns as witnessed by the rapid increase in research and publication, environmental responsibility remains a peripheral issue to other seemingly pressing issues within an ingrained culture of consumerism. Where change is occurring, it is typically a 'superficial change layered on top of an unchanged core organization' instead of questioning, challenging and changing the core itself. [3] However, the emphasis and priorities evident in state-of-the-art building design derive from the commitment and actions of specific individuals clients and members of the design team - irrespective of or despite the prevailing trends and context. The primary emphasis of this paper is this relationship between the specific set of circumstances and the broader context that affect progress in environmentally responsible design.

The paper uses the specific example of the C.K. Choi building for Institute of Asian Research at the University of British Columbia to raise a series of general questions pertinent to the current progress being made in the environmental performance of buildings. Like many other significant environmental buildings, the physical characteristics of the Institute of Asian Research building are well documented in the technical and professional press [4-6]. What is perhaps more interesting is that, with time, the unique circumstances of their development, the frustrations, the conflicts and compromises are often lost and supplanted by highly rationalized and exalted explanations of the process. Although this is an inevitable consequence given the problems of describing 'design,' it disguises many of the considerable difficulties that were faced and overcome in striving for environmentally responsible building design -- lessons which could have potentially profound value to others aspiring to make progress in their own work.

\section{Context}

Over the past eight years, the University of British Columbia has conducted a $\$ 500$ million building expansion program. To date this has been manifest in the construction of some thirty or so completed projects with several others currently in the construction and planning stage. Of these, only two stand represent examples of environmentally responsible design - the C.K. Choi Institute of Asian Research and Earth Science Building. Moreover, although the completed schematic design of Earth Science Building embodies a number of significant environmental strategies, its construction has yet to be funded, thereby making it difficult to fully critique.

The implications of the original 1915 decision to locate the University of BC on a peninsular remote from the city are evident daily in the environmental impacts associated with transporting its 30,000 plus students, staff and faculty to and from the campus each day. More significantly, the original electricity, water and gas supply and sanitary waste infrastructure are nearing their limit to meet current demand. Irrespective of the environmental benefits, significant reduction in demand will negate the massive costs of increasing supply. The Institute of Asian Research building, while typically presented solely in terms of its environmental merits, represents a clear direction for sound economics -- if, of course, comprehensive cost accounting were an instrument in both funding and subsequent decision-making.

\section{Product}

The Institute of Asian Research houses Centres for China, Japan, Korea, India and South Asia, and Southeast Asia Research and presents holistic image of Asia without reference to single 
countries. This $\$ 4.5$ million (Canadian) building was funded by donors from Canada and Asia, including C.K. Choi family and BC. Government.

The approach to the site selection in itself is revealing. The site for the building was a former long, narrow 300' by 60' parking lot on a north-south axis bounded by a major vehicular route on the east and a wooded area to the west linking to the existing Asian Centre. The decision was made at the outset not to encroach on the wooded area and retain as much of the existing vegetation. Only selective pruning was employed and, as such, constrained the building form.

The overall form of this $32000 \mathrm{ft}^{2}$ building was largely dictated by the proportions of the selected site and the programmatic necessity of five distinct sub-groups under one common roof presenting both opportunities and difficulties for accommodating environmental strategies:

Naturally Conditioned: The natural conditioning of building interiors is regaining acceptance and the Institute of Asian Research shows a welcome reversion back to simple, straightforward, user controls to condition the offices -- wherever and whenever taking advantage of ambient natural conditions. Operating energy is reduced by the elimination of traditional ducted air systems, natural ventilation with few fans, operable windows, fresh air vents, louvers, and atria:

- By creatively using full height atria as the punctuations between the individual centre, stack ventilation could be induced throughout all occupied spaces. Air enters through operable windows and fresh air vents and is carried out through louvers near the roof in the atria providing $100 \%$ fresh air at all times;

- The narrow floor plate, in combination with the atria, provides high quality daylighting in the office areas. The power consumption for lighting $-0.9 \mathrm{~W} / \mathrm{ft}^{2}-$ is less than half that of a typical office building - manual switches for lights, daylight monitoring dimmer switches, automatic shutoff switches for rooms when vacant;

- The north-south axis limits the ability to use passive solar gain - placing the emphasis on high performance windows to reduce heat loss and daylighting as the primary energy strategies;

- Domestic hot water is preheated from the waste heat from the campus steam heat distribution which runs adjacent to the site -- a strategy which raises the larger question about re-using legitimate by-products or 'wastes' which could be eliminated at source.

Healthy Workplace: Office interiors must be healthy and productive environments. Following the principle that source control is the most effective strategy for improving indoor air quality, careful selection of building materials, finish products and construction practices in the building insures good indoor air quality:

- In the selected areas where carpet is used it was laid without adhesives;

- The millwork was constructed from formaldehyde-free materials and all finishes are solvent free;

- Copy machine areas are vented directly to the exterior.

Resource Reduction: Reduction is the primary method of conservation. If the scale of demand for energy, materials and other resources is not managed, then other strategies such as reuse and recycling will ultimately prove irrelevant:

- More than $50 \%$ of the total materials and components have recycled content or were salvaged:

- Salvaged heavy timbers from a demolished campus building on an adjacent site form the basis of the buildings structural system - itself design using mechanical fasteners for future recovery and reuse; 
- The brick cladding was derived from locally salvaged street bricks.

- The architects chose to deliberately exclude or only selectively employ many traditional interior finishing materials:

- Polished concrete on major common areas;

- Elimination of suspended ceiling elements.

- Use of composting toilets: waterless system that saves 1500 gallons of water per day and enables the building to be disconnected from the University sanitary system.

Landscape design: Indigenous plants used, especially those needing little maintenance

- Columnar Gingko trees selected to clean air and not block the light

- Existing soil used and amended with organic matter

- Chemical pesticides avoidance and non-toxic biological fertilizer

- Water efficient subsurface irrigation system utilized

- Storm water stored for gradual absorption and a subsurface trench recycles greywater with marsh vegetation

Three important outcomes can be discussed:

Reassessment of expectations: Many of the environmental strategies used in the Institute of Asian Research building are quite different from conventional practice and expectation:

- The elimination of the finishing materials exposes the hitherto unseen building services and reveals harder surfaces which change the acoustic environment;

- Perception over the operation and performance of the composting toilets;

- The thicker and coarser mortar joints to accommodate the irregularities in the reused brick creates a finish not consistent with 'conventional' expectations for a new building.

Many of these are, of course, a function of familiarity and will change over time.

Absence of Quantification: With the exception of reductions in energy and water use, no indication of the degree of performance is reported in the building's environmental features, e.g., the amount of recycled materials, amount of re-used materials. While current research aims at formulating tools to provide a more comprehensive, objective and quantifiable descriptions many criteria will centre on the direction of change rather than the degree.

Skepticism often parallels state-of-the-art building: Universities, like many other clients do not like to be the first to try new technologies or ones without a proven track-record. As such, failsafe precautions are incorporated into the design - increasing both the capital cost and design effort.

\section{Process}

The way in which the Institute of Asian Research project was initiated and the subsequent collaboration between all consultants from the beginning, is now viewed as vital to its success. This was manifest in three ways: 
- An initial agreement by the senior university personnel and future building users to use the project as a demonstration of sustainable building design and construction practices.

- Making environmental issues an explicit part of the selection of the architects.

- A two-day workshop involving the entire team, users and campus at the outset of the project which concluded in a joint statement of goals and principles for the project.

The first two actions exemplify the fact that if building design is to emphasize and incorporate environmental criteria, clients must both raise such criteria as explicit concerns and issues, and communicate this intent and expectation of environmental responsibility to their design teams.

The workshop was critical in two ways:

- It established a shared vision for the project - a notion that is seldom possible within the traditionally linear approach to building design.

- It provided performance targets that were far beyond those of other campus buildings and the previous experience of the design team:

- $50 \%$ less water use than normal

- No sewer connection

- $50 \%$ re-used/recycled materials

- $50 \%$ recyclable materials

- Reduction of energy use 65\% less than ASHRAE/IES 90.1 standards

- Lighting densities less than $0.5 \mathrm{~W} / \mathrm{ft}^{2}$

The setting of these demanding performance goals at the outset was profound. Though not met in all instances, they became a necessary 'gauntlet' to challenge the design team. More interestingly, these targets emerged from a working sessions in a loose and, to a degree, arbitrary way. The research community continues to seek precision and has yet to recognise that sustainability is a complex issue and has social, political, economic and environmental dimensions and there will be no simple solution to such a inadequately understood problem. Notwithstanding the difficulties, architects as with other sectors of society must continue to make decisions and act within this uncertainty.

Sustaining Commitment: Though they had a general understanding of broader environmental concerns, the architects were neither exceptionally knowledgeable or noted for accounting for environmental issues in their prior work. Despite cautious beginnings, the team progressively engaged environmentally considerations. The gaining of interest and momentum throughout the design and the desire to aspire to greater levels of environmentally responsible remains the critical point.

The willingness of the design team to reassess the evolving design brought about by the availability of better environmental options is another important feature of the process:

- The structural system was originally to be concrete, but revised upon the availability of a heavy timber structure from an adjacent demolished building.

- The quantity and quality of the brick and other reused components, require keeping options open until the supply is confirmed.

Sensitivity to Site: Having the contractor selectively excavating strips into the existing carpark covering for the building footings rather than indiscriminate clearing on the basis of not further 
violating the site ecology. There is insufficient scientific evidence to validate the ecological merits of this strategy nor the indirect, but probably profound, impact it had on changing the attitudes of the contractor and crew members - reassessing former practices and being selective in their application is the transferable skill.

\section{Environmental Guidelines for University and College Facilities}

Despite the considerable number of accolades that the Institute of Asian Research buildings has received locally and nationally, only one subsequent building within universities building program has yet to aspire to or achieve the same degree of environmental commitment. This clearly indicates the limited extent to which an environmental ethic has fully permeated the institution to date. Irrespectively, the Institute of Asian Research has begun to change the perception of what is possible in a similar way that the workshop goals set new boundaries for the design team. Indirectly but none-the-less linked to the development of the Institute of Asian Research building was the changing expression of commitment of British Columbia universities, colleges and institutes and the BC Ministry of Skills, Labor and Training to environmentally responsible building design and operation.

Representatives from the operations and development departments from these institutions jointly formulated the following general objectives as an expression of this commitment during the period at which the Institute of Asian Research building was being designed:

- Respect for Natural Systems: New university, college and institute facilities should be conscious of, and responsive to, the ecology of the site and of existing natural systems.

- Energy Use: Institutions should strive to reduce overall quantities of energy used and to use sustainable energy sources as much as is technologically possible.

- Resource Use: Institutions should approach facilities development and operation with the aim of using land, material and water resources in the most efficient and effective manner.

- Health and Well-Being of Users: Institutions should ensure that indoor environments are healthy and comfortable.

- Integration of Principles: Institutions should strive to effect a comprehensive and holistic environmentally sustainable approach to development and operation by consideration of all of the above issues.

These were the underpinnings of a set of environmental guidelines developed for new facilities for higher educational in BC. [7] The mere existence of the Institute of Asian Research building as a point of reference, made it possible for the review committee to accept and subsequently incorporate more far reaching performance targets and strategies than would have probably been otherwise possible.

\section{Conclusions}

Probably the most important conclusions from the examination of this, or for that matter, any other case-study building is not in their technical features but are in the circumstances which led to its creation - the process, the conflicts and types of compromises that were met and overcome during the design. Several important lessons seem evident from this case-study: 
- Environmentally responsible building design must be 'kick-started,' i.e., a mechanism is needed to challenge preconceptions and accepted design norms.

- It is important to establish challenging goals at the outset without the expectation that they will necessarily be met. Many goals are often formulated on the basis of realistic, achievable targets - far reaching challenges may be a more powerful basis for reassessing strategies. The goals established for the Institute of Asian Research project were, for the main part, quite arbitrary but none-the-less effective at producing the desired effect.

- Personalities can drive change toward dramatic improvements in environmental performance despite information, cost or regulatory constraints. The environmental emphasis of this project can be traced to the advocacy and commitment of a few key personnel.

- Environmentally responsible building design must be sustained. At this point - and for the foreseeable future - environmentally responsible design will be moving into uncharted territory. The design team must see value in committing additional effort to a project - in particular the added professional competitiveness that the newly acquired experience and knowledge can and should bring.

What remains difficult, of course is that we have to make judgements of these and other innovative buildings so soon after their completion. The extent and rate at which new emphases to design are introduced is a function of momentum created by the approaches and technologies used in state-of-the-buildings. Unfortunately there is little, if any, time before true strengths and problems to fully reveal themselves. The potential dangers of propagating myth could be an unfortunate outcome - but time will inevitably tell!

\section{References}

1. Stafford, C B., et al., (1992) Designing with Vision: Public Building Guidelines for the 21st Century, Stafford Architects, Seattle, WA

2. Ingersoll, R., 1991, Unpacking the Green Man's Burden, Design Book Review, Spring 1991, pp19-26

3. Sexton, M.G., The Prajna Approach to Sustainable Construction, Proceedings Environmental Impact of Buildings and Cities Workshop, Florence, Italy, September 1995

4. Asia Pacific Report, Vol. 20 No. 1, Spring 1996

5. Pagani, F., Energy-Efficient Initiatives at the University of British Columbia, Paper presented at the Fourth National Energy Efficient New Construction Conference, Vancouver, BC, Sept 30-Oct 2nd 1996

6. Ledger, B., Swooping for Air, Canadian Architect, July 1996, p 17

7. Environmental Guidelines for British Columbia University, College and Institutions Facilities, Ministry of Skills, Labour \& Training, Victoria, BC April 1995

\section{Credits}

C.K. Choi Buiilding for the Institute of Asian Research:

Architects: Matsuzaki Wright Architects; Structural: Read Jones Christoffersen; Mechanical: Keen Engineering; Electrical: Robert Freundlich \& Associates; Landscape: Cornelia Hahn Oberlander; Contractor: Country West Construction. 



\title{
THE QUEENS BUILDING AT DE MONTFORT UNIVERSITY, LEICESTER, UK The new School of Engineering and Manufacture, a working example of a naturally ventilated, naturally lit, inner-urban public building.
}

\author{
SHORT, C. Alan, Visiting Professor, De Montfort University, and partner in \\ Short * Ford and Associates, Chartered Architects, \\ 15 Prescott Place, London SW4 6BS, UK
}

tel. 01717209994 fax 01717208857

\begin{abstract}
The Queens Building, opened October 1993, accommodates a complete University School of Engineering and Manufacture. It is designed to be a low energy building. The teaching and research relates to the practical business of Manufacturing Technology, and much of it is heat producing at a prodigious scale. The conventional response would seem to be to seal and air condition a building of this type. However this building is almost wholly naturally lit and naturally cross-, and stack-ventilated, and the first results are very encouraging. The Building was awarded the UK Green Building of the Year Award for 1995.
\end{abstract}

\section{Introduction}

The School of Engineering and Manufacture at De Montfort University, is re-housed within the all new 10,000 square metre Queens Building. In excess of two thousand undergraduates, graduates, research students, fellows and staff are connected with the building, if not full time occupants. It was built very precisely to meet the strict Polytechnic \& Colleges Funding Council cost and space limits, its construction cost being $£ 8.5$ million, excluding fitting out. No further funding was introduced to increase its cost allowances and in fact its fitting out budget was very restricted. The University very deliberately describes the building as a School of Engineering and Manufacture. The teaching and research generally relates to Manufacturing Technology, particularly in the Textile Industry, and so it replicates typical computer laboratory and factory situations.

As remarked, much of this work is heat producing at a prodigious scale. The electronics laboratories may generate 84 watts per square metre, such is the density of computers and other electronic equipment, twice the heat gains in a City dealing room for example, three times that in a conventional office building. However this building is almost wholly naturally conditioned, that is naturally lit and passively cross- and stack-ventilated. Less than $2 \%$ of the floor area is mechanically ventilated or air conditioned. Design work commenced in 1989, supported by the UK Department of Trade and Industry. Research physicists at the Cambridge University Department of Applied Mathematics and Theoretical Physics simulated the likely air flow within the Architects' proposed configurations using a physical model immersed in a saline bath, and colleagues at De Montfort University using the dynamic thermal model ESP, to simulate the thermal behaviour of key spaces through time. 
Through the scheme design phase, a series of extremely productive and intense meetings were held in Cambridge, at which the configuration of the principal volumes of the proposed building was debated, as it was generated, by the very diverse team of scientists, designers, structural and environmental engineers, and cost consultants, chaired by the architects. The broad strategy proposes a combination of heavy masonry construction and the judicious provision of natural ventilation paths. An appreciable cooling effect through the overheating months was predicted.

\section{The Building in Use}

The first results are excellent. In late June the auditoria just reached $23.5^{\circ} \mathrm{C}$ whilst external temperatures exceeded $31^{\circ} \mathrm{C}$, with little or no consumption of energy. Our client's ideas for academic reintegration, the City Authority's urban design notions, and the environmental strategy, in concert, suggested a series of fundamental configurations; a tight courtyard of electronics laboratories is introduced to the northwest of the site, the 'poor' orientation maintaining a sump of cooler air to cross-ventilate the laboratories, whilst a large single volume mechanical engineering hall is placed at the opposite end of the school. The two are connected by a 50 metre long double height general laboratory in which mechanical and electronics engineers combine forces to invent new applications of robotics, mechatronics, and artificial vision to related production fields. A full height concourse forms the main circulation space in which much of the very important informal meetings and discussions occur. It contains most of the balancing area allowable within the PCFC floor area recipe. Its air volume stabilises the thermal behaviour of the surrounding spaces.

Two full raked amphitheatres for 160 people each, sit opposite above similar, radial plan, flat floored teaching rooms. Their ceiling slabs support north lit drawing and design studios, half devoted to $\mathrm{CAD}$ and half to drawing board design activity. General purpose classrooms occupy the ground floor, supported by a computer node and common room. Staff and research fellows occupy the attics, encircling the design studios. A specialist Engine Test Cell sits a little apart from the main building on Mill Lane.

\section{Energy Usage at Queens Building, De Montfort University}

September 1993 - July 1994

The building was compared with the BRECSU 'Energy Consumption Guide'. This gives figures for typical and best practice offices for delivered amounts of gas and electricity.

FUEL

\author{
USAGE \\ ACTUAL \\ $\left(\mathrm{kWH}\right.$ per $\mathrm{m}^{2}$ ) \\ TYPICAL BEST \\ PRACTICE
}

GAS

ELECTRICITY
200

85
95

61
USAGE

(kWH)

TYPICAL

BEST

PRACTICE

2,000

950

1,140

850

610

630 
From these figures it can be seen that the electricity usage is very much in line with 'best practice', but the figures include the electrical consumption of all the laboratory equipment. Sadly it is not possible to disaggregate the figure for artificial lighting.

The Gas consumption is slightly higher than 'best practice'. This is expected in a heavyweight building where the structure of the building itself stores quite a lot of heat which has to be re-input after every weekend. The benefits and savings of the heavyweight building of steady internal temperatures and the avoidance of air conditioning far outweigh the small additional cost of heating in winter.

\section{A Natural Conditioning Strategy may promote a more flexible and sympathetic approach to urban planning}

Our hypothesis is that the optimal form for such a building dissolves its considerable volumes into narrow section elements, with free elevations on two or even three sides. We believe that it is possible for such a building, whilst it is attempting to strike a rhythm with its immediate environment, also to exploit its inherently more flexible form to mend a hole in the surviving urban fabric. Our researches show that this prototypical site was densely occupied by terraced houses, interspersed with hosiery mills, and that the concave shape of the main street, Mill Lane, was established before Robert's 1741 City map was surveyed, and is therefore, in our view, significant.

The block plan experienced a huge extraction in the early 1960's under the direction of the then Chief Planning Officer, an enthusistic demolisher.

The more manoeuvrable building volumes resulting from the notion of introducing light and air from both sides and above, enable, for example, the street elevation to flex so as to reinforce the old route whilst tuning the orientation of the various elements. The drawing studios are very deliberately slewed to make northlit spaces, and receive high levels of diffuse indirect light. An imaginative regional architecture, primarily in masonry but highly perforate, was developed through the nineteenth century in the English Midlands to satisfy the requirement for high natural light levels in the Lace-making industry.

External spaces are more deliberately formed at different scales around the building. A new Great Court is proposed between the Mechanical Laboratory and the Kimberlin Library. Smaller scale outdoor rooms intended for teaching are formed between the southfacing classrooms, transepts and the electronics laboratories. The area is unsafe at night, and the contents of the building represent a high security risk. Approaching visitors enter the courtyard in full view and cross its full length before presenting themselves at the door. This is a very deliberate entry sequence.

The Interdependence of the passive cooling strategy and the structure, and the potential for making the strategy intelligible

Crucial to the environmental strategy is the thermal stability provided by the massive brick masonry construction. Furthermore this masonry must be exposed to the air volume within. 
Its potential for thermal admittance would be very reduced by a lightweight applied finish. Blockleys mellow grain pink bricks are used externally with silver buff and red syncopated stripes. Internally solid load bearing walls are made in calcium silicate bricks by Ryarsh in a variety of pastel colours, set in flemish bond or collar - jointed to fairfaced blockwork walls.

Polychromatic expression of various of the bond types reveals their pattern to the student engineers. The greater the degree of polychromatic density the less load bearing is the element. The mortar colour is matched to the brickwork to increase the apparent sheerness of the masonry planes, a quality we admire in Richardson's work amongst others, for example Sever Hall in Harvard Yard. Typically heavy masonry buildings develop a very occluded ground floor plan. We borrow Viollet Le Duc's notion of propping masonry up above head height. Pin - jointed steel frames along the length of the concourse lift masonry ventilation stacks up to the first floor level. The stacks are very visible and have become a popular 'leitmotiv' of the campus.

The imagery conveyed by the paraphernalia of air conditioning, its grilles and 'penthouse units' is avoided. Air inlets and extract stack terminations are designed specifically within the natural materials of the building. There are small areas of lightweight timber enclosure, heavily insulated and clad in cedar shingles impregnated with intumescent material, one of its first uses on a public building in Britain, but very familiar to a North American audience.

\section{The Central Strategy}

One issue, the source of some scepticism inevitably, is that with a naturally-ventilated building, as compared with an air conditioned building, there is no spare capacity in the system, for example the chiller cannot be turned up. This means that everything must work to its maximum potential for the building to work correctly. As a result the control system must be relatively sophisticated so that the optimum can be extracted from the natural ventilation.

At De Montfort, an extensive building management system (BMS) has been installed with approximately 900 control and monitoring points. One of the best features of this particular system is that its control algorithms are written in plain English and can be easily altered by the user. This means that it is easy to continually fine-tune the controls. This is particularly important bearing in mind the radical design of this building for which there was little previous experience to fall back on, although this is not the case now, six years on.

The building will be used at a wide variety of times throughout the day and during the year and it was therefore divided in to ten zones to allow the maximum control over the heating of the occupied spaces. If it is found to be necessary, the building can be further split up simply by using software as the motorised valves are already in place.

One condensing boiler and two conventional gas fired boilers, together with a gas fired packaged combined heat and power (CHP) system, provide the heat source for the building. These four heating units are connected in parallel to each other as well as to the heating load. The CHP unit is more efficient than either the condensing boiler or buying in electricity but only provided that most of the electricity and the hot water which it produces are being used. The CHP will usually be the lead heat producer, followed by the condensing boiler and then 
the conventional boilers. Before the BMS enables the CHP unit, it checks to see if sufficient heating and electricity is being used. If this is not the case, the CHP will be deactivated and the condensing boiler will become the first to fire. Delays have been built-in to ensure the lead does not fluctuate between the CHP and the condensing boiler. The CHP unit was sized so that its hot water output was roughly the same as the hot water load in the building. This means that the CHP will be used virtually all year round, except for summer nights, and will thereby guarantee the fastest payback of the cost of the unit.

The building is generally heated by perimeter mounted radiators or natural convectors. A few areas have underfloor heating, and in the mechanical laboratory there are high level radiant panels. These heaters are controlled by two-port valves and averaging thermostats. All heating set-points are set centrally from the BMS computer (largely to prevent fiddling by the student, although fiddling by staff has turned out to be a problem). These temperature settings are set back at night, and in summer so that the structure of the building can be pre-cooled at night by natural ventilation. At times it will be possible to cool down the building slightly below its heating set-point and in this eventuality it is important that the controls prevent the building from being re-heated the following morning.

The controls in the auditoria function in a very similar way to those in the rest of the building. There are, however, many more sensors in the auditoria and this allows a greater degree of control over the space. The basic requirements is for liberal supply of fresh air (10 1/s/person) when the auditoria are in use and then for enough air to provide the required cooling. Generally, the dampers and stacks will open to cool the room as required. The controls are best explained in tabular form.

The air inlet dampers and the stack outlet dampers will open if the room requires cooling and the external temperature is less than the internal temperature. When the room is occupied, as determined by the $\mathrm{CO}_{2}$ sensor, the air inlets and outlets will maintain a minimum position. In both cases the positions of the air inlet dampers and the stack dampers will be modulated based upon the air velocity up the stack. This is to ensure that, in summer draughts are not created on windy days and in winter, the amount of cold fresh air entering the building is kept to a minimum. Furthermore the stack dampers will be partially closed if it is raining and the wind is sufficient to cause the rain to enter the building. There is one further refinement to the controls: if the inlet damper attempts to go below $10 \%$, the stack dampers will close instead. This ensures that the inlet damper does not create too much air turbulence and hence noise.

The lighting in the building is controlled by the building management system via passive infra-red detectors. During the occupied period of the day, the lighting circuits are energized by the BMS, and are subsequently controlled by the local switches. Out of normal hours the BMS will de-energize any lighting circuits which serve an area where no occupants are detected. The lighting circuits will be re-energized when an individual enters a room.

It is intended to extend the use of the system during the occupied period so that the lights inside certain areas of the building are switched off dependant upon the external light level. Obviously this extension of the control system will have to be implemented with care and with the users approval, so that the occupants do not feel they have lost control over their building. 
The services in this building have the desirable characteristic of being simple and the building characteristics are, in many ways, similarly straightforward. Paradoxically, a sophisticated well tuned control system is required to ensure that such relatively simple systems work well together.

\section{Conclusions}

Every space in the building is different, adapted to its orientation, activity, and its desired lighting, acoustic and ventilation pattern. We believe that this has already had a very beneficial effect on the morale of its occupants. A variety of window openings is employed; Gothic head openings on the ground floor make arcaded bases to the teaching courtyards and lift glazed area up between the deep floor structure downstairs. The emphasis is on de-institutionalising a very large University School, on reinforcing the genius loci of the existing place, which is more powerful than one might think, and making new places in the same spirit. The students, staff and principals of the University know very well the significance of their new building, and the Vice Chancellor reports that it has helped to attract a very gratifying level of new engineering based research contracts. 
The New School of Engineering and Manufacture, 'The Queens Building', at De Montfort University, Leicester, 1989-1993

Alan Short, Brian Ford, Anne Goldrick and Peter Sharratt, with Catherine Hoggard, Mark Hewitt, Michael Betts, Jo Ki, Bruce Graham, Gary Stewart and others, Max Fordham, Randall Thomas, Edith Blennerhesset, services and environmental engineers, Stephen Morley of Anthony Hunt Associates, structural engineer.

1. Mary Whittaker, "Ring in the Old", Architecture Today, Vol. 9, September 1993.

2. Alan Short, "A Well-Tempered Environment : Peake Short at Leicester", Architecture Today, Vol. 23, November 1991, drawing by Alan Short on cover.

3. "Detail - The Engineering and Manufacture School at De Montfort University", Architecture Today, Vol. 35.

4. Philip Arcidi, "School of Engineering and Manufacture, Leicester Polytechnic, England", Progressive Architecture, Sustainable Design Within Reach?, March 1993.

5. Helena Russel, "Test Case", New Builder, May 28th 1993.

6. Mark Swenarton and Peter Rickaby, "Low Energy Gothic", Architecture Today, Vol. 41, September 1993, photos by Peter Cook.

7. Roderic Bunn, "Learning Curve", The CIBSE Journal, Building Services, Vol. 15, No. 10, October 1993.

8. Gillian Darley, "A Smart Line in Mediterranean Cool", The Observer, Review Section, 17th October 1993.

9. Hugh Pearman, "The Battle of the Buildings", The Sunday Times, 10th October 1993.

10. "Review of the Year", Building Design editorial, 10th December 1993.

11. Lucy Young, "Basic Green", Metropolis Magazine, September 1994, New York.

12. Jeremy Hunt, "Engineering A New Breed of Student", The Engineer, 27th January 1994.

13. "Daylighting in Buildings, Thermie", The European Commission Directorate-General for Energy (DG XVII), School of Engineering De Montfort University, UK Case Study, p $12,16$. 

De Montfort University.

16. Hazel Conway and Rown Roenisch, "Understanding Architecture", Routledge, 1994, p65-66.

Robert Webb, "Offices That Breath Naturally", New Scientist, 11 th June 1994.

18. Dean Hawkes, "User Control in a Passive Building", The Architects Journal, 9th March 1994, photographs by Peter Cook.

19.

Hugh Pearman, "Building of the Year" review of finalists, The Sunday Times, The Culture Section, 15th May 1994.

Alan Powers, "The New Gothic", Perspectives, February 1995. Education Supplement, 31st March 1995, p6 of Buildings and Estate Management Supplement.

22. "Green Building Award Goes to 'Gothic' Design", The Independent newspaper, 24th May 1995.

23. David Nicholson-Lord, " 'Medieval' Building wins Green Award", The Independent on Sunday, 28th May 1995.

Anthony Oliver, "Green Leicester", New Builder, Vol. 16, June 1995, photographs by Grant Smith.

25.

Colin Davies, "Green Gothic", also editorial by Deborah K. Dietsch, "Green Culture", Architecture, The Journal of the American Institute of Architects, July 1995, USA.

"AIA", Environmental Resource Guide, Washington, 1996.

\section{Books}

27.

Charles Jencks, "The Architecture of the Jumping Universe, A Polemic: How Complexity Science is Changing Architecture and Culture", Academy Editions, 1995, pp97-99. 
28. Scorpio, "It's Like Wow! Cosmic and Jumping, Man", review of Jencks book in Building Design, 12th May 1995.

29. Bill Addis, "The Art of the Structural Engineer", Artemis, London 1994.

\section{Radio coverage of the Queens Building}

30. Presented by Dr. Mark Swenarton, Joanna van Heyningen and Dr. Peter Rickaby, "Friday Feature: Home is Where the Hearth Was", BBC Radio 3, Friday 10th June 1994. 


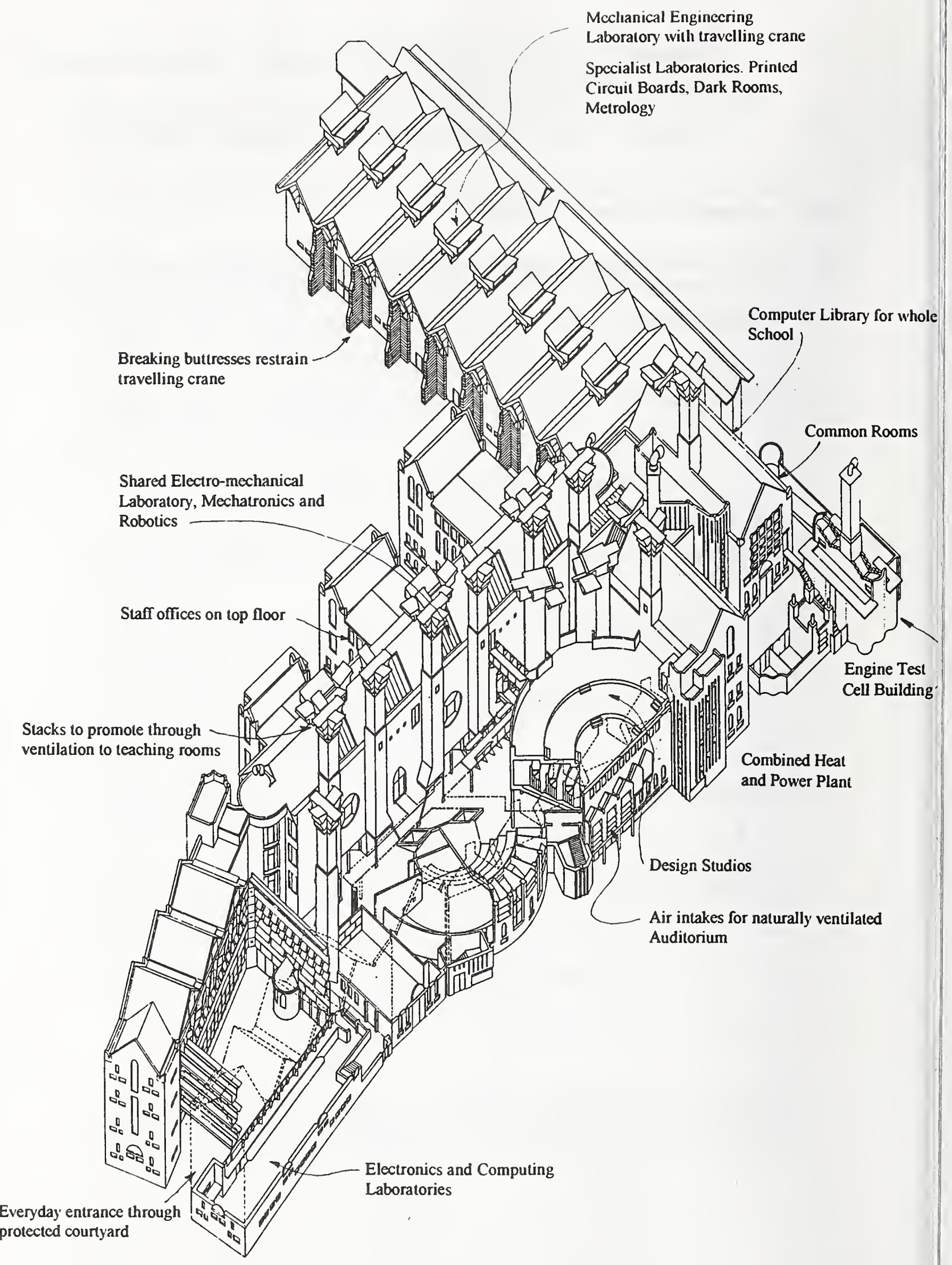




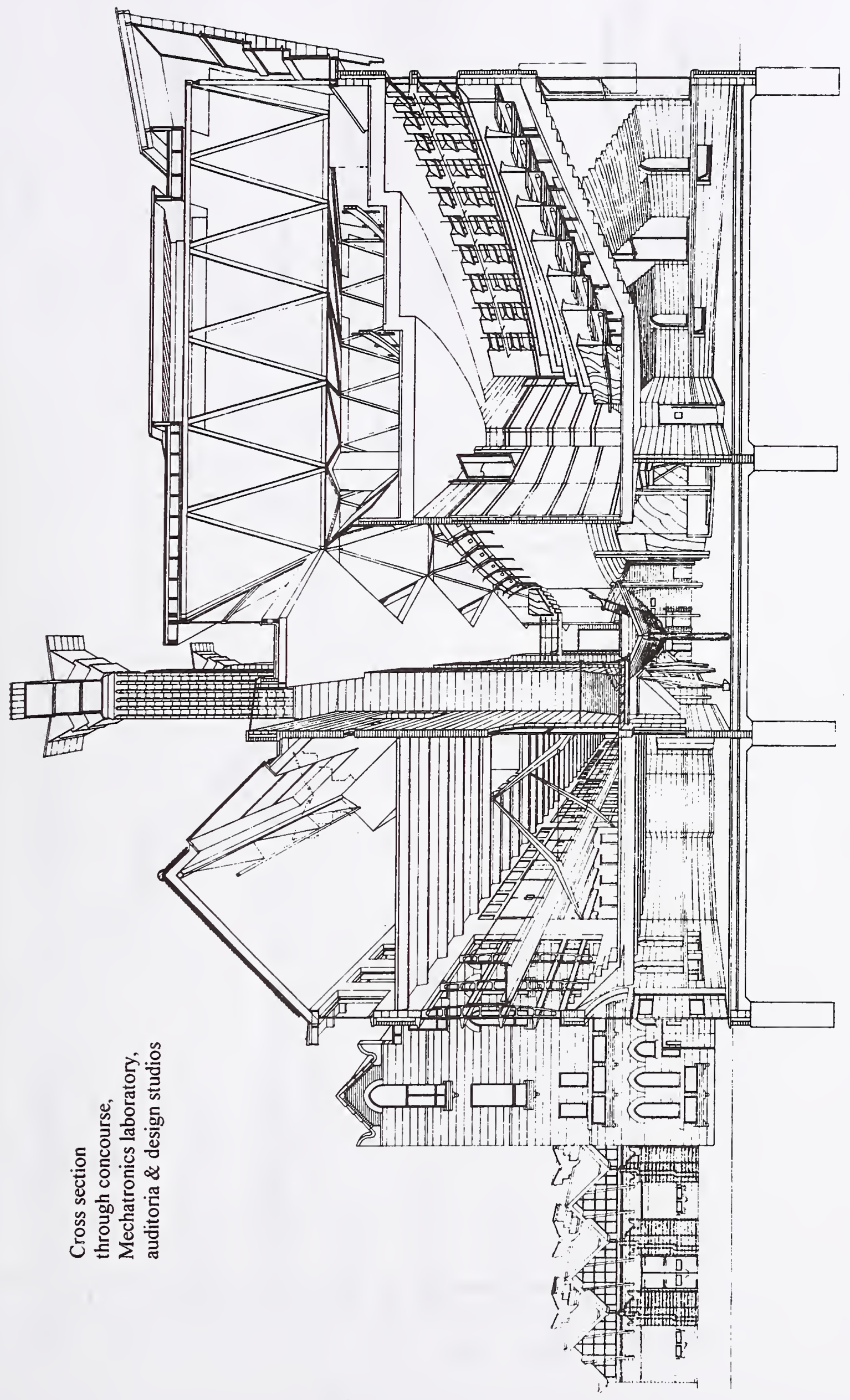


蒡势 음

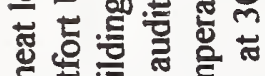
论

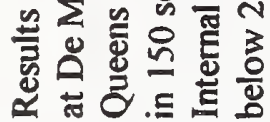
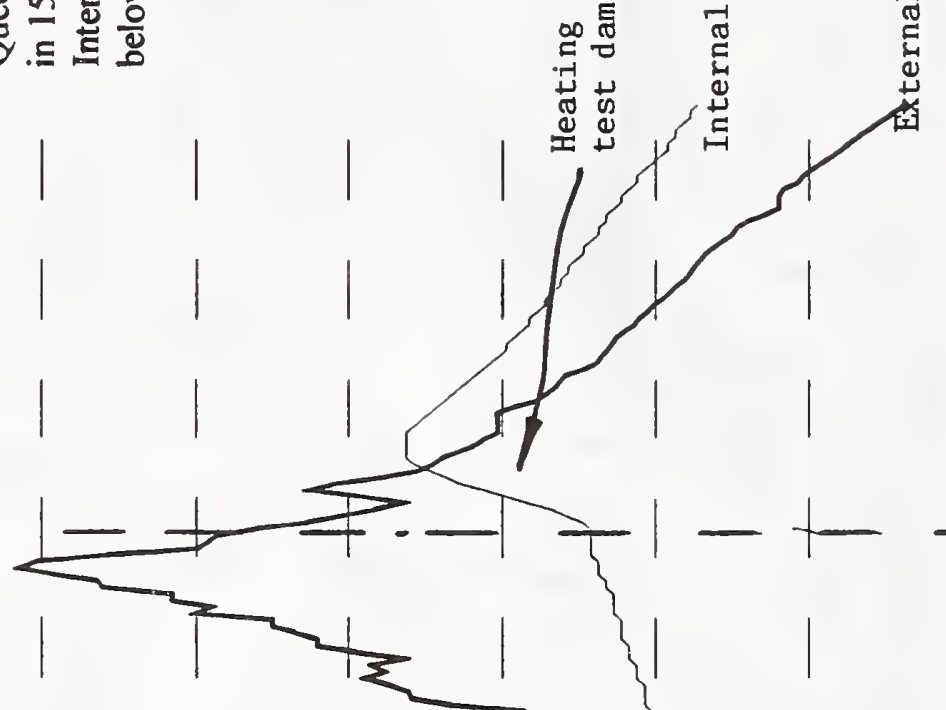

1
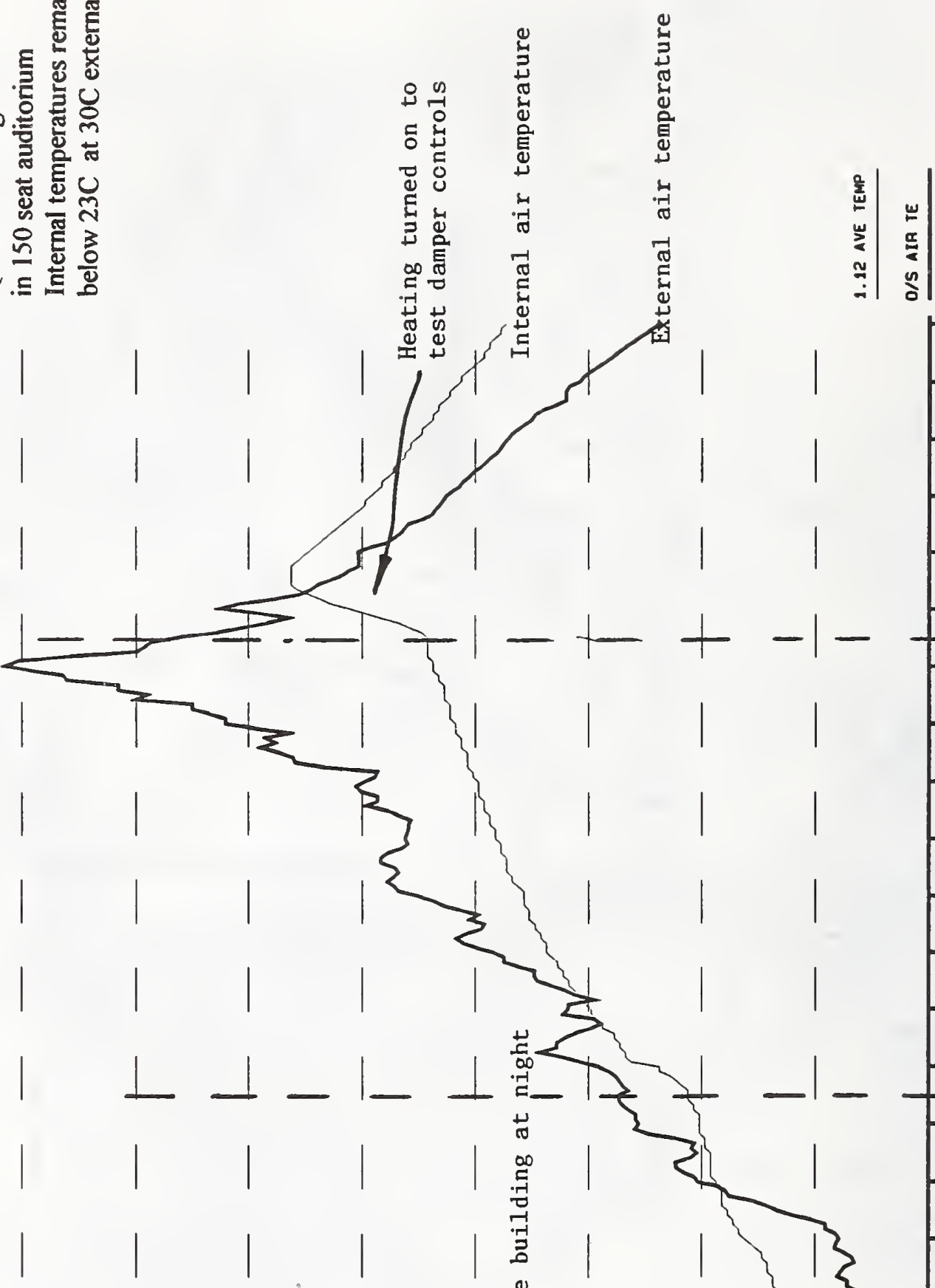

|
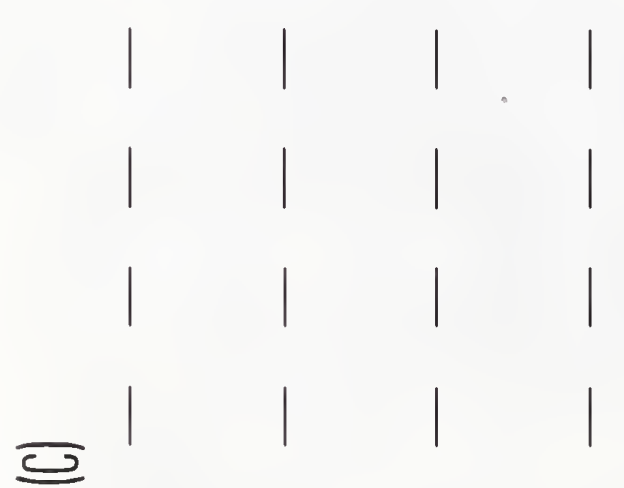

ए?

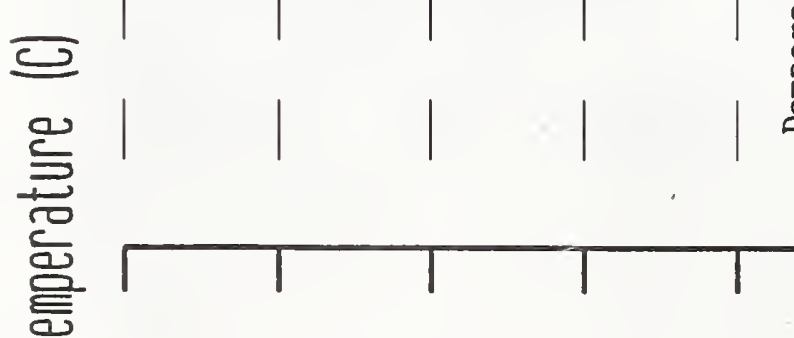

유 


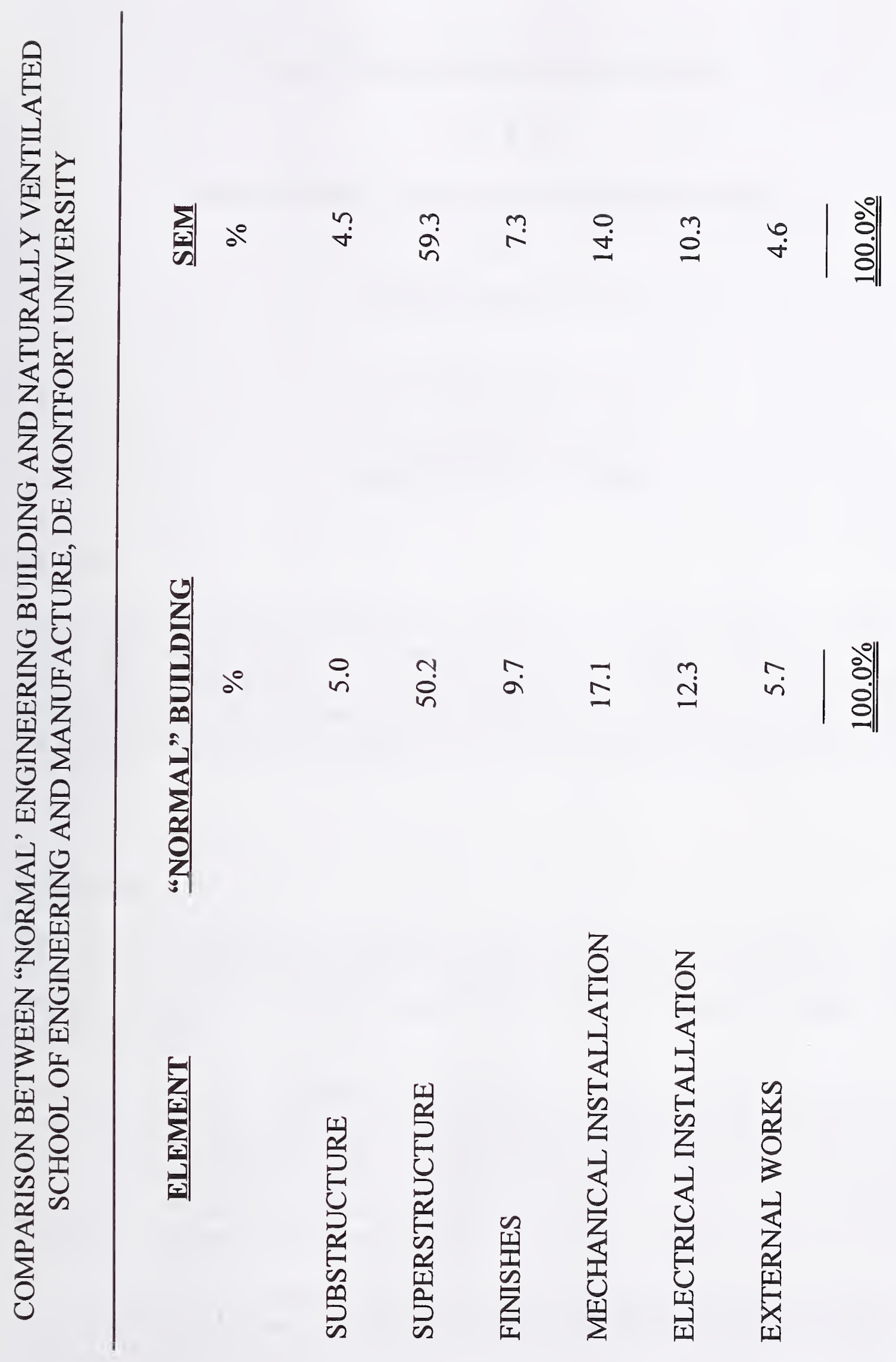





\title{
Environmental Responsibility
}

\section{At The \\ Jean-Michel Cousteau Fiji Islands Resort}

by

\author{
Richard C. Murphy, Ph.D. \\ Jean-Michel Cousteau Institute \\ 1933 Cliff Drive \\ Santa Barbara, California 93109 \\ 805/8998899ph, 8998898fx \\ email -rmurphy000@aol.com ( $0=z e r o)$
}

\begin{abstract}
The Jean-Michel Cousteau Fiji Islands Resort uses the coral reef as a conceptual model for sustainable and responsible design. We use the free services of nature to minimize environmental impact and economic investment. Integrated systems are designed to give guests a high quality environment for mental, spiritual and physical enrichment. Coral reefs, mangroves, rainforests and traditional Fijian culture offer guests a wide range of options for connection to Nature and local people.
\end{abstract}

\section{Introduction}

For most of our 3 million years of evolution we have struggled to survive under the overwhelming forces of nature. Now we seem to have separated ourselves from nature in many ways, both physically and spiritually. This is an illusion! We are very much connected to nature - more than most people realize.

Even though we may not consciously think of it, our fundamental connection to all life and a need to feel this is what drives most of us to travel and seek spiritual, mental and physical restoration in nature. This is a reconnection to our ancestral heritage. In taking the public to islands for over 20 years and offering an opportunity for connection and restoration, we have found a quality setting, and simple yet tasteful amenities are the essential qualities for rejuvenation. Since our origins are with the sea, exploring the underwater wonders is an important ingredient to these experiences.

Our involvement in the Jean-Michel Cousteau Fiji Resort (JMC Fiji) on the island of Vanua Levu is an opportunity to put into practical application many of the things Captain Cousteau has been emphasizing for the last 40 years. 
Our design objectives are to create an environmentally responsible facility which is elegant, yet simple, so as to promote an appreciation of, and connection with, the natural and cultural qualities of Fiji. Diving is superb and we have a full-time marine biologist on staff to guide our guests through the magnificent coral gardens in our front yard. I we hope our facility will become a model for the tourist industry in Fiji and elsewhere.

\section{Design Philosophy}

We take a pragmatic approach to development and environmental protection. Nature has value and as the demand for an experience in nature increases, due to the depletion of natural resources worldwide, so will the value of our facility. Consequently, we must do everything possible to protect our natural resources to insure the highest economic return on our investment. Economic sustainability requires ecological sustainability. This is not a constraint but rather a guiding principle which offers numerous possibilities for those who understand ecology and environmental design. Our design ethic is to use, as much as is possible, the services of nature because nature does work without human input, renews and repairs itself for free, replaces itself for free, adapts to change naturally and runs totally on solar energy. Thus we employ what have been called living machines, biosystems and functional landscapes in our Fiji design. Energy sustainability, integrated food production, water conservation, and waste reduction strategies are be the foundation of our integrated systems.

There are a number of benefits derived from this design approach. People are connected to, rather than separated from nature, visitors see that it is possible to live in harmony with nature and still enjoy a high quality of life, and most importantly, we can demonstrate that environmentally responsible design is practical and economically viable. The fact that it is less expensive to employ environmental systems, than to use traditional approaches, is obvious when one remembers that nature does its work for free.

As we endeavor to minimize ecological impact and design with nature, so we must consider the social environment and implement culturally responsible design. We are very sensitive to the fact that we are guests of the Fijian people and as a member of the regional community we are obliged to accept certain responsibilities. In a very real sense the resort owners and local people are partners in this development, and this has been reflected in the planning process. It is the locals who staff the resort and it is local people with whom we visit in villages or along the beaches. They have much to gain from a well designed program and, as we have seen elsewhere, they have much to lose if their culture is undermined by poor design. For these reasons we have worked very closely with local chiefs and villagers to ensure our facility and activities are compatible with their culture, traditions and aspirations for the future. We have invited them to participate our development and tried to incorporate their suggestions and concerns in the design and operation of our facility. We schedule regular meetings to keep the dialogue open and the exchange of ideas flowing.

Our commitment to environmental design goes beyond the boundaries of the resort. We have established a relationship with the University of the South Pacific in Suva, Fiji to ensure that lessons learned can be shared with students from throughout the South Pacific. We consider this as a demonstration project to educate others about the long-term benefits of responsible design ecologically and economically. In addition, sustainability goes hand in hand with self-sufficiency 
which is critical for communities in isolated areas. The keystone of sustainability and selfsufficiency lies in integrated systems which produce less waste and use what is created in a productive way to minimize the need for external products. We hope to prove what we preach that human beings can have a high quality of life without destroying the natural resource base which supports all activity.

\section{Site Selection}

Environmentally responsible development implies a minimization of human impact on nature. As there is already excessive development in many parts of the world an important challenge is to keep additional development to a minimum and make better use of what already exists. JMC Fiji has taken advantage of an existing facility and revitalized it to meet our standards. We were fortunate to find this facility located on a prime site at the tip of the peninsula directly south of the town of Savusavu and constructed on the theme of a traditional Fijian village. The retrofit process is actually a form of recycling in which existing materials and resources are used and upgraded. It will also involve habitat restoration as certain areas of the coast were mismanaged in the past. The village theme is also critical to our design ethic as it dignifies the cultural heritage and uses design characteristics refined by generations to meet unique Fijian geography and climate. Our recycling/retrofit ethic and respect for local culture will be a key element in demonstrating creative approaches to responsible development.

\section{Construction}

Construction at JMC Fiji is guided by a number of principles: minimize impact on the landscape, use natural materials and systems when possible, use materials fabricated in an environmentally responsible manner, minimize construction waste, and design for flexibility to implement more environmental technologies and systems as they become available.

Landscape management is particularly important at JMC Fiji because of the potential for coastal erosion. In the past mangroves were cut, resulting in erosion. We are restoring the natural landscape so that mangroves can do their job of protecting the coastline as they did in the past.

\section{Energy}

Solar and wind energy systems, with diesel back-up generators, will eventually provide power to JMC Fiji. As the process of retrofit continues the most energy efficient systems will be used. Passive solar design will maximize utilization of nature's free services to condition and cool the air, to heat water and for drying laundry.

\section{Water}

Tropical systems are extremely fine tuned and thus sensitive to perturbation. The coral reef is the most extreme example and thus deserves special attention since protecting the beauty and vitality of the coral reef is essential to our operation. Although reefs suffer from many factors, the impact 
of nutrients and sediments are among the most devastating. The coral reef is adapted to an environment of low nutrients. Increased nutrients stimulate algae to overgrow corals, increase planktonic growth, reduce light to corals, and upset coral physiology. Consequently, the management of domestic waste is critical for coral reef health and vitality.

Consistent with our ethic of designing with nature, we intend to implement an integrated system of constructed wetlands for waste treatment. Treated water will irrigate gardens or "edible landscaping" to keep nutrients cycling within the system. The cycling will revolve from waste to fertilized irrigation water to tropical fruits and vegetables for resort use, ultimately completing the cycle. In this way waste becomes a resource to be used and also protects the reef from pollution.

Such integrated systems have been proven extremely beneficial ecologically and economically. Once constructed they function with minimal human input, run on natural solar energy, repair themselves and adapt as conditions change. They produce useful products and turn damaged landscapes into aesthetic natural habitats and gardens. At JMC Fiji the priorities will be the production of food and natural products such as thatching, and the restoration of natural habitats which invite indigenous birds, and other creatures, back to the resort.

Both the constructed wetlands and multicrop agriculture system will be based on known, tested and demonstrated strategies which are general enough to be replicated elsewhere. As these programs get underway they will be coordinated with the University of the South Pacific so as to insure theory and implementation strategies will be of use to others in the Pacific.

\section{Waste}

Waste minimization and reuse are the foundation of our operations. Gray water, kitchen waste and sewage are considered resources to be utilized for beneficial purposes. Packaging materials have been reduced dramatically through our buying procedures and staff education. Fortunately, the local staff find uses for most cardboard and metal so our waste is primarily limited to plastic which is almost impossible to avoid in packaging of materials purchased from outside. We have gotten the local drinking water distributor to recycle the plastic water bottles used by guests. We have convinced the major paper recycling company in the Suva, the capital, to take work with us. A difficulty is by being efficient our waste stream has become so small it is not economical for recyclers to work with us so we are trying to get the nearby town of Savusavu to become part of our recycling program to get the volume up to something interesting to the recycling company.

\section{Operations}

It is essential that all the staff understand the environmental ethic of JMC Fiji and how to operate and maintain the resort according to this ethic. Regular staff education seminars are conducted. Here the challenge is that the locals associate luxury with waste so they think we are a bit strange to have a nice facility and then want to scrimp and save on things. I remind them that this is what they do in the village but they say, "Of course, we do at home but you have money and don't have to worry about such things." It is a challenging process to make-up for all the bad examples the outside world has conveyed to these people about luxury and quality of life. 


\section{Conservation practices at JMC Fiji}

\section{Nature}

- a full time marine biologist is dedicated to interpreting the reefs, mangroves and forest for visitors, this person presents evening lectures as well

- all visitors receive a brief orientation soon after arrival and are instructed in ways to minimize their impact on the environment and local culture

- interpretation panels are provided for guests about diving and walking along the shoreline and the critters they may encounter

- construction is kept to a minimum and we try not to impair scenic vistas of the sea

- collecting of shells, even empty ones, and other sea life is forbidden

- all divers are given training in ecological diving by the JM Cousteau dive master before entering the water

- all dive sites have moorings to prevent damage from boat anchors dive sites are rotated to control visitor impact

- $\quad$ some dive sites are held in reserve for rest and recuperation from past diver impact

- certain dive sites of particular vulnerability will be dived only by experienced divers well versed in the techniques of ecodiving

\section{Chemicals}

- photographic processing chemicals are chemically rendered inert and the silver is extracted and sent back to the USA for reuse

- no toxic pesticides (long-lived chlorinated hydrocarbons) or chemical fertilizers used on the landscape

- all cleaning products are non-toxic (soaps, cleaning sprays, detergents, kitchen products, etc.)

- no aerosols will be used which contain CFC or HCFC

\section{Environmental products}

- $\quad$ artifacts are not sold that come from animals or endangered species

\section{Tranquillity}

- neither televisions nor radios are provided in the bures to encourage appreciation of the natural beauty of the setting

\section{Health}

- $\quad$ facilities for handicapped people will be provided

- food is purchased from local growers whenever possible

- a demonstration program of constructed wetlands and gardens will be used to encourage local people to create organic gardens with the resort as a stable buyer

\section{Local culture}

- $\quad$ guests are instructed as to proper etiquette and a respect for Fijian culture

- as many products as possible are purchased from local vendors to support the regional economy

- over $90 \%$ of the staff are local Fijian, including one of the two managers 


\section{Improvement}

- an expert in environmental technologies and systems is retained to constantly monitor advances and offer suggestions for improvement

- regular staff meetings are convened to review and improve environmentally sound operations

- guests are invited to offer suggestions for improvements

\section{Scientific Research and Education}

The foundation of knowledge on which sustainable management is based comes from scientific research. We cannot protect and manage something we don't understand. Since the environment is the most important aspect of the visitors experience at JMC Fiji we are obliged to insure its protection. Consequently, we are implementing a long-term coral reef monitoring program. Our data is sent to an international enter for reef studies in the Philippines and incorporated into a world-wide monitoring system to asses health and vitality of coral reefs.

Before contact with Europeans, Fijians traditionally used the marine and terrestrial resources for a few thousand years without substantially depleting them. Their cultural knowledge is extremely valuable as we seek to achieve respectful and sustainable relationships with our surroundings. Unfortunately, this knowledge is being lost as culture changes due to outside influences. Consequently, we are working with village and government people to promote and revive traditional practices in both the forest and reef environments. We hosted a women's workshop on traditional use of medicinal plants and now have created our own medicine garden on the Resort grounds as a demonstration project for villagers and guests alike.

Students from local schools visit the resort regularly and for talks and nature walks by our naturalist. Our live diver uplink system gives many of them the first views of the ocean world at their doorstep. This program is integrated with the Ministry of Education's environmental educational program to insure our message enhances it's curriculum.

We want each guest who leaves JMC Fiji to be mentally and physically rejuvenated and committed to living more environmentally responsible lives. To this end we have crated a booklet designed to inspire guests to apply some of what they have learned and experienced at the Resort into their own lives back home. This "Guide for Responsible Living" offers case studies on what others have done to live more gently on earth, environmental organizations which one can join or contribute to and a list of publications to guide students, home makers and business people in helping achieve sustainability. 


\section{Conclusion}

If our species is to continue on this planet, we must create new strategies for sustainability. Being at a resort on a remote island in the middle of the ocean offers a microcosm view of the world but in an easier to understand setting. It gives us an opportunity to educate people in a subtle yet concrete manner the benefits of protecting nature and the fact that living responsibly does not mean a reduction in quality of life. Certainly, we don't have all the answers, but we are searching. In addition, we encouraging our guests to participate in this quest for more sustainable ways of organizing our business and personal lives.

We we have tried to create an environment and experience from which our guests will return home physically, mentally and spiritually enriched and charged with a sense of hope that it is possible to live in harmony with the planet.

Richard C. Murphy 



\title{
RIDGEHAVEN GREEN BUILDING DEMONSTRATION PROJECT
}

\author{
Charles Angyal, AIA \\ Chief Architect, New Business Development Services \\ San Diego Gas \& Electric
}

Ahstract. Creating a green building on a budget is a challenging prospect. The City of San Diego's Environmental Services Department has successfully met this challenge in their new offices on Ridgehaven Court. In this renovation project, they emphasized the importance of longterm operating and maintenance costs, environmental protection and worker comfort and health. The integrated design team of architects, engineers, and specialized energy and environmental consultants, together created an award winning building embodying sustainable design, energy efficiency and economic innovation. This green building demonstration project now serves as a teaching and learning tool for the surrounding metropolitan community and a catalyst for further strides towards sustainable design nationwide.

\section{Introduction}

Nothing about the three-story office building on Ridgehaven Court in San Diego looks particularly unusual. The 73,020-square-foot commercial structure typifies developments of the 1980 's, when low first costs of materials and systems took precedence over long-term operating, environmental, and maintenance costs.

But when the City of San Diego's Environmental Services Department (ESD) chose the Ridgehaven building as its new home, the Mayor of San Diego, the Director of the ESD, and San Diego Gas \& Electric pushed for energy efficiency and other environmentally sustainable criteria in the renovation. That idea guided the many participants in a "green building" demonstration project that has drawn national interest.

This project proves that any city could have a green building on a limited budget. According to the entry that won the AIA / SDG\&E Savings Through Design award, the estimated construction cost of the $\$ 37$ per square foot for both the base building improvements and new tenant work falls within a range typical of municipal remodels.

\section{Energy Use in Lowest 10 Percent}

However, the project is anything but typical in terms of energy use. Based upon DOE-2 (Department of Energy) computer simulations projecting performance of upgraded mechanical and electrical systems, the Ridgehaven building is expected to consume between 8.5 and 10 kilowatt-hours per square foot per year, putting it into the lowest 10 percent of commercial energy users in San Diego County. That works out to energy savings of approximately $\$ 66,000$ per year compared to the 15 year-old building's historical annual bill of over $\$ 125,000$. 


\section{HVAC System}

A wide spectrum of energy-efficiency measures are included in the Ridgehaven project to help cut utility costs by over $50 \%$. The mechanical engineer chose to modify the water-source heat pumps system used for heating, ventilating and air conditioning. This type of HVAC system has been considered economical due to its low first cost, but it has a high operating cost. Through technological advances and with some innovative thinking, the team turned this system into an economical operating system.

The plan to reuse some parts of the existing system, such as the boilers, and replace motors on pumps produced a virtually new, high-performance system of the same type. Features of the new energy saving system include:

- High-efficiency water source heat pumps with an EER of 14.9 (32 percent more efficient than the current industry standard).

- Heat pump/condenser water isolation valves, which save pumping energy by diverting condenser water around the heat pump if the compressor does not require cooling.

- An adjustable speed drive (ASD) for condenser water pumps. The ASD senses the reduced need for pumping energy as the number of isolation valves going to the closed position increases.

- New radial fiberglass cooling towers that use a two-speed, 5 horsepower fan motor in lieu of the original 15 horsepower fan motor.

- A direct digital control system to optimize all equipment performance and control.

- An experimental "floating loop controller" recently developed by the Electric Power Research Institute (EPRI) allowing the condenser water temperature to float within prescribed limits. The limits are dynamic, based upon a simultaneous analysis of current ambient conditions in conjunction with time-corresponding building performance. The controller could save up to 5 percent of cooling tower energy.

\section{Lighting Design}

The design of the lighting system is another key area in which the Ridgehaven building will accrue energy savings. Lighting specifications call for 0.78 connected watts per square foot - a net reduction of 52 percent from levels allowed by California's Title 24 energy standards.

Key components that were used to achieve this included T8 fluorescent lamps, electronic dimming ballasts, $2 \times 4$ deep parabolic fixtures, reflectors, occupancy sensors for each room, daylight savings sensors in perimeter rooms with exterior windows, lumen maintenance control devices in core areas not subject to daylight, and photo cells. Energy-efficient task lighting at workstations will reduce the general area lighting requirement in the open office environment.

In addition to increasing comfort, the lighting design offers ongoing net savings for 10 to 20 years after the initial installation cost is recovered in three to five years. Another bonus, the lower lighting loads will decrease cooling requirements. Mechanical equipment sizing is also reduced by 
the use of anti-solar window film with a shading coefficient of 0.34 , which limits solar gain into the building.

\section{Original Vision}

Energy Efficiency was just one element of this lean, green design model. The vision of the Mayor and the Environmental Services Department included providing the department staff with an environmentally sound workplace while providing the city as a whole with a model for appropriate design in this day and age. The real struggle was to bring these lofty goals into conformance with an ever-shrinking municipal budget. After persuading the city to purchase the $\$ 3$ million building, the project team came up with a set of objectives that demonstrate the original vision. The criteria included:

- Using construction materials that are least toxic and least carcinogenic. Materials also were chosen with minimized volatile organic compounds (VOC) emissions and potential for growth of mold, mildew and bacteria to protect indoor air quality.

- Selecting construction materials to have substantial recycled content, to be recyclable themselves or, in the case of virgin materials, to be renewable or sustainably produced. Contractors were required to show receipts documenting the reuse or recycling of materials removed from the building during remodeling.

- Modifying the HVAC system to provide high-quality indoor air, prevent the growth and transmission of molds and bacteria, and minimize the circulation of VOCs. If nothing else, good indoor air quality helps increase worker productivity by having fewer absences due to sickness.

- Using construction methods compatible with the goals set for the building.

\section{Many Contributors}

To fully realize the Ridgehaven project's potential, many people contributed to the effort. The project's Architectural and Engineering team included:

Platt/Whitelaw Architects, Inc. - Architects

Jackie Lu, Project Architect

Lynn Froeschle, AIA - Environmental Consulting Architect

Lynn Froeschle, Environmental Consultant

McParlane \& Associates, Inc. - Consulting Mechanical Engineering

Mitch Hart, Project Engineer

Turpin \& Rattan Engineering, Inc. - Consulting Electrical Engineers

Pervez Mobin, Project Engineers 
The environmental consulting architect did extensive research and analysis of materials to meet the green guidelines set forth for the project. The carpeting, for example, was chosen for its significant recycled content, its low VOC emissions and its tile-size sections that can be replaced easily in minimal quantities, reducing future rehabilitation costs. These carpet tiles will be rotated, so that the entire carpet will last longer than one continuous piece of carpet that can't be moved. The carpeting also reflects creative budgeting. It will be leased form the manufacturer under an innovative "evergreen lease," only the second such arrangement in the U.S. at the time, so it is considered an operational cost rather than construction cost. The manufacturer will rotate, maintain, and replace it over the lease term. Innovative materials selections were just one of the significant contributions made by including this specialized consultant on the design team.

Another major contributor to the project was Gottfried Technology, Inc., an environmental technology and consulting firm. In conjunction with it's subcontractor, Flack \& Kurtz Engineers, Gottfried Technology used the complex DOE-2 software to project the building's energy performance under different design scenarios, then cost out and rank the energy-savings opportunities. SDG\&E provided further analysis of the building's potential with an eye toward giving cash incentives and financing for energy-efficient mechanical and electrical measures.

\section{Partnership Program}

Gottfried Technology also created a partnership program for the city. Through this program, Ridgehaven will showcase manufacturers and others who are donating or discounting products and services for use in the renovation. Educational exhibits by participating partners will be set up in an environmental display area open to the public, along with a resource library that includes information on green construction, resource conservation and energy efficiency. SDG\&E and EPRI are a few of the major supporting partners.

\section{Conclusion}

To promote green building on a budget to other local governmental agencies and utilities nationwide, Gottfried Technology has prepared a case study, available from the Environmental Services Department, that discusses the process in full. It is evident that green development is surging across the country. Projects such as Ridgehaven serve as a catalyst for this design direction, and as practical, economical example of how to make it work. 


\title{
BUILDING DURACELL'S NEW CORPORATE HEADQUARTERS AN ENVIRONMENTAL SUCCESS STORY
}

\author{
Glenn R. Machemer, Manager \\ Facilities Planning \\ Duracell Inc. \\ Berkshire Corporate Park \\ Bethel, CT 06801
}

\begin{abstract}
In November 1995, Duracell employees moved into our new worldwide headquarters in Bethel, Conneticut. The goals, methodology of how a 44 acre natural site was developed in a sustainable manner; the story of how a building was designed to use energy efficiently and was constructed with recycled materials; and the story of cooperation among a team of employees, senior management, the project team and conservation groups is described. This is the story of how the new headquarters has become a symbol of Duracell's worldwide environmental commitment.
\end{abstract}

\section{Project Goals}

Duracell is committed to becoming an environmental leader in the worldwide consumer battery industry. Accordingly, a goal was established to incorporate the principles of sustainable development into the new headquarters.

This commitment is reflected in the following comments:

"I wanted to ensure that we did not end up with the standard corporate headquarters of a gray monolith with tinted glass set in immaculately manicured lawns with no sensitivity or relationship to the surrounding environment. It was particularly important that as the building matures it should grow old gracefully, integrating with the environment in which it resides." Wade Lewis, Senior VP and Chief Financial Officer

"The architecture (of this complex) is the trees." Herbert S. Newman, Chief Architect

"On June 8, 1993, I conducted a comprehensive survey of the site with the Project Manager and members of the Ecology Task Force. Later, I presented Duracell with a proposed habitat plan. The plan, which called for not only preserving - but enhancing - wildlife was largely implemented over the next 3 years." Darlene Pais, Biologist, Wildlife Habitat Council (WHC) 


\section{Strategies}

In order to embody sustainable development principles into the new headquarters, a project team was assembled (refer to an organizational chart). Strategies were developed and organized into twelve groups: site design, natural planting and landscaping, habitat and wildlife, storm water runoff, architectural design, construction waste management, building materials, energy conservation, water conservation, preparing for the move, waste management, and employee safety.

\section{Site Design}

\section{Objectives}

To minimize the impact of the new corporate office facility on the environment.

To manage the storm water run-off in a manner which will provide wildlife, vegetation and employee benefits; and

To enhance the property's landscape through the preservation of native vegetation, the creation of meadows in open areas and along roads, and the design of wildlife gardens to attract songbirds, hummingbirds, and butterflies.

\section{Results}

The building location on the 44 acre site was selected primarily because of its general topography. The location was the flattest area of the property and straddled a small ridge. Prior to Duracell's selection of this site, one area had been disrupted to create a helicopter landing area. This was the largest area on the site which was already void of trees and other vegetation. Therefore, this site was selected because it required the least regrading, the least additional disruption to existing drainage patterns and the least encroachment on existing woodlands.

In order to minimize the disturbance to mature woodlands and to wildlife habitats, the following actions were taken: The siting of the actual building location was adjusted slightly into the open areas to the east;

Roadway alignments were changed;

The ridge line to the west of the complex which served as a wildlife trail was preserved;

The service access of the building was relocated to the north side in order to take advantage of the flatter areas and to minimize disturbance to the site for both the loading area and the service drive; 
Areas of woodlands that were cut off from surrounding forest by roadways and/or buildings were kept as large as possible in order to mitigate against the effects of forest fragmentation; and

The property wetlands were not disturbed. Protecting these sensitive ecological areas required the project team to perform multiple building siting layout and grading analyses.

Refer to chart on Page for description of site following development.

\section{Natural Planting and Landscaping}

\section{Objectives}

To preserve as many mature trees as possible in order to maintain the surrounding woodland habitat.

To preserve plant wildlife in order to promote opportunities for wildlife forage and shelter.

\section{Results}

Trees were preserved throughout much of the site during construction, including along the entry roadway, within the circular drop-off area and immediately adjacent to the building to the north and northwest. The project team was also able to maintain greater tree coverage around the parking structure because of greater distances to roadways and more rapid transitions of building levels. Some shading of the parking structure was also achieved.

Protecting the bark and structure of the trees and the prevention of soil compaction around their roots during construction were critical design objectives. In addition, tree protection fencing was utilized in all areas of woodlands that were to be preserved.

Both the size and alignments of utility corridors were adjusted in order to preserve specific native vegetation.

Trees that had to be removed were recycled either as fire wood which was given to employees or as wood chips for use on nature trails to minimize compaction and erosion. Economic incentives for preservation were incorporated into the design team's construction specifications; therefore, penalties were levied if damages occurred to designated trees or other vegetation.

Native, water tolerant plants were utilized in wetland areas and around drainage basins in order to emphasize opportunities for forage and shelter. 
Meadow grasses were used rather than turf in open areas and along the road sides in order to benefit wildlife, and to avoid acres of grass that would require chemical fertilizers, watering and energy-intensive maintenance.

In the selection of grasses, special attention was given to enhancing the habitat for the wild turkey that populate the site.

A distinctive quality of the site prior to development was the absence of understory plants. A minimum number of small trees, shrubs, and herbaceous plants were disturbed. These were replanted onto the site at the newly created forest edge as one would expect to find in naturally occurring woodlands transition zones.

Seven new trees were planted adjacent to the parking garage in order to celebrate Duracell's worldwide Green Teams.

\section{Habitat and Wildlife}

\section{Objectives}

To preserve the natural habitat;

To build awareness of environmental issues, including wildlife resources;

To serve as a model for others who wish to preserve the habitat in new construction projects;

To develop a comprehensive management plan that focuses on enhancing the land to make it more supportive to native plants and animal species; and

To create educational and recreational opportunities for employees, employee families, visitors, and the local community.

\section{Results}

Habitat Plan: A plan was developed for managing the wildlife and habitat of the site. The plan is administered by a Wildlife Committee which delegates to five project teams. The habitat plan was formed with help from the Wildlife Habitat Council (WHC, and other local wildlife groups.)

Wildlife Committee: The site is managed by a Wildlife Committee. The Committee is responsible for implementing and maintaining the overall habitat plan and for coordinating all nature projecis. It consists of seven to eight members and meets monthly or every other month. Goals are to improve upon the wildlife plantings, manage the right-of-way, and maintain a suitable habitat for wildlife. In addition, 
the Committee coordinates with local groups such as Ducks Unlimited, Girl Scouts of America, and Boy Scouts of America.

\section{Storm Water Runoff}

\section{Objective}

To enhance wetlands; and

To protect downstream water quality.

\section{Results}

The site is divided into two drainage basins:

Approximately one-quarter of the site drains to the north through a wetland area in the northwest quadrant. Although the original plan called for the creation of a detention pond, the project team developed a storm water drainage system which allowed water to be detained in the wetlands without the need for such a pond. By having the drainage system located above the wetlands area, the water flows naturally into the wetlands; thereby, resulting in no change in outflow from the site. In this way, the wetlands area has been preserved.

The remainder of the site drains generally to the east toward the adjacent corporate park. There are no wetlands near the bottom of this system in which to drain; therefore, a detention pond was created to avoid any change in surface water outflow from the site. The pond was also designed to serve as a temporary sedimentation basin both during and after construction. Thus, the storm water run-off plan maintained or slightly improved downstream water quality.

The planting around the detention pond utilize native, water tolerant plants in order to emphasize the opportunity for forage and shelter for wildlife. In addition, the pond was sited quietly into the natural landscape, thereby maintaining the natural aesthetics and environment.

\section{Architectural Design}

\section{Objective}

To build a facility that complements the landscape and reinforces the connection between the inhabitants and the site.

\section{Results}

Duracell's decision to build a parking garage rather than develop on-grade parking 
is probably the single most important (and I might add costly) habitat preservation strategy of the project. Approximately, nine acres were saved from development (clear cutting) by utilizing a multi-story garage at a cost of approximately $\$ 7$ million. The 700-car parking area is tucked unobtrusively into the side of a hill. Trees close to the building help shade and cool it, while natural habitats for indigenous wildlife were preserved.

The floor plan for the building was configured in several relatively narrow wings. This approach allowed more flexibility in siting the large building footprint; thereby minimizing disturbance, accommodating the rolling terrain, and preserving special site features. The building perimeter allows windows in all offices, in 75 percent of shared conference spaces, and in a significant proportion of the interior general office space. In addition, the use of floor to ceiling high windows and continuos interior clerestory glazing at the private office/corridor wall allows natural light to reach into the center of each wing.

An arcade connects the parking garage to the building's main entry lobby. It allowed best siting of both the headquarters building and the parking garage while protecting building users from rain and snow. The configuration of the parking garage was adjusted to better respond to the existing slopes. A reduction in the size of the garage was accomplished by obtaining a variance to provide substantially fewer parking spaces than the zoning code required. This action significantly reduced environmental disturbance to the site.

Since the building closely follows topography of the landscape, the impact on drainage patterns is minimal. Also, where roadways traverse slopes and interrupt the existing surface run-off patterns, storm drainage systems have been designed to maintain original watersheds.

A partial fourth level was added to the northwest wing of the main building to make it more closely follow the existing terrain.

\section{Construction Waste Management}

\section{Objectives}

To properly manage all construction waste material including recycling of unavoidable waste.

\section{Results}

All salvageable scrap metal was collected and sold for reclamation. Refuse (e.g., cardboard, wood, metal) was separated and recycled. All tree wells and the stone wall behind the dining area were created from on-site material. Approximately 8,000 cubic yards of blasted rock were collected and used as structural fill. 


\section{Building Materials}

\section{Objectives}

To maximize the number of building materials containing recycled content (minimum of 50 percent);

To minimize the use of hazardous materials used in construction;

To minimize the negative effects of building materials on employee health and safety.

\section{Results}

The New Building Ecology Task Force set a goal at the beginning of the project to ensure that a minimum of 50 percent of all building materials, both interior and exterior construction, must contain some recycled content.

At the end of the project, 50.8 percent of all building materials contained some amount of recycled content. The incremental cost was approximately $\$ 200,000$. Examples of materials with recycled content include:

floor tiles containing 70 to 100 percent recycled glass (including crushed light bulbs;

partitions in restrooms made from recycled plastic;

recycled steel in the superstructure, 25 percent of which is recycled from such sources as automobiles and demolished buildings;

water main piping, containing 50 percent recycled steel;

all paving material containing recycled asphalt;

acoustical ceiling made from recycled newsprint, wood fibers and wool; and roofing shingles containing 95 percent recycled aluminum;

One recycled material used in the new building deserves special recognition. Byproducts from Duracell's manufacturing process in Lexington, North Carolina were used in the bricks that cover the exterior of the headquarters building. The bricks contain 1.3 percent (by weight) of scrap manganese dioxide powder. This powder, which is an important raw material in Duracell's batteries, gives the brick their dark color. Duracell began sending waste manganese powder to brick makers several 
years ago and currently sends approximately 460,000 pounds per year to brick makers in North Carolina and in Belgium. Cunningham Brick Company of Lexington, North Carolina and Cherokee Sanford Brick of Sanford, North Carolina used approximately 5,400 pounds of scrap manganese in supplying over 400,000 bricks for the new headquarters.

In order to minimize any off-gassing of hazardous chemicals into the new building, the following materials were used during construction:

Low volatile organic compound (VOC) paints;

Water based adhesives; and

Carpets made of stable recycled plastic with natural fiber backings.

A concerted effort was made to use a non-fiberglass insulation material in the external walls.

Numerous fiberglass substitutes were evaluated, including mineral wool, a cottonbased material, a foam material, and a wood pulp product made from recycled newspapers; however, none of these materials were able to meet fire, insulating, and physical dimension requirements at an acceptable incremental cost.

As a result, a fiberglass-containing insulation was used. However, two points should be emphasized:

1. Fiberglass-containing insulation was installed in a manner that is safe. It was applied only in the external walls in conjunction with a special plastic barrier that prevents any friable glass fibers from entering the inside of the building.

2. The fiberglass-containing insulation contains recycled materials.

To further ensure optimal working conditions, the design includes:

A high level of air ventilation (e.g., 25 cubic feet per minute per person and 100 percent fresh air make-up when weather permits).

Filtration of all air to remove 90 percent of particulates.

Humidification of all air in the winter.

A very high degree of acoustic attenuation to provide a very quiet environment. 


\section{Energy Conservation}

\section{Objective}

To minimize energy consumption.

\section{Results}

Overall Energy Efficiency: It is estimated that overall annual energy efficiency of the building is 15 to 20 percent better than typical office buildings designed to current national energy standards.

Lighting Control Systems and Occupancy Sensors: Energy saving lighting control systems and occupancy sensors have been installed in the new facility in order to conserve electricity. Occupancy sensors are located in every office and conference room.

Building Automation: The automation system consists of a direct digital control system (DDC) using electrical devices, optimum start/stop and economizer operation. This increases both building and equipment efficiency.

Lighting: The lighting consultant and electrical engineer's design achieved an energy efficiency equivalent of 1.2 watts per square foot. This is very impressive for a building of this type. Typical office buildings generally have energy efficiency equivalents of 2.0 to 2.5 watts per square foot. This was achieved in part through the use of: energy efficient fluorescent lamps and electronic ballast; compact fluorescent lamps; high pressure sodium lamps; metal halide lamps; and low voltage tungsten halogen.

In addition, all lighting complies with the US EPA Green Lights specifications.

Passive Solar Energy: The building has numerous skylights to provide natural lighting and passive solar heating.

Windows: All windows have double paned glass with a low emissivity coating to prevent heat loss in winter, maximize passive sun in winter and minimize cooling loads from direct solar in summer.

Windows have an insulation value of R-3.0, which is over 50 percent better than the R-1.9 ASHRAE standard. This additional insulation is expected to save over $200,000 \mathrm{kWh}$ 's per year.

Insulation: All external walls have vapor seals and an insulation value of R-20, which is approximately 60 percent better than the R-12 ASHRAE standard. This additional insulation is expected to save $37,000 \mathrm{kWh}$ per year. The roof has an 
insulation value of R-20 which complies with ASHRAE energy standards.

Heating/Ventilation/Air Conditioning (HVAC) System: HVAC represents the largest use of electricity for a commercial office building; therefore, the selection of the HVAC represented one of the most critical environmental decisions in the entire project.

Various energy source systems were evaluated including geothermal heat pumps. Such systems involve the circulation of water through pipe wells deep in the ground to harvest the Earth's heat in the winter and cooling in the summer. However, geothermal systems are still an emerging technology. Although a geothermal insulation at our headquarters site appeared to be feasible, this unconventional technology was dropped from consideration due to uncertainties about cost, reliability and applicability of the site.

Following extensive performance modeling and calculations by our project engineers, a gas-powered HVAC system, consisting of two gas fired chillers totaling 900 tons, was selected to provide heating and air conditioning. Compared to an electric chiller system, the gas system had an incremental capital cost of $\$ 300,000$. The gas system was selected for the following reasons:

1. It avoided the use of any ozone-depleting refrigerants (e.g., it fully complies with the Federal Clean Air Act);

2. Although an equivalent electric chiller uses slightly less overall energy, the gas system uses less electricity and therefore has an overall fuel mix with considerably less environmental impact (e.g., emits less pollutants). By using gas instead of electricity for cooling in the summer, the following emissions are avoided each year:

284,922 pounds of carbon dioxide;

5,280 pounds of sulfur dioxide;

497 pounds of nitric oxides;

1,077 pounds of methane;

5.7 pounds of load; and

304 pounds of airborne particulates.

It should be noted that the above data was given to Duracell by Northeast Utilities in October of 1993. 
3. Fuel costs are less with gas due to special incentive rates. For example, the electric chiller would use expensive electricity in the summer while the gas system uses inexpensive gas in the summer resulting in major cost savings HVAC Fans \& Motors: All supply and return air fans use premium efficiency motors and fans, with the exception of several small constant volume units, use energy efficient variable speed motors.

Air Distribution and Waste Heat Recovery: Conditioned air is distributed by ceiling hung, fan-powered terminal boxes. These distribute variable quantities of cold air mixed with warmer ceiling plenum air to provide proper temperature and ventilation year round to each zone. Waste heat from lights in the ceiling plenum is mixed with primary air to warm perimeter zones in winter before the supplemental gas boilers and hot water coils turned on. This minimizes the use of fossil fuels and improves the building energy efficiency.

By participating in the Energy Conscious Construction (ECC) Program, Duracell received approximately $\$ 300,000$ of rebates from Northeast Utilities. These energy conservation measures are projected to save annually approximately $\$ 125,000$ of energy costs.

\section{Water Conservation}

\section{Objectives}

To minimize water use and water discharges; and

To minimize contaminants in waste water.

\section{Results:}

Native landscape plantings were used which require substantially less watering than typical non-native ground coverings.

A special water filtration system will be installed in early 1997 which will remove trace impurities from incoming city water. By removing these impurities, water and energy usage involved with maintenance of all building operations and equipment (including the HVAC) will be decreased.

Where practical, a limited number of "low flow" bathroom fixtures were installed. (Such fixtures require much less water than standard fixtures). 


\section{Preparing for the Move}

\section{Objective}

To maximize recycling of files, paper and other supplies prior to moving into the new headquarters

To conserve resources.

\section{Results}

Since over 600 Duracell employees moved from six leased office buildings in the adjacent corporate office park, our Bethel Green Team launched a major effort to discard and recycle all unnecessary files and supplies prior to the move. Three halfday "file flings" were held at which hundreds of employees struggled through mountains of files! The results were impressive:

Approximately $\$ 200,000$ of used office furniture was distributed to community charities, such as schools and service organizations. Some items were also donated to municipal offices.

160 tons of office material was recycled in preparation for the move, which is equivalent to 2,714 trees. The total is broken down as follows:

Day-to-day, office paper recycling: 121 tons (2,061 trees)

Special "file flings": 31 tons (525 trees)

Archives: 8 tons (128 trees)

Approximately $\$ 16,000$ was saved on mover fees as a result of the file flings.

\section{Waste Management - Post Move-In}

\section{Objectives}

To maximize recycling;

To minimize the amount of waste generated; and

To conserve natural resources.

\section{Results}

Pantries: To facilitate recycling, several pantries are located on each floor. Each pantry has three recycling chutes: one for trash (such as food material); one for 
metal; and one for glass. The chutes flow into an adjacent recycling room which is used to sort and store collectibles.

Cafeteria: With only few exceptions, paper products (plates and cups) used in the dining and pantries have been replaced with permanent products which can be washed and reused. For example, by converting to plastic take-out trays, over 1,000 cardboard trays have been eliminated every week.

Offices: Each is office is equipped with its own recycling bin with daily pick-up of trash provided. The unique "Copper Top" recycling bins were designed, ordered, assembled and distributed by the Bethel Green Team. Over 900 of these bins are now located throughout the building. Daily pick-up from the collection bins is performed by clients of DATAHR, a Danbury, Connecticut rehabilitation center for physically and mentally challenged people. As a result of the Green Team recycling program, two DATAHR employees have been provided with full-time employment.

\section{Employee Safety}

\section{Objectives}

To achieve "zero accidents" during the building construction.

\section{Results}

The construction project involved employees from 40 subcontractor companies, working a total of 480,000 hours over a period of 18.5 months.

A total of eight lost time injuries occurred which is an "OSHA Lost Work Day Case Rate" of 3.2. All of these accidents were minor injuries, the most serious being a sprained ankle.

This means that approximately 3 lost time accidents occurred for each 100 construction employees working an equivalent of one year. For comparison, according to the US Bureau of Labor Statistics, general building contractors have an average "OSHA Lost Work Day Case Rate" of 5.6. Thus, the lost time accident rate during the construction of the Duracell Headquarters was over 40 percent lower than the national average for construction workers.

Although we did not meet our "zero" accident goal, we are proud of our safety record. The low number of lost time accidents was the result of a high degree of safety awareness among workers and supervisors. Regular safety meetings were held throughout the project. 


\section{CONCLUSION}

We feel our project is an exciting example of sustainable design. The environmental planning took into account the total life cycle of building materials and technologies including production, transport to the site, energy use, operating cost impacts and the effect on occupants. And I might add that now that the project is completed, the wild turkeys have returned. 


\author{
PROTOCOL DEVELOPMENT FOR ASSESSING THE \\ ANCILLARY BENEFITS OF GREEN BUILDINGS: \\ A CASE STUDY USING THE MSQA BUILDING \\ James A. Wise, Ph.D., Human Factors Scientist \\ Judith Heerwagen, Ph.D., Environmental Psychologist \\ David B. Lantrip, Ph.D., Environmental Planner, Architect \\ Michael Ivanovich, Environmental Engineer \\ Pacific Northwest National Laboratory \\ Battelle Seattle Research Center \\ Seattle, WA 98105
}

Abstract. Widespread anecdotal reports and some focused evaluations have indicated that "green" buildings may be as beneficial to their occupants as to the environment. These are purported ancillary benefits beyond the expected energy and operational savings, and take the form of improved health, morale and well being for occupants, along with enhanced human performance that may increase productivity. Such benefits could be significantly higher than those from energy savings alone. The Department of Energy, in cooperation with Herman Miller corporation and the Green Building Council, is undertaking a multi-year quasiexperimental study to develop benefits measures and assessment techniques utilizing a new 'green' building --the MSQA facility. This combines office, manufacturing and shipping and receiving functions in a $200 \mathrm{Kft} 2$ building in western Michigan. This paper reviews the organization of the study, its' rationale, and progress to date in creating a protocol to assess ancillary benefits of green buildings. Building assessment results will be presented at the USGBC conference session.

\title{
Introduction
}

The U.S. Department of Energy's Office of Building Technologies (DOE-OBT) has tasked Pacific Northwest National Laboratory (PNNL) to develop a scientifically credible protocol for identifying and assessing potential ancillary benefits of "Green" Buildings. These are benefits that may accrue to owners, operators, occupants and others that are different from traditional benefits such as energy efficiency and cost savings. Such benefits have been reported mostly as anecdotal information or highly focused investigations, and have been attributed to improvements in occupant, health, morale, well-being and performance that are induced by Green Building conditions or features. But there is currently no overall theoretical model explaining or predicting such benefits, nor is there sufficient empirical evidence to substantially confirm a general benefits condition. An earlier study performed for OBT [1] on purported ancillary benefits from energy efficient lighting retrofits at Boeing manufacturing plants in the northwest was suggestive of such benefits, but inconclusive due to other significant organizational and personnel changes that had occurred within Boeing during the same time period as the retrofits.

Another difficulty for assessing benefits is that there has been no formal definition in the architecture and building professions of what constitutes a "Green Building." Rather, there have 
been (increasingly) more building projects that incorporate environmentally or energy conscious features of different kinds. There are "shades of green", as it were, in how buildings may be regarded. Our benefits study does not attempt to provide a universally accepted definition because such efforts are currently under way within the U.S. Green Building Council and American Society for Testing and Materials (ASTM) standards committees. Rather, this study selected a building as an exemplar because it has a large number of the "green" characteristics normally associated with such projects, and because the owner and design and construction team had committed themselves to a Green Building from its inception. A paper in last year's Green Building Conference Proceedings [2] provides a full description and background brief on the selection of the Miller SQA building and that company's business. For convenience, background information on Miller SQA and their buildings is summarized below.

The building chosen for development and test of a benefits protocol is a new multi-purpose facility for Miller SQA, a subsidiary of Herman Miller Inc that is a combined plant, office, and warehouse building in a naturalistic setting. The chief architect of the new Miller SQA building is William McDonough and Partners, who are architectural leaders in the Green Buildings field. The landscape architect firm is Pollack Design Associates, with a history of landscaping with native vegetation. Herman Miller Inc, Miller SQA, William McDonough and Partners, and Pollack Design Associates have been instrumental in the success of this research project by providing access to design and construction specifications of the new building, in studies of the old Miller SQA building, and to the historical information that will enable refinement of the protocol as it is being developed.

Miller SQA is a fast-growing re-manufacturer, manufacturer, and vendor of office furniture that has been in business for approximately 10 years. Miller SQA has a niche market providing "just in time" products for small businesses and nonprofit institutions. Miller SQA has a total quality metrics (TQM) program that generates performance data which is used to help make business decisions and to inspire staff in the manufacturing plant. The plant operates in three full-time shifts. Other performance data, such as errors in orders, delivery faults, and accidents are tracked through other internal programs. Employee health and safety records are kept and are being made available to this study, as are energy consumption data and other operations and maintenance (O\&M) statistics. Approximately one year of consistent, historical data and information are currently available for this study as is future operating information throughout its duration.

Miller SQA formerly leased space in a building that we call the "baseline building", and they own their new "green' building, which they occupied in October of 1995. A partial list of the new building features that are "green" includes these features of lighting and heating, ventilating and air conditioning (HVAC) systems:

- Air turners (requiring no ducting) used in plant area instead of centralized heating system

- High-efficiency (89\%) filters installed in the air turners in plant area

- $45 \%$ filters used in office areas (exceeds the A.SHRAE 62-1989 ventilation standard)

- High-polluting plant tasks located on "exhaust-side" of building downstream of inlet

- Hydronic floors on window-side of office-side of building to dampen transients 
- Peak-shaving efforts will be made through HVAC direct digital controls

- Twelve levels of control available in screw chillers

- Generous use of daylighting throughout plant and warehouse areas

- Lighting levels modulated automatically using photosensitive controllers

In addition, the facility is finished with low VOC emitting materials and finishes, has direct access to a surrounding outdoor site that is landscaped with natural vegetation, ponds and wetlands to control water runoff, and enjoys outstanding view access to the outdoors from most places inside.

In most all respects, then, the MSQA building fulfills what is generally expected in the features of a "green building". The protocol under development in this study is not concerned with how 'green' the MSQA building is, but rather, given that it is 'green' in various features and operating functions, how do these get transformed into ancillary benefits of the type that have been reported elsewhere, and how can those benefits be scientifically assessed?

\section{Green Building Benefits}

We began this study by examining the nature of benefits that were being reported and to what aspects of green buildings they have been attributed. We then identified and prioritized underlying elements of Green Building characteristics in how the building's design and construction might accrue to

- its occupants,

- the outdoor environment, in general (including energy),

- its community,

- its owners.

We chose to focus primarily on the first one because within this category are the topics of worker performance (productivity), energy efficiency, indoor air quality, pollution prevention, and interior lighting that figure prominently in discussions on Green Buildings. It is also the impacts on people (occupants) that are the least understood in the arena of Green Buildings, and that have potentially the highest multiplier effect when it comes to assessing the true worth of 'green' or 'sustainable' design.

With this simplification, a research framework for the Green Buildings Benefits Study was derived from theoretical considerations in biological psychology and habitat selection. The framework breaks the project down primarily into environmental qualities that have demonstrated consequences for human performance and well being. These are interior air quality, the thermal environment, the luminous environment, the acoustic environment, spatial orders and territories, viewscapes, haptic (touch) qualities, and meaning and symbolism in setting features.

The framework is predicated on the supposition that buildings are habitats for people, and that building features and qualities of the environments they create can be framed within the context of preferred habitats. Humans are biological creatures, genetically adapted to the kinds of natural conditions that proved so accommodating to early Man. Work by E.O. Wilson $[3,4]$ and Orians 
and Heerwagen $[5,6]$ suggest that modern environmental preferences derive from the behavioral, physiological, and psychological adaptations of our hunting and gathering ancestors in natural environments. For instance, Wilson's "Biophilia Hypothesis" [3] proposes that human evolution in an "outdoor" world created brain structures attuned to extracting, processing, and evaluating information from natural settings, events, and stimuli. Fitness in this ancestral habitat meant the difference between life and death, so it is not unreasonable to expect that people have been somewhat genetically "tuned" to the natural world. For example, there is increasing crosscultural evidence that particular kinds of settings are preferred over others, that natural environments are preferred over built settings, and that built settings with trees and vegetation are more liked than settings that lack natural elements[7,8].

If true, the 'Biophilia Hypothesis' provides an explanation for why green buildings may be capable of producing a wide variety of benefits seen in the health and behavior of their occupants. If the modern interior environment of a green building recreates, in an analogous manner, the essential habitability features of ancestral savannah habitats, these are likely to be especially appealing and to have positive biological and psychological impacts (benefits) on people. Green buildings may be beneficial for people because in relying more on daylighting, natural ventilation, passive and varied thermal control and natural materials, and avoiding the building systems that homogenize interiors, they have inadvertently recreated the most biologically preferred conditions that first gave rise and support to the human species. In the assessment of the MSQA building, we are making a special effort to test this 'Biophilia Hypothesis' for Green Building design by making sharp predictions of the kinds of benefits one ought to see given the sorts of biophillic conditions created by the particulars of this building's design.

\section{Design of the Study}

Four major subtasks of this study were conducted by PNNL for OBT in FY 1995:

1. Baseline the Existing Building and Staff. Collect data and information on the "old building" that establishes a context for "before and after" comparisons of the Miller SQA performance after the new building is occupied for a sufficient period of time. This includes an environmental qualities survey of the staff, an examination of the Total Quality metrics package that MSQA uses to track business performance, and a record of environmental conditions in the baseline building to compare with those in the new.

2. Track Construction of the New Building. Collect design and construction information on the new building during 1995 and prepare to collect post-occupancy data on the new building and its occupants in 1996.

3. Develop a Draft Benefits Assessment Protocol. Perform background research and analyses of collected data and information. Compose a first draft of the benefits assessment protocol that will be the primary product of this study.

4. Communicate Progress and Findings to DOE and the U.S. Green Buildings Council.

During 1996, all of the activities in 1. above are being repeated in the new building, with some added emphases on building features or conditions that may have been revealed by the earlier survey results. Some new data-gathering activities were also performed in the new building using 
protocols developed in the course of this study. The staff questionnaire was revised slightly to add questions asking for more explicit comparisons with baseline and new buildings. The protocol for the lighting survey was completed late last year when it became apparent that standard lighting measures were not appropriate to assess what would be high quality 'biophillic' lighting conditions. These were subsequently tested first in the new building in June of 1996.

All data from the baselining effort has been summarized., with early statistical analyses on MSQA's Total Quality and Productivity metrics completed by June of 1996. This allowed any adjustments to procedures to be made before full scale comparisons before and after the move. Full statistical analyses of the business performance metrics, the occupant surveys and environment measurements will be used to identify building features and occupant outcomes that most readily distinguish between the old and new buildings. These "vital indicators" will become the core of the subsequent protocol. Additional measures or assessments can be added to the core protocol, depending upon the specific interests of its future proposed uses.

\section{Survey}

A questionnaire was developed by PNNL researchers to survey Miller SQA workers about their experiences in the baseline building and their feelings and attitudes about the building's physical and social work environments. The survey was an extensive questionnaire of nine major sections and a total of 23 questions. Many questions expanded into subparts resulting in a total of 173 possible responses in each questionnaire. The survey had a response rate of well over $50 \%$, which is good for industrial settings, and perhaps reflects the interest of the staff in the forthcoming move. The survey included questions about perceived indoor air quality that will supplement the IAQ measurements taken in both baseline and new buildings. The questionnaire was administered a second time (in late July of 1996) and is scheduled for a third time (in 1997) to capture changes in staff perceptions of their new working environment that would now have gone through its 'shakedown' period.

The entire questionnaire takes approximately 10 minutes to complete. Most of the questions were multiple choice; a few were fill-in-the-blank; and a few were open-ended solicitations for comments. The Background Information section in the questionnaire is sufficient to enable us to compare answers given by the same person to both surveys. The pre-occupancy results will be compared with the post-occupancy results on both a statistical and individual basis.

Surveys were prepared following a literature search for studies of work places and associated human factors and design issues (9). Several versions of the questionnaire were reviewed by representatives from the Facilities Design group at Herman Miller, Inc. and Human Resources from Miller SQA. Separate questionnaires were prepared for plant and office staff, but the difference between them is a single question that pertains only to shift times. The questionnaire takes into consideration the wide range of education among the Miller SQA staff, ranging from high school diplomas to graduate engineering and management degrees. Table 1 shows the survey breakdown with the number of possible responses in each of the 9 major categories. 
Table 1: Major Sections of Benefits Study Questionnaire for Miller SQA Staff.

\begin{tabular}{|c|c|}
\hline Soetion Hame (Humber of Questiong) & Deseriftion \\
\hline 1. Your illigh Plose (Gr) & 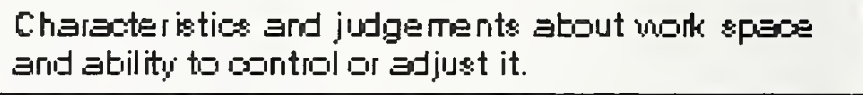 \\
\hline 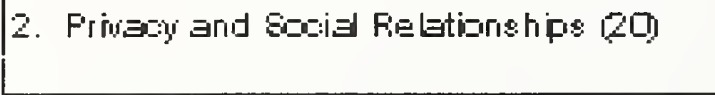 & 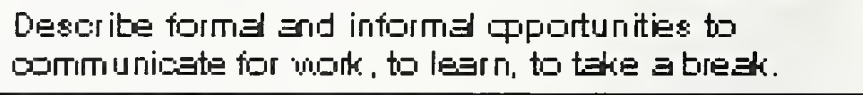 \\
\hline 3. illion- Rieleted Experiences (19) & $\begin{array}{l}\text { Persongl feelings ataut work ; p higsical comifort at } \\
\text { work. }\end{array}$ \\
\hline 4. Euibing Operaions (B) & 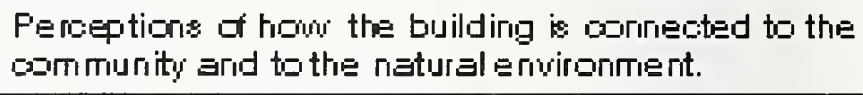 \\
\hline 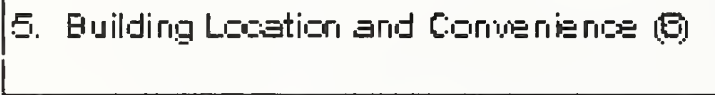 & 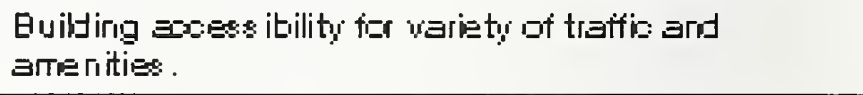 \\
\hline Ei. Aesthetios and Favorite Flares (5) & $\begin{array}{l}\text { Hentify the more faucred festures of the buibing: } \\
\text { and dosument the most unplessent. }\end{array}$ \\
\hline 7. Envirumentel Repurt Card (9) & $\begin{array}{l}\text { Simple rating of } \Xi \text { variety buibing and Envircnmerit=l } \\
\text { parameters. }\end{array}$ \\
\hline B. BEs:kgrournd Inficrmation & 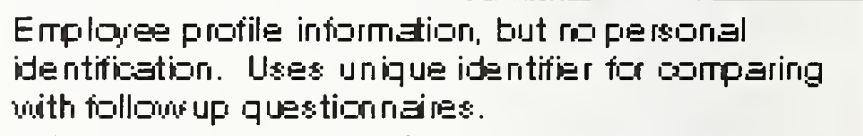 \\
\hline 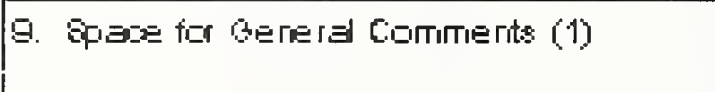 & $\begin{array}{l}\text { Encourage ment for any comments: atout the } \\
\text { Euiluing gr site. }\end{array}$ \\
\hline
\end{tabular}

The questionnaires were distributed to approximately 400 Miller SQA staff, 100 office workers, and 300 plant workers. 259 surveys were returned, 76 from office workers, 183 from plant workers. The overall response rate was approximately $65 \%$; for office workers the response rate was $76 \%$; for plant workers, $61 \%$. In inspecting the responses, we noted that only a very small percentage were partially or incorrectly completed, and that many workers wrote in information where appropriate (such as questions that had an "Other:" category). We are creating a spreadsheet database and a data entry procedure that will enable the forms to be translated into an electronic format suitable for statistical analysis. This database structure and procedure will be reused whenever the survey is re-administered. Having the results in electronic form will make it faster and easier to compare pre- and post-occupancy results throughout the study period.

\section{Indoor Air Quality \& Acoustics Survey}

Fresh, clean air is important for a healthy work environment, and good indoor air quality (IAQ) is a presumption of Green Buildings. The new building is designed to be well-ventilated and to perform extensive air filtration. Also, high-polluting manufacturing processes (such as painting) are located in a closed room near the building's exhaust outlet for ventilation air. In order to assess the benefits of this conscientious clean-air approach, we initiated an IAQ survey of the baseline building in October, 1995. A similar investigation in the new building was taken in summer of 1996 as well. We are comparing data between the baseline building and the new building, and between data taken from the new building during different seasons. We are also 
comparing data from the IAQ surveys to the corporate performance data and staff questionnaires. Some of the potential impacts of high IAQ that we will be looking for are fewer sick days and higher acceptability of the indoor air in the new building than in the baseline building. A cursory look through the responses to the IAQ-related questions indicate that many of the Miller SQA staff graded the IAQ as below average or poor in the baseline building, so this seems to be an area of potential high improvement.

For additional insights into the IAQ conditions at the baseline building, we interviewed the Herman Miller industrial hygienist responsible for the Miller SQA building, and the facilities manager at Miller SQA regarding IAQ. In some cases, there were discrepancies in perceptions about the history of IAQ problems at the baseline building. For example, while industrial hygiene records showed no documented IAQ problems in the baseline building, facilities management reported that the front office had complained of "stale" air and frequent headaches which cleared up after leaving the building.

Because indoor air quality surveys can be very costly and still yield inconclusive results, we designed a protocol for taking intensive measurements at a few strategic sites and several instantaneous readings at a larger number of sites. We selected measures based on their relevance to the activities that are performed in the building (e.g., painting and finishing, which led us to measure volatile organic compounds), and based on their generalizability about the HVAC systems for ventilation and comfort control. Table 2 on the next page summarizes the parameters that were measured in the baseline building. Locations for continuous monitoring over a 24-hour period in the baseline building were determined based on where the activities will be moved to in the new building where they will be similarly monitored. Figure 1 on the succeeding page shows the floorplan of the MSQA baseline building, with functional areas and the locations of the IAQ sampling points.

The office area monitored in the baseline building had carbon dioxide levels that averaged 874 parts-per-million (ppm) during a 23-hour monitoring period, with a range of 599 ppm to 2304 $\mathrm{ppm}$, indicating this area may have been under-ventilated during the monitoring period. A level of $1000 \mathrm{ppm}$ is the ASHRAE standard for using CO2 as a surrogate for ventilation effectiveness (US EPA 1991). Findings such as these will be correlated with questionnaire data when it is fully analyzed and a summary of findings will then be written.

In a brief review of the survey responses to the baseline building, many of the staff also seemed to be bothered by noise, so acoustical measurements were made as part of the IAQ survey in the baseline building and will be repeated in the new building. Noise is a well documented impairer of human performance as well as increased physiological stress, so improvements in a building's acoustic environment could show up in both productivity and health and well-being measures. 


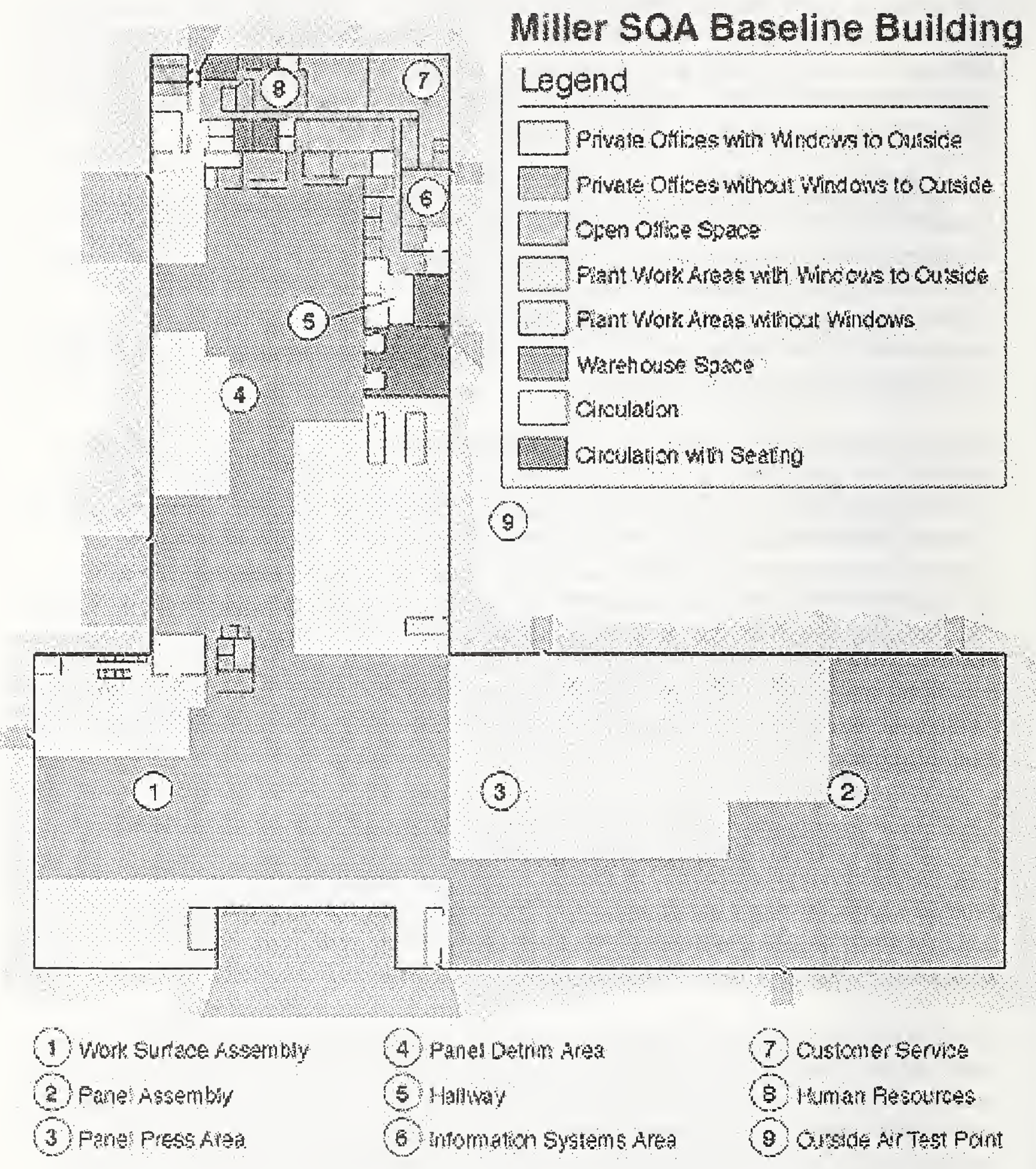

Figure 1: Floor plan of the baseline Miller SQA building showing indoor air quality monitoring points. 
Table 2: Summary of Indoor Air Quality Survey Parameters.

\begin{tabular}{|c|c|c|}
\hline IAQ Parameter & Rel evance & Ho wh Mleagured \\
\hline Cerbon o ioxide $\left(\mathrm{CO}_{2}\right)$ & $\begin{array}{l}\text { Product of human respiration and } \\
\text { oombustion. Measurement has a wariety of } \\
\text { uses, but most common is } \Xi \text { a tracer for } \\
\text { uentilation effectiveness. }\end{array}$ & $\begin{array}{l}\text { Monitored at } 3 \text { boations } 12 \\
\text { Sampled at } 11 \text { koations } 3 \\
\text { Non-dispersive infrared } \\
\text { (ND IR) serso. }\end{array}$ \\
\hline Carbon Monoxide (co) & 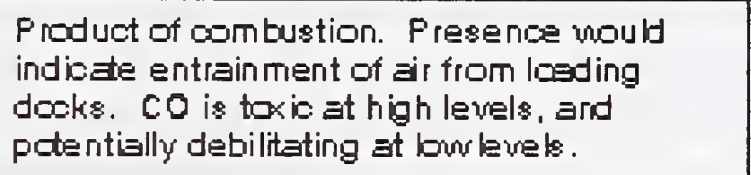 & Continuous data logger 1,2 \\
\hline $\begin{array}{l}\text { Voletile Organio } \\
\text { Compounds (WOC) }\end{array}$ & 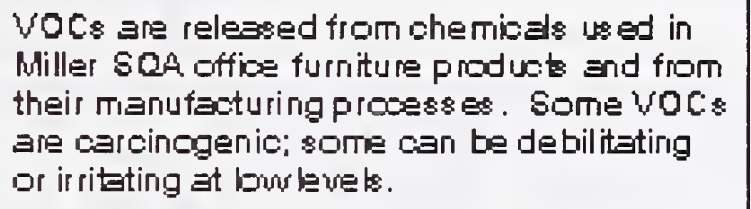 & $\begin{array}{l}\text { Hand-held meter } \\
\text { Photowa: MioroTIP HL-20OO } \\
\text { photo ionization detector. }\end{array}$ \\
\hline Relatire Humidity & $\begin{array}{l}\text { Product of respiration, oombustion, outdoor } \\
\text { air entrainment, and certain menufacturing } \\
\text { processes. Tracer of comfort, and HVAC } \\
\text { Performance. A fator in VOC rate of } \\
\text { emissions. }\end{array}$ & $\begin{array}{l}\text { Continuous data logger } 12 \\
\text { Thin-film cepacitive sensor. }\end{array}$ \\
\hline Temiperaure & 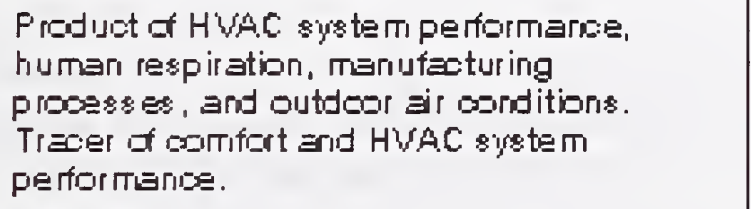 & $\begin{array}{l}\text { Continugus data logger } 12 \\
\text { Thermistor sersor }\end{array}$ \\
\hline $\begin{array}{l}\text { Respirable Partioulate } \\
\text { Matter (dust, pollers) }\end{array}$ & 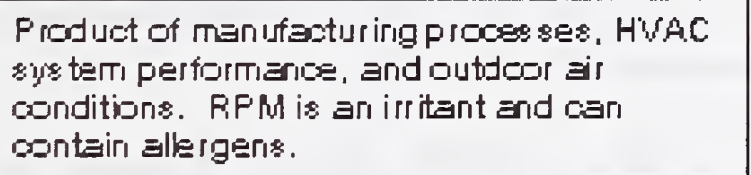 & 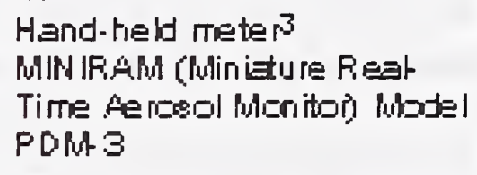 \\
\hline BEckgriand Møize & 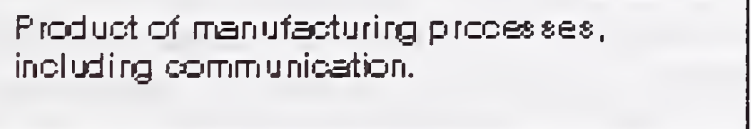 & $\begin{array}{l}\text { Hand-held meter } \\
\text { Quest M-27 Noise Logging } \\
\text { Docirmeter. }\end{array}$ \\
\hline
\end{tabular}

1 Q-Trak with CO, Model 8551 data logger measures $\mathrm{CO} 2, \mathrm{CO}$, relative humidity, and air temperature using a single probe.

2 The same data logger was placed for approximately 24 hours at three different locations.

Sample rates for all parameters was 20 seconds; 5 minute averages were recorded and downloaded to diskettes.

3 Sample data (spot measurements) taken at 11 locations over four consecutive weekdays between 9:30 am and 10:30 am, and on one weekday of the following week between 9:30 am and 10:30 am. Data were recorded in field notes. Weather conditions were noted and outdoor air measurements were taken. 


\section{Performance, Health, and Wellness Data}

The purpose of collecting and analyzing performance, health, and wellness data is to determine if Green Buildings with features like MSQA benefit building occupants so much that their work related performance is noticeably enhanced. Miller SQA has been maintaining performance, health, and wellness data for several years on staff, and this database offers an excellent basis for comparison of any discernible trends in these indicators.

There are two general approaches to specifying measures of corporate performance. The first approach emphasizes theoretical definitions of measures and can be found in various publications and research papers. The second approach, used for this study, is to learn as much as possible about the corporate mission, goals, values, and activities and then define measures based on these values. In other words, our approach is to measure what has largely already been identified by the company as important. Miller SQA has a well-organized quality management program called 6 Sigma and regularly monitors several measures of their corporate performance. The name of the program comes from the goal of reducing all defects in products or service to less then 6 standard deviations from the mean (depending on the complexity of the product, this may approximate 1 defect or error in one million products shipped). Indicators include what they call efficiency, effectiveness, productivity, quality and profitability, which are all higher level global indicators that can reasonably be inferred to be affected by facility conditions.

To accomplish the 6 Sigma goal, Miller SQA managers routinely (often daily) collect, analyze, and distribute company-wide reports summarizing measures of performance. All employees are trained to read and interpret these reports in terms that relate to their activities for the purpose of encouraging improved individual and collective performance. It is important to recognize that even though some of the measures are intended to improve the performance of individual employees, the entity being measured is the company.

With the assistance of the Facilities Design group at Herman Miller and the Miller SQA operations manager, quality systems manager, human resources manager, interior designer, and a member of the finance department, we have selected a subset of measures for this study. The data and measures are described in Table 5 on the next page.

Trends of five measures from data that we have received for 1995 show that some measures can vary dramatically from month to month, while others are relatively steady. These variations follow seasonal trends in the office furniture industry, as well as the addition of temporary workers to the staff during busy periods. Such trends have to be partialed out in the statistical analysis of before and after move comparisons, and represent another difficulty in using business performance data to assess effects induced by facility design and environinental conditions. 
Table 5. Performance Dimensions and Measures for the MSQA building study

\begin{tabular}{|c|c|}
\hline Parformanca Di mengiona & Pukasuras and Puletloud af Tragking \\
\hline Eftectiveness &  \\
\hline Effizienty & 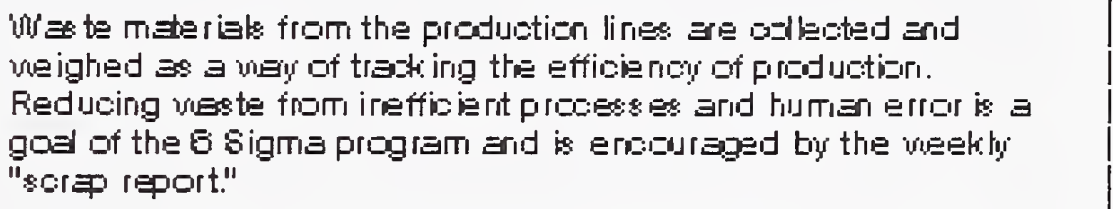 \\
\hline Q џеlity & 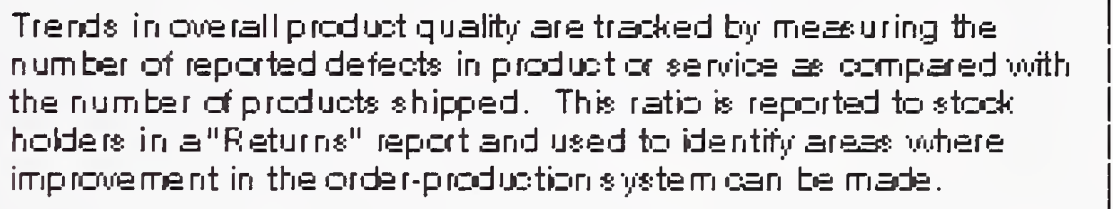 \\
\hline F'roductiuity & 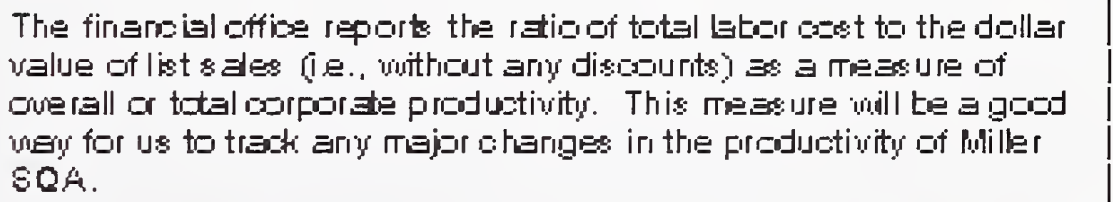 \\
\hline 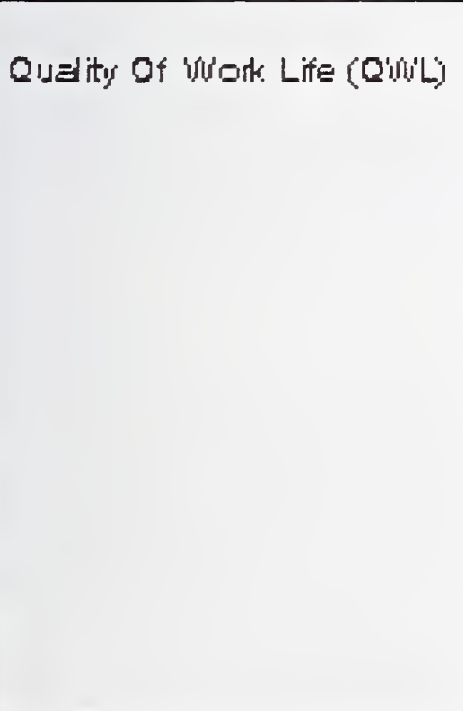 & 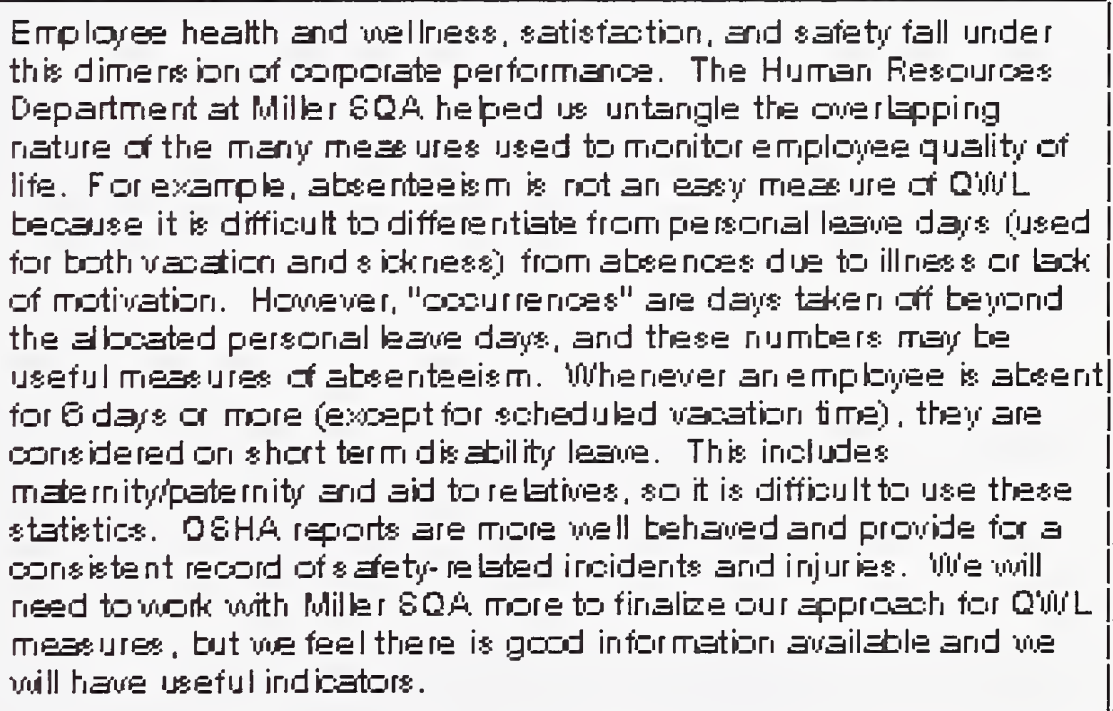 \\
\hline 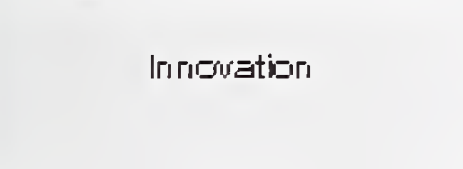 & 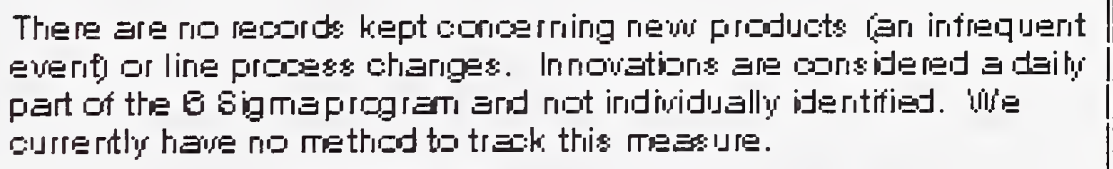 \\
\hline Frofitzbility & 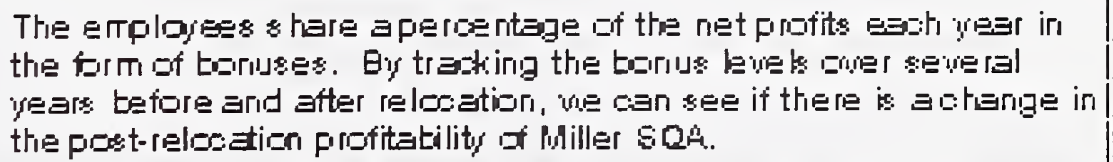 \\
\hline
\end{tabular}




\section{Energy Efficiency Data for the Baseline Building}

As part of the baselining effort, we attempted to gather energy consumption statistics for the existing building. These were to include:

- Energy use per square foot of space (including the plant area)

- Percent of lighting requirement met by daylighting

- Windows as a percentage of total wall area

- Electrical costs for lighting (based on lighting survey that will be performed in 1996)

- Illuminance levels

- Lamp types and controls

- Plant energy costs (machinery and operations)

- Office energy costs (lighting, HVAC, machinery)

- Rated efficiency of HVAC system

- Fuel types

- Peak-shaving efforts

- Building materials that explicitly address energy efficiency (special glazing, insulation levels)

- Energy-saving programs or efforts

Some of these parameters were not monitored separately by Miller SQA and were therefore not recoverable. For example, Miller SQA does not currently have an explicit energy conservation program in place. Their baseline building was not designed to be an exemplar for energy efficiency. It has a 1 million BTU natural gas system manufactured by Applied Air Systems, Inc. The offices have conditioned air and fluorescent lighting (ballast types are unknown); the plant area does not have conditioned air and has large floor fans near work stations to help cool the plant workers. Given the attention to energy efficiency in the new building, we predict that total energy consumption per worker will decrease as a result of explicit design for energy conservation, better materials, better construction practices, new HVAC equipment, and extensive use of daylighting.

\section{Lighting Survey}

Lighting is a major consideration for Green Buildings for two distinct reasons. First, most anecdotal (and some evidential) reports of ancillary benefits have to do with energy efficient lighting retrofits to buildings. This has caught people's attention because of the long history of prior arguments between lighting designers and energy engineers over the energy allowance for lighting in buildings. Those disagreements centered on how many watts-per-square-foot (watts/ $\mathrm{ft}^{2}$ ) of power should be allotted to different spaces. Such disagreements were unnecessarily destructive because they focused consideration on sheer quantity of illumination, when in reality lighting effects on people's performance and well-being are hardly ever a function of quantity measures alone. The Green Buildings movement has neatly resolved this argument by both substituting daylight for lighting energy, and by calling attention to more global issues of lighting quality. Through the combined use of daylighting and new energy efficient lighting systems, it appears that very satisfactory lighting quality can be had at sufficiently low watts/ft 2 to make both lighting designers and energy engineers successful at their previously opposing purposes. 
Second, lighting does provide the single largest opportunity to reduce energy costs of a commercial building because it typically accounts for about $40 \%$ of its electricity usage. Lighting is justifiably a big target for energy cost reductions, so a Green Building can be attractive from a sheerly economic perspective if its energy load is reduced through energy-efficient lighting. If the lighting energy reductions are also incidentally beneficial to occupants in ways that improve business performance and reduce human resources costs, lighting design becomes an attribute of major importance in Green Building design.

The purpose of the lighting survey performed at Miller SQA was to look for explicit evidence of ancillary benefits related to particular kinds of lighting quality that result from Green Building design strategies. The provision of at least minimal needed illuminance to work surfaces and the avoidance of glare have been traditional concerns of interior lighting quality. The Biophilia Hypothesis makes much more specific predictions about the aspects of lighting quality that are important to occupants. In particular, the hypothesis proposes that natural illumination of a kind most likely to be found in highly preferred natural settings ought to be the most conducive to health and well-being. Such lighting quality will be the most restorative to human ability to focus, to maintain attention, and to engage in productive social commerce.

What kind of lighting is this? Using the Biophilia Hypothesis as a guide, we propose that building light should be similar to the spatial distribution, intensity, and psychological impact of sunlight as it is experienced at the edge of a tree canopy. Several lines of reasoning support this assertion. First, there is strong evidence that early human encampments occurred in areas with clustered trees adjacent to water. Second, the tropical habitats of our early ancestors would have made trees a highly likely source of refuge from both midday sun and sudden storms. And third, trees are likely to have been used for sleeping, escape from predators, and as viewing platforms for assessing the environment. Although caves are commonly regarded as the first surrogate "home" for humans, it is likely that large shade trees also served this purpose. Light from a Biophilia perspective has the following features: (1) it produces a relatively higher luminance in the surround field of view, both from vertical surfaces and through window views; (2) it produces filtered illumination on the observer; (3) it displays mildly varying distribution in the immediate surroundings and with a local illumination vector centered on 45-degrees from the vertical; (4) it contains highlights and sparkle on vertical and horizontal surfaces similar to sun spots penetrating a tree canopy; and (5) it resembles daylight in its power spectrum.

Recent studies by an Illumination Engineering Society committee on lighting quality have been independently confirming some of these characteristics of "high quality" lighting in a purely empirical way. These also demonstrate that traditional lighting measures are insufficient to capture aspects of the luminous environment that may be most important in establishing such 'high quality'. It is heartening to see that laboratory work is confirming the purely theoretically derived predictions of the Biophilia Hypothesis. What remains to be shown is whether the more naturalistic lighting approaches taken in Green Building design also reproduces the highly preferred natural lighting conditions, and whether these are associated with measurable benefits to occupants of the work setting. 


\section{The New Miller SQA Building}

This aerial photo shows the new Miller SQA building and it's distinctive crescent shape. The loading docks are in the foreground of this picture. Clearly visible are the square roof monitors allowing daylight into the factory area, and the large cupola that is over the wellness center.

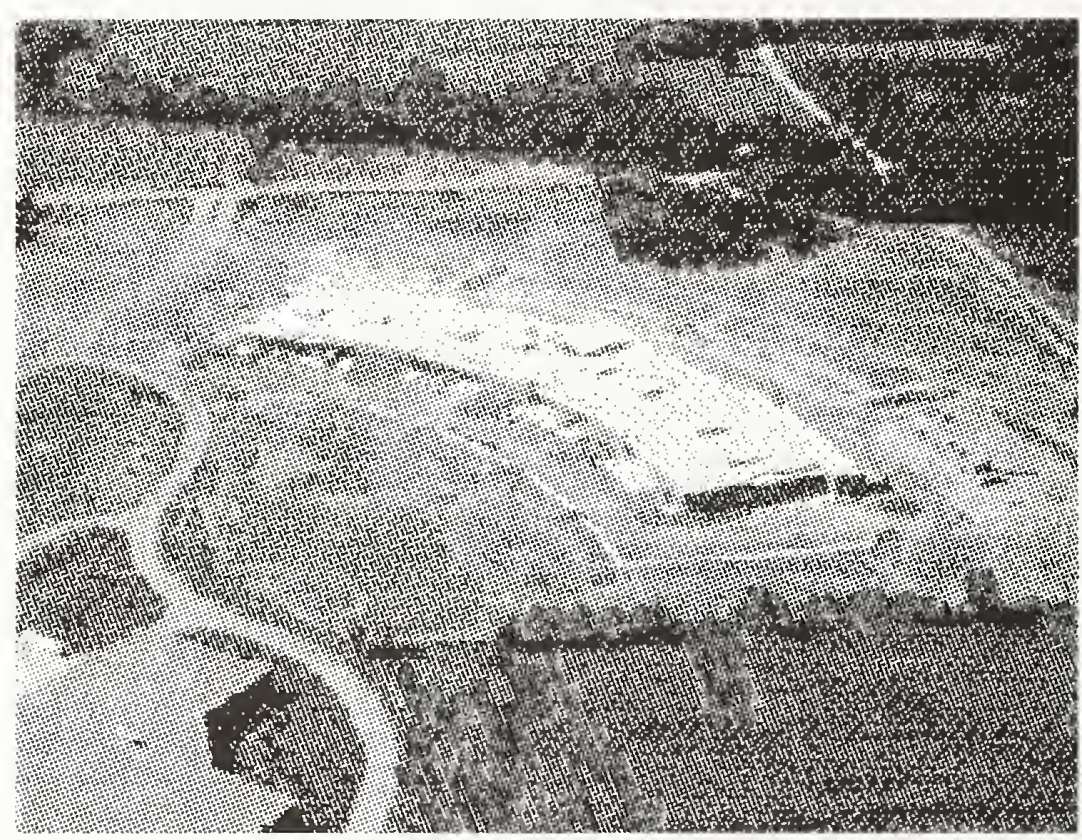

The building's design and construction characteristics that are relevant to Green Buildings are summarized in Table 6 . and are based on design documents and information available during the construction of the building.

Table 6: Features of the New Miller SQA Building that are "Green."

\begin{tabular}{|c|c|}
\hline Fasture & Attributea \\
\hline Lands caping fulan & 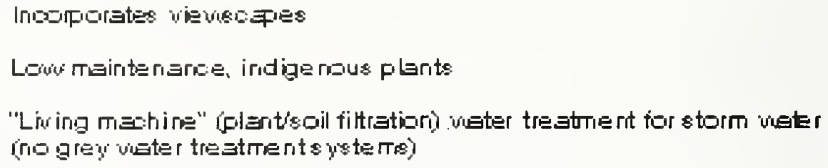 \\
\hline Interior Finish lulaterials & 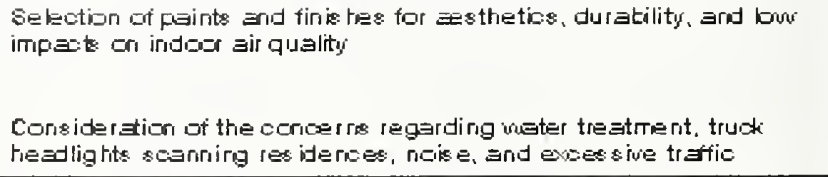 \\
\hline $\begin{array}{c}\text { Community Inwahiement snd } \\
\text { initegration }\end{array}$ & 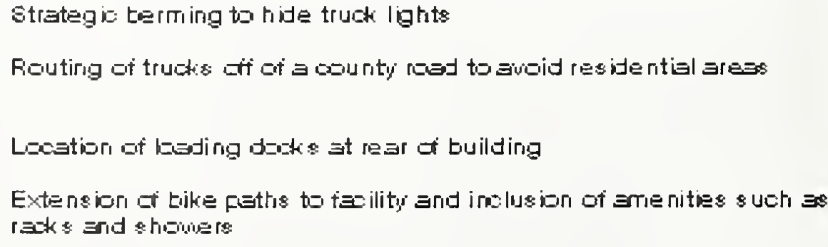 \\
\hline Steff Involvermient & Lasdirıg dochs arrareed so mbterials delivery is rear fuoint of use \\
\hline Constructian luliterisk & Uses localy marutiastured mater iats where feas ible \\
\hline $\begin{array}{c}\text { Participating in EFA Grean } \\
\text { Lighte arid Energy Star } \\
\text { Prograrre }\end{array}$ & Should result in energy \& arings \\
\hline
\end{tabular}




\begin{tabular}{|c|c|}
\hline Fegture & Attributes \\
\hline Building Architecture & 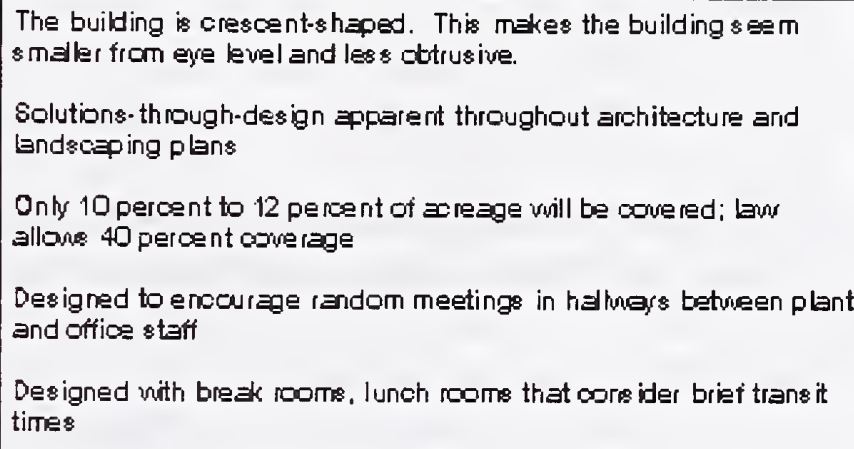 \\
\hline HVAC Syetem Design & 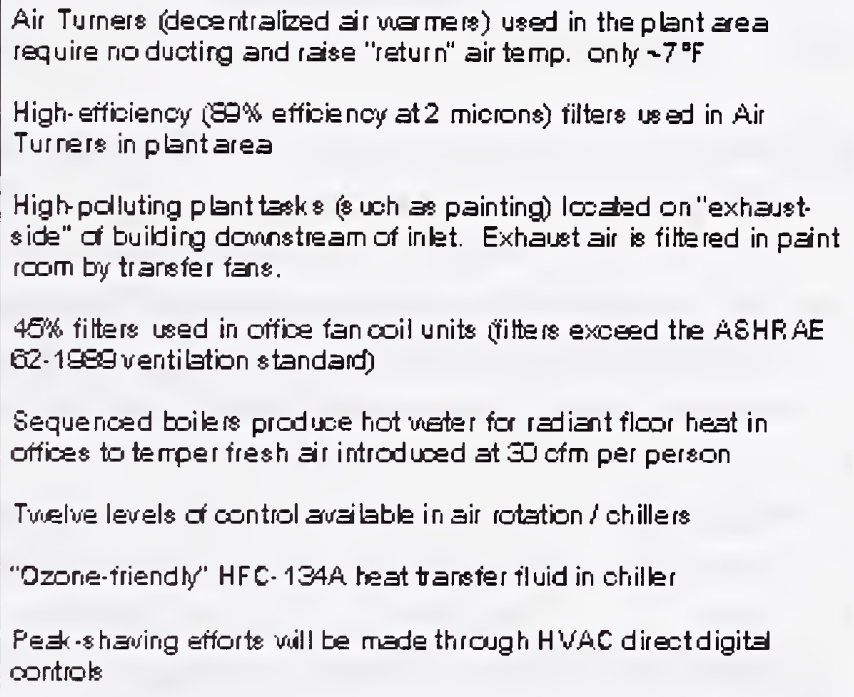 \\
\hline Lightirg Design & 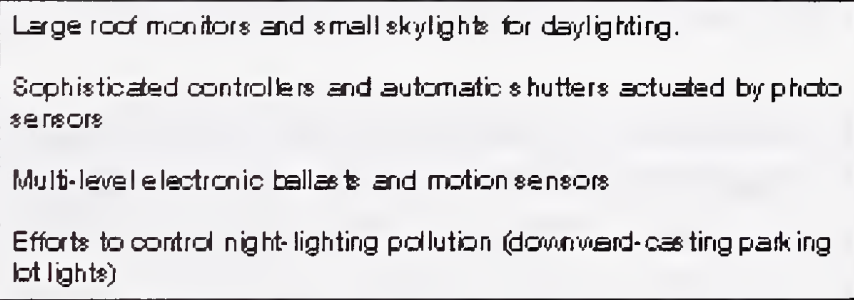 \\
\hline Eye. Evel windous & $\begin{array}{l}\text { Eye-level windowne around moest of the building } \\
\text { Vevecapes of the autside environment are natural istic }\end{array}$ \\
\hline
\end{tabular}

The new Miller SQA building shows many of the attributes common to 'Green Building' design. It is efficient in layout and in building systems, making exceptional use of daylighting. It covers a relatively small proportion of it's site, and is minimally impactful from ground level in a visual sense, despite it's mass. It allows large use of wetlands and natural landscaping on the site to treat runoff, and is a 'good neighbor' to nearby residential areas in the sense that loading operations are kept out of view by landscape berms and that traffic related disruptions around the facility have been minimized. Green buildings are meant to be good for the environment, the community, and their occupants. Where do the benefits in this one lie? 


\section{Using the Protocol to Assess MSQA Building Benefits}

As stated earlier, the first lighting, acoustics, and air quality surveys in the new MSQA building have been taken in the summer of 1996, along with a second administration of the environmental survey of the staff. At the time of preparation of this manuscript, no definitive results are ready for publication, but these will be reported and discussed at the USGBC Conference in November.

However, a cursory look at the survey returns and experiences of the research team on a walkthrough indicate that the new MSQA building is still in transition three-quarters through it's first year of occupancy, and that the total benefits picture will probably be a 'mixed bag' until design details are finished and the building's operations are sufficiently 'tuned' through experience with the facility. These include details that directly affect fundamental habitability conditions of ambient light, temperature and noise level, so we expect to be able to detect and track meaningful changes in occupants' responses as these are addressed.

We are seeing early confirmation of our working hypothesis that 'green buildings' produce ancillary benefits to the degree that they produce enhanced habitability conditions, and that these appear dependent on how a green design's potential is carried out in the actual performance of the building. The testing of specific 'biophillic' aspects of the design awaits a closer inspection of the data, but we currently suspect that the standardized measures used in performing assessments of general interior environmental conditions are not particularly suitable for detecting and reporting those conditions that may actually be most beneficial to human occupants. General indicators such as $\mathrm{dbA}$ weighted noise level, ambient temperature, and average foot-candles on the floor or work surface may succinctly reflect the absence of deleterious ambients, but they are hardly sufficient to capture the sort of enhanced interior environments that it is possible to create through a total and careful 'green design'. We are testing some new measures in attempt to capture such qualities that biophilia actually suggests are important to building occupants.

Recovery and comparison of historical health, well-being and performance data from the MSQA database has been much more difficult than expected, due largely to peculiarities of the particular database management system, which was not designed to be able to recover and group records based on smaller work units or with tags that have relevance to particular locations in the facility. Where records have been analyzed, we have found variations in measures driven largely by workflow demands created by cyclable influences in the industry, and by demographic changes in the workforce that accompany these. Isolating facility environment effects in the midst of these is requiring more data and more indepth analyses.

Creation of a protocol that can accurately and reliably assess the effects of green building design on worker health, well being and human performance is proving challenging but worthwhile. Since this project was started, the anecdotal and quasiscientific evidence of benefits from pollution prevention and ecologically conscious construction has only become stronger (9), and are well established in certain related forums such as Interior Air Quality. The opportunity to use the Miller SQA building for comprehensive study is providing the means to extend the scientific knowledge of human-centered building benefits to the entire context of green building design. 


\section{References}

1. Wise, JA., F Weaver, and D Fong.. Boeing energy benefits study. Prepared for the U.S. Department of Energy by Pacific Northwest National Laboratory, Richland, Washington 1994.

2. Ivanovich MG, JA Wise, DB Lantrip, JH Heerwagen, L Doremus. "Status on the development of a protocol for assessing potential benefits of green buildings." In Second international green buildings conference and exposition-1995, eds. AH Fanney, KM Whitter, and TB Cohn. NIST Special Publication 888. Gaithersburg, Maryland, 1995.

3 Wilson EO. "Biophilia and the conservation ethic." In The Biophilia Hypothesis, eds. SR Kellert and EO Wilson. Island Press, Washington, DC, 1993.

4. Wilson, EO. Biophilia. Harvard University Press, Cambridge, 1984.

5. Heerwagen JH and GH Orians. "Humans, habitats, and aesthetics." In The Biophilia Hypothesis. eds. SR Kellert and EO Wilson.. Island Press, Washington, DC, 1993.

6. Orians GH and JH Heerwagen. "Evolved responses to landscapes." In The adapted mind: evolutionary psychology and the generation of culture, eds. J Barkow, J Tooby and L Cosmides. Oxford University Press, Oxford UK and New York, 1992.

7. Ulrich RS. "Biophilia, biophobia and natural landscapes." In The Biophilia Hypothesis, eds. SR Kellert and EO Wilson. Island Press, Washington, DC, 1993.

8. Kaplan R and S Kaplan. The experience of nature: a psychological perspective. Cambridge University Press, Cambridge UK and New York, 1989.

9. Lantrip DB. Environmental constraint of human movement: a case study of the effects on office worker environmental satisfaction and self-rated productivity. Unpublished doctoral dissertation, University of Michigan, 1993.

10. Browning WD and JJ Romm. "Greening the bottom line: increasing productivity through energy-efficient design." In Second international green buildings conference and exposition-1995, eds. AH Fanney, KM Whitter, and TB Cohn. National Institute of Standards and Technology (NIST) Special Publication 888. Gaithersburg, Maryland, 1995. 



\title{
GREENING THE PRESIDIO \\ A CASE STUDY OF THE THOREAU CENTER FOR SUSTAINABILITY
}

\author{
Marsha Maytum, AIA - Tanner Leddy Maytum Stacy Architects \\ Lynn Simon - Simon \& Associates \\ Tom Sargent - Equity Community Builders
}

ABSTRACT. The Thoreau Center for Sustainability, located in the rehabilitated historic wards of the Letterman General Hospital, is the first privately financed project in the new Presidio National Park in San Francisco. The 75,000 square foot complex, opened in April of 1996, provides a place for twenty non-profit organizations committed to research and educational activities focused on the complex and inextricable connections between human society and the natural environment. This case study presents the goals, design process and final project developed by the design team, the client and the National Park Service. All parties involved were committed to integrating environmental materials, sustainable building and landscape practices, and energy efficient building systems from the inception of the project to final completion.

\section{INTRODUCTION}

The Presidio of San Francisco, transferred from the U.S. Army to the National Park Service in October of 1994, is being developed as a model park for the 21 st century. The Presidio's mission goes beyond the traditional goals of national parks - preserving, improving and interpreting natural and cultural resources for future generations. The Presidio will be a global environmental center and working laboratory illustrating the principles of sustainable design.

The Thoreau Center serves as an important model for sustainable development and innovative private/public partnerships which maintain and enhance the historic resources at the Presidio and beyond. The next decade will see an unprecedented opportunity to restore and renovate the available resources at closed military bases across America. Creative solutions will be required to fully realize the potential of these important architectural and cultural resources as models for a sustainable future.

The Thoreau Center for Sustainability, located in the historic wards of Letterman Hospital, is the first public/private partnership project completed at the new Presidio National Park, a part of the Golden Gate Recreational Area. The Thoreau Center opened in April of 1996 as the new home for Tides Foundation, Tides Center, Energy Foundation and the Institute for Global Communications and sixteen other non-profit organizations that are working directly on environmental and sustainable development issues. The 75,000 square foot complex is named after Henry David Thoreau, who introduced into American literature the central concept of human interrelatedness with nature which underpins modern environmental thought. The 
Thoreau Center provides a place for organizations committed to research and educational activities focused on the complex and inextricable connections between human society and the natural environment.

\section{Project Description}

The design of the Thoreau Center provides an excellent example of the important relationship between historic rehabilitation and sustainable development. By transforming older buildings into new uses, there is a net reduction in the utilization of resources and building materials, as well as the preservation of important architectural and cultural landmarks. More importantly building rehabilitation reinforces the concept of using what already exists within the boundaries of our existing developed areas; thereby stopping the continued development, decentralization and sprawl of our urban and suburban areas.

The creation of this new center provides an unprecedented opportunity to showcase sustainable design principles and sound environmental practices. It also presented a major challenge in transforming the historic hospital wards into new office space integrating new energy efficient building systems and "green" materials while maintaining the historic integrity of the landmark structures. In addition to the rehabilitation requirements of the National Park Service for historic landmark buildings and landscape, the project also had to conform to the rehabilitation requirements for the federal historic tax credit program which was critical to the financial viability of the Thoreau Center.

Constructed by the U.S. Army between 1899 and 1933, the buildings were in bad repair and needed complete new electrical, mechanical, plumbing and life safety systems as well as basic building maintenance and accessibility upgrades. In addition the hospital wards needed to be transformed and reconfigured into office space appropriate for a variety of non-profit organizations. Public exhibit space was also included in the program for the new Center.

Building 1016, the original Letterman Hospital administration headquarters, is a three story wood frame building. This is the main public entry to the Thoreau Center. The upstairs offices are devoted to "incubator space" for a variety of small non-profit organizations. Adjoining Building 1016 are buildings 1012, 1013 and 1014 which form an E-shaped two story concrete structure. These buildings originally served as wards, research laboratories and operating rooms. These buildings were renovated to provide offices for the Tides Center, The Tides Foundation, The Energy Foundation and the Institute for Global Communications.

A north facing gallery, linking all of the original buildings of the complex, serves as the new "Main Street" for the center and also provides opportunities for exhibit space and a cafe. Sitework included restoration of the surrounding grounds, and the creation of the Thoreau Courtyard to the north of Building 1012-14. The renovation had to be accomplished within a budget of $\$ 4.1$ million for base building and tenant improvements, excluding sitework (approximately $\$ 55 /$ sq.ft.). 


\section{Schedule}

In the spring of 1994 the first public call for Park Partners was announced by the new Presidio National Park. The Tides Foundation and Equity Community Builders, a San Francisco based developer of infill housing and mixed use projects, responded with a proposal to develop the Thoreau Center in the historic wards of the Letterman Hospital Complex. They were one of two organizations selected to begin negotiations in the summer of 1994 for a lease agreement with the National Park Service.

The Tides Foundation and Equity Community Builders formed Thoreau Center Partners L.P., to serve as the lessee in a 55 year master lease with the National Park Service. Tanner Leddy Maytum Stacy Architects was selected to lead an interdisciplinary team during the design process which began in the fall of 1994 and was completed during the summer of 1995. Construction began in September of 1995 and was completed in March of 1996.

\section{Goals}

In September of 1994 a joint resolution was signed by the U.S. Department of Energy and the Department of Interior (including the National Park Service) calling for the "Greening of the Presidio". These two organizations have helped to guide the development of the Presidio into a model of environmentally sustainable design. Sustainability as defined by the World Commission on Environment and Development is "meeting the needs of the present without compromising the ability of future generations to meet their own needs."

The most important environmental goal for this project was to prove that it is possible and economically viable to transform and recycle existing historic building resources into new uses for the next century. Historic rehabilitation is a fundamental act of sustainable development. Other project goals included the efficient use of resources, integration of energy saving systems, and the use of environmentally sound building materials and practices

The interdisciplinary team; including the architect, engineers, lighting designer, and environmental materials consultant, worked in conjunction with the developer, tenants, National Park Service, Lawrence Berkeley Laboratory and the National Renewable Energy Laboratory to develop a strategy for implementing specific energy and environmental goals for the Thoreau Center including:

- Integrating state-of-the-art energy efficient systems and environmentally friendly building materials within the limitations and constraints of a historic landmark structure.

- Maximizing daylighting in the new office spaces

- Providing natural ventilation throughout with only minimal use of air conditioning

- Using energy efficient mechanical, electrical and lighting systems throughout

- Using recycled, and/or environmentally responsible materials and products 
- Integrating alternate energy systems

- Providing a safe, healthy working environment

- Integrating sustainable landscape practices

- Reducing overall energy usage and minimizing on-going operating costs

- Incorporating environmentally appropriate maintenance, operations and recycling procedures within the Center.

\section{Context}

The Presidio is a 1,480 acre reserve located near the Golden Gate Bridge at the edge of the San Francisco peninsula. During its 220 year history as a military base, under three flags (the Spanish, Mexican and the United States), the Presidio has developed as a rich cultural, architectural, ecological and environmental landmark. The Presidio will pioneer a new role as a national park and global center dedicated to the world's environmental, social and cultural challenges.

The historic ward buildings, housing the new Thoreau Center, comprise an important remnant of the overall Letterman Hospital complex. The hospital was constructed between 1899 and 1935, and substantially demolished by the Army in the 1970's. As remaining elements of the original campus plan, they contribute significantly to the architectural and cultural history of the Presidio. The buildings and surrounding landscape are designated landmarks. These structures are important examples of Greek and Mission Revival styles typical of Presidio buildings of this era. The exterior of the buildings have remained relatively unchanged and stand as excellent examples of this period in the Presidio's history. The interiors, although modified over time, are important examples of clinic/hospital architecture of the era. The many important medical innovations developed over the decades at Letterman and countless lives saved attest to the cultural significance of this landmark. The hospital complex was the Army's first permanent general hospital; providing continuous operation through five wars until 1969.

Although the climate of the Presidio falls under the official California Climate Zone 3, there is a great deal of variety and microclimates within the boundaries of the Presidio as is typical throughout the San Francisco Bay region. In general the climate is very temperate that only infrequently exceeds 80 degrees F. "Natural air-conditioning" provided by the coastal fog keeps the summer time temperatures relatively cool. The high thermal mass construction and plan configuration (small floor plates and access to exterior windows) of many of the Presidio's existing buildings is also advantageous for limiting the mechanical requirements for the buildings. The unique climate and building conditions make this site an ideal candidate for natural ventilation and "freecooling" which have minimal environmental impact, low first cost and low operating cost.

As apart of the overall Presidio masterplan other critical environmental issues such as transportation, waste management, infrastructure and natural habitat management will be addressed in the on-going development of the new national park. The National Park Service the 
U.S. Department of Energy, Department of Interior, National Renewable Energy Laboratory and the Lawrence Berkeley Laboratory are actively involved in research studies and recommendations for the future development of the Presidio.

Given the current political climate and general budgetary limitations, a critical component for the successful transformation of the Presidio from military base to national park is private investment and partnership with the government. The Thoreau Center is the first privately funded park project. In today's political and economic context, the successful completion of the Thoreau Center, without government funds, will serve as a model for the future success of the Presidio and for all other base closures throughout America.

\section{Team Organization}

The tenants, developers, design team and governmental reviewing agencies were all equally committed to the integration of sustainable design practices into the Thoreau Center. The shared goals and mutual understanding facilitated the successful results of this project.

The Presidio Project Group of the National Park Service, represented by Robert Wallace and Steve Kasierski, represented the landlord and also the reviewing agency for building permits and inspections. Tom Sargent and John Clawson from Equity Community Builders represented the Thoreau Center Partners during the process. They were instrumental not only in project management, and tenant representation but also in creatively structuring and securing the required private bank financing and historic tax credits.

The design team was led by Marsha Maytum of Tanner Leddy Maytum Stacy Architects. Thoreau Center provided an opportunity to combine the firm's expertise in historic renovation and adaptive reuse with their experience in energy efficient and alternative energy design. The interdisciplinary team included Steven Tipping Structural Engineers, Flack \& Kurtz Consulting Engineers, David Malman of Architectural Lighting Design, Cheryl Barton Landscape Architect, Lynn Simon of Simon \& Associates Environmental Building Consultants and GL\&A Civil Engineers.

The design team worked together throughout the process with the National Park Service, Thoreau Center Partners, and the tenants as well as the Western Regional Office of the National Park Service, the State Historic Preservation Office in Sacramento and the Lawrence Berkeley Laboratory for energy evaluation and review.

The decision making process was complicated by the perceived conflicts between tenant required plan reconfigurations, maximizing of energy efficiency, minimizing the impact on the historic fabric of the landmark structures and of course the balance with desires and the realities of the budget. As in any design process a collaborative dialogue continued throughout the process to reach the final design solution. 


\section{Intents}

At the time that the hospital wards were originally designed, buildings were planned to respond to the need for natural light and ventilation. Buildings could not rely on artificial light and large mechanical systems for climate control. The narrow width of the buildings and abundant access to exterior windows provides for excellent daylighting conditions and natural ventilation for the interior spaces. The new office spaces were designed to maximize the penetration of the daylight and natural ventilation into the work areas. The office area was designed with a layering of private and open work areas. The private and semi-private offices were located at the perimeter of the building, defined by a seven foot high glass and aluminum wall system to assure that both the natural light and air flow would reach the interior open work areas. The new custom work stations were designed with adjustable desks for maximum ergonomic control by the tenants.

As a historic landmark, the retention of the existing materials, configuration and character was very critical to the National Park Service. The original circulation and general plan configuration were maintained. New interior tenant space was recaptured by enclosing the original portecocheres of two of the ward buildings. New restrooms, elevator and handicapped access were discreetly incorporated into the original plan.

The new architectural features needed to be designed in a way which could be "reversible" and not damaging to the original structure if the use of building changed again in the future. Key existing elements could not be altered; such as the original windows. The upgrade and energy enhancement of these windows could not be accomplished. The balancing of energy performance and retention of historic fabric was an important part of the design dialogue on this project.

\section{Building Envelope Improvements}

Building 1016, a three story wood framed structure, had only minimal thermal insulation in the attic area. New cellulose insulation (made from recycled newspaper and paper products) was installed in the attic area and in the wall cavities. Insulation was also installed in the crawl space. One difficulty occurred during construction at the existing walls. There is a historic stained wood wainscoting installed on almost all walls in this building. Due to the diagonal blocking behind the wainscoting, the cellulose insulation could not be installed without severe damage to the historic woodwork. It was decided to drill access holes only through the upper plaster wall which could be easily patched and install the cellulose insulation only in the upper half of the wall. The thermal insulation was compromised but the integrity of the wood wainscoting was not.

Buildings 1012-13 had very thick concrete perimeter walls. Cellulose insulation was only installed in the attic area. Cotton batt insulation, in lieu of fiber glass insulation, was installed in the interior walls where acoustic insulation was required. 
As mentioned above, the existing windows could not be improved by double glazing or installing window film. However the new windows installed at the entry to Building 1016 are double glazed with low- E glass. The new entry skylight is also dual glazed and will have photovoltaic panels installed in the summer of 1996.

\section{Photovoltaics}

As a separately funded project by the National Renewable Energy Laboratory and the National Park Service, a small demonstration installation of photovoltaic (PV) panels will be added to the Thoreau lobby skylight and canopy. The project schedule and warrantees precluded completely integrated PV panels in the skylight system. The laminated glass panels, provided by Atlantis Energy and Solarex will be installed as a separate layer above the skylight glass. The electricity produced by the panels will go back into the building electrical system. There will be a public display in the lobby on photovoltaics, a meter monitoring the amount of energy produced by the panels and an interactive computer program setup to explain this new alternative building material and energy system.

The U.S. Department of Energy's Federal Energy Management Program (FEMP) in conjunction with the National Renewable Energy Laboratory and Sandia National Laboratories, has provided assistance to the National Park Service to install a photovoltaic electric vehicle charging station near the Thoreau Center. The mobile photovoltaic array can be used as a stand alone system for battery recharging or grid connected to use utility-provided electricity as auxiliary power or to send excess electricity produced by the PV system back into the grid.

\section{Mechanical \& Electrical Systems Design}

The Thoreau Center was initially viewed as a good opportunity to consider natural ventilation in lieu of mechanical cooling. Located near the Pacific Ocean the site has a very temperate climate that only infrequently exceeds 80 degrees $\mathrm{F}$. The building geometry further encouraged natural ventilation because of the shallow floor plates that places occupants within close proximity of a window. The knowledge of historical building performance and comfort supported the decision of using operable windows and natural ventilation.

The following mechanical/electrical items were considered

- High efficiency boilers

- Hot water radiators with greater heat transfer surface to allow lower hot water supply temperatures

- High efficiency motors

- Simple and effective controls

- Variable speed pumps

- Reduced-flow plumbing fixtures 
The use of pulse combustion water heaters was initially proposed because of their greater efficiency (90-95\%, depending on water temperature). These were also selected because smaller, modular equipment could be used that reduced part-load inefficiencies and stand-by losses. However, during the cost evaluation a high efficiency, standard combustion boiler was selected because the operating savings, in the relatively mild San Francisco climate, could not justify the cost premium.

The selection of radiators allowed for the evaluation of heat transfer efficiency. By selecting units of greater efficiency the hot water supply temperature could be reduced. This results in both lower thermal losses in the piping distribution and greater efficiency with the boiler.

High efficiency, or premium efficient, motors were specified because they are known to have an immediate cost payback and typically operate with higher reliability.

For all systems it is important to look at system part-load efficiencies because the building seldom operates at its peak design condition. Thus variable speed pumping was seen as an essential feature for the hot water distribution system that allowed the pump output to vary and match the building requirement, with energy tracking this variable output. Variable speed drives (VSD) were seen as becoming widespread in the marketplace and the cost effectiveness of this measure has been demonstrated on numerous projects.

Building controls were considered for their simplicity and effectiveness. Following the project's underlying theme that "less is more" the project was not seen as requiring a central computerbased system. Simple on-off controls were selected because they provided the greatest value. Radiators were provided with local thermostat control that monitored comfort conditions for a small, discrete area. At the system level the hot water heating temperatures were reset based on outdoor air temperature such that thermal distribution losses were reduced.

Low flow plumbing fixtures were specified because they conserve water as well as reduce distribution pumping energy and lower domestic hot water heating energy.

Lighting controls in large office areas and common corridors were equipped with occupancy sensors to automatically switch off lights when the building is not occupied. Occupancy sensors were seen as providing the most flexibility to the various tenants for after hours use and avoids timed overrides by each user.

The use of electrically operated cars are encouraged to help reduce pollution and help the environment, so special outlets were provided at select parking stalls to enable electric powered cars to be charged during the day ensuring a fully charged vehicle for the trip back home.

From an engineering perspective the project appropriately did not embrace a technologicallydriven comfort solution. The elegance of providing comfort with a minimum of equipment should never be lost, even when a project may not have the same advantage of benign climate 
and optimum building floorplate. The design team should look at how buildings and nature have worked in the past, not take the "easy way out" and simply install energy-intensive mechanical equipment that solves the problem by brute force.

\section{Lighting}

By far the most important component for energy efficiency in the San Francisco Bay Area, due to the mild climate, is electrical use, in particular lighting use. The primary goal for the lighting design of the Thoreau Center was to minimize energy use while providing a pleasant quality of light. David Malman, of Architectural Lighting Design, designed the lighting to be very comfortable for the users to whom "fluorescent lighting" had a bad connotation. Fluorescent uplighting was selected because of its soft, shadow-free, low-glare quality of light, particular good for the high computer use. Some of the fixtures also emit a small quantity of downlight which adds visual interest and increases fixture efficiency.

Fixtures were kept very simple and generic to make it possible for several manufacturers to bid on the lighting systems. At the Owner's request, the project uses tried-and-true technology with low initial cost and fast payback. F32T8/730 fluorescent lamps and electronic ballasts are used for silent, flicker-free, low energy lighting with a pleasant warm color that complements the natural wood finishes of the casework. Incandescent lighting is limited to a few locations where accent lighting was required. Corridors are lit with pendant lights using compact fluorescent lamps in "schoolhouse" white glass globes that blend harmoniously with the historic architecture of the old hospital buildings.

Controls are ordinary wall switches combined with occupancy sensors in many areas to assure energy savings, particularly in intermittently used rooms. Due to budget constraints, we evaluated and ultimately rejected more advanced technologies using daylight sensing combined with fluorescent dimming.

The lighting consultant prepared computer calculations to plot out the lighting levels in the work spaces to assure that the light levels would be adequate. Light levels in the Tides Foundation and Tides Center offices range from 15 to 45 foot-candles, and the connected power density is 1.06 watts per square foot. Refer to attached diagram of the foot-candle computer model.

Although the Thoreau Center does not set any records for low energy use, it does demonstrate that a historic rehabilitation with a low budget can successfully integrate energy conserving measures and greatly reduce the energy usage of the buildings resulting in substantial energy savings per year. 


\section{Tools And Techniques}

The energy performance of the project was modeled using DOE2 with special assistance from Lawrence Berkeley Laboratory, the Department of Energy and input and review by Flack + Kurtz Engineers, and Architectural Lighting Design. Following is a summary of results from the Lawrence Berkeley Laboratory report dated April 16, 1995.

To evaluate the energy efficiency of the planned renovation, a hypothetical Base Case was defined for the proposed renovation of the hospital ward buildings to the new office use without any conservation measures. The base case assumed no additional thermal insulation, standard mechanical and electrical systems, a lighting level assumed to be 1.5 watts/square foot, typical office internal loads and occupancy schedules. This scenario represented how the buildings would perform if they were used as offices without any attempt to improve their energy efficiency. The planned design was then modeled incorporating the energy efficiency measures integrated into the renovation design.

Compared to the hypothetical base case, the planned design will have an estimated annual energy savings of $\$ 22,000$ or a $1 / 3$ reduction in the total energy budget of the buildings. Almost all of that savings is in electricity usage from the typical office lighting wattage of 1.5 watt/square foot to the $.59-.9 \mathrm{watt} / \mathrm{square}$ foot in the planned design. The lighting electrical use in the base case accounts for nearly half of the entire energy bill. The savings in space conditioning energy use is minuscule in comparison, roughly $\$ 500$ in heating and $\$ 100$ in cooling. The reduction in energy consumption will provide meaningful energy savings $(+\mathbf{-}$ $\$ 1,210,000)$ for the Thoreau Center over the life of the fifty five year lease. The results are summarized in the attached charts.

\section{Materials And Systems Specifications}

Green buildings are environmentally designed and operated to lessen their impact on the environment through energy and resource efficiency, and to provide good indoor environmental and air quality, in order to assure occupant health and productivity. Ideally, green building concepts are applied throughout the whole building, and over its entire life-cycle -- from site planning through operations and maintenance. The primary goal is to design, construct and operate an aesthetic building which meets all the occupants' and owner's needs, including budgetary constraints, while performing at optimum levels of efficiency.

One of the primary goals of the Thoreau Center is to fulfill and promote the principles of sustainable design. One way this goal is achieved is through the research and selection of environmental materials and products. From the initial stages of the design process Lynn Simon with Simon \& Associates provided design review, research and input in the selections of materials and systems to assure environmental performance. This process lead the design team to a series of informed choices which were made based upon environmental criteria and real-world issues including project schedule, budget, available resources, and aesthetics. 
The material selections have environmental and health merits that traditional materials have typically not considered. The production and use of these materials means less energy consumption, less natural resource depletion and pollution, and are generally less toxic for both the planet and its occupants. The selection of green building materials began with preliminary criteria including:

- recycled content

- sustainably acquired or renewable resource

- in-plant energy efficiency and recycling

- low-emissions plant

- minimum recycled, recyclable packaging

- maximum transport efficiency

- minimum installation hazards

- low-toxic emissions

- durable

- easy to maintain

- reusable and salvageable

- recyclable

Manufacturers who had established credentials as environmentally concerned companies or as having products with some environmental or health benefits were then selected and their products researched. Environmental product guidelines based upon the preliminary criteria were then used to evaluate each product. In addition, product brochures and Materials Safety Data Sheets (MSDS) were requested and evaluated. Following is a matrix of the materials researched and used on the Thoreau Center.

see attached matrix of materials

\section{Landscape Design}

The landscape features surrounding the Thoreau Center are also included in the landmark designation. The large open grass areas, significant historic plantings and exterior circulation patterns are all apart of the historic cultural landscape. As such, the design of the new landscape elements must also meet the requirements of the Secretary of the Interiors' Guidelines for Historic Rehabilitations. In addition to the restoration and maintenance of the existing features, Cheryl Barton the landscape architect, also incorporated the following sustainable landscape practices:

- rehabilitation rather than removal of historic plant materials

- minimization of earthwork - new grades work with the existing slopes

- soil building with organic amendments in lieu of synthetic fertilizers

- water conservation through the introduction of drought tolerant plants, low flow irrigation systems, and the capture of rainwater for supplemental irrigation

- excavation and use of historic drainage structures to minimize runoff 
- removal of evergreen trees (replaced with deciduous trees) on south side of buildings to maximize interior daylighting

- reduction in asphalt paving and parking areas

- installation of alternatives to turf lawns such as low growing groundcover, unmown grasses and wildflowers, and decomposed granite

- updated National Park Service standard landscape specifications via research from "green" data bases and product literature on sustainable materials and products

To the north of Buildings 1012-14, the Thoreau Courtyard has been created where two original ward wings were demolished by the U.S. Army. This area will be developed over the next few years as a public garden and demonstration area for sustainable landscape practices, medicinal and herbal plants, as well as wind and solar energy demonstration projects.

\section{Construction}

Plant Construction Company was selected at the beginning of the project and was an integral part of the design team from the feasibility phase. Given the nature and complexity of the renovation and the fact that this was the first private project to be undertaken in the Presidio, the developers decided that it was important to have the input of a qualified renovation contractor in the initial planning. Plant Construction Company is experienced in the challenges of historic renovations and also has an ongoing commitment to environmentally sound building practices. They provided on-going cost estimating and review through all phases of the project. Through a negotiated bid process the subcontractors were brought in at the design development phase to provide field research and systems input with the team engineers.

In addition to complying with the environmental requirements of the specifications for the building materials and systems, the construction team supported the goals of the project by recycling building materials and debris.

Construction debris and material waste are major contributors to the land fill crisis in America. Waste prevention, sorting and recycling of debris at the construction site can greatly reduce the tons of material annually dumped into land fills. California Assembly Bill 939 requires a 50\% reduction in the amount of solid waste disposed by the year 2000 .

At Thoreau Center, Plant Construction Company organized and managed a waste prevention program throughout the course of demolition and construction. The company has a long term commitment to recycling of building materials. At the end of each year, Plant donates the money received from material recycling to local charities.

The contractor provided separate debris bins designated for scrap metal, brick and concrete, wood, and general debris. Wood products were removed and stored at the Plant yard for use on future projects. Wood removed from the project during demolition was used for new infill framing where ever possible. The general contractor trained all personnel on the job site to 
separate and use the designated debris bins. Golden Gate Disposal, the local refuse company, accepted pre-sorted materials from the job site for recycling. They also monitored the quantities of materials delivered during the course of construction.

At the Thoreau Center for Sustainability, over $73 \%$ of all debris was recycled. The typical recovery rate for recycled construction material at Golden Gate Disposal is $40-50 \%$. The increase in the amount of recycled material is due to the careful labeling of debris bins on site and the training and commitment of the general contractor and crew.

\section{Summary Of Recycled Construction Material}

Scrap Metal: Inert Fill:

Wood:

General Debris: 199 tons discarded (General debris was not able to be recycled due to the presence of various contaminates.)

Total:

735.2 tons of material hauled 536.2 tons of material recycled $73 \%$ of material was recycled

\section{Use And Operation}

Since the building has only been occupied for two months there is not yet any operating data available for review. However, the feedback from the users, the developers and the National Park Service has been very positive. The transformation from hospital wards to new energy efficient offices is complete. The Thoreau Center is now a thriving community of related nonprofit organizations dedicated to community development and environmental stewardship. At the building dedication ceremonies on June 7, 1995 U.S. Representative Nancy Pelosi said, "If anyone were to choose the right organization to be a part of the Presidio, the Thoreau Center is it."

c:partners:/marsha/presidio/usgreen/greenbld.doc 


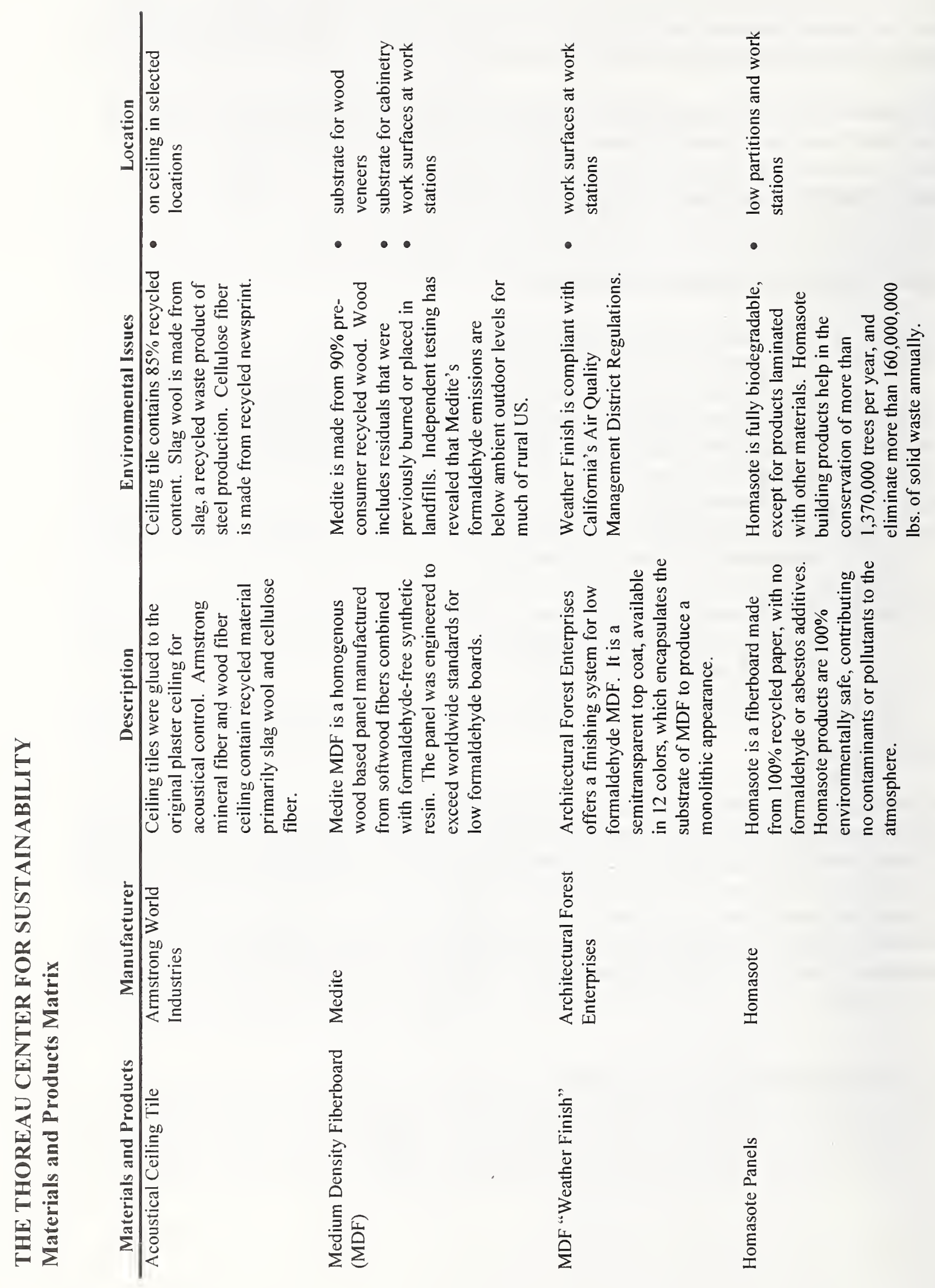


言

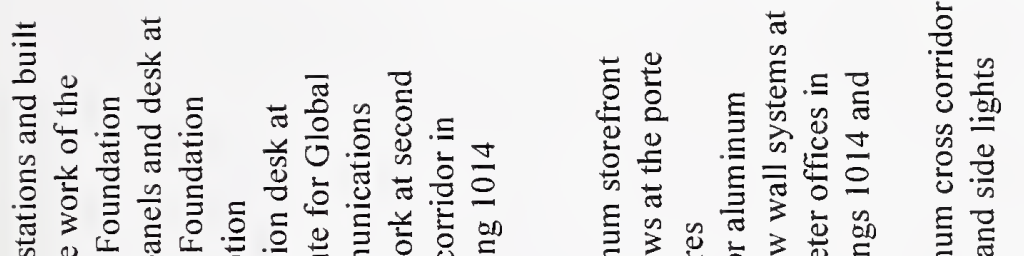

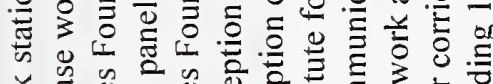

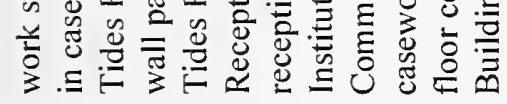

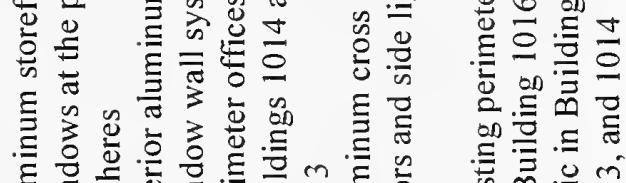

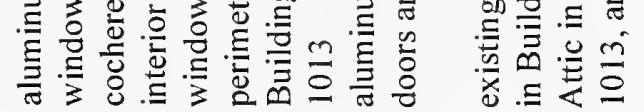

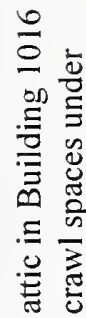

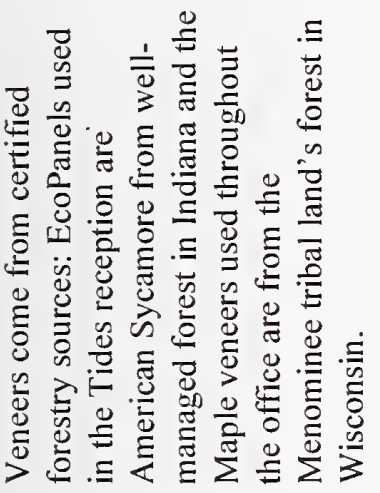

.$\cong$

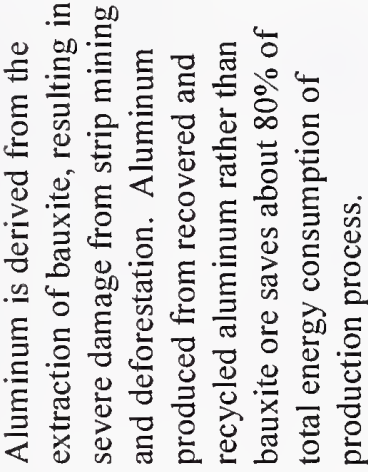

芯 荵.





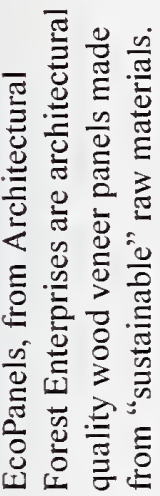

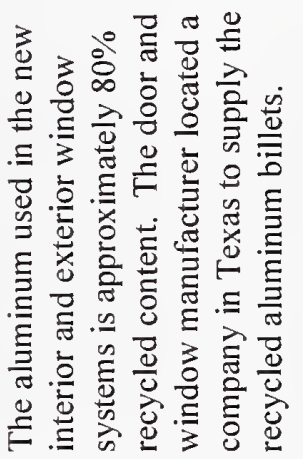

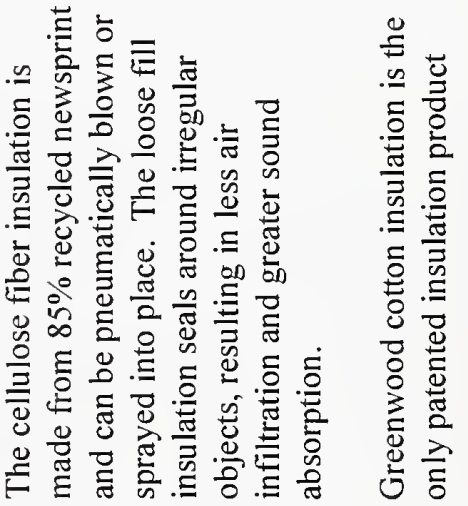

$\frac{n}{0}$
$\frac{0}{\pi}$
0
0
0
0

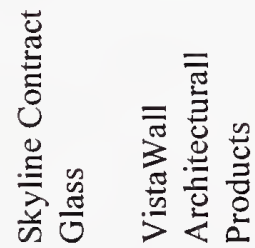

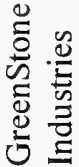

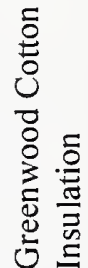

$\frac{n}{0}$
$\frac{\pi}{5}$
$\frac{8}{8}$
3

志

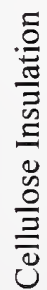

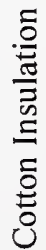




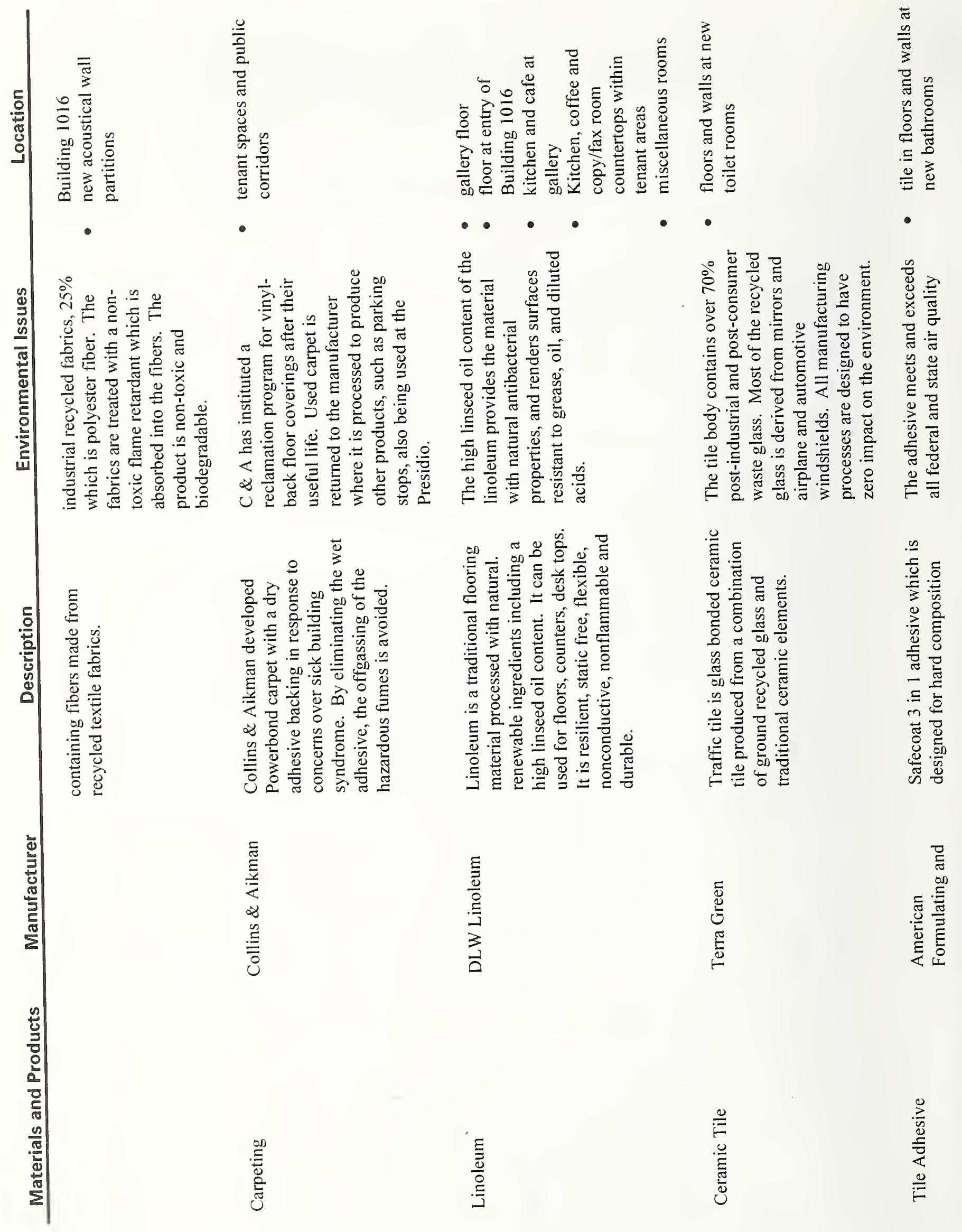




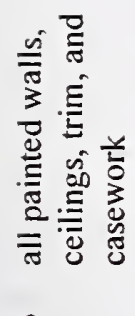



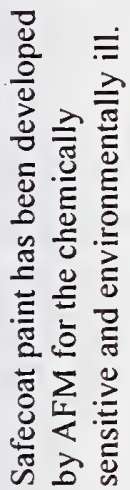

莺

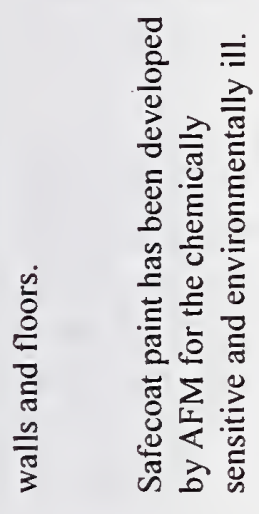





\title{
CIVANO VILLAGE
}

\author{
John Laswick, Project Manager \\ City of Tucson Office of Economic Development \\ P.O. Box 27210 \\ Tucson, AZ 85726
}

Abstract. The goal of the Civano project is to demonstrate the marketability of sustainable community development on a large scale at affordable prices. This 820 acre traditional neighborhood development will utilize proven, available technology to reduce natural resource usage substantially below current levels. Extensive community involvement in its planning gives Civano a solid base of local support. The property is located on former State Trust land in the City of Tucson, southeast of Houghton and Irvington Roads.

Civano takes its name from the golden era of native Hohokam civilization, which exhibited a balance between human needs and the natural environment. Civano addresses the growing desire for a new development pattern that enables people to meet their economic needs, yet maintain social values and ecological harmony. Recent local consumer research indicates substantial interest in a traditional community with strong environmental values. Civano's master plan envisions construction of 2,500 homes and apartments using significantly lower natural resources than conventional homes. The challenge to builders is to develop housing with these features in a wide range of prices. The City is committed to assisting builders who accept this challenge.

In eight to twelve years, Civano will become home to more than 5,000 people and the location of light industry, offices, and retail businesses. Commercial, cultural, and civic activity clustered in the village core will foster a small town ambiance. Half the population and two-thirds of the jobs will be within a five minute walk of the Civano village center. Businesses in Civano will provide jobs for some of the residents, reducing the need for automobile travel and its attendant air pollution. The plan aims to create one job for every two housing units, although not all jobs will be held by Civano residents. Residents and employees alike will enjoy access to active recreational facilities and natural desert open space.

Civano's buildings initially will utilize passive solar designs to reduce energy demand. As photovoltaic (PV) electric generation and similar technologies become economical, Civano hopes to use such supply systems as grid-connected PV to provide power to major portions of the community. Harvested and reclaimed water will irrigate vegetation and conserve precious potable water. Improved collection and disposal methods will facilitate solid waste recycling. Extensive walking and biking paths will reduce auto usage for internal circulation and create a more livable community. The City has established construction requirements to achieve the highest possible standards of resource conservation.

The City of Tucson has acted as a catalyst in the State's auction of the property to a private master-developer. This involved cooperation among the State Land Department, the development community, utilities, financial institutions, and advocates for energy conservation and nextgeneration neighborhood design. The City's Office of Economic Development has lead 
responsibility and worked closely with an advisory group of interested parties, as well as with an interdepartmental team of public agencies. The State Land auction took place on July 24, 1996, with sale to the Community of Civano LLC, a joint venture of the Trust for Sustainable Development and Case Enterprises; construction of the first buildings should begin at Civano by mid-1997.

Ultimately, successful development of Civano will demonstrate community design and construction methods that will enable Tucson and other cities to meet the demands of growth without straining the supply of natural resources. For additional information, use the Internet to view the Civano Web Site at http://www.civano.com or contact Project Manager John Laswick at (520) 791-5093. 


\title{
A SIMPLIFIED ENVIRONMENTAL SCREENING METHOD FOR BUILDING MATERIALS
}

\author{
Nadav Malin and Alex Wilson \\ Environmental Building News \\ RR 1, Box 161 \\ Brattleboro, VT 05301
}

\begin{abstract}
Sustainable design encompasses many strategies and considerations. Not least among these is the selection of products and materials with minimal environmental burdens over their life cycle. Ideally a green building designer would have access to a complete life-cycle analysis for each material under consideration in order to choose those with the lowest impacts. For most materials, however, the majority of environmental burdens occur at just a few points in the life cycle. By focusing on the "pressure points" outlined in this paper, designers can make wise choices without pouring through reams of information, and manufacturers can concentrate their efforts where there is most to be gained.
\end{abstract}

\section{INTRODUCTION}

Life-cycle analysis or life-cycle assessment (LCA) has generated enormous interest over the past decade as a method for determining the total environmental impacts of a particular product. The process includes a life-cycle inventory, in which a researcher must identify and quantify all of the raw materials and energy consumed in the production, use, and disposal of the product, as well as pollutants and byproducts generated. Following the inventory, the task remains of determining the environmental impacts of these material and energy flows. This step is an inexact science, because it involves tracking ecological impacts as they ripple endlessly through the world's natural systems. In the context of a specific product, the final stage is often one of identifying areas for improvement. In a broader sense, this screening method is a means of improving the life-cycle impacts of an entire building through optimal materials choices.

Given the level of complication involved in analyzing the life cycle of a specific product, it is not surprising that such tasks are usually undertaken only by relatively large manufacturers who are committed to learning about and reducing the environmental impacts of their processes. Unfortunately, such detailed information is rarely made available to the public. Even if it were, it is unlikely that architects and specifiers-who must make decisions about hundreds of products for each project-would be able to digest and utilize the information. In addition, if detailed information is available for a product from one manufacturer but not from competitors, the designer still has no way to ascertain which products have the lowest cumulative impacts.

Given this predicament, most practitioners of sustainable design end up learning what they can about products, and then make their decisions based on intuition and an informal (and usually undocumented) assessment of the options. The process outlined in this paper, while still very informal, aims to bring out into the open the primary considerations needed to put these decisions on firmer footing. 
A number of efforts are underway to adapt the life-cycle assessment process in order to make it more useful to building designers. Most notable among these efforts to date are The American Institute of Architects' Environmental Resource Guide (1) and the Athena ${ }^{\mathrm{TM}}$ database from Forintek Canada Corp. (2).

As these general assessments cannot be product-specific, they are necessarily imprecise in LCA terms. They consider the flows of materials and energy that are considered typical in each industry (3), and the environmental impacts that commonly stem from those flows. Joel Ann Todd, author of the Environmental Resource Guide methodology, refers to her process as a "streamlined" LCA. These studies each break up the life cycle of products into significant stages as illustrated in Figures 1 and 2 below.

Figure 1: Life-cycle stages as per ERG (4)

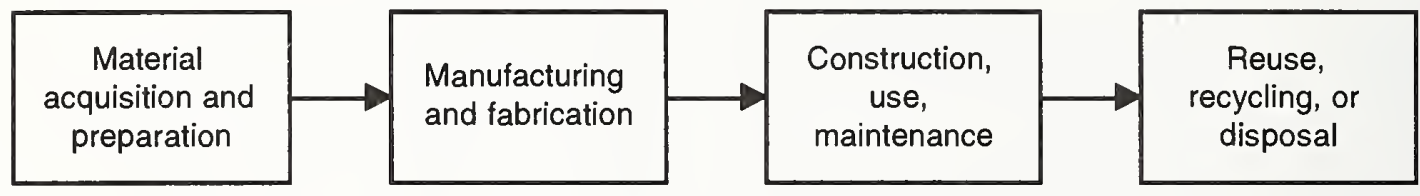

Figure 2: Life-cycle stages as per Athena ${ }^{\mathrm{TM}}$ (5)

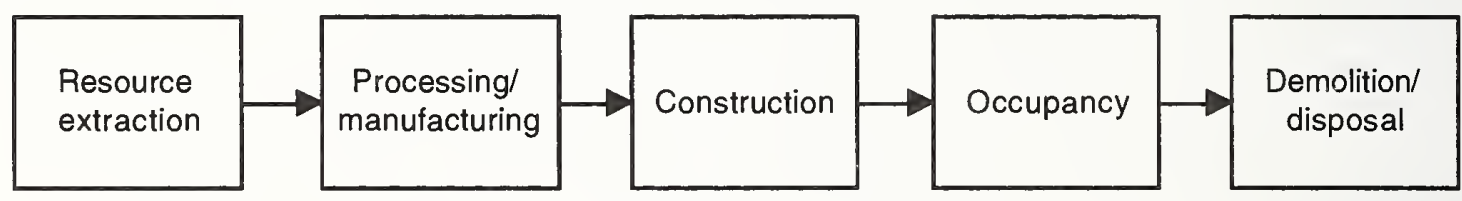

These streamlined and generalized LCA studies are valuable tools for the environmentally aware designer, yet they have significant weaknesses in practice. First, even these generalized studies have only been completed for a fraction of the materials available to designers. Second, although significant efforts are underway to make the information more accessible (6), much of the material is available only in detailed technical reports, which many designers may not take the time to read.

Articles on materials published in Environmental Building News (7) aim to be more accessible, but only a handful of materials have been covered in such articles to date. Developing these articles, however, has lead to the creation of a methodology that knowledgeable designers can use to make their own informed choices. Outlined below are EBN's twelve steps for environmental screening of building materials. This method is not intended to replace true life-cycle assessment, but merely to offer a framework for identifying the most significant factors for each material. It is a work-inprogress that evolves each time we use it, and we welcome ideas for modifications and improvements.

\section{HIERARCHY OF LIFE-CYCLE STAGES}

The twelve steps of this method span the life cycle of the materials in question, but not in the normal, chronological order. While the LCA of many consumer products focuses on the production and disposal issues, with most building materials it is the use phase of the product that is most significant because of the relatively long lifetime over which building materials are in service. In this sense, Todd refers to building materials as having a "use-dominated life cycle." This does not mean that use phase is the most important stage for every material one might consider, but it does suggest that in many cases this is where the most significant environmental considerations can be found. Like the Environmental Resource Guide, we have included the act of assembling the materials into a building as part of the use phase of the material. 
Following the use phase, the raw materials extraction phase is usually the most important with building materials. This is primarily because buildings are relatively large objects, and large quantities of raw material are used in their construction.

The manufacturing or production stage is typically next in importance, as many materials contain hazardous or toxic components, or generate toxic intermediaries as part of their production process.

Finally, the disposal stage can be important due to the shear volume of material that buildings embody. It falls at the end of this list, however, because of the long useful life of most building materials and the recyclability of many of them. Additionally, much of the mass of buildings can often be utilized as clean fill in many cases, so the potential impact on solid waste landfills is mitigated. Figure 3 below illustrates this hierarchy.

Hierarchy of Life-cycle stages:

1. Construction and Use

2. Raw material acquisition

3. Manufacturing

4. Disposal/Reuse

It is important to note that while this hierarchy is a useful guide, it is not meant to suggest that all materials will have their environmental burdens ranked in this order. The most significant impacts of some synthetic materials, for example, may be found in the manufacturing stage. And products such as preservative-treated wood may be most problematic in terms of disposal.

\section{THE FIRST THREE STEPS: THE USE PHASE}

Two of the most significant sources of environmental impact from building materials are energy use in the building and effects on occupant health. Considering a specific application and a list of possible materials to suit that application, the following three decision points are a good place to begin.

Step 1 - Energy use: Will the material in question, as used in the relevant application, have a measurable impact on building energy use?

If no, proceed to step 2.

If yes (for example, materials such as glazing, insulation, and mechanical systems), avoid options that do not minimize energy use. Also take care to design the application to minimize energy use. For materials that can be used in an energy-efficient manner only with the addition of other components, the impact of including those components must be factored in. Examples include glazing systems that require exterior shading systems for reduced energy use, or lightgauge steel framing, that requires foam sheathing to prevent thermal bridging.

Step 2 - Occupant health: Might the material in question, as used in this application, affect the health of building occupants?

If no, proceed to step 3 .

If yes (such as interior furnishings, interior finishes, and mechanical systems), avoid materials that are likely to adversely affect occupant health, and design systems to minimize any possible adverse effects when sources of indoor pollution cannot be avoided. 
Step 3 - Durability: Is this material, as used in this application, likely to need replacement, special treatment, or excessive maintenance/repair during the life of the structure?

If no, proceed to step 4.

If yes (for example, roofing, coatings, and sealants), avoid products with short expected lifespans. An exception to this rule might be a product made from low-impact, renewable materials that is easily applied and easily recycled. Also, design the structure for flexibility so that materials that might become obsolete before they wear out (such as wiring) can be replaced with minimal disruption and cost.

\section{NEXT STEPS: THE RAW MATERIALS STAGE}

The remaining steps are less application-specific. They require some knowledge of the raw materials that go into each product.

Step 4 - Resource Limitations: Are any of the component materials from limited or endangered resources?

If no, proceed to step 5 .

If yes (for example certain sources of old-growth timber), avoid these products. It may be possible to obtain comparable materials through salvage.

Step 5 - Impacts of Resource Extraction: Are there significant ecological impacts from the process of mining or harvesting the raw materials?

If no, proceed to step 6.

If yes (such as damage to rainforests from bauxite mining for aluminum, or clearcutting on steep slopes with unstable soils), seek suppliers of material from recycled stock, or those with credible third-party verification of environmentally sound harvesting methods.

Step 6 - Transportation: Do the raw materials require significant shipping energy because of distance, weight, or other factors?

If no, proceed to step 7.

If yes (for example, petroleum, Italian marble, and tropical timber), seek appropriate alternative material from more local sources.

\section{FURTHER STEPS: MANUFACTURING}

Step 7 - Hazardous byproducts: Are significant toxic or hazardous intermediaries or byproducts created during manufacturing, and if so, how significant is the risk of their release to the environment or risk of hazard to worker health?

If these are not significant, proceed to step 8.

Where toxic byproducts are either generated in large quantities (for example, certain plastics) or in small but uncontrolled quantities, the building material in question should be avoided if possible.

Step 8 - Energy use: How energy-intensive is the manufacturing process? 
If not very intensive, proceed to step 9.

If the manufacture of a building material is very energy-intensive compared to the alternatives (aluminum and plastics, for example) its use should be minimized. It is not the energy use itself that is of concern, however, but the pollution from its generation and use. So industries using clean-burning or renewable energy sources have lower burdens than those relying on coal or petroleum.

Step 9 - Waste from manufacturing: How much solid waste is generated in the manufacturing process?

If not much relative to the quantity of product manufactured, proceed to step 10 .

If significant amounts of solid waste are generated that are not being reused for other purposes (for example, carpet manufacturing scrap or steel slag), seek alternative materials. The degree of reuse can vary by manufacturer, so product-specific information may be needed at this step.

\section{FINAL STEPS: DISPOSAL OR REUSE?}

Step 10 - Demolition waste: Can the material be easily separated out for reuse or recycling after its useful life in the structure is over?

If yes, proceed to step 11 .

While most materials that are used in large quantities in building construction (such as steel and concrete) can be at least partially recycled, products that combine different materials (such as thermoset plastics and composites) are less recyclable, and may become a disposal problem in the future. Consider the future recyclability of products chosen.

Step 11 - Hazardous materials from demolition: Might the material become a toxic or hazardous waste problem at the end of its useful life?

If no, proceed to step 12 .

If yes (for example, preservative-treated wood), seek alternative products for the application, or seek to minimize their use.

Step 12 - Review the results: Go over any concerns that have been raised about the products under consideration, and look for other life-cycle impacts that might be specific to a particular material. For example, with drywall and spray-in, open-cell polyurethane foam insulation, waste generated at the job site is a major problem. Finally, factor this information into all the conventional product selection criteria — price, availability, appearance, ease of installation.

\section{SOME RESULTS}

Figures 3,4 , and 5 below illustrates some of the issues that emerge as a result of this process for a few specific materials. Depending on your goals and the criteria for the particular project, these concerns may be "knock-out criteria" (8), meaning that the product in question is eliminated from consideration. Or, they may simply be factors to be aware of and to mitigate through careful design. 
Figure 3: EBN's simplified method applied to oriented-strand board sheathing

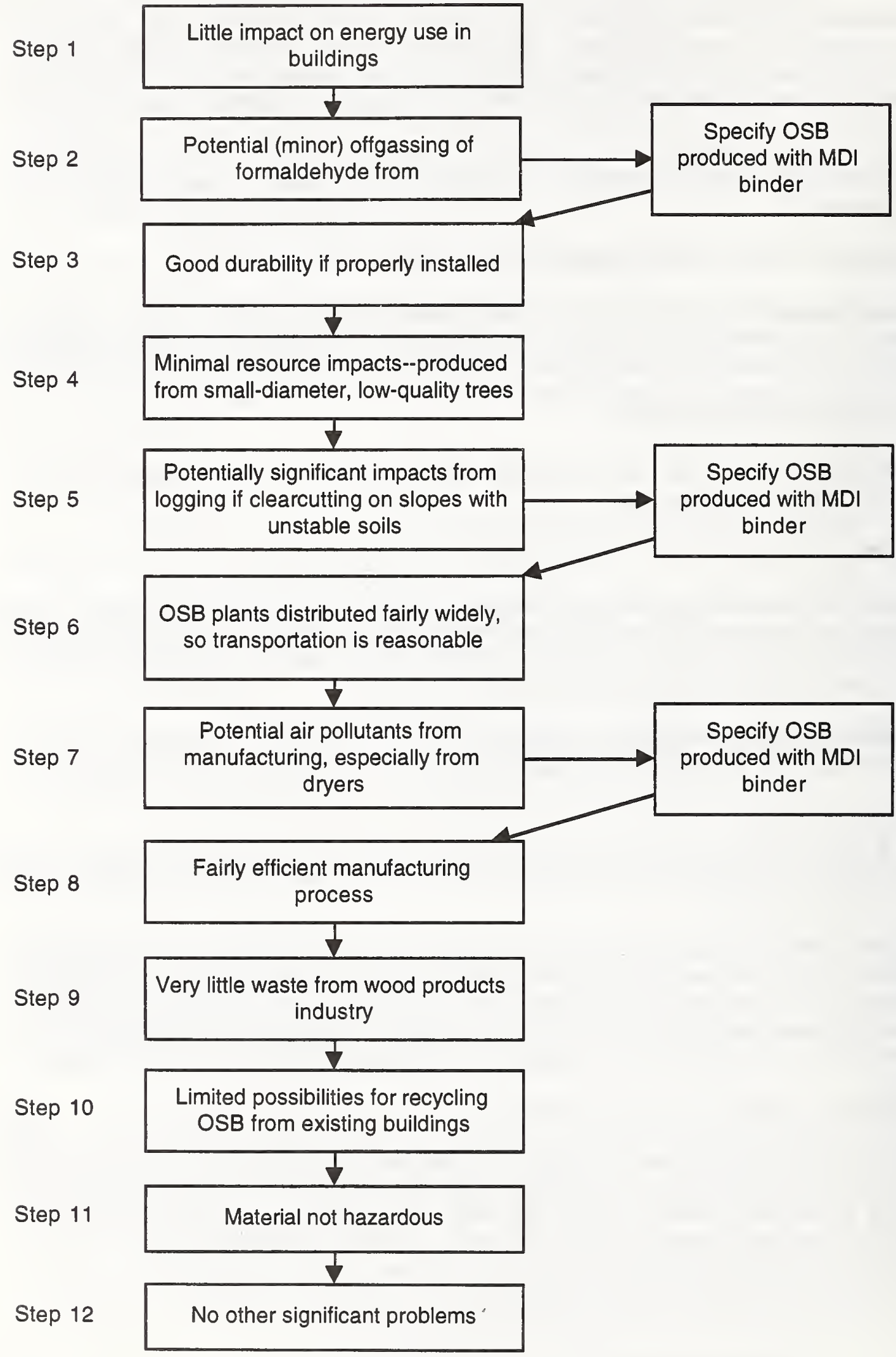


Figure 4: EBN's simplified method applied to aluminum-frame windows

Step 1

Unacceptable thermal performance of frame material in nearly all climates

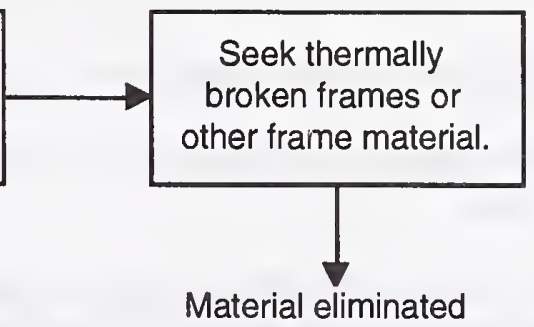

Figure 5: EBN's simplified method applied to old-growth cedar siding

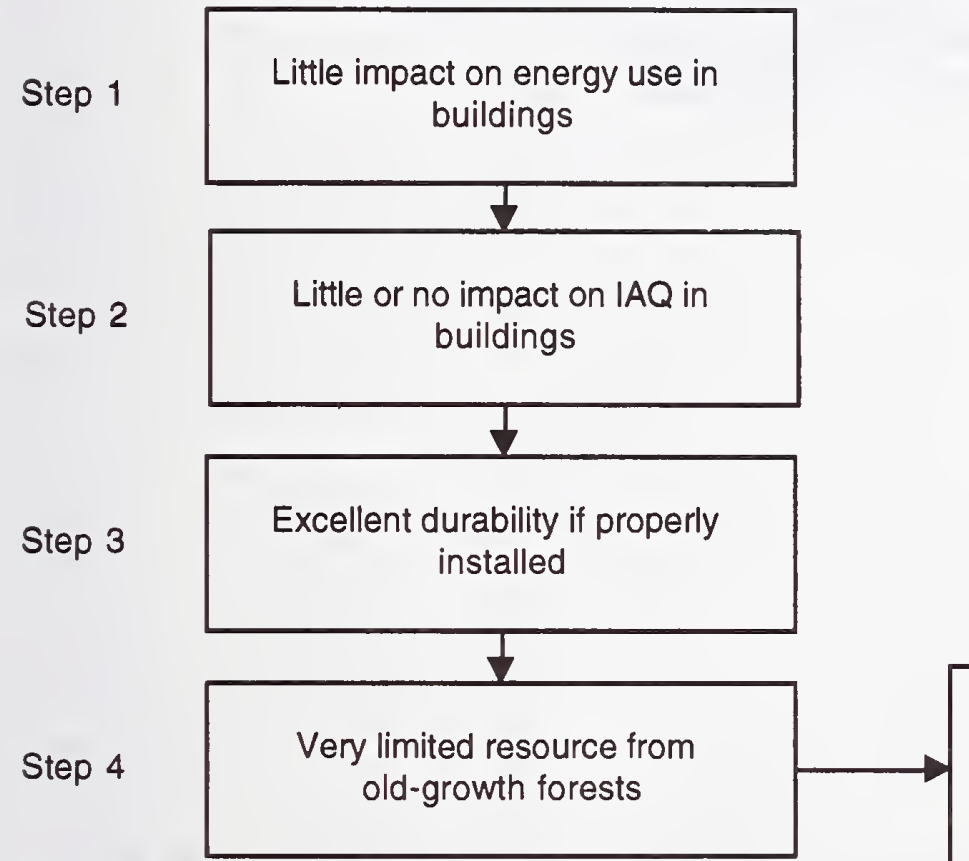

Seek alternative siding, or cedar from salvaged sources or certified forests.

Material eliminated

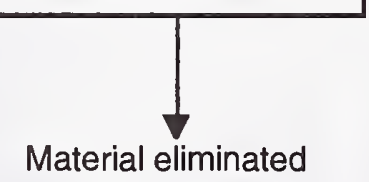

1 Now published annually by John Wiley \& Sons, New York.

2 Forintek Canada Corp., 319 Rue Franquet, Sainte Foy, Quebec G1T 4R4 Canada

3 The Forintek assessment of steel, for example, is based on the inputs and outputs of a hypothetical "typical" steel mill.

4 American Institute of Architects. 1996 "Materials Research Framework" in Environmental Resource Guide. Ed. by Joseph A. Demkin, AIA. NY: John Wiley \& Sons, Inc.

5 Forintek Canada Corp. and Wayne B. Trusty \& Associates Limited. 1993 Building Materials in the Context of Sustainable Development: Phase II Summary Report. 
6 Environmental Resource Guide Application Reports and Athena database

7 A bimonthly newsletter on environmentally sustainable design and construction, published in Brattleboro, Vermont.

8 A phrase used by William McDonough, in reference to toxic byproducts in the textile manufacturing process that were avoided in the manufacture of his line of textile from DesignTex, Inc. 


\title{
AN OVERVIEW OF WORLDWIDE DEVELOPMENT ACTIVITY IN BUILDING-INTEGRATED PHOTOVOLTAICS
}

\author{
Steven Strong \\ Solar Design Associates \\ Harvard, MA 01451
}
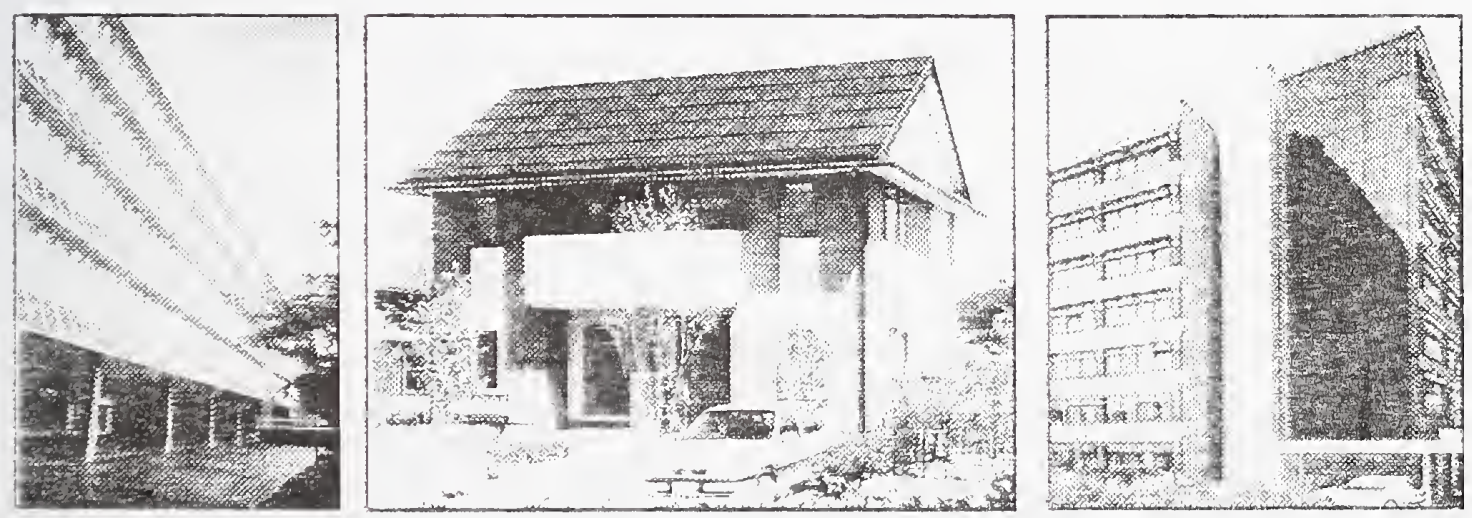



\section{The Dawning of Solar Electric Architecture}

The last two decades have brought significant changes to the design profession. In the wake of traumatic escalations in energy prices, shortages, embargoes and war along with heightened concerns over pollution, environmental degradation and resource depletion, awareness of the environmental impact of our work as design professionals has dramatically increased.

In the process, the shortcomings of yesterday's buildings have also become increasingly clear: Inefficient electrical and climate conditioning systems squander great amounts of energy.

Combustion of fossil fuels on-site and at power plants add greenhouse gasses, acid rain and other pollutants to the environment. Inside, many building materials, furnishings and finishes give off toxic by-products contributing to indoor air pollution. Poorly designed lighting and ventilation systems can induce headaches and fatigue.

Architects with vision have come to understand it is no longer the goal of good design to simply create a building that's aesthetically pleasing - buildings of the future must be environmentally responsive as well. They have responded by specifying increased levels of thermal insulation, healthier interiors, higher-efficiency lighting, better glazings and HVAC equipment, air-to-air heat exchangers and heat-recovery ventilation systems. Significant advances have been made and this progress is a very important first step in the right direction.

However it is not enough. For the developed countries to continue to enjoy the comforts of the late twentieth century and for the developing world to ever hope to attain them, sustainability must become the cornerstone of our design philosophy. Rather then merely using less non-renewable fuels and creating less pollution, we must come to design sustainable buildings that rely on renewable resources to produce some or all of their own energy and create no pollution.

One of the most promising renewable energy technologies is photovoltaics. Photovoltaics (PV) is a truly elegant means of producing electricity on site, directly from the sun, without concern for energy supply or environmental harm. These solid-state devices simply make electricity out of sunlight, silently with no maintenance, no pollution and no depletion of materials. Photovoltaics are also exceedingly versatile - the same technology that can pump water, grind grain and provide communications and village electrification in the developing world can produce electricity for the buildings and distribution grids of the industrialized countries.

There is a growing consensus that distributed photovoltaic systems which provide electricity at the point of use will be the first to reach widespread commercialization. Chief among these distributed applications are PV power systems for individual buildings.

Interest in the building integration of photovoltaics, where the PV elements actually become an integral part of the building, often serving as the exterior weathering skin, is growing world-wide. PV specialists from some 15 countries are working within the International Energy Agency's Task 16 on a 5-year effort to optimize these systems and architects in Europe, Japan and the US are now beginning to explore innovative ways of incorporating solar electricity into their building designs.

A world overview of building-integrated PV activity follows with a country-by-country description of component and systems development along with selected examples of Solar Electric

Architecture. View these early PV-powered buildings as a first glimpse into the coming new era of energy-producing buildings where this elegant, life-affirming technology will become an integral part of the built environment.

Steven Strong, Solar Design Associates Harvard, MA, September 1995 


\section{Japan}

Interest in building-integrated PV has been growing steadily in Japan over the past decade and the government has funded a number of R\&D contracts which address this area. For example, Sanyo has developed and prototyped two types of a-Si PV roof modules for residential roof integration. Both are direct-mounted on a sloped roof surface over the roof deck. The first was a curved tile similar to the traditional Japanese ceramic roof tiles. This curved tile measured $305 \mathrm{~mm}$ square, was quite elegant and blended well with the traditional Japanese roof tile system but, with an output of only 2.7 Wp per tile, was very expensive to produce and install.

The second Sanyo effort introduced a larger-area, flat-panel shingle measuring approximately $1.1 \mathrm{~m}$ by $.54 \mathrm{~m}$ with an active area of approximately $.5 \mathrm{sq}$. $\mathrm{m}$. It did not integrate as well with the traditional Japanese architectural style but the results were pleasing and it was far more cost effective to produce and install. The concept is very similar to the rectangular roof shingle developed in the US using single-crystal cells in the early 1980's by General Electric.

A-Si technology appears to be a better choice for direct-mounted roof applications when compared to thick-crystal technologies because it is far less sensitive to the higher operating cell temperatures resulting from reduced module cooling. The first generation of the Sanyo PV roof shingle is shown in Figure 1.

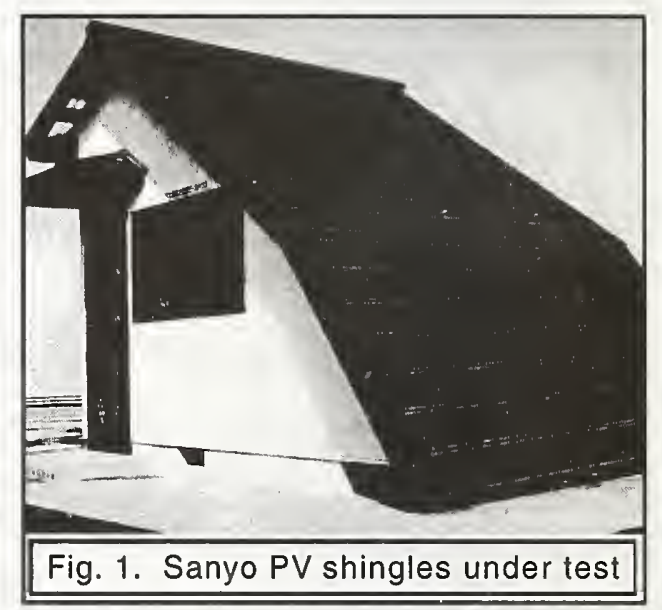
The traditional roofing material in Japan has been tile. However, an asphalt-based roof shingle similar to that produced in the US is now being used increasingly on new residences because of cost. Sanyo has recently revised their flat-panel shingle, changing its scale to better integrate with these new conventional roofing materials. The latest version, shown in Figure 2, is

Fig. 2. Latest Sanyo glass a-Si PV Shingle

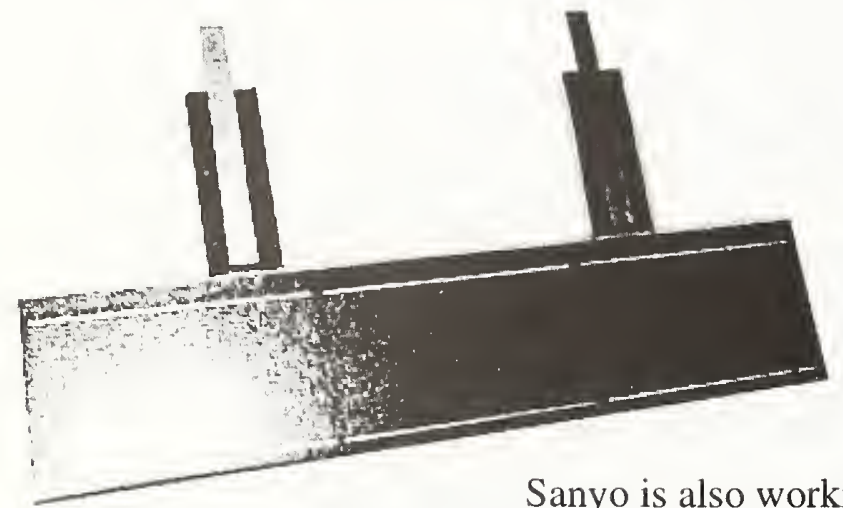
approximately $90 \mathrm{~cm}$ wide by $35 \mathrm{~cm}$ high with an exposed area of about $15 \mathrm{~cm}$ high.

The module is a-Si on a glass superstrate and small plug-in connectors are employed to facilitate module-to-module interconnection. Installation is direct-mount over the structural roof deck. A test house employing this new Sanyo roof shingle has been completed at the Japanese PV test site at Rokko Island operated by Kansai Electric. This house is shown in Figure 3. wall applications. Their vertical facade PV element is a semi-transparent a-Si glass panel with uniformly-spaced, laser-cut microscopic holes, using a process developed at Sanyo in 1986. This technology, which generates electricity while allowing $30 \%$ light transmission, is well suited for auto windows and sunroofs as well as residential windows and commercial curtain wall construction. The integration of the semi-transparent a-Si PV into a conventional building curtain wall reduces glare from direct sun while also reducing the building's cooling demand from unwanted solar gain. Companion opaque (full power) a-Si panels could be installed on the non-view surfaces of the building. 
Module construction employs: glass cover, EVA, glass, aSi thin film with microscopic holes, EVA and a clear plastic back sheet. Prototype modules measure $1.22 \mathrm{~m}$ by $.370 \mathrm{~m}$ by $9 \mathrm{~mm}$ thick and weigh $6.4 \mathrm{~kg}$. All modules are custom order. In addition to commercial curtain wall view panels, many other varied applications such as individual skylight units, sloped glazing systems and residential window units are possible with this versatile product.

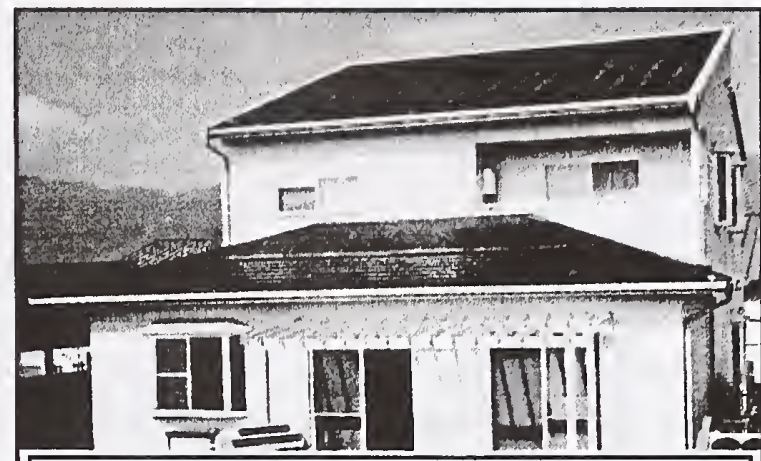

Fig. 3. Kansai Electric's PV demo house

Following the classic Japanese model for market entry, Sanyo began marketing this transparent a-Si technology to automotive companies first for see-through PV sunroofs which are a high-value-added product, while working to develop a market for building integrated power products which is potentially a very large market when unit costs are lowered. Sanyo is the largest Japanese PV manufacturer, reportedly producing 6.5 MWp in 1992.

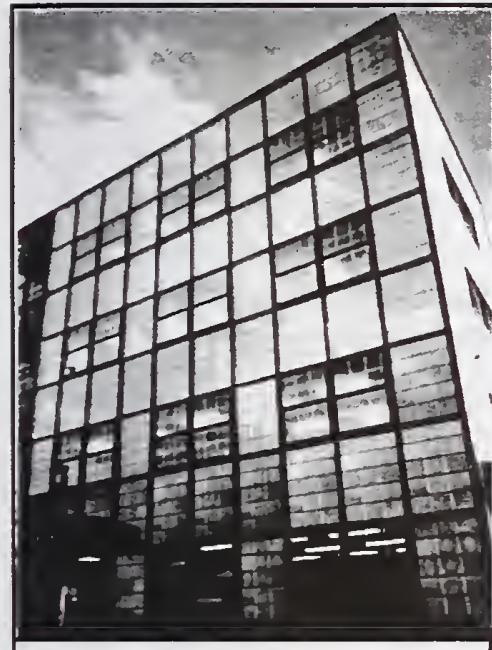

Fig. 4. Sanyo a-Si PV facade
Recently, Sanyo has fielded several prototype installations of its a-Si curtain wall modules in commercial buildings including their own office building and a building for Hokuriku Electric Power Company. A building for the Tsukasa Electric Industry Company, shown in Figure 4, features a full south facade of Sanyo a-Si PV with opaque modules used in the non-view areas and see-through modules used as view glass.

Other Japanese companies are gearing up for the domestic market for distributed PV systems in Japan. Misawa has built a demonstration called the Eco Energy House which is shown in Figure 5. The home features a PV roof employing custom glass-superstrate polycrystalline PV modules from Solarex and an innovative framework of extrusions which provide physical clamping and a weather seal to create an integral PV roof over a sloped residential roof deck.

The Japanese government subsequently sponsored another effort for "The development of a (low-cost) roof-mounted PV array for existing Japanese residences". The prime contractor for this effort is Kandenko Co., Ltd. The program involved an assessment of existing Japanese housing stock and resulted in the development of a new large-area, single- and poly-crystal PV module $1.3 \mathrm{~m}$ by $.650 \mathrm{~m}$ and a stand-off mounting system to install the arrays above the existing roof. The results are quite similar to the 30 residential systems fielded in the US by Solar Design Associates in 1985 for New England Electric in Gardner, Massachusetts..

The Japanese government is also funding participation in

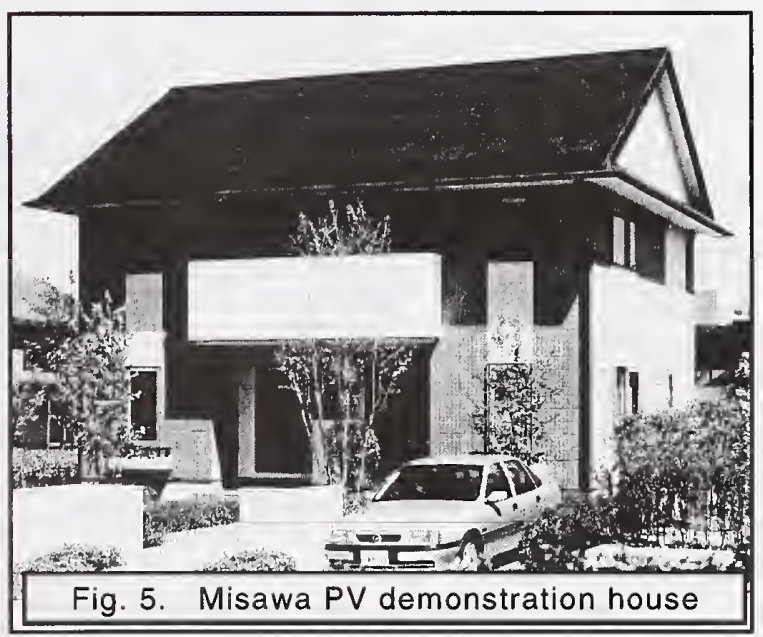
the IEA Task 16, Photovoltaics in Buildings. In addition to representatives from the Japanese MITI, the Government Research Institute and Project Sunshine, PV professionals from Sanyo, Kandenko and the 
Central Research Institute of Electric Power (Japan's EPRI) are representing Japan in this multi-country development effort.

In 1993, the Japanese government invested 206 million yen in component development, 45 million yen in standards and 1,224 million yen on PV demonstrations. Another area of interest has been the development of combined PV/thermal systems for buildings in Japan. Figure 6 shows a prototype combined PV/T system developed for residential applications. This system employs hybrid collectors using polycrystalline PV cells backed by a thermal absorber to produce $3.2 \mathrm{kWp}$ of electricity and $25 \mathrm{~kW}$ of thermal energy.

At their Rokko Island test site, the Japanese have some 500

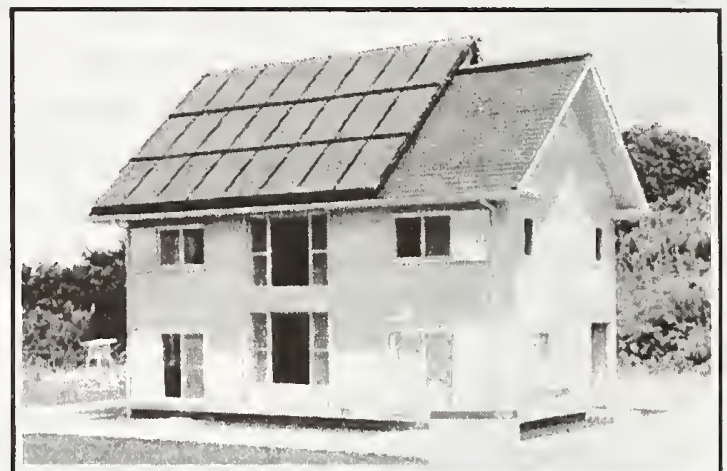

Fig. 6. Japanese PV/T test residence $\mathrm{kWp}$ of small, distributed PV systems under test. Most of these systems are $2 \mathrm{kWp}$. Some are mounted on test houses as shown in Figure 7, while others are ground-mounted and all are connected to the same distribution feeder through a complex of switchgear that allows simulation of any possible combination of events. When representatives of Solar Design Associates visited Rokko Island, Mr. Kitamura, the Program Manager, stated that:

- Distributed PV systems are safe and reliable and will be encouraged in Japan

- The issues surrounding "islanding" and power quality have all been technically resolved

- All utilities must follow the same national uniform interconnection standards

- All utilities must provide Net Metering, two-way power flow connections to small power producers

- Utilities are 'encouraged' to offer a 10\% premium for renewables for the good of the country

These statements were later confirmed and elaborated on in various presentations at the 7th PVSEC held in Nagoya in November, 1993 in a special session entitled: "PV Residences Now Ready". The Japanese have concluded that distributed PV systems on buildings are the most attractive way to field



Fig. 7. $2 \mathrm{~kW}$ PV test systems at Rokko Island photovoltaics and appear ready to dive into this market and make it happen to the direct benefit of their country and their PV manufacturers and the indirect benefit of the rest of the world.

To get things started, the Japanese Ministry of International Trade and Industry (MITI) announced a domestic program, in January 1994, to subsidize distributed, utility-interactive PV systems for residential roof-top applications. The subsidy, of up to 2.7 million yen ( US $\$ 27,000$ ), is meant to cover only up to $1 / 2$ of the price of the PV systems up to $3 \mathrm{kWp}$ per house.

At least 700 residential installations are planned for 1994, the first year of the program; 1,500 in 1995, 2,000 in 1996 and so on, building toward a total of 62,000 and $185 \mathrm{MWp}$ over seven years. The $1 / 2$ subsidy will remain for the first three years of the program and then step down to zero after seven years. The subsidy is proposed to be paid to the PV system supplier, not the homeowner. 


\section{Germany}

In the aftermath of the disastrous nuclear plant meltdown at Chernobyl, the "Green political revolution" gained a strong following momentum all across Europe as environmental consciousness grew. The German government has lead the way in the acceleration of its renewable programs, allocating about 300 million DM in FY 1993. Out of this, 100 million was set aside for PV.

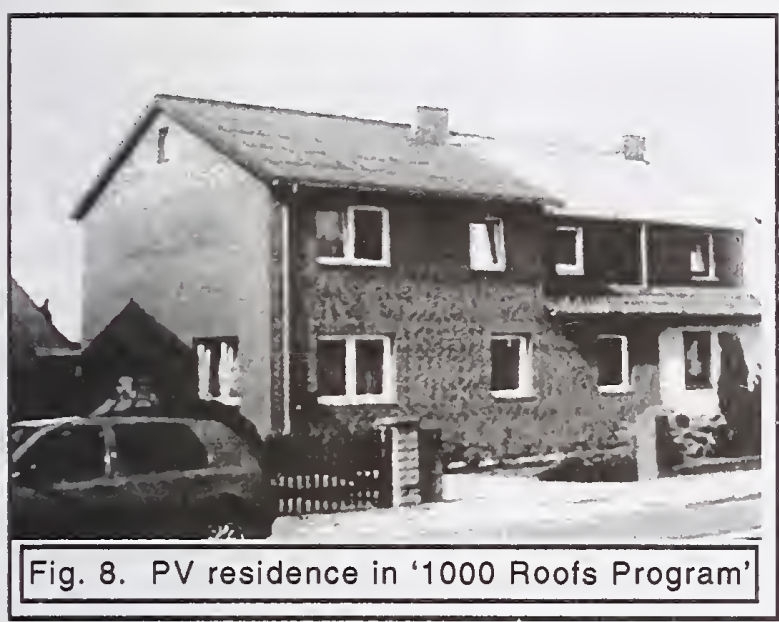

With the implementation of the "1,000 Roofs" program, the German government assumed a leadership role in supporting distributed PV systems for buildings in Europe. In this program, grid-connected PV systems sized at 1-5 kWp are fielded on residential roof tops with up to $70 \%$ cost-sharing from the German government.

Figure 8 shows a typical PV installation under the 1,000 Roofs Program. This residence in Helmstedt received a $4 \mathrm{kWp}$ array of 80 standard (frameless) Siemens M-50 modules integrated into the roof using off-the-shelf aluminum profiles from the German facade company Schüco, replacing the traditional red-clay tile roof. Shortly after the program was started in the fall of 1990, it was expanded to include some 2,500 roof-top installations. By the spring 1994, over 4 MWp of roof-top PV systems had been installed on 1- and 2-family homes across Germany.

In 1993, the headquarters of the Bavarian Environment Ministry received a building-integrated facade of amorphous silicon modules and sun-controlling "eyebrows" over the south-facing windows using mono-crystalline PV modules. This installation, shown in Figure 9, was engineered and supplied by Deutsche Aerospace, (now a partner with RWE in the new German PV joint venture $\mathrm{ASE}$ ), and provide a total of $53.4 \mathrm{kWp}$ of capacity.

Germany's strong commitment to distributed PV systems for buildings has spurred considerable activity in the development of PV modules specifically for building-integrated applications. Phototronics Solartechnik (PST) of Putzbrunn (near Munich and also now a part of ASE) is developing an a-Si commercial curtainwall module approximately $1 \mathrm{~m}$ by $.6 \mathrm{~m}$ with $6 \%$ efficiency. These modules were used on the PV facade at the Bavarian Environment Ministry.

The PST line includes custom-made modules on thin glass superstrates of $1 \mathrm{~mm}$ to $3 \mathrm{~mm}$ thick and $1 \mathrm{~m}$ by $.6 \mathrm{~m}$ in size. Larger modules can be made up of multiple a-Si panels on a larger sheet of face glass. The maximum output claimed is 60

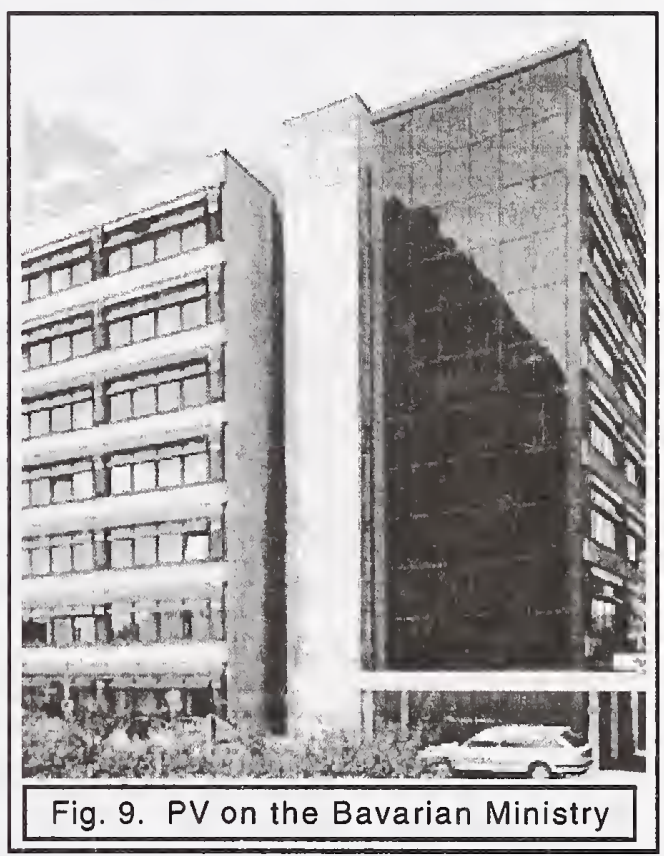
Watts / sq. m. Both opaque and semi-transparent panels are available. Power reduction for semitransparent panels is said to be only $15 \%$. 
This product is designed for vertical facades of commercial and residential buildings. Four basic product approaches are offered for vertical building facades: opaque PV panels for "cold" facades, opaque PV panels backed by thermal insulation, semi-transparent PV panels for view windows within an insulated glass sandwich and a hybrid combined PV/thermal panel incorporating semi-transparent PV panels for view windows within an insulated glass sandwich with warm-air heat recovery. All orders are custom. A roofing tile is also available which fits into standard tile roof systems with an a-Si

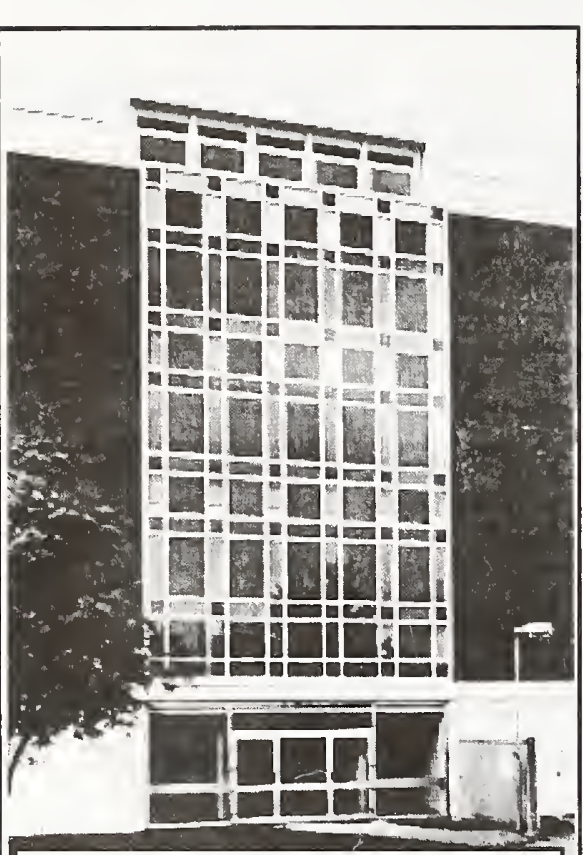

Fig. 10. STAWAG PV Facade glass module top surface measuring $.6 \mathrm{~m}$ by $1.0 \mathrm{~m}$.

Telefunken System Technik (TST) and Nukem (both now part of ASE) have each developed large-area, glass-on-glass, frameless modules using thick-crystal cells for vertical wall and sloped roof integrated applications. Nukem, which is wholly-owned by the German electric utility RWE, offers a full line of PV modules including special custom large-area frameless modules.

Modules are available with either CZ or polycrystalline cells in sizes up to $1.5 \mathrm{~m}$ by $2.5 \mathrm{~m}$ at up to $360 \mathrm{Wp}$. Module construction is glass-on-glass lamination with a poured and cast methyl methacrylate resin as the cell encapsulation and lamination adhesive. Large-area module voltage and current parameters can be configured to suit project requirements. ASE also recently acquired the assets of Mobil Solar Energy Corporation in the US and will be marketing an unframed version of Mobil's large-area $300 \mathrm{Wp}$ module to the building-integrated market.

Flachglas Solartechnik (Flagsol) in Köln, a subsidiary of Flachglas, a major producer of architectural glass in Europe, has embarked on an ambitious development program for both thick-crystal and thinfilm commercial curtain wall applications and is looking at semi-transparent thin-film curtain wall modules similar to those produced by Sanyo in Japan. Flachglas sees PV as a means to add additional value to their glass products.

In May 1991, Flachglas installed a prototype $4.2 \mathrm{kWp}, 50 \mathrm{~m}^{2}$ array in the south facade of the administration building of the Stadtwerke Aachen AG (STAWAG), a local municipal utility in Aachen, Germany. The facade, shown in Figure 10 , employs $10 \times 10 \mathrm{~cm}$ polycrystalline cells laminated between two sheets of $4 \mathrm{~mm}$ glass backed by an air space and two more panes of glass ( $3 \mathrm{~mm}$ and $4 \mathrm{~mm}$ ).

Four different size panels were specified by the architect to provide balanced daylighting for the stair hall while creating a pleasing design pattern. The interior of the STAWAG PV facade is shown in Figure 11. The system is utilityinteractive. Flachglas provides complete system design and integration as desired by the client and recently received a contract for design and construction of a $300 \mathrm{kWp}$ utility-

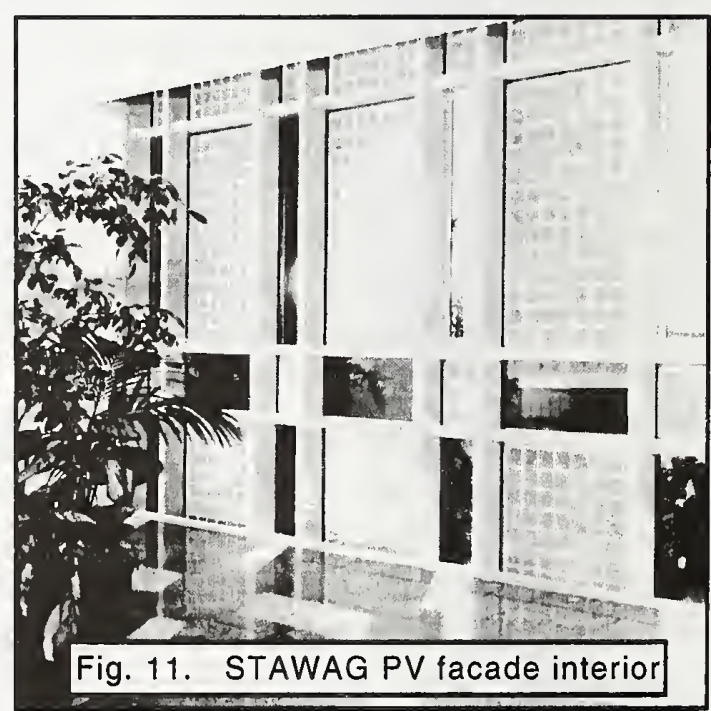
interactive PV roof to be installed at the Science Park Gelsenkirchen near the Essen, Germany. This 
system will cover some $2,130 \mathrm{~m}^{2}$ making it the largest building-integrated PV system in Europe.

Other German companies have also developed innovative approaches to building integration. The commercial building shown in Figure 12 features a facade of "structural glazing" elements which incorporate PV modules and operable view glass in a prefabricated assembly. Close design collaboration between the architect, (Planerwerkstatt Hölken and Berghoff of Vörstetten), the PV system engineers, (Solare Systemtechnik of Freiburg) and the construction contractor, (Greschbach of Karlsruhe), allowed the entire building facade to be installed in half a day. The combined capacity of the PV facade and the roof-top array is $18.5 \mathrm{kWp}$. The building was completed in 1993.

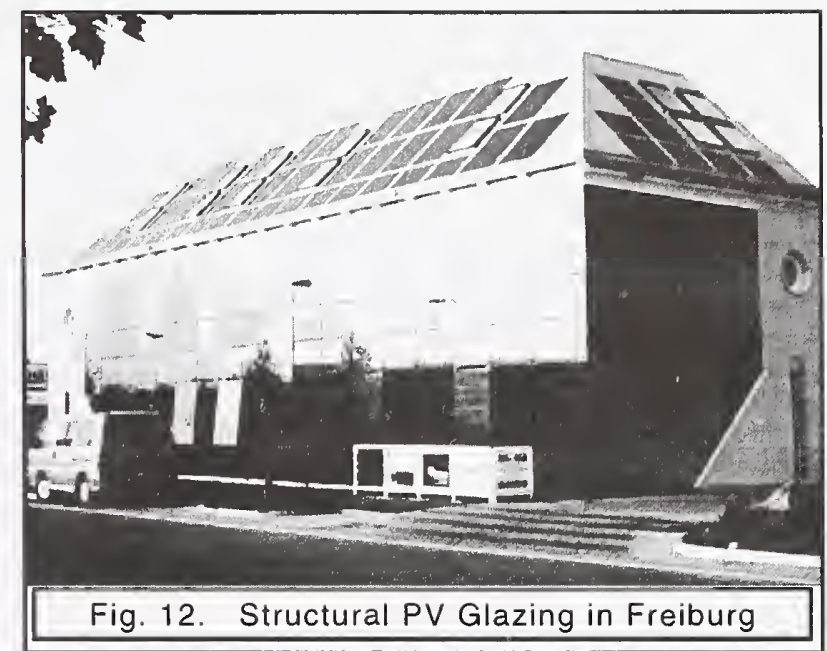

The Institut für Solare Energieversorgungstechnik (ISET) in Kassel is also developing and refining methods of mechanical and electrical integration of PV elements into commercial building facades as well as working on other 'balance-of-system' issues for building-integrated PV including small, modular, DC-to-DC maximum-power-point tracking devices and DC-to-AC power converters.

The Fraunhofer Institute for Solar Energy Systems in Freiburg has active research efforts underway in a

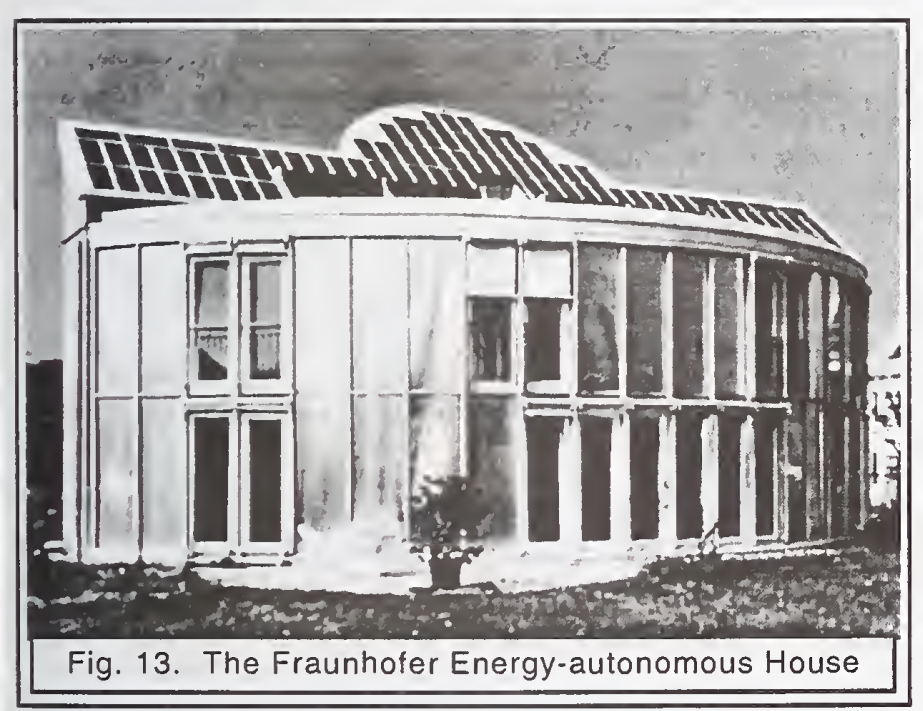
number of areas related to PV-in-buildings and has recently completed the design and construction of an energy autonomous house in Freiburg which incorporates PV, active solar thermal, passive solar gain, super insulation and a hydrogen system consisting of an electrolyzer, storage and a fuel cell. This house is shown in Figure 13.

Under the leadership of Dr. Jürgen Schmid, who realized very early on the many benefits of PVin-Buildings, Germany took the lead in establishing the IEA Task 16, Photovoltaics in Buildings and is the operating agent. In addition to representatives from the Government's Federal Energy Office, PV professionals from several government-funded research institutes, universities and PV companies are representing Germany in this multi-country development effort.

The immediate future for building-integrated PV in Germany will certainly be affected by the current budget strain on all branches of government due to the enormous costs of the re-unification of east and west Germany. PV is said to still be an important priority but things like housing, schools, etc. are first in line. Program managers say the best they are hoping for is level funding but some budget reductions seem certain in the near term as the country struggles to accommodate the fiscal burden of reunification. 


\section{Switzerland}

Political fallout from the nuclear disaster at Chernobyl has also had a very significant impact on Swiss policy making. The Swiss declared a 10-year moratorium on new nuclear plant construction in mid1990 and, shortly thereafter, announced a dramatic increase in support for photovoltaics and other renewable energy sources with the pledge to field 50 MWp of PV by the year 2000.

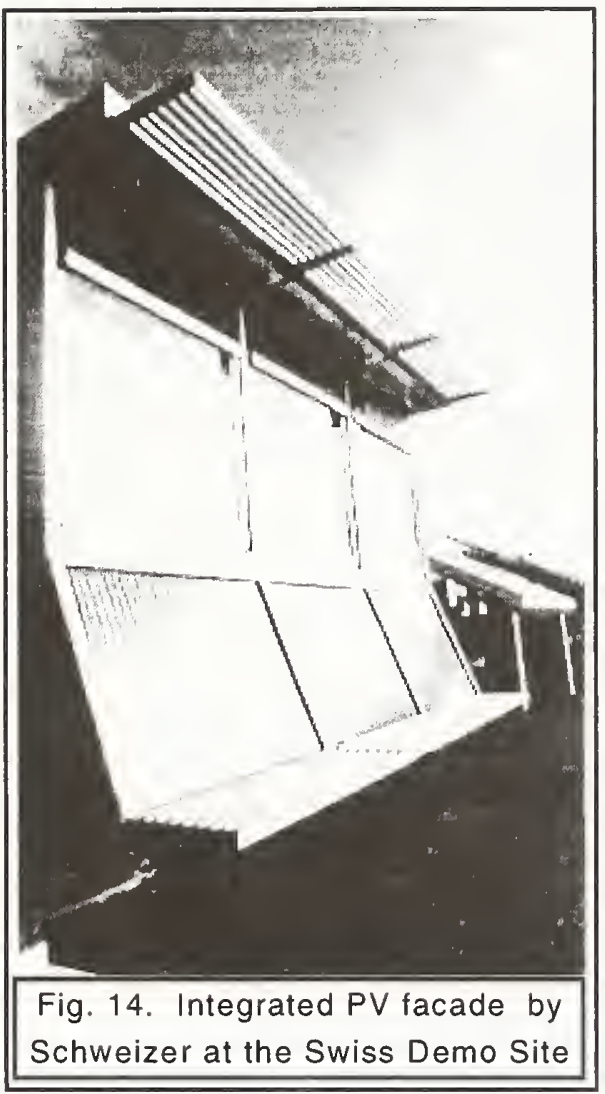

Large areas of flat, open land are not common in Switzerland and, accordingly, activity in photovoltaics for buildings has increased significantly. A substantial amount of funding $(6,100,000 \mathrm{SF})$ has been allocated by the Swiss Federal Energy Office to support the development of building-integrated PV, including component and systems development, systems integration issues, utility interface, demonstration projects, and education / information dissemination.

As a part of the Swiss Federal PV in buildings program, the Solar Energy Laboratory at the Swiss Federal Institute of Technology (EPFL) in Lausanne has recently dedicated a demonstration site for the testing and evaluation of building-integrated PV systems. At present, some twelve demonstration pavilions are complete, presenting different approaches to roof and facade construction.

Figure 14 shows an innovative integration of PV into a commercial building facade on display at the 'Demo Site'. The system, developed by the Swiss firm of Ernst Schweizer in Hedingen, places the PV elements at $20^{\circ}$ to the vertical, creating a suncontrolling overhang for the floor below.

Sponsors of the Demo Site envision it as an "international center for the architectural integration of PV" in support of the IEA Task 16. A sort of 'shopping market' where architects, engineers and building owners can go to see a variety of working building-integrated PV systems on display. Sites for additional systems are still available and manufacturers the world over are invited to participate.

In addition to the Demo Site, the EPFL has a number of innovative installations of PV on their campus. Figure 15 shows the integration of PV elements into daylighting roof monitors on the EPFL Administration Building. The PV modules are fabricated with a clear back skin and a slight spacing between the cells to allow in a gentle pattern of direct sunlight while the primary daylighting comes from the north-facing clerestories.

Engineers at the EPFL's Laboratoire d'Energie Solaire (LESO) have designed other PV systems

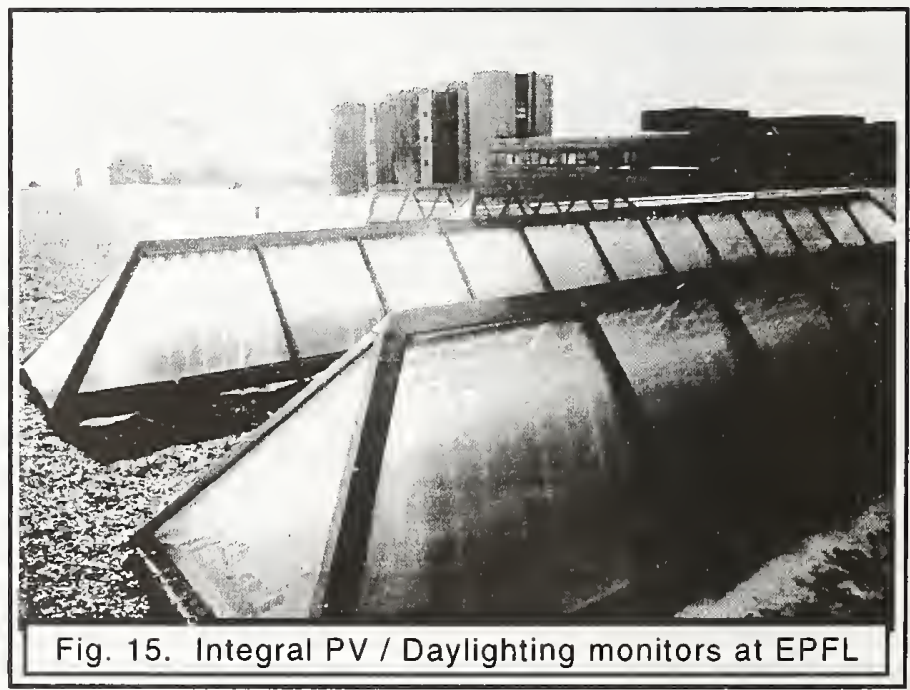


for new and existing buildings on the campus including PV elements used as sun shades, retrofits of existing roof monitors, a novel flat roof system and a facade retrofit.

A privately funded program started before the German "1,000 roofs" program was instituted to install a megawatt of capacity in distributed roof-top PV systems. Using specially-arranged private, long-term financing with low interest rates and volume purchases, 333 grid-connected PV systems, each rated at $3 \mathrm{kWp}$, have been constructed by the Zurich company Alpha Real.

Alpha Real is also developing a novel PV roof tile system in collaboration with Plaston LTD. (Widnau) with funding from the Swiss Federal government. These tiles have an active area of about $.25 \mathrm{sq} . \mathrm{m}$ and employ $2410 \times 10 \mathrm{~cm}$ silicon cells to produce approximately $30 \mathrm{Wp}$ each.

Quick-connect, plug-in connectors are employed. The tile design is very clever in that they integrate directly into the system of conventional tiles as shown in Figure 16 and are thus appropriate for both retrofit as well as new construction. Several prototype residential installations have been fielded.



With well over $90 \%$ of the sloped roofs in Switzerland and most of the rest of central Europe constructed with clay tile, the potential market for new and retrofit installations of PV roof tiles is very large across Europe and in other countries such as Japan where clay tiles are also the traditional roofing.

The Swiss government has embarked upon an ambitious nation-wide educational program on photovoltaics. The program goal is to inform the Swiss people of the virtues and benefits of solar electricity. The program includes public information (including the Swiss DemoSite) and technical seminars and workshops for electricians, roofing craftsman, architects and building engineers. In an effort to reach all segments of the population, PV systems have been fielded on Swiss school buildings as a way to acquaint the next generation with photovoltaics.

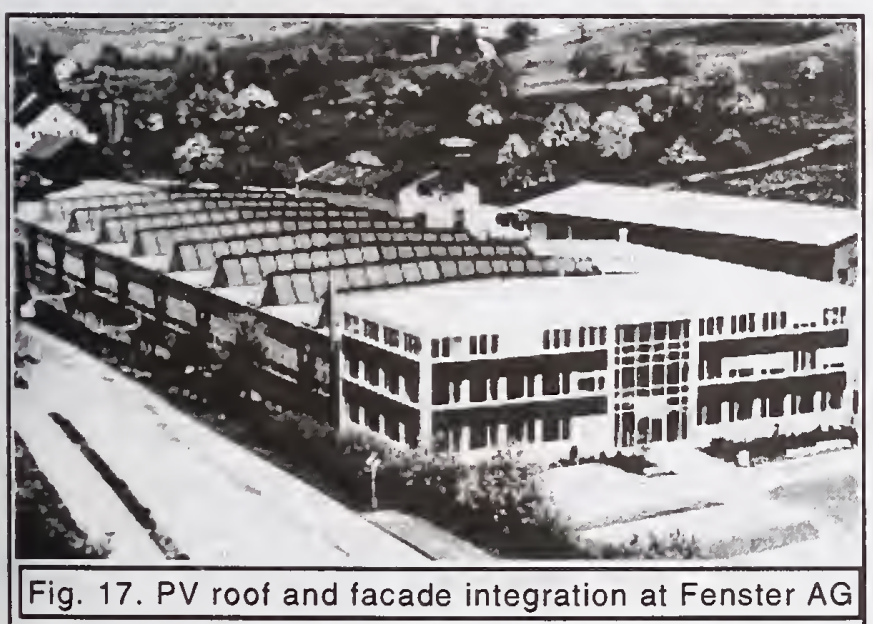

Solution AG fur Solartechnik (Härkingen) has developed a line of large-area, glass-superstrate PV modules custom made to project specifications which employ either single-crystal or polycrystal silicon cells. Modules can be made up to $1.7 \mathrm{~m}$ long by $1.3 \mathrm{~m}$ wide. Combined PV / thermal hybrid designs have also been produced using air to scavenge heat from the back of the modules and deliver it to storage or a load.

Working in collaboration with Atlantis-Energie AG (Berne), Solution has fielded several demonstration projects with building-integrated PV arrays. Figure 17 shows a new industrial plant and office building in Arisdorf $(\mathrm{CH})$ completed in 1991 for window 


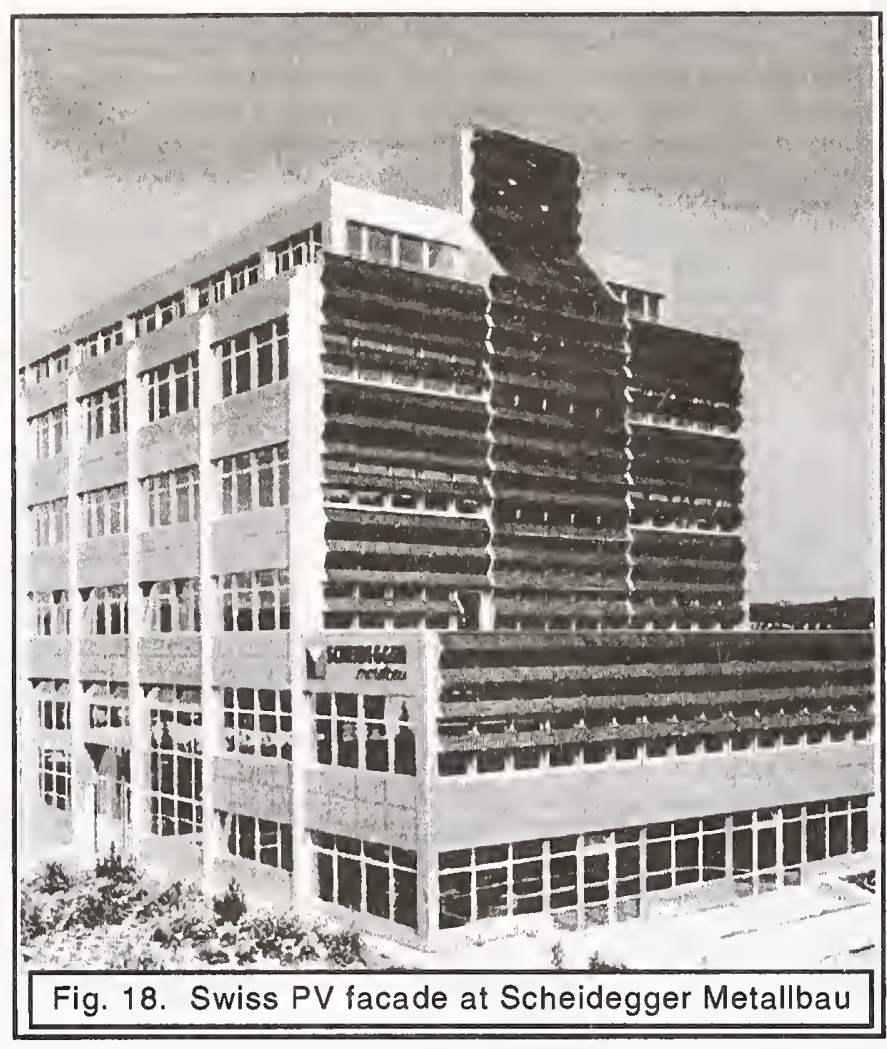

manufacturer Aerni Fenster, AG where Solution installed a $62 \mathrm{kWp}$ grid-tied system. $9 \mathrm{kWp}$ of modules were integrated into the office building's facade and $53 \mathrm{kWp}$ of modules were integrated into the roof of the production facility on the south side of north-facing daylighting clerestories.

Another significant project realized by Solution and Atlantis is the new office and manufacturing building for Scheidegger Metallbau in Kirchberg, shown in Figure 18. Completed in 1992, the south-facing facade of the building incorporates a multifunctional PV system employing PV elements for sun shading and facade cladding with reflector augmentation in the spandrel areas, while scavenging thermal energy from the center section to temper the stairhall. The system peak output is $18 \mathrm{kWp}$.

The Swiss government is also heavily involved in the IEA Task 16, Photovoltaics in Buildings. In addition to representatives from the Government's Federal Energy Office, PV professionals from several government funded research institutes, universities and PV companies are representing Switzerland in this multi-country development effort.

The immediate future for buildingintegrated PV in Switzerland looks very promising. With generous government incentives to underwrite the cost of introducing a new technology, Swiss architects and engineers have responded with very innovative concepts in the design of building-integrated PV.

They have also fielded some innovative systems integrated with other "built forms" such as the system shown in Figure 19 which is integrated with the

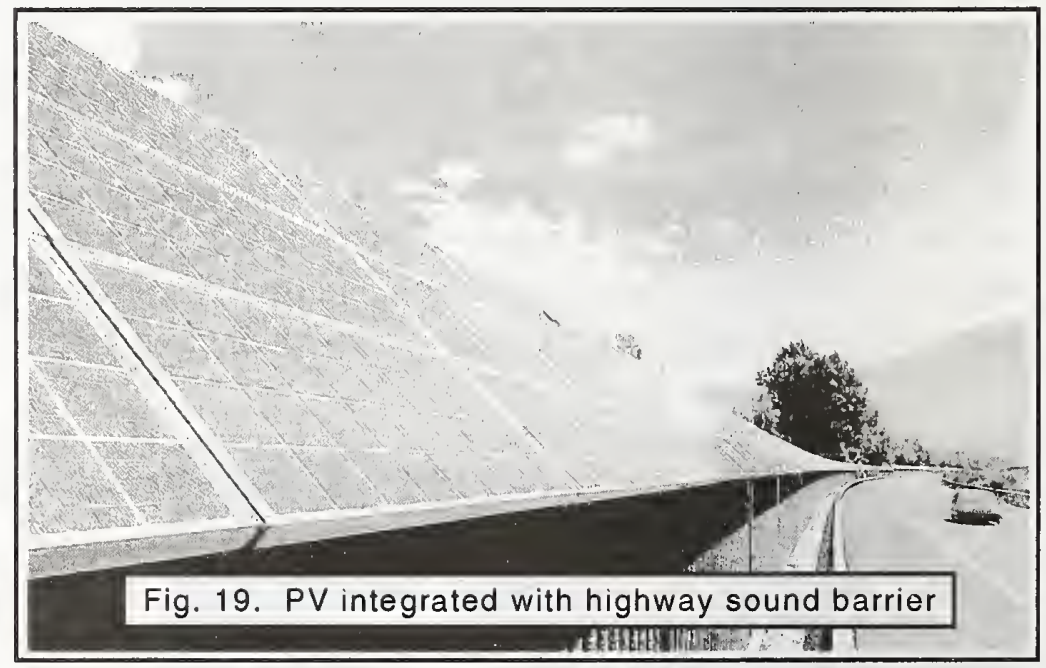
sound barrier along highway N13 south of Chur. Other PV systems have been fielded along rights of way of the Swiss railroads which are, of course, electric.

A number of Swiss companies have begun to produce custom PV modules to meet special design requirements with some even producing custom triangular modules to architect's specifications. In addition, the country has instituted net metering and uniform interconnection policies on a national basis which, in itself, represents a major national commitment to PV since Switzerland has over one thousand individual electric utility companies. 


\section{The Netherlands}

Interest in PV and distributed systems for buildings has also grown in the Netherlands just as it has across the rest of Europe. Recent R\&D activities have concentrated on improvements in the development of PV building elements and improved power conditioning. Government funds have been appropriated for a pilot program of grid-connected, distributed PV systems with building-integrated PV arrays. In the next 4 years, some 1,000 homes will be built with roof-integrated PV systems. In this effort, the Dutch will study the influences of PV on architecture, town planning, home financing and ownership.

Figure 20 shows a 10 -unit multi-family housing development in Heerhugowaard, a town $50 \mathrm{~km}$ north of Amsterdam, where a roof-integrated 25 $\mathrm{kWp}$ utility-interactive PV system was installed as a demonstration of building-integrated PV applications.

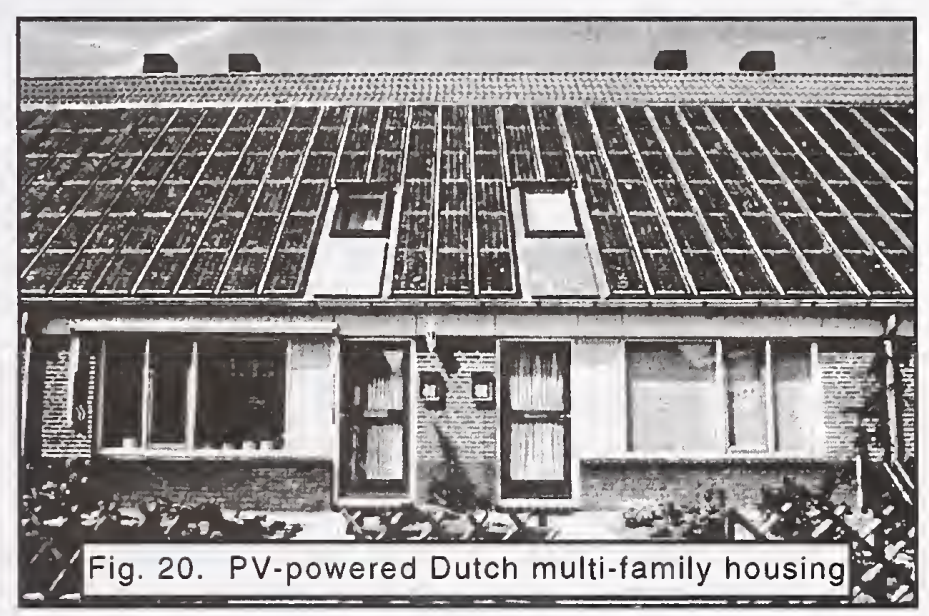

Financed largely by the Dutch regional utility PEN with additional support from the Netherlands Office of Energy and Environment, (NOVEM), the PV system uses standard polycrystalline PV modules from R\&S (Netherlands), integrally mounted with off-the-shelf aluminum profiles adapted from a greenhouse glazing system. Each individual unit has its own $3 \mathrm{~kW}$ power inverter.

The Dutch PV program has provided funding for the development of building integration techniques for both residential and commercial buildings. In addition to the multi-family housing demonstrations, a number of detached, single-family homes have received roof-integrated PV systems such as the home shown in Figure 21 in Lekkerkerk which features an integral $3 \mathrm{kWp}$ array of glass-superstrate crystalline silicon PV roof tiles from Switzerland.

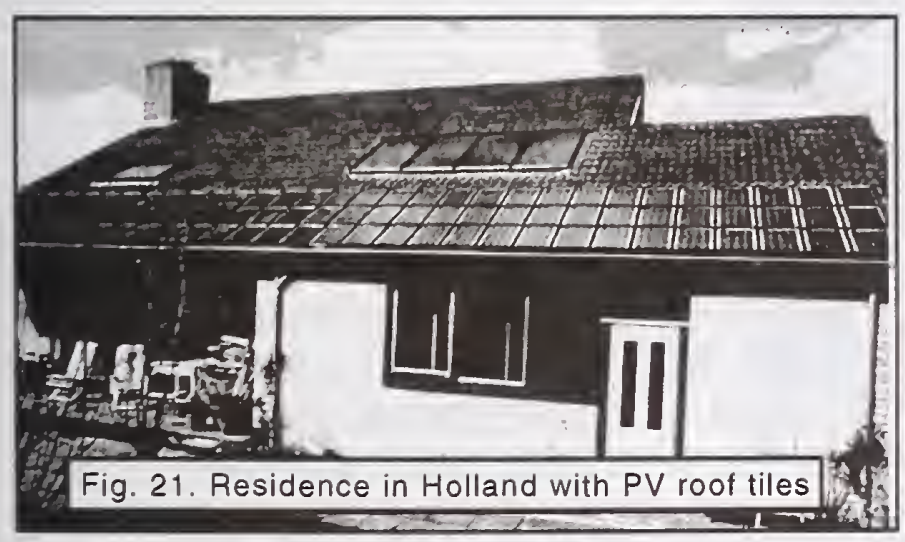

A PV-powered, energy autonomous
demonstration house was constructed in
Woubrugge, a small village between Amsterdam
and Rotterdam. The PV array incorporates
standard (unframed) polycrystalline modules in a
roof-integrated mount using aluminum profiles
similar to those employed in the Heerhugowaard
project. Space and domestic water heating are
provided by solar thermal collectors. As would
be expected, the house is heavily insulated and
employs high-efficiency glazings and appliances.

The Dutch have also explored other methods of integrating PV into their lives, including the use of PV on-board the hundreds of house boats that line the canals in and around Amsterdam as well as on cargo barges so important for the shipment of goods. Figure 22 shows a "roof-top" PV system atop the wheelhouse of a Dutch canal barge. The PV system provides power for lights and communications equipment allowing the Captain to shut down the ship's diesel when the vessel is not underway. 
Similar PV systems on the roofs of Dutch houseboats allow boat owners to live independent of the utility mains without operating an on-board generator. Nearly all PV systems on watercraft are installed flat because of variable orientation. The first of these systems were fielded by ECOFYS (Utrecht) as demonstrations. Now that they have been shown to be reliable and costeffective, boat owners are installing these systems themselves. As might be expected, the Dutch government has long ago instituted

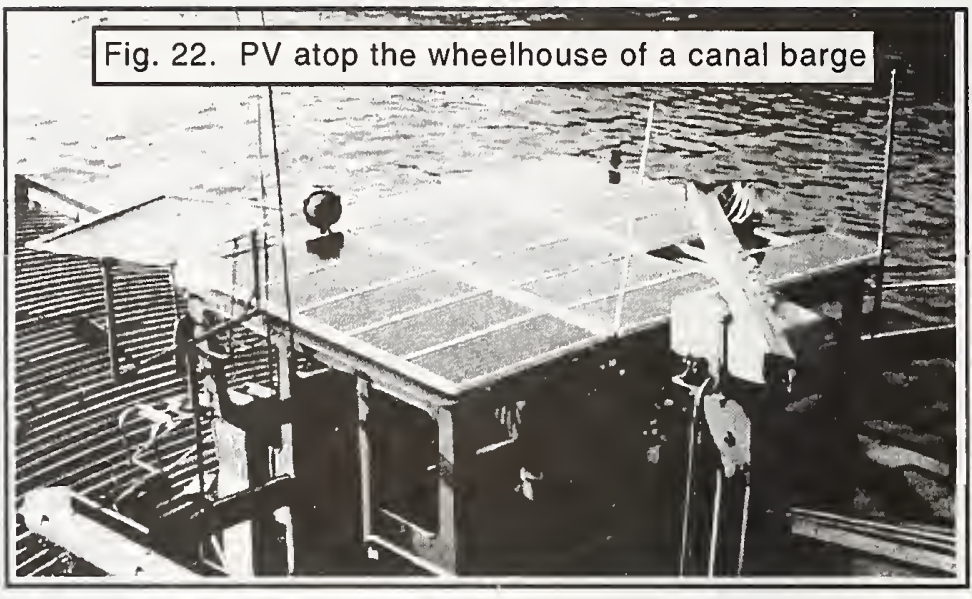
a program to power the thousands of aids to water navigation with PV.

In the interest to further integrated PV solutions that utilize existing aperture area and available structural elements, the Dutch have also developed PV for highway soundbarriers. Figure 23 (below left) shows a prototype section of a pre-cast concrete soundbarrier element with integrated PV. The Dutch government will complete the first $80 \mathrm{kWp}$ demonstration in 1994. Also being considered are the rights-of-ways along the Dutch railroads, where a recent assessment has shown that PV placed in the available area would provide enough capacity to completely power the rail system.

The Dutch government has announced plans for a large-scale PV-in-buildings project on 100 units of new housing to be constructed in Nieuw Sloten, a new city district of Amsterdam. The project is being funded by the Energy Company of Amsterdam (the electric utility), as part of its Environmental Action Plan, in cooperation with NOVEM and EU-Thermie. Plans call for PV to be installed on some 70

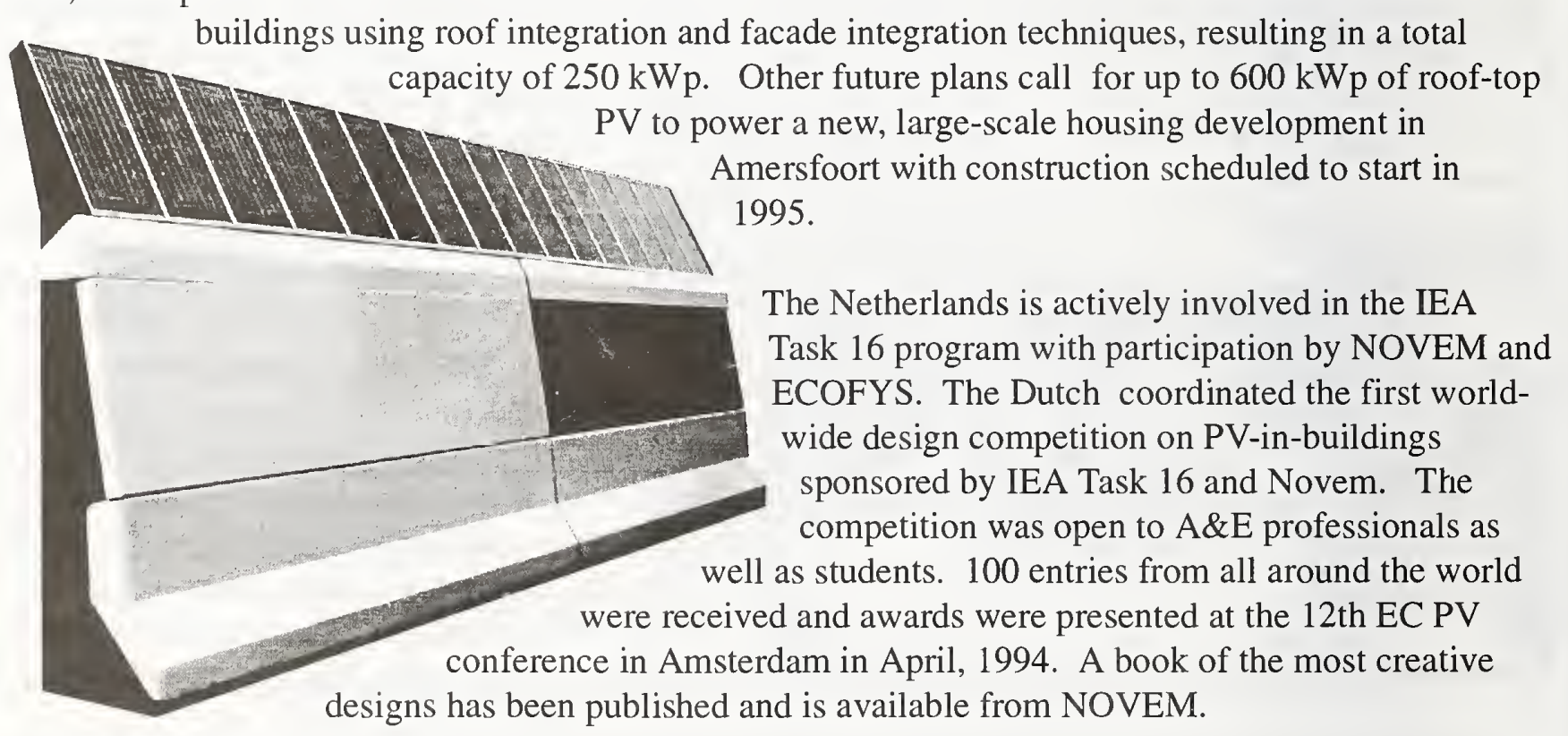

The prospects for advancement of building-integrated PV in the Netherlands look very promising. Budgets and research activity are increasing and significant demonstrations are planned over the next few years. The Dutch see PV as a significant part of their 20-year National Environmental Policy Plan and, if the Dutch program goal of fielding 250 MWp of PV by the year 2010 is to be achieved, there will surely be thousands of PV-powered buildings. 


\section{Austria}

Interest in distributed PV applications has increased in recent years in Austria along with the rest of Europe. The Austrian government has announced a comprehensive plan to reduce $\mathrm{CO}_{2}$ emissions and PV is seen as an important part of this effort. Over the past ten years, Austria has fielded a number of stand-alone and grid-connected PV systems totaling some $800 \mathrm{kWp}$ including a $30 \mathrm{kWp}$ utilityinteractive system at Mount Loser, high in the Alps and a $40 \mathrm{kWp} \mathrm{U.I.} \mathrm{system} \mathrm{along} \mathrm{the} \mathrm{A1} \mathrm{motorway.}$

In May 1992, the Austrian government announced a distributed roof-top PV demonstration program modeled after the German "1,000 roofs" effort. This program will initially include some $200 \mathrm{kWp}$ of PV systems financed with support from the government and the electric utilities. In addition, several local district authorities have offered additional funding of up to $50 \%$ of the systems cost.

A good example of the Austrian roof-top PV program can be seen in the energy-efficient, private, single-family residence constructed in 1992 in Gleisdorf, a small town in southern Austria. The house was designed as a 'low-energy' house and, as such, incorporates solar thermal collectors for domestic water heating, extra-heavy insulation, high-quality glazings, passive solar gain and state-of-the-art highefficiency appliances. The home's detached garage, shown in Figure 24, incorporates a $2 \mathrm{kWp}$ roofintegrated PV array employing frameless Siemens laminates. The array has provisions for free air flow behind the modules to provide back-surface cooling.

In 1993 another 'low-energy' house was completed near Vienna. With support from the local electric utility, Wiener Stadtwerke Wienstrom, and the Austrian Roof-top PV Program, a $3 \mathrm{kWp} \mathrm{PV} \mathrm{system} \mathrm{was}$ installed with approximately one half the capacity mounted on the roof and the remainder integrated into the south facing facade. The house also incorporates solar thermal collectors for domestic water heating. The utility is monitoring the output of the energy systems to determine the amount of possible reduction in $\mathrm{CO}_{2}$ from large-scale use of PV and solar thermal systems.

Within the first five months of the Austrian roof-top PV program, over 160 $\mathrm{kWp}$ of systems were committed with significant cost-sharing from the homeowners. Many of these systems are building integrated. Nearly all of the systems under the first $200 \mathrm{kWp}$ roof-top program are presently complete and in operation, and discussions are now underway to expand the program by

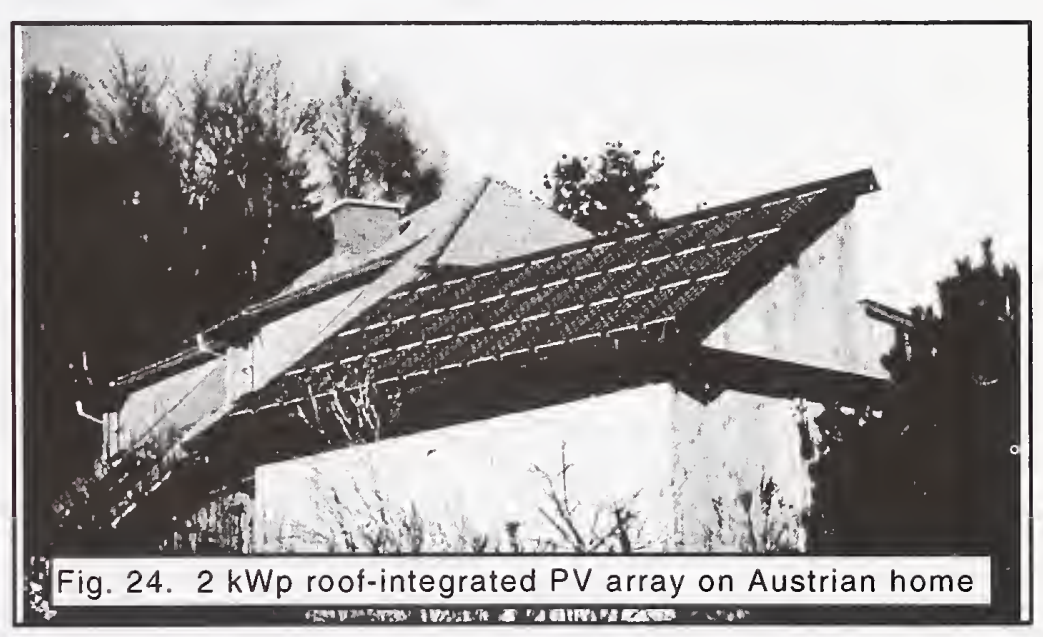
another $100 \mathrm{kWp}$.

As in most of Europe, tile is the traditional material for sloped roofing in Austria. In an effort to make residential PV arrays compatible with the majority of existing roofs, a flat-glass roof tile using singlecrystal technology has been prototyped in Villach, Austria by a private group headed by a Dr. Kroner. The tiles are a glass-on-glass laminate with silicon gel used as the encapsulant. Each tile measures approximately 12" wide by 9 " high in active area and incorporates twelve 3 inch square cells to deliver 
about $12 \mathrm{Wp}$. A prototype residential roof system, shown as Figure 25, was successfully fielded in Gleisdorf and the group is now looking for development capital.

With much of Austria alpine, efforts have been made to utilize other available sites for PV in addition to buildings. In 1992, the Austrian electric utility Oberösterreichische Kraftwerke AG, (OKA) completed a $40 \mathrm{kWp}$ PV system atop the existing soundbarriers along the southern motorway A1 near Salzburg.

The system, shown in Figure 26, incorporates standard Siemens modules preassembled into subarrays and lifted into place with a light crane reducing field labor. An advanced IGBT pulse-width-modulated inverter feeds system output directly into the OKA distribution feeder.
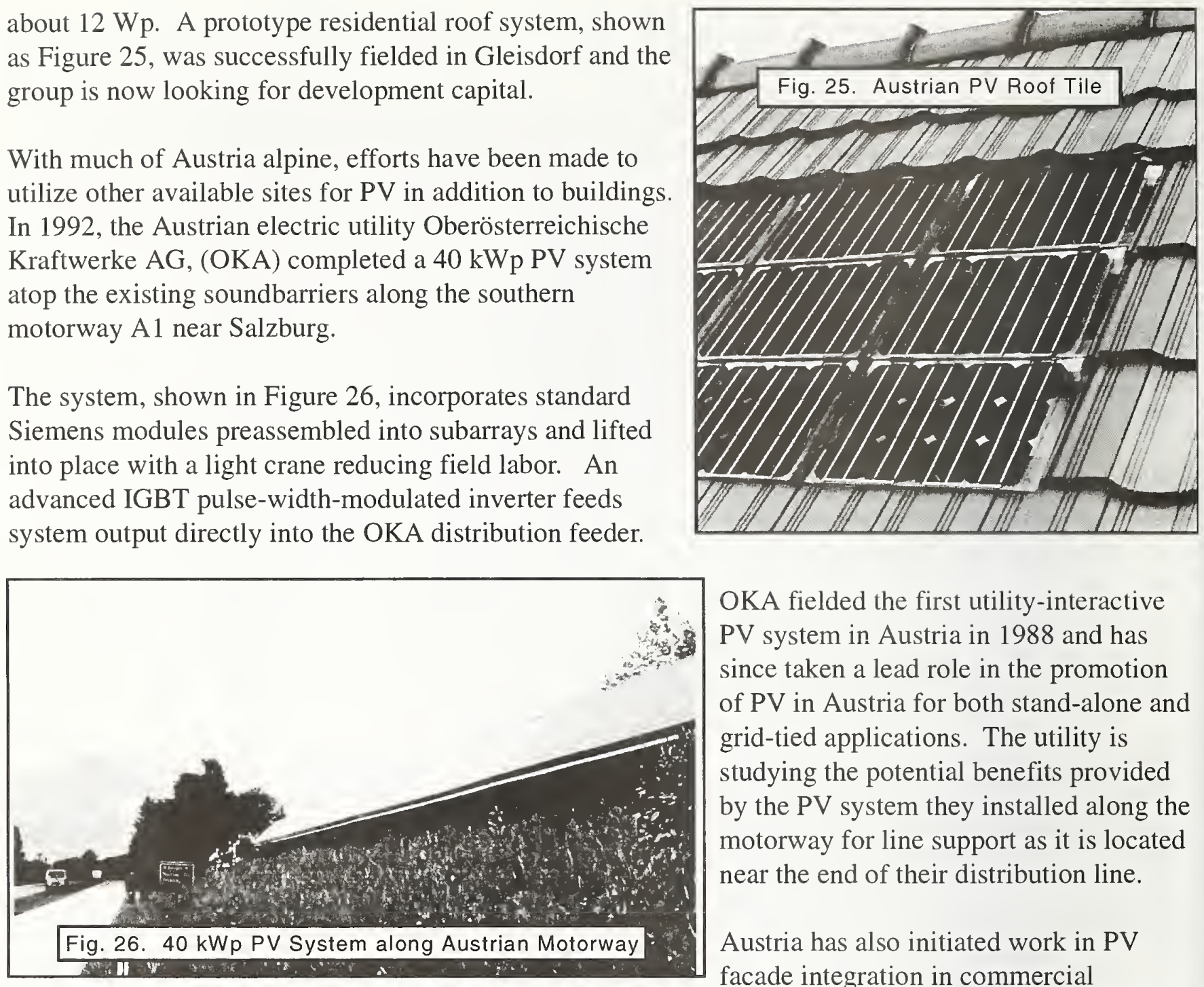

OKA fielded the first utility-interactive PV system in Austria in 1988 and has since taken a lead role in the promotion of PV in Austria for both stand-alone and grid-tied applications. The utility is studying the potential benefits provided by the PV system they installed along the motorway for line support as it is located near the end of their distribution line.

Austria has also initiated work in PV facade integration in commercial

buildings with the recent construction of the $13 \mathrm{kWp}$ system on an office building in Innsbruck shown in Figure 27. The building was an existing structure which was scheduled for extensive renovation. During the reconstruction process, the idea was proposed to incorporate a PV array on the south facade as a sun screen to limit unwanted sun-driven summer cooling loads from direct solar gain through the glazing.

The grid-connected system employs largearea single-crystal PV modules manufactured by DASA in Germany (now ASE). The system's output is estimated at $10,370 \mathrm{kWh}$ per year and will be monitored as part of the programme of the Austrian Utilities Association (TIWAG).

Austria supports IEA Task 16 effort with representation from the Technical University at Wien and OKA participating.

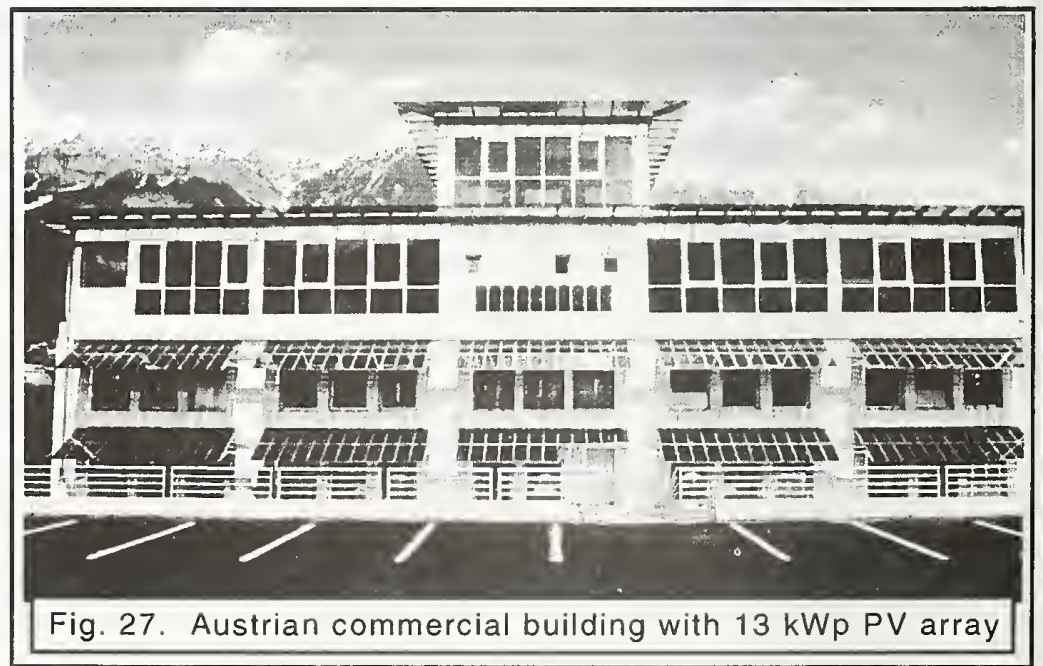




\section{United States}

Photovoltaics was born in the US with the invention of the silicon solar cell at Bell Labs in the early 1950's. With the first world oil shock in 1973, interest blossomed in terrestrial applications of PV and, a conference was held at Cherry Hill, NJ where experts in all aspects of PV convened to plan the best strategy for the development of the PV industry. As a result of the Cherry Hill meeting, the United States embarked on a comprehensive, multi-level program of research, development and demonstration of PV for large-scale terrestrial power use.

Many major corporations including US industrial giants such as Atlantic Richfield, Exxon, Texaco, Shell, General Electric, Westinghouse, Boeing, and Martin Marietta, jumped in, investing hundreds of millions of dollars in PV research and development and the race was on! With its considerable resources, focused program and federal government leadership, the US quickly became the acknowledged world leader in the development of PV. After just five years, costs had been reduced dramatically and efficiencies had improved significantly.

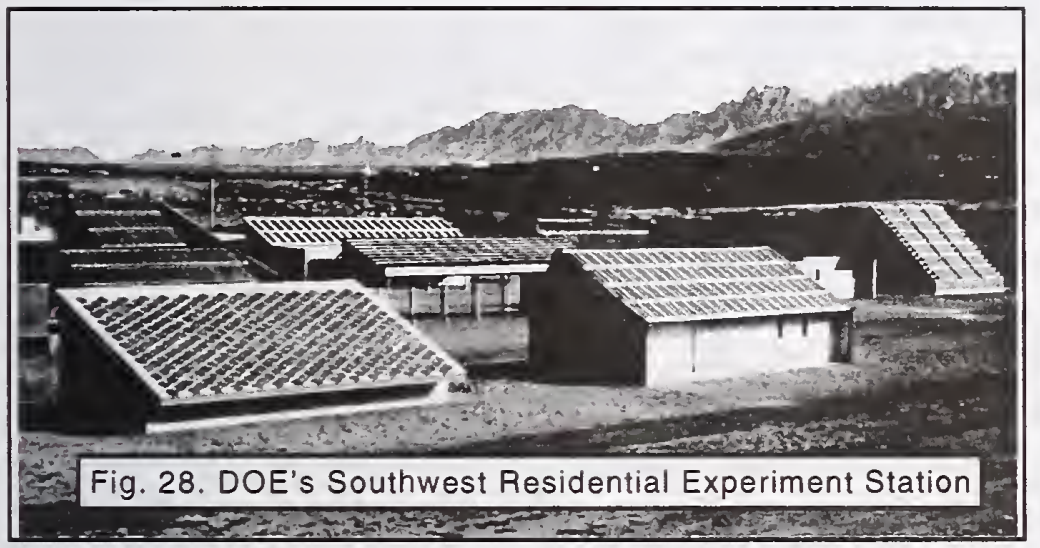

In the late 1970s, a well-planned program of development of distributed PV was established by the US Department of Energy (DOE) at MIT which included the design and demonstration of many different approaches to building integration. A number of hardware and building designs were commissioned and three demonstration sites were established across the country where prototype building-integrated PV systems were

fielded for evaluation under different climate conditions. The DOE's Southwest Residential Experiment Station (SWRES) constructed at New Mexico State University in Las Cruces, NM to test PV systems in the hot, dry, desert climate is shown in Figure 28.

Working under contract to the US DOE, Solar Design Associates developed the first building-integrated PV system employing large-area $.9 \mathrm{~m} \times 1.8 \mathrm{~m}$ PV modules and, in 1979, constructed prototype residential roofs for testing and evaluation at the DOE-sponsored residential experiment stations. Based on the results at the residential experiment stations, the US DOE and MIT commissioned Solar Design Associates to design the energyefficient, passive solar residence powered by photovoltaics, shown in Figure 29.

The 'Carlisle House', as it became known, was constructed in 1980 in Carlisle, MA with participation from MIT and the US DOE. The residence features passive

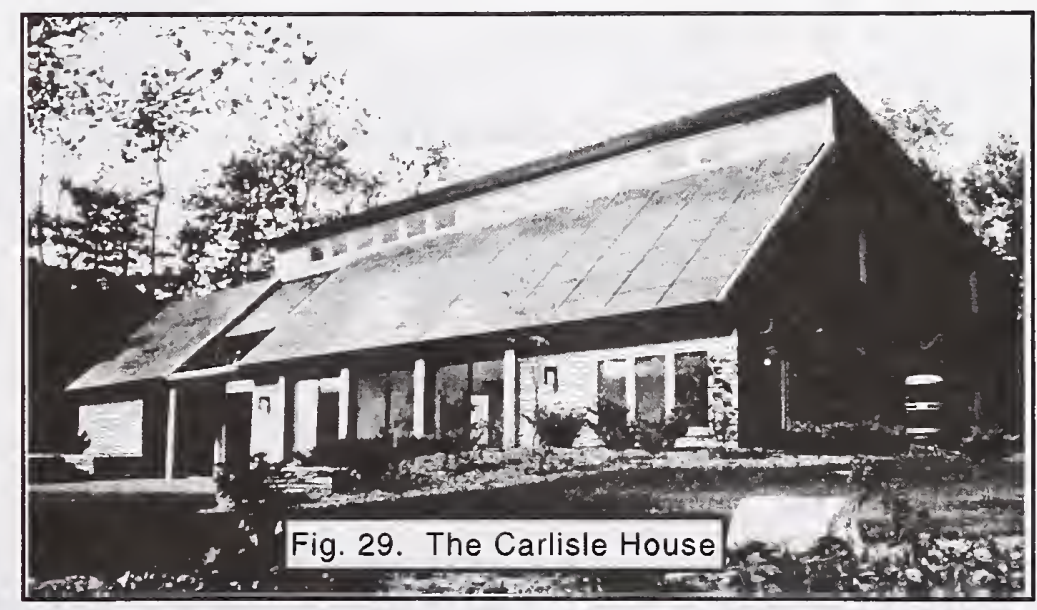


solar heating and cooling, super-insulation, internal thermal mass, earth-sheltering, daylighting, a roofintegrated solar thermal system and a $7.5 \mathrm{kWp} \mathrm{PV}$ array of polycrystalline modules from Solarex. The home is heated and cooled by a high-efficiency, dual-compressor heat pump system, needs no fossil fuel and shares its surplus power with the utility via a net metering connection. This first residence ever to be powered by a utility-interactive PV system received world-wide attention.

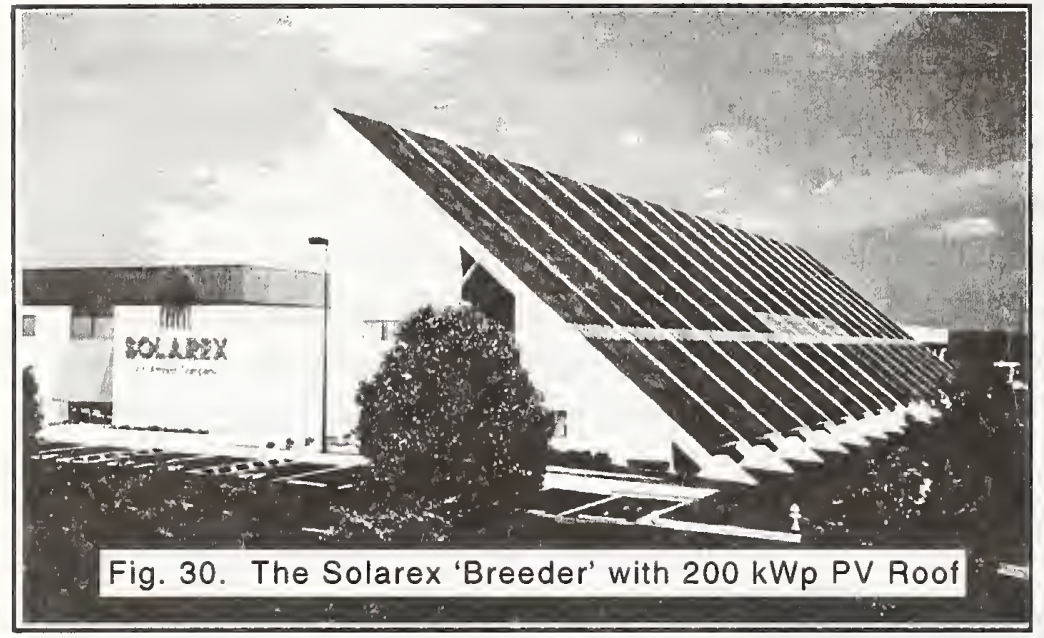

In 1982, Solarex Corporation made a most significant commitment to PV-inBuildings by powering their new manufacturing plant with their own solar modules. The facility, located in Frederick, MD, was designed specifically to receive a $200 \mathrm{kWp}$ array as the entire south roof. A large bank of storage batteries provides a UPS capability for critical plant systems. The 'Solarex Breeder', as the plant became known, was the vision of Solarex founder Joseph Lindemeyer and is shown in Figure 30.

In 1983, the Boston Edison Company commissioned Solar Design Associates to design the Impact 2000 residence as a demonstration of future trends in energy technology and design that would be commonplace early in the next century. The house, shown in Figure 31, features passive solar heating and cooling, super-insulation, internal thermal mass, earth-sheltering, daylighting, a roof-integrated solar thermal system and a $4.5 \mathrm{kWp} \mathrm{PV}$ array of large-area modules, each $2.5 \mathrm{~m}^{2}$, integrated as the finished weathering skin of the roof. Heating and cooling are supplied by a high-efficiency, groundcoupled heat pump system and no fossil fuel is required on site. Like the Carlisle house before it, this house shares its surplus electricity with the Boston Edison grid via a net metering connection. The building of the house was the subject of a national TV series on energyefficient construction.

In 1984, a significant commercial-scale buildingintegrated PV system was completed at Georgetown University in Washington D.C. The project, sponsored by the US DOE, integrated a $300 \mathrm{kWp}$ PV array of Solarex polycrystalline

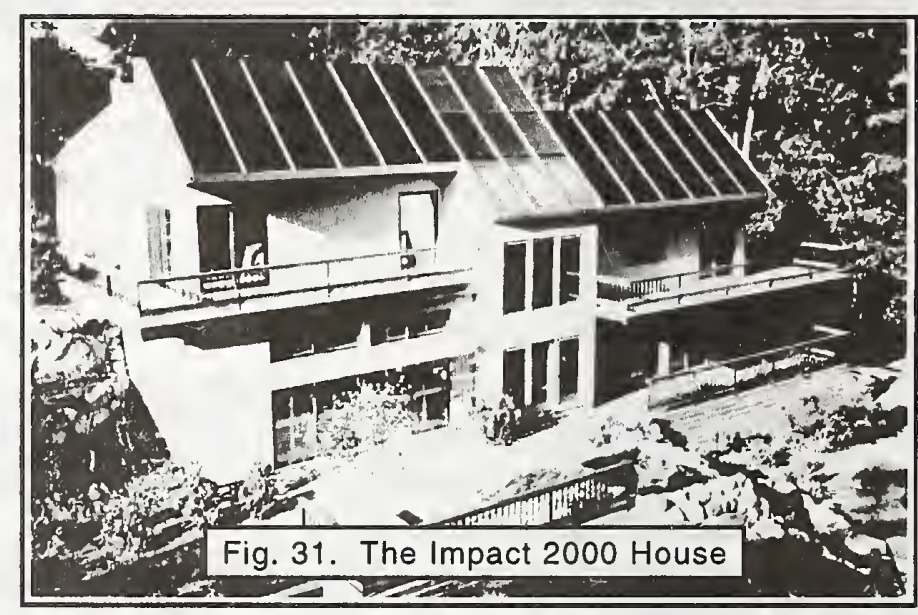
modules into the stepped south roof of the new Intercultural Center. The project architect worked closely with the PV system engineers to design the building specifically to receive the PV array. The electricity generated serves the building's loads and the surplus is used to support the campus utility grid. The Georgetown Intercultural Center is shown in Figure 32.

In 1985, Solar Design Associates fielded $100 \mathrm{kWp}$ of distributed, roof-top PV systems in a demonstration sponsored by the New England Electric System which includes the world's first PVpowered neighborhood, in the central Massachusetts town of Gardner. Following the NEES pioneering 
example, far-sighted utilities, such as the Sacramento Municipal Utility District (SMUD) in California, are now beginning to install distributed PV systems on buildings to support their grid, helping to meet their peak demand while reducing dependence on traditional sources of power and improving the environment.

According to SMUD board Chairman Edward Smeloff, their multi-year program will field some $850 \mathrm{kWp}$ of distributed PV systems in 1993 with 1 MWp in 1994 and another $1 \mathrm{MWp}$ in 1995. Southern California Edison has also recently announced plans for a distributed, roof-top PV program and other utilities such as Niagara Mohawk (NY), Delmarva Power and Light (DE), the New York Power Authority and the City of Austin (TX) Electric are also fielding PV-powered buildings.
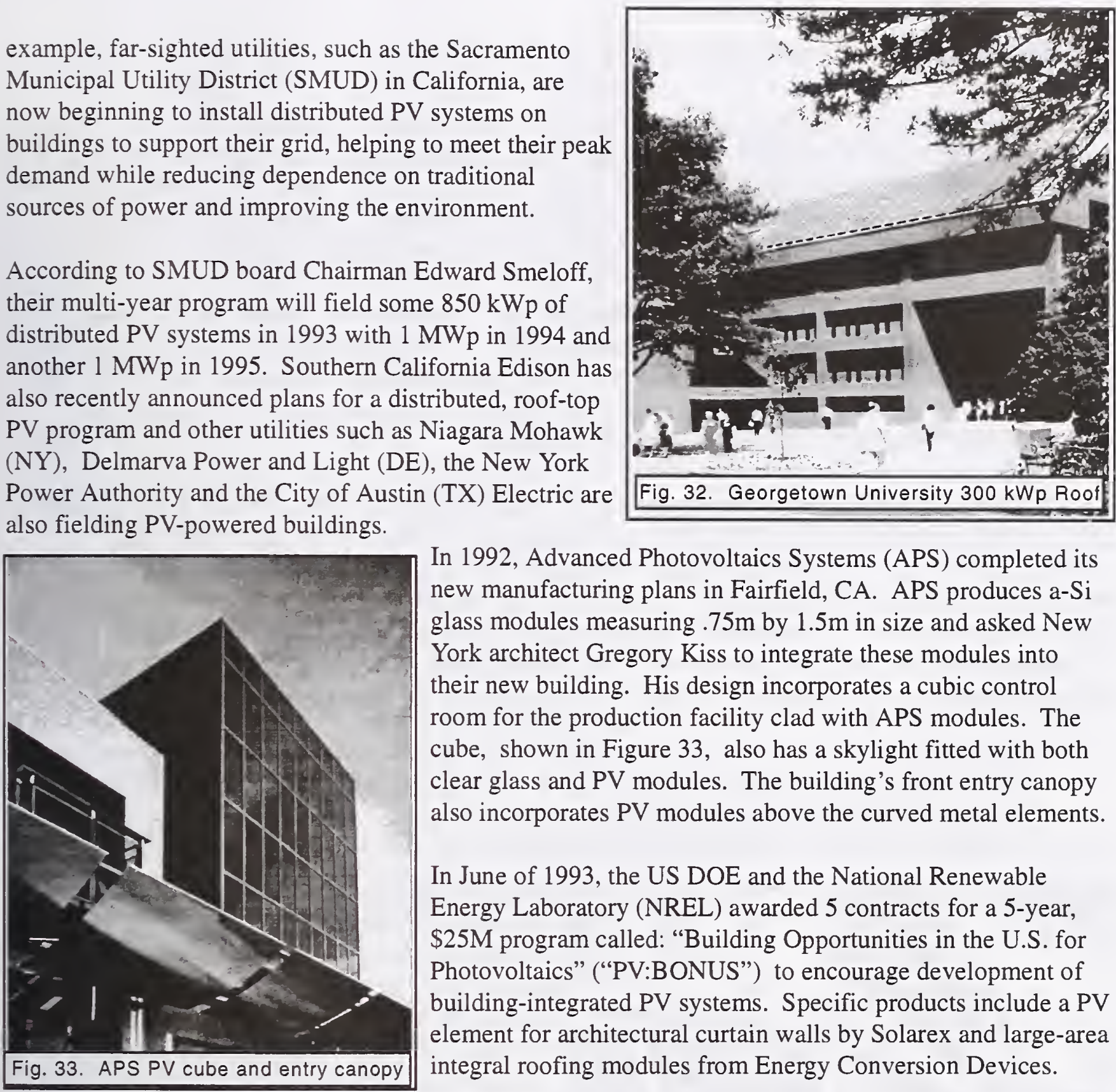

In 1992, Advanced Photovoltaics Systems (APS) completed its new manufacturing plans in Fairfield, CA. APS produces a-Si glass modules measuring $.75 \mathrm{~m}$ by $1.5 \mathrm{~m}$ in size and asked New York architect Gregory Kiss to integrate these modules into their new building. His design incorporates a cubic control room for the production facility clad with APS modules. The cube, shown in Figure 33, also has a skylight fitted with both clear glass and PV modules. The building's front entry canopy also incorporates PV modules above the curved metal elements.

In June of 1993, the US DOE and the National Renewable Energy Laboratory (NREL) awarded 5 contracts for a 5 -year, \$25M program called: "Building Opportunities in the U.S. for Photovoltaics" ("PV:BONUS") to encourage development of building-integrated PV systems. Specific products include a PV element for architectural curtain walls by Solarex and large-area integral roofing modules from Energy Conversion Devices.

The US PV program was invited to join the IEA Task 16 development effort in PV systems for buildings and, in January 1994, the US DOE's Office of Building Technology accepted this invitation. The potential market for building-integrated PV systems in the US is enormous and many companies are beginning to work at the development and commercialization of building-integrated PV components and systems. If consistent government support can be assured, this potential will be realized.

Fig. 34. The US National Renewable Energy Laboratory's new SERF building features a $15 \mathrm{kWp}$ PV system

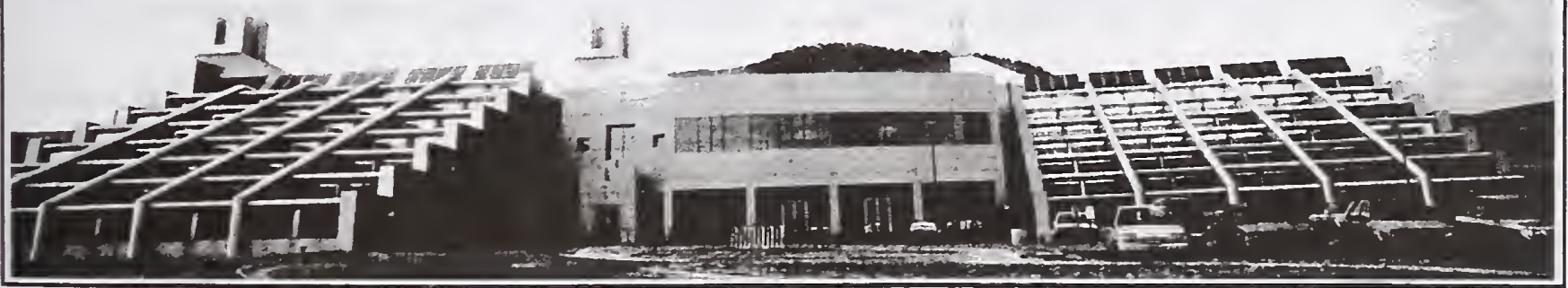




\section{United Kingdom}

Until recently, the UK PV industry has concentrated on traditional export markets for remote PV power systems. In 1990, a review for the UK Department of Energy (now part of the Department of Trade and Industry or DTI) indicated that the status of PV had moved from a 'long-shot' to a 'medium term' solution as an energy resource for the UK. This conclusion was based on the decreasing costs of PV devices and perceived advantages of applying this technology to commercial buildings.

The report concluded that daytime loads of commercial buildings are a good match for PV power systems and commercial building facades are often clad with expensive materials - such as marble or stone - which can be replaced by the PV panels in an integrated structure. These factors together with avoided costs of land and array support structure could make building-integrated PV systems cost effective in the UK within 10 years for optimum designs.

An initial two years of studies have looked at the potential resource; feasibility of building integration; grid interconnection guidelines and practical roof integration. A recent white paper (R62) has formalized PV as a technology requiring R \& D support within the Government Renewable Energy Research, Development, Demonstration and Dissemination Programme. This strategy for PV started in 1994 and builds on the previous studies to assist industry to develop a capability in building-integrated PV systems and then field demonstration systems. This segment of the PV programme will look at technical and non-technical barriers to market development in the following areas:

- Resource studies

- Cladding and roof integration methodologies

- Technical issues for grid interconnection

- Examples of building integrated PV system types
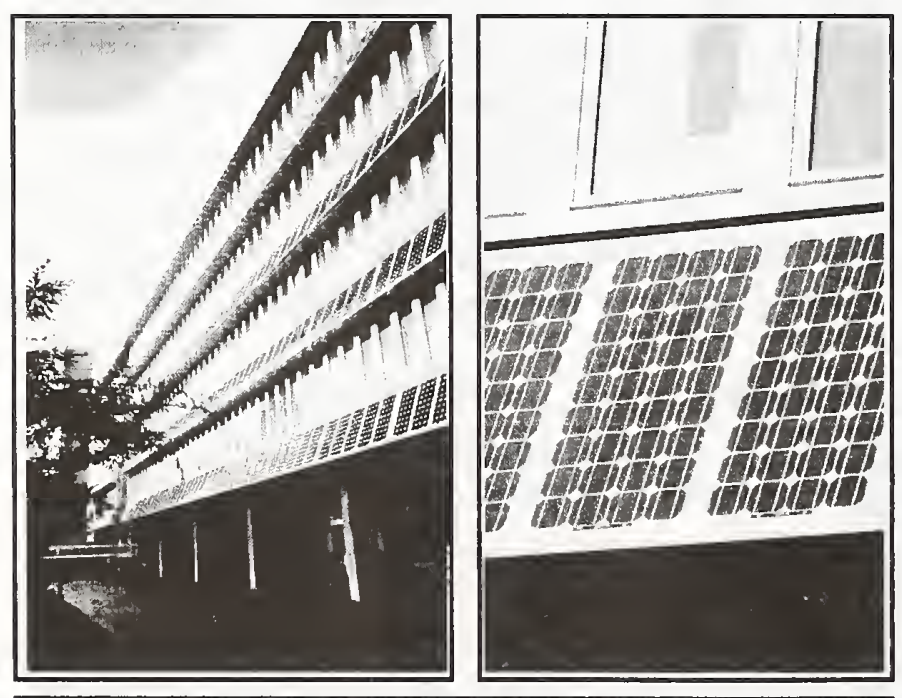

Fig. 35. PV 'Recladding' of UK Building Facade
Many of these topics were examined during the realization of the UK's first commercial PV curtain wall facade at the University of Northumbria at Newcastle. This project, shown in Figure 35, is a refurbishment of an existing university building and incorporates $40 \mathrm{kWp}$ of high-efficiency BP Solar PV laminates into a new rainscreen overcladding spandrel system which also provides integrated sun shading on the south face of the building. The project was realized under the direction of Professor Robert Hill and received support from the local regional electricity company (REC) and other members of the electricity supply industry in addition to DTI and EU THERMIE demonstration programmes.

Although residences are not expected to be the first cost-effective application for building-integrated PV systems in the UK, there is a growing interest from domestic consumers and there are some projects completed or under construction which use PV in grid-connected application. Another demonstration project will incorporate a $10 \mathrm{kWp}$ array into the roof of a visitor center at the Center for Alternative 
Technology in Wales. Significant attention is being paid to the combination of PV with passive design principles to optimize daylighting, heating and PV power use.

The UK PV community is discussing options for market stimulation with the UK Government. One strategy would be to include PV in the legal requirement for RECs to buy Renewable Energy at a premium rate (the Non-Fossil Fuels Obligation - NFFO). The 1989 UK Electricity Act created a special "non-fossil fuel obligation" (NFFO) requiring the 12 English and Wales regional electric utilities to produce or purchase a specified portion of their capacity from renewable sources. This has created the vitally-important "market pull" needed to introduce renewables to the utility community. The initial goal of $102 \mathrm{MWp}$ was easily reached and the government has set a target of 1,000 MWp by the year 2000. This initiative has helped to increase interest and activity in photovoltaics in the UK.

On the technology side, BP Solar International LTD. now has working prototype modules using cadmium telluride technology with efficiencies approaching the 10\% range. BP also has single crystal modules in the $17 \%$ range using high-efficiency, laser-grooved cell processes developed by Martin Green at the University of New South Wales in Australia. BP has established a manufacturing plant in Spain (BP Solar Espana) and plans to look at large area module fabrication of the CZ modules and the use of its CdTe thin film materials in modules developed specifically for building facades. Initially, modules of $.5 \mathrm{~m}$ by $1.0 \mathrm{~m}$ are planned with CdTe technology and CdTe module selling prices in the area of US $\$ 1.00-2.00 / \mathrm{Wp}$ are forecast by the end of the decade.

The British government has funded a comprehensive evaluation of the potential of building-integrated PV systems in the UK. The study, conducted by Professor Robert Hill and his colleagues at the Newcastle PV Applications Centre, was initially only to include the south-facing facades but was expanded to include all building surfaces regardless of orientation and concluded there were 111 Gigawatts of potential generating capacity available from distributed PV systems on buildings. Another related study now underway is investigating the various types of curtain wall systems for commercial buildings. It is expected that a follow-on study will pursue the development of specific PV products designed for building integration.

The British government is also funding participation in the IEA Task 16, Photovoltaics in Buildings. In additional to UKDOE personnel, PV professionals from BP Solar and IT Power are representing the UK in this multi-country development effort.

\section{Finland}

Activity in Finland relative to distributed PV applications has also increased in recent years along with the rest of Europe. Finland has recently embarked on a three-year plan which includes the development of improved load management systems, demonstration of PV / hydrogen systems with hydrogen storage and the fielding of distributed, grid-connected PV demonstration systems on buildings.

There are over 400,000 vacation cottages in Finland and about half of them are located off the grid where PV systems are an ideal source of power. Today there are some 20,000 summer houses around Finland powered by small PV systems. A typical system is designed to meet lighting, home electronics, water pumping and refrigeration needs from April to September. 
Figure 36 shows a Finnish summer cottage with a $2.4 \mathrm{kWp}$ roof-top array of a-Si modules from NAPS France. This system was installed in 1992 and includes a battery bank and stand-alone $2.5 \mathrm{~kW}$ $\mathrm{DC} / \mathrm{AC}$ inverter to power lighting, refrigeration, home electronics and small appliances, vacuum cleaner, washing machine and dishwasher. The house is located some $260 \mathrm{~km}$ north of Helsinki at $62^{\circ} \mathrm{N}$ and $26^{\circ} \mathrm{E}$.

Since 1991, the Fins have retrofitted 10 residences with PV power systems. Five

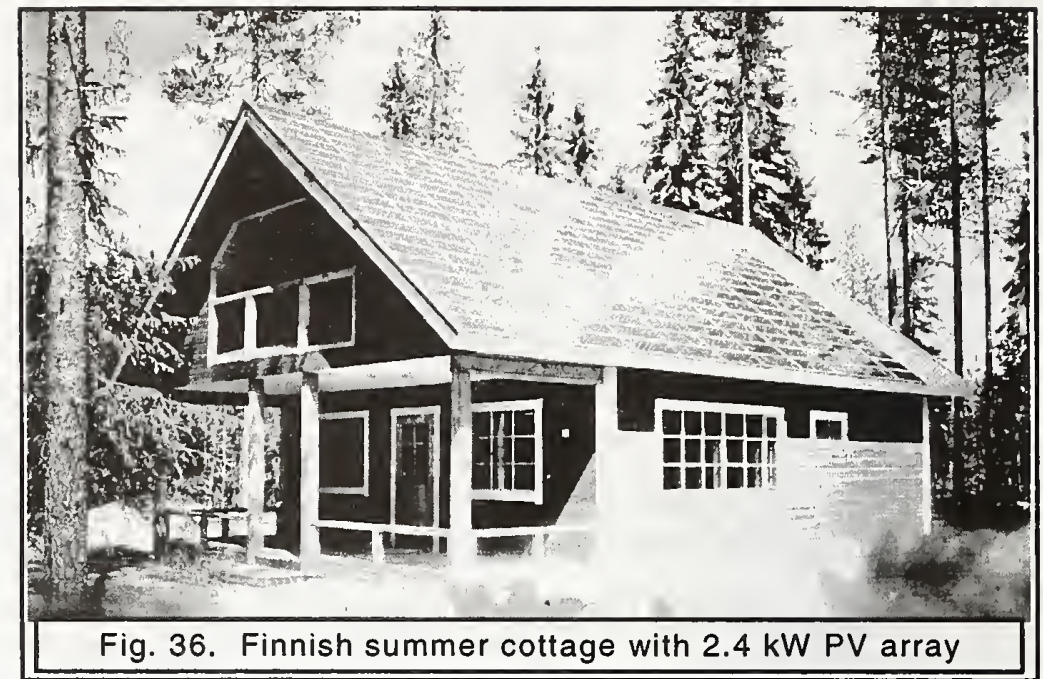
are stand-alone and five are grid-connected. R\&D programs underway are presently investigating the development of building-integrated PV systems and engineers from NESTE have fielded two demonstration projects.

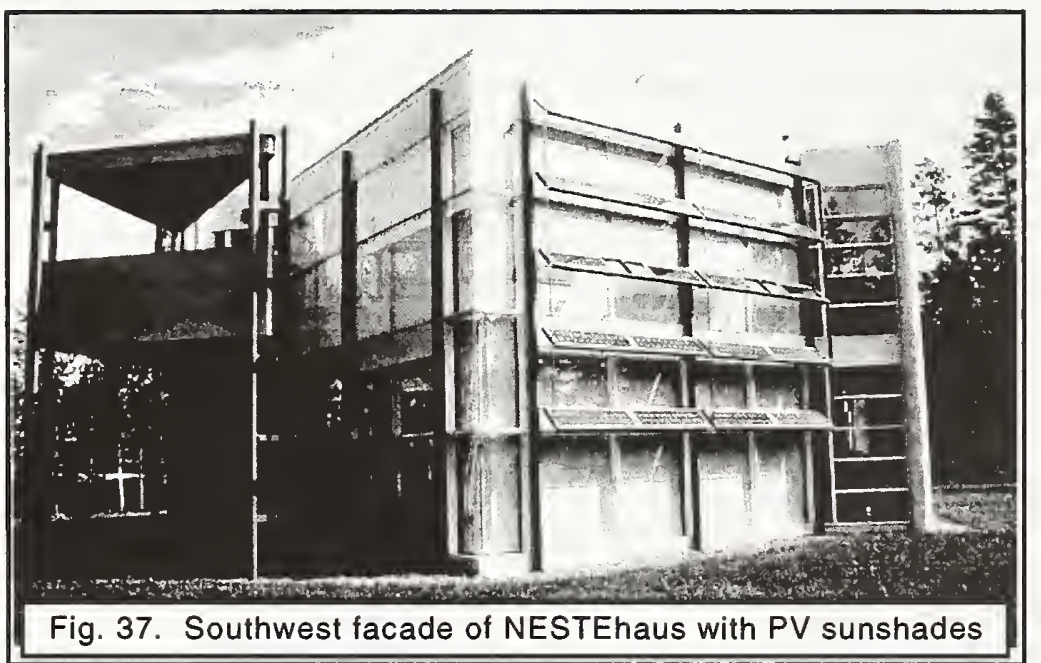

The first, shown in Figure 37, is a demonstration house designed and constructed by NESTE as an experimental house incorporating many building components and materials made of plastic. The house features see-through aSi modules as window glass and crystalSi sun shades on the south facade to reduce summer cooling loads. The house is located $35 \mathrm{~km}$ east of Helsinki in Porvoo, $60^{\circ} \mathrm{N}$ and $25^{\circ} \mathrm{E}$.

The second, shown in Figure 38, is a private house located in Pietarsaari, Finland $63.5^{\circ} \mathrm{N}$ and known as the Pietarsaari low energy house. This residence features a roof-integrated $2.4 \mathrm{kWp} \mathrm{PV}$ array of a-Si modules along with a $10 \mathrm{~m}^{2}$ array of solar thermal collectors. The PV array is mounted using novel custom designed profiles of glass fibre which have nearly the same expansion coefficient as glass. The house is a demonstration of energyefficiency and solar design and serves as the Finnish IEA demonstration house. It was completed in 1994.

Finland has also joined the IEA Task 16 effort with representatives from Helsinki University and the engineering firm NESTE OY participating.

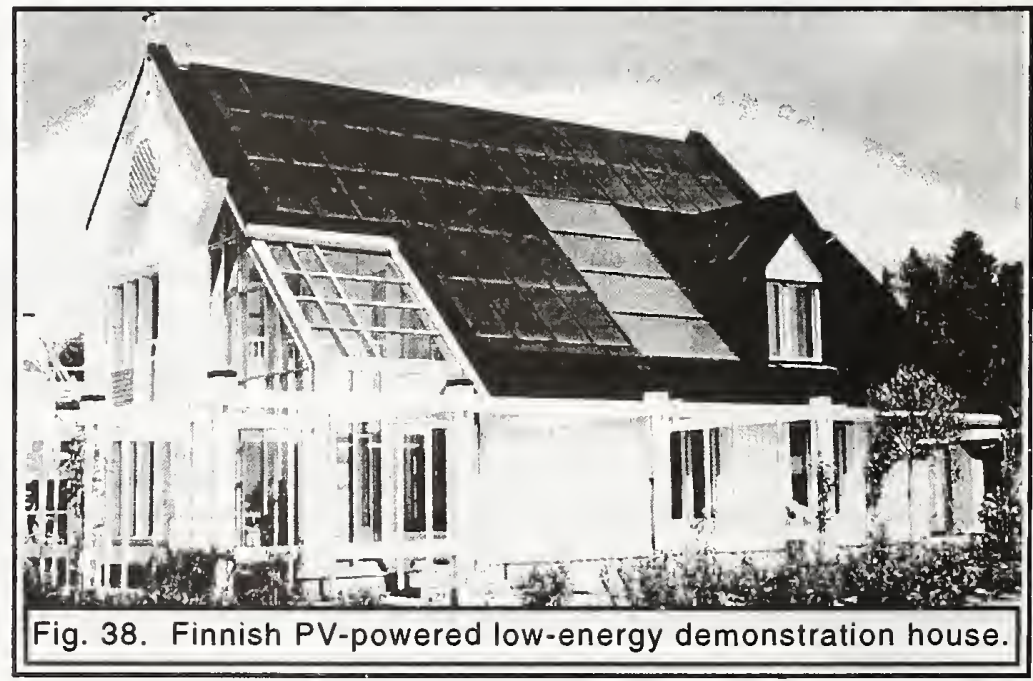




\section{Spain}

Spain's interest in distributed PV applications has also increased in recent years along with the rest of Europe. The potential market for remote PV applications in isolated areas of Spain is considered the most significant in the European Community.

Spain has already fielded hundreds of stand-alone and grid-connected PV systems totalling well over 5 Megawatts in capacity including a 1 Megawatt central plant under construction at Toledo.

Spain has a number of PV R\&D and manufacturing activities underway including the production facility of BP Solar and ISOFOTON. Spain's recent activity has focused on systems design, utility

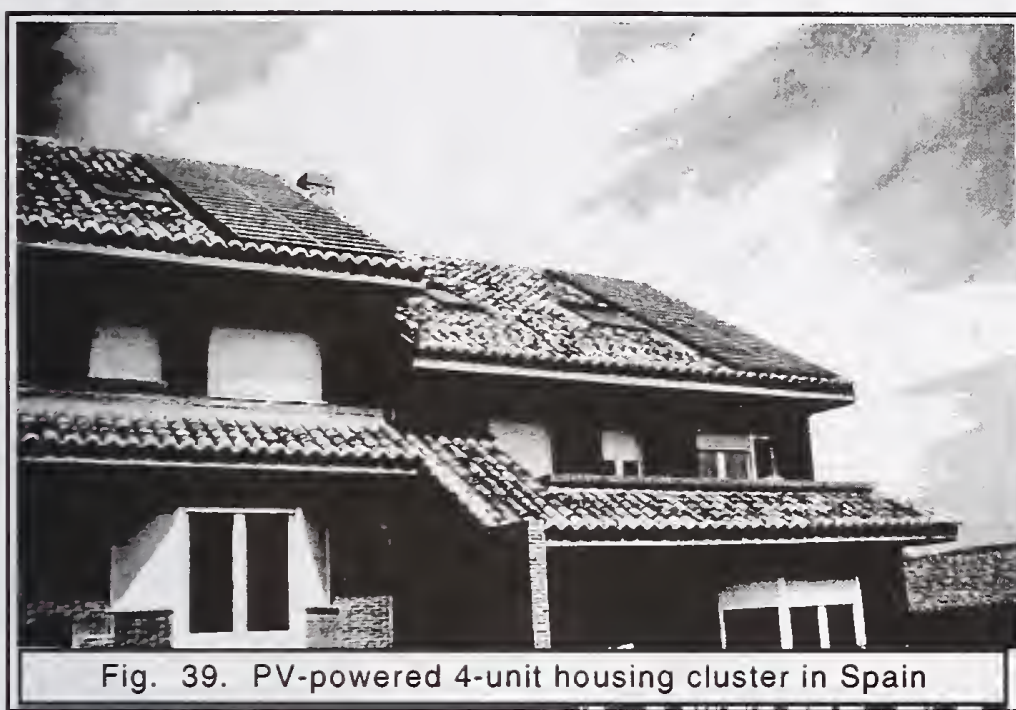

interface, demonstration monitoring and testing. The area of building integration of $\mathrm{PV}$ is beginning to receive research and development attention.

Spain has joined the IEA Task 16 PV-inBuildings development effort and was the host of the second meeting of the Experts' working group held in Madrid at CIEMAT in February 1992.

Figure 39 shows the Spanish Task 16 demonstration house which is a four-plex incorporating 4 roof-integrated $\mathrm{PV}$ arrays of $2.2 \mathrm{kWp}$ each. The systems are utility interactive. There are thousands of PV-powered off-grid residences in remote areas of Spain and utilityinteractive PV systems are now starting to be installed on residences with the cooperation and support of Spanish utilities. Additional building-integrated PV projects are now in the planning stages.

\section{Sweden}

In Sweden, as well as in Norway and Finland, PV is often employed to power remote vacation cottages. There are now over 20,000 such PV powered cottages in Sweden and the market is increasing rapidly with over 5,000 new installations every year. In addition, several hundred lighthouses along remote stretches of the Swedish coast are now powered with PV.

Sweden's activity in distributed PV has increased along with that of other European countries. Present program activities include both stand-alone and grid-connected distributed PV systems. Development and testing of DC-AC inverters and battery charge control regulators is being undertaken. PV research and development activities in Sweden are concentrated at the Royal Institute of Technology and the University of Uppsala for cell research and, Catella Generics AB and Vattenfall Utveckling AB (the largest utility in Sweden) for systems.

In 1990, a $3.5 \mathrm{kWp}$ grid-connected demonstration was completed on a single residence in Linköping 


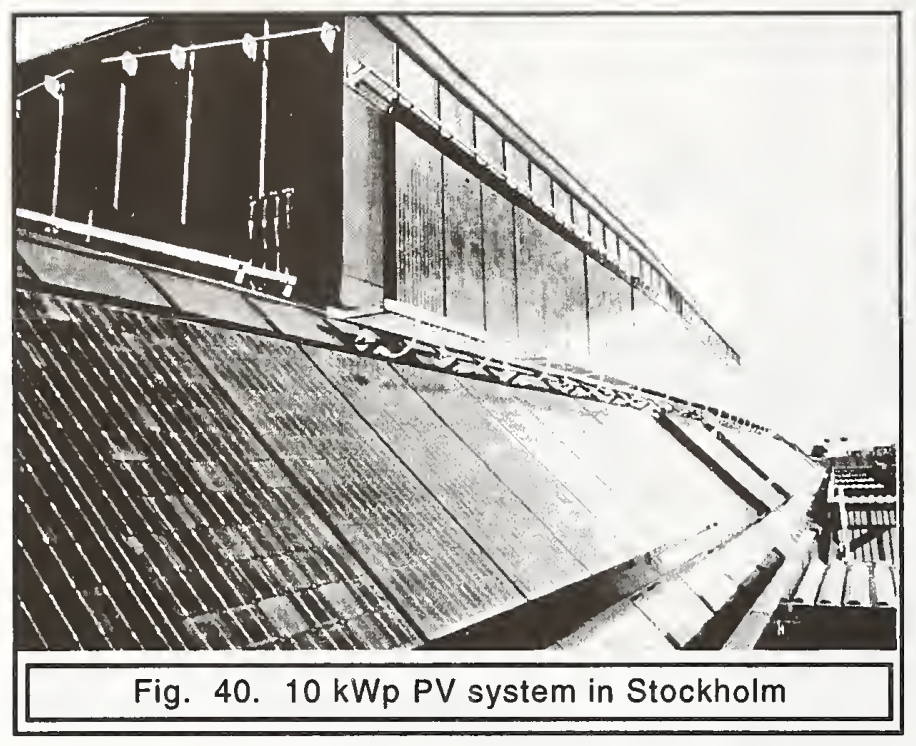

approximately $200 \mathrm{~km}$ south of Stockholm.

A Swedish company called GPV has recently started manufacturing PV modules. The modules are of standard construction with a glass top skin and tedlar back and come in sizes up to $100 \mathrm{Wp}$. The company has expressed an interest in participating in the development of PV modules for direct building integration.

In 1993, the Swedish utility, Stockholm Energi $A B$, installed a $10 \mathrm{kWp}$ utility-interactive PV system on an existing apartment building in downtown Stockholm. The system, shown in Figure 40, serves as the IEA Task 16

demonstration building and features three parallel arrays of $3.3 \mathrm{kWp}$ each with its own inverter. Sweden has also joined the IEA Task 16 effort with representatives from the Swedish National Testing Institute and Catella Generics representing the county's effort.

\section{Italy}

Italy's federal funding has increased significantly for $\mathrm{PV}$ in recent years and interest in building-integrated $\mathrm{PV}$ applications is growing in Italy along with the rest of Europe. As a result of growing environmental concerns and the dependence of Italy on foreign oil, the government has launched a program to field some 25 Megawatts of PV by 1996. Italy's National Agency for New Technology Energy and the Environment (ENEA) will be responsible for research and development and the National Electrical Board, ENEL will be

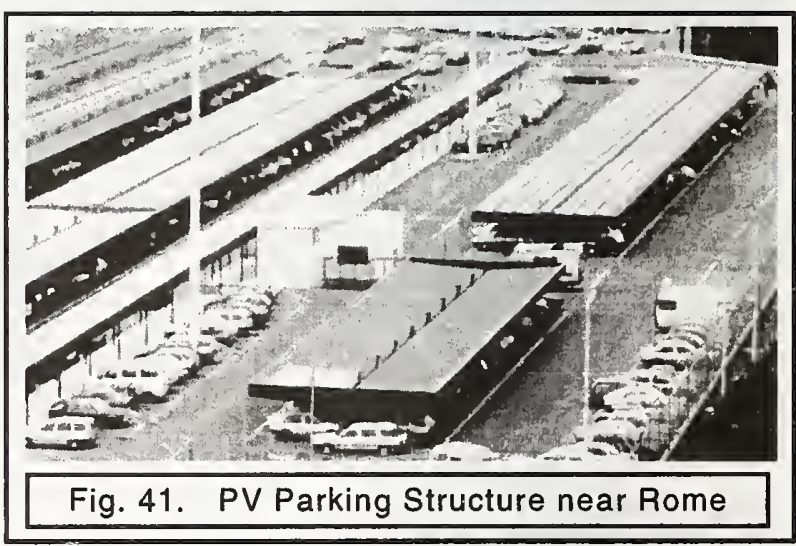
responsible for implementation of the demonstration program and construction of the plants.

The Italian PV program includes plans for a number of building-integrated PV demonstrations. One of

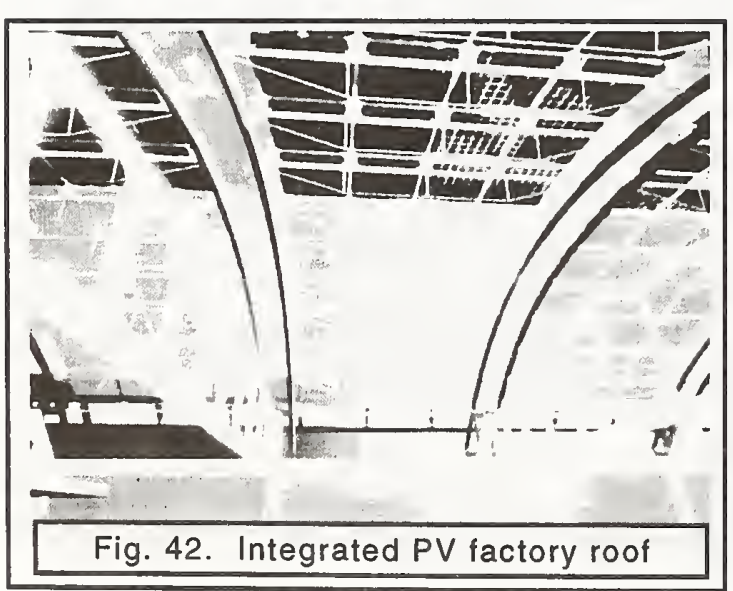
the first is a PV parking structure in Rome shown in Figure 41. Others include an innovative $30 \mathrm{~kW}$ integrated PV roof for the Eurosolare factory of Nettuno near Rome shown in Figure 42 which combines PV with daylighting, a $20 \mathrm{~kW}$ terrace at the German School of Rome and a $4 \mathrm{~kW}$ shading structure at ENEL headquarters in Rome. A second series of 10 systems is planned for 1995 with cost-sharing from the Thermie Project. These will include ENEL offices, training and information centers and parking structures.

Mr. Robert Vigotti of ENEL is a very strong proponent of 
PV and its use in buildings and has considerable influence on the development of the government's policy to promote the technology. Italy has recently joined IEA Task 16 and appointed an architect from Rome to represent the country. Italy has also sent a representative from ENEL to participate in IEA Task 16 meetings as well as in the new IEA PV Task 5.

\section{Canada}

Interest in PV has increased in Canada in recent years even though conventional energy resources are plentiful and inexpensive. Present activities within the Canadian R\&D program center on improved system design and performance modeling. Projects underway include further software development for system optimization

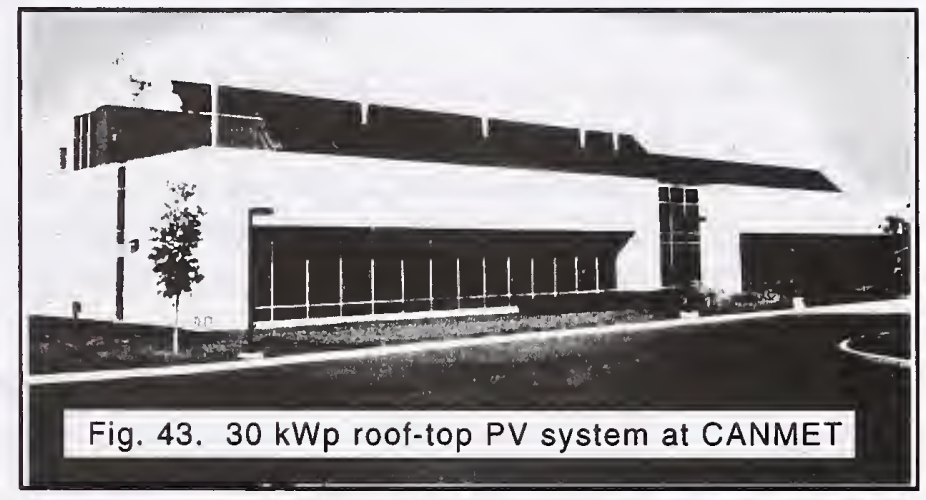
and simulation including modeling of battery storage characteristics. Over a dozen PV systems are being monitored, and codes and standards for PV systems are being developed.

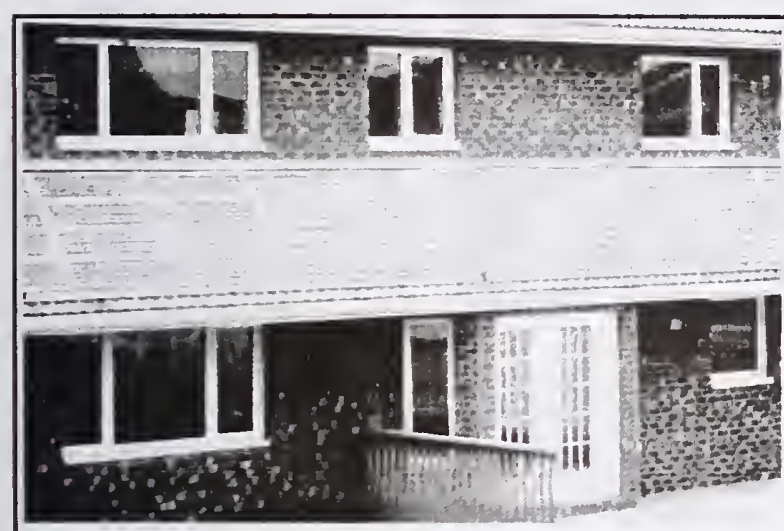

Fig. 44 Stand-alone PV house in Saskatchewan

PV powered buildings are also beginning to be fielded such as the stand-alone residence in Saskatchewan shown in Figure 44. The Canadian Department of Energy, Mines and Resources (CANMET) has installed a $30 \mathrm{kWp}$ array atop their research laboratory near Montreal. The system, shown in Figure 43, works as a building peak shaver while providing PV power to support research efforts in power conditioning development and system simulation modeling.

In Toronto, the Canadian utility Ontario Hydro, in collaboration with the Canadian Energy Diversification Research Laboratory (EDRL), has fielded a $75 \mathrm{kWp}$ roof-top PV system at the McMillian Rehabilitation Center as a demand-side management measure to help shave the hospital's summer air conditioning peak.

Canada has also joined the IEA Task 16 effort. Representatives from the University of Ottawa, PV systems companies and the government (EDRLCANMET) are representing Canada in Task 16.

Ontario Hydro was influential in the installation of PV on the "Innova House", a low-energy demonstration home in Ottawa which is shown in Figure 45. This system, which features a $2.7 \mathrm{kWp}$ array, is the first grid-connected PV residence in Canada and has been selected as an IEA Task 16 demonstration house.

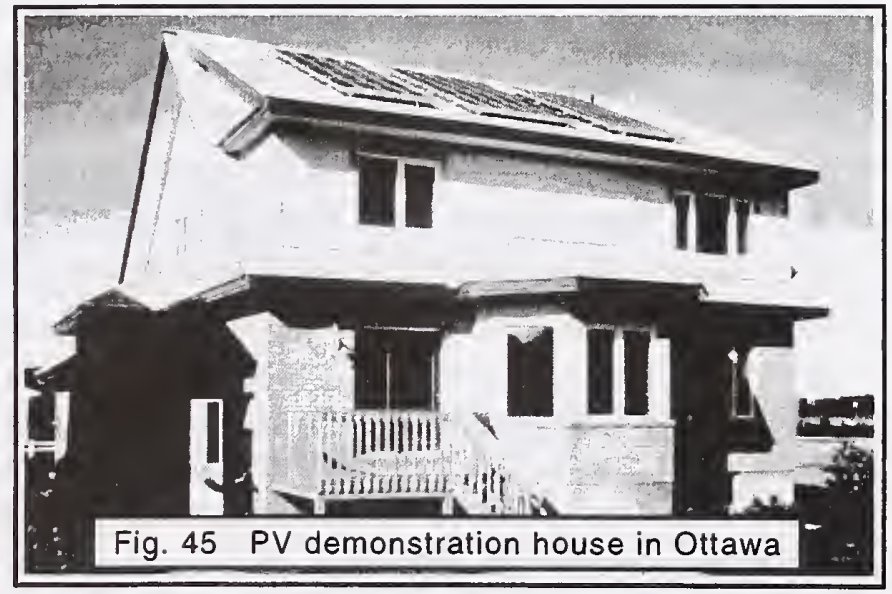




\section{Norway}

Norway has long had a strong market for small distributed residential PV systems with the large number of vacation cottages located off the power grid. There are presently over 50,000 PV-powered vacation homes in Norway with over 8,000 new installations completed every year.

A substantial part of the energy R\&D activities in Norway has been allocated to medium-scale hybrid power generation plants for isolated communities along the coast. Wind/diesel systems of $50 \mathrm{~kW}$ installed power have been developed and are being commercialized. The integration of PV in such stand-alone systems is being investigated and development of supervisory control systems for shortterm scheduling of diesel start/stops has received much of the $\mathrm{R} \& \mathrm{D}$ attention in the last 5 years.

A demonstration low energy row-house with 3 apartments has been constructed in Hamar to provide housing for foreign journalists at the 1994 Winter Olympics. The project, shown in Figure 46,

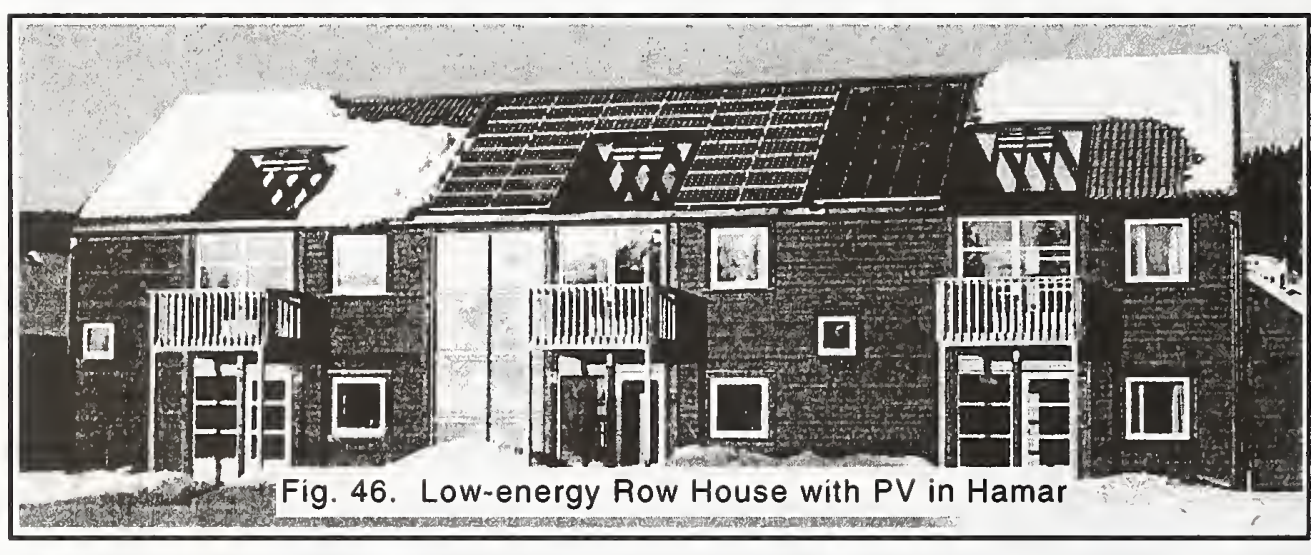
established a new level of integrated design incorporating passive solar, super insulation, air-tight construction with controlled ventilation, active solar water heating, highefficiency heat pumps for backup space and water heating as well as nontoxic building materials.

The center apartment gets its electricity from a $2.2 \mathrm{kWp} / 27 \mathrm{~m}^{2}$ roof-integrated, utility-interactive PV system. The array incorporates standard Siemens modules mounted over a watertight membrane. A detail of the PV array installation is shown as Figure 47. The project supports Norway's work in IEA Tasks 13 (Low-energy Buildings) and Task 16 (PV-in-Buildings) and will serve as a model for new building codes to be introduced in 1995 incorporating very high energy efficiency standards.

As Norway has introduced a deregulated electricity market with spot-pricing, utilities are interested in testing electronic meters with 2-way communication for remote metering of small and medium size customers. The impact on this market regime from all kinds of local generation by new renewable energy sources, along with equipment reliability and power quality issues are subject to increasing interest by the distribution utilities in Norway.

Fig. 47. PV array installation in Hamar

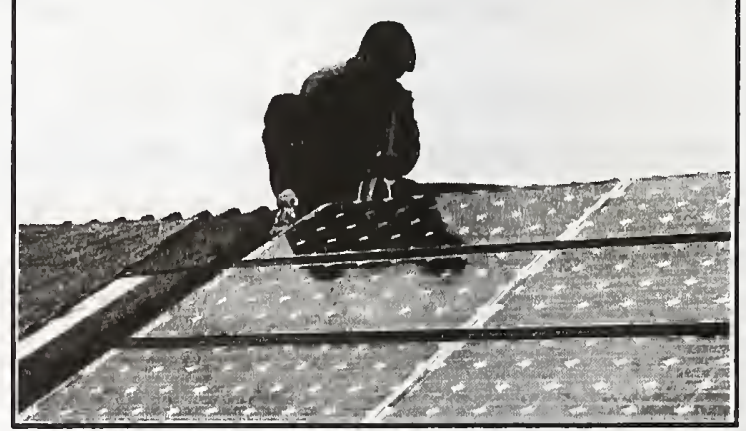

Interest in distributed, grid-connected applications has increased along with that of other countries in Europe. As a result, Norway has increased its program involvement in this area and participates in the IEA Task 16 effort. Representatives from the Norwegian Institute of Technology and SINTEF are representing Norway in Task 16. 


\title{
BEST SUSTAINABLE INDOOR AIR QUALITY PRACTICES IN COMMERCIAL BUILDINGS
}

\author{
Hal Levin, Research Architect \\ Hal Levin \& Associates \\ 2548 Empire Grade \\ Santa Cruz, CA 95060-9748
}

Abstract. This paper describes commercial building indoor air quality practices and then discusses them in the context of total building environmental performance. "Green buildings" generally have included some effort to address indoor air quality issues along with an unspecified number of other environmental concerns. Rarely, if ever, is analysis conducted to evaluate trade-offs made among environmental features considered important in "green" buildings even though conflicts occur among design features intended to improve a building's environmental performance. One "green building" feature may reduce certain environmental impacts while increasing others. A method is needed to examine the total environmental impact of designs. In order to identify best sustainable indoor air quality practices in commercial buildings, a newly-developed, comprehensive approach to building ecology is presented. This approach, tentatively titled the Systematic Evaluation and Assessment of Building Environmental Performance (SEABEP), uses sustainability criteria as the basis for comprehensive evaluation of the environmental performance of design features.

\section{Introduction}

Many building design professionals are now involved in "green" building design or "sustainable design" in response to expressed interest or requirements from their clients. Some building design professionals initiate "environmentally-responsible" design based on their own recognition of the need for reducing human impacts on the environment - local and global. This appears to be occurring more frequently in Europe and North America during the past half-decade. In the future, economic criteria and regulatory mandates are likely to motivate more and more designers' clients, building owners, and other both public and private organizations to create "environmentally-responsible" buildings. As this occurs with increasing frequency, designing buildings with low environmental impacts will become both a necessary and a challenging part of building design professionals' work. It will also offer new opportunities for developers, product manufacturers, and others in the building industry.

The trend toward environmental protection is gaining momentum. Public opinion in the United States (and around the world) indicates that people are supportive of environmental protection even if they must pay a modest additional economic cost. Innovations in economic analyses are emerging that value environmental resources and quality more highly and modify the outcome of "bottom line" calculations to favor less environmentally harmful behavior (1). In many cases, as for example in the production of aluminum and steel building products, recycling already appears 
Energy conservation features: insulation. efficient lights and mechanical equipment

Solar energy utilization: passive space heating, cooling; water heating; photovoltaic electricity generation Water conservation features: low consumption fixtures

Incorporation of recycled materials, or materials with large fraction recycled content

Low emitting material selection and ventilation for improved indoor air quality

Reduced building construction waste and re-sourcing waste products

Less environmentally-destructive site development: run-off control, small footprint, preservation of water courses, natural vegetation and habitats

On-site wastewater treatment

Reduced or zero use of ozone-depleting compounds in refrigeration and fire suppression systems

Life cycle assessment ("cradle-to-grave") of materials or building systems

Formal (regulatory) environmental impact assessment of the total building project

Recycling provisions (in building design) for occupants

to make both economic and environmental sense. It is clear that the environmentally preferred solution is also better economically. Social and political forces will bring additional pressure for more environmentally-sound technological decisions. Regulations will continue to evolve to protect the environment from technological development including the construction, operation, use, and disposal of buildings.

\section{“Green Building” Practices}

To date, efforts to implement "green" design practices have consisted largely of adoption or eclectic adaptation of various technologies and solutions to perceived environmental problems. Normally these solutions have been incorporated to reduce harmful environmental impacts (2). Collectively, they have come to be known as the elements of a "green" building design. Some examples of common "green building" features are listed in Table 1.

\section{Indoor Air Quality "Best Practice"}

Many building design, construction, and operational measures necessary to create good indoor air quality in commercial buildings are well-established. The challenging opportunity facing designers today is to implement the measures in the context of a so-called "green building" project or "sustainable" building design. Table 2 below provides an overview of the major measures required to create good IAQ in a commercial building. Following the table is an elaboration and discussion of each of the ten best practices. That is followed by consideration of how to integrate these with other sustainable design objectives in a rational and comprehensive fashion. More detailed guidance for indoor air quality can be found in several referenced publications (3-9). 
Table 2. IAQ best practice concepts for commercial buildings

$\begin{array}{ll}\text { 1. } & \text { Relationships between indoor air pollution sources, ventilation, and concentrations. } \\ \text { 2. } & \text { Simple dose response basis for health effects: "the dose makes the poison" } \\ \text { 3. } & \text { Overall design consideration of indoor air quality: from cradle to grave } \\ \text { 4. } & \text { Source identification: } \\ \text { 5. } & \text { Source control options and strategies } \\ \text { 6. } & \text { Ventilation system design and operation } \\ \text { 7. } & \text { Material selection and specification } \\ \text { 8. } & \text { Construction procedures } \\ \text { 9. } & \text { Maintenance and operation } \\ \text { 10. } & \text { Change of Use, Renovation, Adaptive Re-use, and De-mounting }\end{array}$

\section{Basic Relationships Between Indoor Air Pollution Sources, Ventilation, and Concentrations}

Concentration = source strength/ventilation rate. There is a simple mathematical relationship that clearly expresses the most important relationships in indoor air quality. Concentration is a function of source strength divided by ventilation. There are many types of contaminant removal mechanisms including filtration and air cleaning, deposition on surfaces, and chemical transformation. But the most important concepts are embodied in the simple relationship between source strength, ventilation, and concentration (7-9).

This relationship is expressed in equation 1.

$$
\text { Concentration }\left(\mathrm{mg} / \mathrm{m}^{3}\right) \text { - Emission Rate }(\mathrm{mg} / \mathrm{h}) / \text { Ventilation Rate }\left(\mathrm{m}^{3} / \mathrm{h}\right)
$$

The emission rate is determined by the emission factor $\left(\mathrm{mg} / \mathrm{m}^{2} \mathrm{~h}\right)$ times the area of the source $\left(\mathrm{m}^{2}\right)$. The ventilation rate is the amount of uncontaminated air introduced into the space (or environmental test chamber) per hour.

Source control is most effective. The most effective strategy for achieving good indoor air quality is source control. Identification of pollutant sources is the first step. Then, elimination, reduction or isolation are the next three strategies that should be applied. For example, completely encapsulating a particleboard sheet material used in casework can reduce significantly the emission rates of formaldehyde and other volatile organic chemicals from the product (7-9).

Major sources: The major sources of indoor pollutants include the outdoors, the building itself, the occupants, building equipment, appliances, and consumer products. The most important sources vary from project to project. Building materials are important, particularly when they are new and for many weeks or months afterwards. Some, such as composite wood products, due to their thickness and their pollutant content, can be sources for years after installation. Major pollutant sources and removal mechanisms are listed in Table 3.

Ventilation principles: The most effective exhaust for point or concentrated sources of pollutants is local exhaust. For distributed sources, dilution ventilation is used. An effective air supply strategy is displacement ventilation, usually involving introduction of air low in a space, then relying on thermal forces to transport low air upwards and create a strata of more polluted air just 


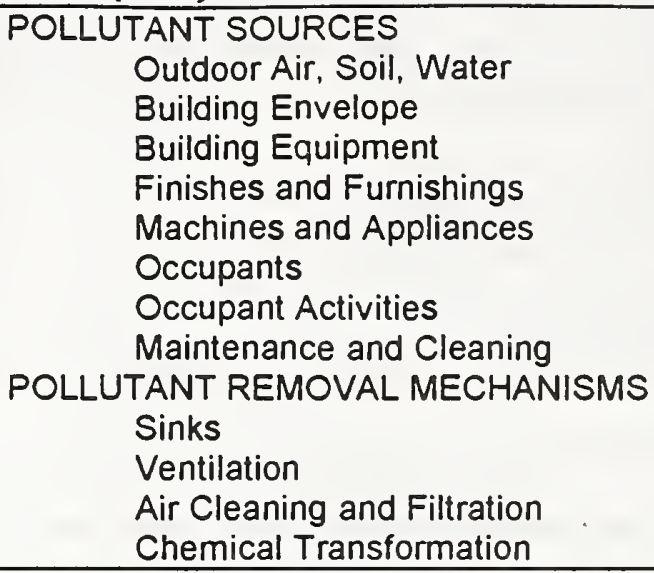

below the ceiling. There the polluted air is collected and removed for exhaust or cleaning and recirculation. It is essential to maintain overall ventilation system balance since it is pressure differences that result in air flows within and between spaces..

Other pollutant removal mechanisms: Among the most common removal mechanisms are filtration, usually incorporated into a mechanical ventilation system, the process of particle or chemical deposition on surfaces, and chemical transformations. These are discussed further below.

Simple dose response basis for health effects: "the dose makes the poison"

The dose makes the poison: This is the fundamental principal of toxicology. Everything is toxic, it is just a matter of dose. Thus, there are no "non-toxic" products or chemicals, there are just more or less toxic ones..

Major health effects: Health effects can range from irritation and discomfort to disability or life threatening disease. Table 4 lists the major effects including health effects of exposure to indoor pollutants.

Major indoor air pollutant classes and their effects: The most commonly discussed indoor air pollutants are volatile organic compounds (VOCs), microbial contaminants (fungi, bacteria, viruses), non-viable particles, inorganic chemicals (nitrogen oxides, carbon monoxide, carbon dioxide, ozone), and semi-volatile organic compounds (SVOC - including pesticides and fire

Table 4. Major Health Effects of Indoor Pollutants:

Infectious disease: flu, cold, pneumonia (Legionnaires' Disease, Pontiac fever), Cancer, other genetic toxicity, teratogenicity - (Ecotoxicity)

Asthma and allergy

CNS, skin, GI, respiratory, circulatory, musculoskeletal, and other systemic effects SBS (Sick Building Syndrome) 
retardants). The VOCs and the microbial contaminants receive the most attention, and, perhaps, deservedly so. Common industrial solvents, adhesives, and other modern chemical products are abundant in most indoor air, although the concentrations are generally far lower than known thresholds for health effects. Nevertheless, the huge number of chemicals present suggests that there may be effects due to additive or synergistic effects.

SBS: causation hypothesis and interactions: Sick building syndrome has received much attention as it has become more widespread in modern buildings. It is now generally recognized as a multifactorial problem; that is, it is caused by a constellation of factors, not by a single building-related factor. It is probable that there are additive and even synergistic effects of some of the environmental factors, not just chemicals or microbes, but also the acoustic, thermal, illumination, and other aspects of the indoor environment that affect the incidence of SBS. It is also likely that work stress and other psychological and social or institutional factors play a role in the incidence of SBS (10-15).

\section{Overall Design Consideration of Indoor Air Quality: From Cradle to Grave}

Planning through construction, commissioning. A major cause of indoor air quality problems is premature occupancy. Buildings are occupied before construction is complete, either with respect to installation of finishes and furnishings, or with respect to the complete testing, adjusting, and balancing of the HVAC system. By considering the need for thorough curing of new products and complete verification of a properly functioning ventilation system, many IAQ problems can be avoided. This requires planning from the outset for adequate time between scheduled completion and initial occupancy.

Operation Design and operation must be consistent. The design team must make appropriate assumptions about the use of the building, document their assumptions, and pass them along to the operators of the building. Operational schedules must be adequate not only to control thermal conditions but also to remove pollutants accumulated during off-hours. Early morning purging, especially after weekends and other extended unoccupied periods is essential. When maintenance or housekeeping activities involve the application of chemicals such as carpet shampoo, solvents, floor wax, or furniture polish, the accumulated emissions from these processes should be removed before re-occupancy.

Maintenance and housekeeping. Neglected or deferred maintenance is often the source of IAQ problems. Design should provide for access to all components of HVAC systems for inspection, repair, and cleaning. Cleaning of surfaces, especially periodic removal of accumulated dust from concealed surfaces above a suspended ceiling used as a return air plenum, is essential. Vertical fabric covered surfaces such as walls or office workstation panels should be vacuumed since small, inhalable particles deposit as easily on vertical as on horizontal surfaces.

Modification and Renovation. During construction activities, construction dust, fumes, and vapors must be contained and not allowed to contaminant building surfaces or the air in occupied spaces. Temporary ventilation and isolation barriers should be employed. 
Adaptive re-use. When the use of a space or building is significantly changed, it is essential to determine whether the building can support the new activities and occupancy loads. This can be done by reviewing record drawings and other documents. If such documents are not available, an engineering assessment should be conducted.

De-mounting and re-source or disposal. Ultimately, buildings or portions of buildings will be demounted and replaced. Care must be taken during demolition to avoid contamination of occupied spaces or of surfaces that will remain in use or be re-used.

\section{Source Identification}

Control of indoor air quality requires adequate identification of pollution sources and development of strategies to address each source.

Outdoors. Sources outside the building include ambient air pollution, emissions from neighboring buildings or activities, contamination in soil adjacent to or under the building,

Building fabric. The building structure, envelope, and floor system are major components that must be considered, even though many of their surfaces will be covered by finish materials or will not be visible to the building occupants. Spray-on fireproofing or acoustic materials have very large surface areas and are often exposed to the circulating air within the building. Contaminants can adsorb on these surfaces and subsequently be re-released. Chemical reactions and emissions from the products themselves can occur due to changes in the humidity. Deterioration of aging binders or erosion by air currents can also result in breakdown of these materials and releases of pollutants into the building air.

Building finishes. As is the case with the building fabric, finishes can be sources and sinks for pollutants. Care in their selection is essential, and major surface areas and masses of materials should be identified and carefully considered as potential pollutant sources.

Building equipment: HVAC systems are increasingly recognized as sources of pollutants. Microbial contamination of filters is a potential source of microbes and their metabolic byproducts, microbial VOCs. Power, illumination, transport, communication, and security system components can also be significant sources.

Occupants and their activities. The most important source, and the one over which building designers and constructors have the least control is the building occupants themselves. The nature of the occupancy and use of the building is an important indicator of the type of contaminants that will originate from the occupants.

Load documentation and calculations Thermal and pollutant loads should be documented and considered part of the design process as well as the building management process. By creating such documentation and including it with materials submitted to the building owner as part of the 
design approval process, designers ensure that there is a common understanding of the use of the building and its implications for pollutant sources.

\section{Source Control Options and Strategies}

Isolation from outdoors. For pollutants such as pesticides used to treat soil or for radon gas, complete isolation of the building from the outside is the most effective strategy. Moisture intrusion is a major contributor to microbial contamination, and, therefore, should be prevented. The integrity of joints in the construction, of coatings, seals, and other barriers is essential. It is also important to control pressure relationships across the envelope to prevent moisture accumulation on or behind surfaces. The placement of vapor barriers is determined by the indoor outdoor humidity ratios and the local climate.

Outdoor air cleaning and filtration. Among the most common pollutant removal mechanisms is filtration, usually incorporated into a mechanical ventilation system. This involves circulation of air through a filter where particles are removed primarily because they cannot pass through the openings in the media, usually made from cellulose or man-made mineral fibers. Recent advances in filter technology allows for much more effective filtration of smaller particles, those in the inhalable size range, without concomitant pressure drops that formerly required larger fän capacity and more energy consumption. In some cases air cleaning is done for gases by use of selective sorbent media.

Some pollutants are removed by the process of deposition on surfaces. To some extent these processes, known as sink effects, are usually reversible, at least to some degree, but the sink effect serves to buffer very high concentrations at the cost of extending the pollutant residence time over longer periods. Frequent cleaning of surfaces can reduce the burden on ventilation and filtration or air cleaning and may be found cost effective in some applications. In any case, surfaces should be cleaned to control contaminant concentrations.

Finally, chemical transformations can take place, as is the case when ozone brought in from outdoors or generated by photocopiers and laser printers reacts with certain organic chemicals, often forming more irritating compounds than were present before the ozone interaction. Ozone is often used to convert a "smoking" room to a "non-smoking" room in hotels. What is not wellunderstood or considered is the nature of the compounds formed by this process.

Outdoor air ventilation rates and schedules. Adequate outdoor air supply involves assessing the quality of the outdoor air as well as the needs to remove pollutants from people and from materials or processes within the building. Starting up to late in the morning or not providing enough ventilation during housekeeping activities can cause unnecessary air quality problems. 


\section{Ventilation System Design and Operation}

Local exhaust for point sources. The most effective way to control indoor air pollutants from sources within a building is to remove them at the source and not allow them to disperse to other portions of the space or building or to deposit on surfaces (sinks) from which they can be emitted later. Kitchen range hoods and bathroom exhaust fans are good examples. Smoking lounges with one-pass, direct-exhaust ventilation are another example.

Air distribution strategy and ventilation effectiveness. Consider air distribution and ventilation effectiveness before establishing outdoor air ventilation rates. Ventilation effectiveness indicates the portion of the supply air that reaches the occupants' breathing zone. To the extent that ventilation effectiveness is less than $100 \%$, then additional outdoor air needs to be provided to compensate for the shortfalls. The location of supply and return registers will affect air distribution and ventilation effectiveness under some conditions. Local supply directly into the breathing zone of the occupants may be the most effective strategy where feasible. In the long run, it can save energy and even first costs for mechanical ventilation and conditioning.

Outdoor air ventilation rate: It is necessary to ensure that there is adequate dilution for the people-related, activity-related, and the building-related sources. Traditionally ventilation rates have been based only on the number of people. This is not adequate since occupant density does not necessarily correlate with the source strengths of processes, building materials, and other potentially important sources.

Accessibility of all system components. This includes filters, coils, drain pans, ductwork, duct liners, plenums, valves, controllers, etc. They must be accessible for inspection, cleaning, maintenance, and repair. While this may seem obvious, it has frequently been neglected and caused serious IAQ problems.

Operator training. Operation of complex, modern HVAC systems requires competent, welltrained personnel. While operator training is often part of the construction contract, it is often skipped over because the operators are pre-occupied with getting a new building or system running at the time when the training is to occur.

Commissioning. Traditional testing, adjusting, and balancing is simply insufficient to ensure a properly function HVAC system. Increasingly in recent years, construction contracts call for complete HVAC system commissioning before final acceptance of the building. This is found to be both cost effective for the owner and beneficial for the contractor as well. Benefits include reduced call-backs, energy-saving during operation, and avoidance of many common IAQ problems in new buildings.

\section{Material selection and specification}

Quantify major materials and identify important sources. Based on mass and area ratios to space volume, target products should be selected for careful review, specification, and installation. 
Some sources will be important although small in area or mass. These include many wet products such as paints, sealants, adhesives, caulks, and chemical additives.

Identify major material selection criteria and alternatives. Criteria include emissions when new and service lifetime for estimating total occupant exposure; acoustic, energy, lighting, aesthetics, maintenance, cost, and other factors. Data are available on the emissions of many products and, increasingly, manufacturers are recognizing the need to provide data on the emissions from their products. Low total emissions is useful for screening but compound specific emission rates are necessary to address health, irritation, and odor effects.

Obtain maintenance, durability, and expected service life for candidate materials The durability of a material or product is a major determinant of its potential importance to indoor air quality. The more durable a material, the less likely it will result in indoor pollution. Maintenance product requirements should be considered at least as important as emissions from new materials.

Deternine indoor air iniplications of removal and replacentent processes. Ultimately, surface materials will need to be replaced, and their removal and replacement can be a very large source of indoor air pollution. This should be evaluated when products are originally selected.

Specify construction practices Temporary ventilation can reduce adsorption on surfaces and subsequent re-emission of contaminants from building products. Construction filters should be specified and changed before occupancy. Moisture protection for porous materials can reduce microbial growth when materials are installed. Moistened materials should be removed and replaced at the contractor's expense. Proper clean-up of exposed and concealed surfaces exposed to circulating air should be completed before initial occupancy. Indoor air quality can be improved by limiting fleecy and porous materials and by isolating them from high VOC concentrations and particles during construction. Specify finish construction installation practices including adequate ventilation (special temporary if necessary) to control concentrations and avoid excessive sink effects.

\section{Construction Procedures}

Review submittals to ensure confornance to IAQ performance specifications. No matter how careful the selection process, materials can be substituted during the construction process. It is necessary to monitor the submittals phase for substitutions that will result in IAQ problems.

Specify and observe construction site practices. It is essential to ensure that porous materials are protected from moisture. Wet or moist construction materials are a common source of microbial contamination once buildings are occupied. Specify and observe adequacy of ventilation conditions during installation of wet products. Specify and observe protection of fleecy and porous surfaces from dust, gases, and vapors. Ensure completion of HVAC Testing, Adjusting and Balancing, and of full HVAC commissioning before occupancy. Ensure ventilation and thermal control systems are operational and effective prior to move-in and initial occupancy. Recommend (if possible, specify) and monitor move-in and initial occupancy procedures to ensure 
indoor air quality and climate. Assemble the project manual to include full documentation of thermal and IAQ loads; HVAC system design criteria, assumption, and equipment; operational sequences and controls; warranties; record drawings and specifications; and, inspection, maintenance, and replacement requirements.

\section{Maintenance and operation}

Inspection, Cleaning, and Replacement. Periodic inspection for IAQ with good record-keeping can create a preventive maintenance environment in which problems are less likely to occur. The records should be archived in an accessible location and protected from deterioration. This inspection should include but not be limited to HVAC systems. It should also be conducted to identify any new or modified indoor pollution sources.

Change of Use, Renovation, Adaptive Re-use, and De-mounting. Evaluate impacts of planned use changes on loads (thermal, IAQ) and determine system design capacities, distribution, etc. and the adequacy for planned changes. Treat renovation projects as new construction with respect to the items discussed above.

\section{TOWARDS A SUSTAINABLE BUILDING PRACTICE}

There can be little doubt that buildings are important contributors to environmental deterioration. Buildings contribute from $15 \%$ to $45 \%$ of the total environmental burden for each of the eight major LCA inventory categories (16). Table 5 shows these contributions.

The data in Table 5 above are from the United States, but the portion of buildings' environmental impacts globally show that this share of total environmental burdens is generally consistent throughout the world (17).

In any design, trade-offs must be made among solutions aimed to optimize building performance for various objectives. Environmental objectives are diverse, complex, inter-connected, and, not infrequently, conflicting. Local, regional, and global objectives may conflict. Natural resource conservation and other objectives often do conflict. Explicitly or implicitly, trade-offs must be made among objectives in choosing a design solution. Decision-making tools such as multiple attribute decision analysis can assist designers and their clients resolve conflicting project goals

Table 5. Environmental Burdens Of Buildings, U.S. Data (16)

\begin{tabular}{|lclc|}
\hline RESOURCE USE & \% OF TOTAL & POLLUTION EMISSION & $\%$ OF TOTAL \\
\hline Raw materials & 30 & Atmospheric emissions & 40 \\
Energy use & 42 & Water effluents & 20 \\
Water use & 25 & Solid waste & 25 \\
Land (in SMSAs) & 12 & Other releases & 13 \\
\hline
\end{tabular}


that normally are part of any project. Yet no comprehensive, systematic analysis based on empirical data has provided the tools necessary for designers and other decision-makers to evaluate the trade-offs they must make explicitly or unwittingly between and among putative "environmentally-friendly" building features.

Until recently, there has been no comprehensive effort to establish a systematic approach for evaluating total building environmental performance. The two notable exceptions are the "Building for Environmental and Economic Sustainability" (BEES) being developed by Barbara Lippiatt at NIST in cooperation with EPA (18), and EcoQuantum, being developed by W+E Consultants in Gouda, the Netherlands Both are comprehensive in their scope, but both are presently years away from full development.

Books and reports abound with discussions, advice, directions, and even scoring or rating systems for assessing the environmental performance of building features. The scoring is usually implicitly or explicitly in terms of a small number of discrete environmental goals. No apparent effort is made to assess the trade-offs among various environmental objectives. This approach, used most notably by BREEAM (19), BSRIA (20), and BEPAC (21), and now proposed by the Green Building Council, provides some guidance to those lacking any other basis for choosing less environmentally harmful building technologies. However, it is clearly an inadequate basis to determine whether a particular design element is "sustainable" or even environmentally benign or beneficial from a comprehensive building environmental performance perspective.

Typically, each green design features addresses a single environmental problem and appears, at least on first glance, to be environmentally beneficial. Often life cycle assessment inventory analysis of the pre-use phase of a product is the basis for the selection. This analysis is performed semi-quantitatively while in-use phase environmental impacts are assessed qualitatively with the usual exceptions of energy and water consumption and waste production. No basis for comparison of the relative importance of energy consumption versus other environmental impacts such as water consumption, soil erosion, habitat destruction, or wastewater production is developed, and, therefore, no basis for weighting the various impacts is available. But because environmental problems are complex and interconnected, optimizing performance of a building material, product, or system may not produce unqualified environmental benefits. It is necessary to weight environmental impacts, normalize sources of similar impacts, and calculate the total environmental performance in order to determine which alternative technology is preferable. Furthermore, it is essential to establish sustainability criteria to determine the performance of an alternative in terms of sustainability.

There are no a priori environmentally benign products (22). In fact, a more complete evaluation is required to assess confidently the environmental performance of a particular design. Implementation of some or all the features listed in Table 1, although often labeled "green" design or "green building," are also promoted as "sustainable design" or sustainable building. No evidence is provided to support these claims. No criteria are presented based on calculated environmentally sustainable impacts in relation to ecosphere carrying capacity. Projections and assumptions regarding population growth, per capita consumption, and impacts per unit of consumption must be made. Further, estimates of ecological carrying capacity must be made that, 
require both scientific knowledge and value judgments that are often unavailable for the former and generally controversial for the latter. Efforts to make such estimates are appearing in Europe, especially in the Netherlands. (23-25). Such an estimate is attached as Appendix A to this paper.

In an attempt to address the shortcomings of previous efforts to guide environmentallyresponsible design, we have developed an approach based on building ecology, the study of the inter-relationships of the building to its inhabitants and to the larger environment (26). A new model for assessing building environmental performance is being developed. It attempts to address the need for comprehensive performance evaluation and assessment based on life cycle assessment, comparative risk assessment, industrial ecology, and the work done to date on the BEES model being prepared at by Lippiatt at NIST $(18,27-33)$. The most rigorous effort to establish relative importance of varioius environmental problems is an international comparative risk assessment completed at Harvard by Norberg-Bohm et al (32). The approach, tentatively called the Systematic Evaluation and Assessment of Building Environmental Performance (SEABEP), is intended to be based on similarly rigorous methodologies. Some progress has been made on portions of the model. A diagram representing the approach is shown in Figure 1.

Figure 1. Systematic Evaluation and Assessment of Building Environmental Performance (SEABEP) Decision Model

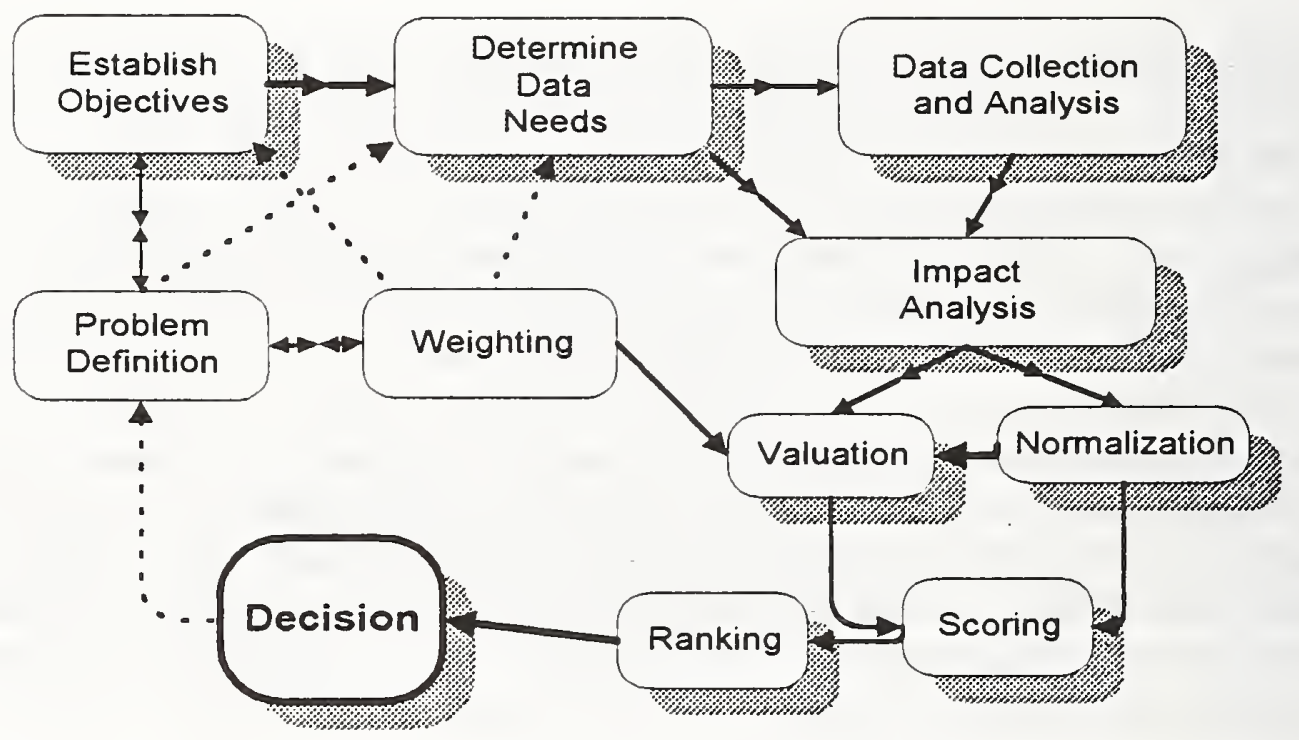

The valuation of various environmental problems requires construction of a list of problems that is both comprehensive and not too detailed. Such a list is shown in Table 6.

In order to assess the overall impacts of trade-offs, the relative importance of various environmental problems must be determined. Following are criteria recommended to develop a weighted set of environmental problems. These criteria are similar to those used by EPA's 
Table 6. Building related environmental problems

\begin{tabular}{|l|}
\hline ECOLOGICAL PROBLEMS \\
TOp priority \\
Habitat destruction / deterioration \\
(directly resulting in Biodiversity loss) \\
Global warming \\
Stratospheric ozone depletion \\
High priority \\
Soil erosion \\
Depletion of freshwater resources \\
Acid deposition \\
Urban air pollution / smog \\
Surface water pollution \\
Soil and groundwater pollution \\
Depletion of mineral reserves \\
(esp. oil and some metals)
\end{tabular}

\begin{tabular}{|l|}
\hline HUMAN HEALTH PROBLEMS \\
Building occupants \\
Indoor air pollution - radon \\
Indoor air pollution - non-radon \\
Accidents in buildings (electrical, fire, falls, \\
etc.) \\
Building workers \\
Building construction / demolition / material \\
manufacturing, etc. \\
\end{tabular}

Science Advisory Board in "Reducing Risk" (29) The first four criteria used for weighting were adapted from reference 28 and the fifth was added here. These are shown in Table 7.

Table 8 shows a sample of "generic" weights created from a global environmental perspective. The weights shown or ones developed by those involved in a project could be used in a scoring system where impacts per problem are to be assessed in a comprehensive environmental analysis. Such weightings can be done on a global scale or on a local, regional, or project scale. The results will often differ. It is important that both sets of weightings be applied. A default set of global weightings can be used, or an original one developed by the project team. The local or project specific weightings must be developed by the project team.

Table 7. Criteria for Weighting Environmental Problems

THE SPATIAL SCALE OF THE IMPACT

(Global, regional, local - large worse than small)

THE SEVERITY OF THE HAZARD

(More toxic, dangerous, damaging being worse)

THE DEGREE OF EXPOSURE

(Well-sequestered substances being of less concern than readily mobilized substances)

THE PENALTY FOR BEING WRONG

(Longer remediation times of more concern)

THE STATUS OF THE AFFECTED SINKS

(An already overburdened sink more critical than a less-burdened one. Sinks = receptors, or environmental compartments) 
Table 8. Weightings for ten environmental (ecological) problems

\begin{tabular}{|lc|}
\hline Environmental Problem Category & Weighting \\
\hline Habitat destruction / deterioration (Biodiversity loss) & 90 \\
Global warming & 80 \\
Stratospheric ozone depletion & 90 \\
Soil erosion & 20 \\
Depletion of freshwater resources & 10 \\
Acid deposition & 25 \\
Urban air pollution / smog & 25 \\
Surface water pollution & 25 \\
Soil and groundwater pollution & 35 \\
Depletion of mineral reserves (esp. oil and some metals) & 50 \\
\hline
\end{tabular}

A similar set of weights should be developed for the environmental problems with direct human impacts, as listed in Table 6 above. One of the most challenging tasks is to develop a single weighting system that integrates both the ecological environmental problems and the human health environmental problems.

\section{Sustainability Criteria for Design Analysis}

There are several possible approaches to developing sustainability criteria. Each has its shortcomings, either involving the need for scientific knowledge or data that aren't available or requiring value-based judgments that vary among individuals, cultures, and locations. Nevertheless, each of these leaves "transparent" the basis for the criteria and, therefore, is susceptible to revision by those who wish to apply new or different data, knowledge, or value judgments to the process. Among these are socio-ecological indicators (34), ecological carrying capacity (23), and I=PAT (35) among others. The last two are similar in that they both establish acceptable levels of consumption and pollution generation based on assumed levels of sustainable environmental impacts. Such determinations of sustainable impacts require value judgments that are often considered outside the purview of scientists. However, James Nash asserts that such value judgments are implicit in many of the requisite scientific components of risk assessment (36). By ignoring them, Nash argues, scientists are accepting certain values by default, not avoiding value based decisions. He points out that issues of social, generational, and genetic justice are at the heart of any risk assessment. These three issues are similar to those identified by Azar et al as indicators of their fourth socio-ecological principle discussed below (34). They clearly are issues in defining sustainability criteria or any environmental goals.

It is important to understand the implications of projected global population growth and consumption to anticipate the level of environmental impacts to be addressed by technological improvement and/or reduced consumption. Table 9 shows global population projections to the year 2100 . 
Table 9 United Nations median population projections (billions of people)

\begin{tabular}{|c|c|c|c|c|c|c|}
\hline Year: & 1900 & 1950 & 2000 & 2050 & 2100 & \\
\hline Industrialized countries & 0.6 & 0.8 & 1.2 & 1.3 & 1.3 & Population \\
\hline Developing countries & 1.0 & 1.7 & 5.1 & 8.7 & 9.9 & in billions \\
\hline World & 1.6 & 2.5 & 6.3 & 10.0 & 11.2 & \\
\hline
\end{tabular}

In Table 10 it is assumed that a doubling of per capita consumption in the industrialized countries and a quadrupling in the developing countries based on a projected $2.5 \%$ annual growth rate in industrialized countries and a projected $3.5 \%$ annual growth rate in developing countries. These are reasonable estimates based on recent experience. When these consumption rates are multiplied by the population growth rates, there is an overall increase in consumption to 3.5 times current levels. There is also a decrease in the fraction of total consumption occurring in industrialized countries from the present $75 \%$ to a projected $43 \%$ in the year 2050 .

By calculating the effects of combinations of projected population growth rates, per capita consumption rates, and environmental impacts per unit of consumption, one can assess in gross terms the seriousness of the coming crisis. If current stresses on the environment such as greenhouse gas emissions, soil erosion, acid deposition, mineral consumption, etc. are approaching the limits of the earth's carrying capacity, then significant reductions in these stresses is required. Only when the magnitude of these reductions is determined and the results used as targets for technological improvement can sustainability be assessed. One of the major limitations of this approach is the insufficiency of scientific data on most environmental problems. Reasonably good data are available for global climate change and ozone depletion, but even the seriousness of these environmental problems remains controversial, if not among most scientists, at least among many policy-makers in the industrialized countries (35). Other problems such as soil erosion, habitat destruction and biodiversity loss are not only subject to political and regional differences, they are also plagued by insufficient scientific knowledge. Most other global environmental problems are similarly insufficiently characterized from a scientific perspective.

A slightly different approach is proposed by Azar et al to avoid focusing directly on environmental impacts because, the authors assert, impacts are so complicated and difficult to assess. The authors argue that there are anthropogenic actions that affect the environment for which establishing acceptable rates based on four simple principles is reasonable (34). These four principles are are presented in Table 11.

Table 10. Global consumption in 2050 based on population and consumption per capita.

\begin{tabular}{|lcccc|}
\hline & Now & $\begin{array}{c}\text { Population } \\
\text { factor }\end{array}$ & $\begin{array}{c}\text { Consumption } \\
\text { factor }\end{array}$ & 2050 \\
\hline Industrialized countries & 75 & 1 & 2 & 150 \\
Developing countries & 25 & 2 & 4 & 200 \\
World & 100 & & & 350 \\
\hline
\end{tabular}


Principle 1: Substances extracted from the lithosphere must not systematically accumulate in the ecosphere

Principle 2: Society-produced substances must not systematically accumulate in the ecosphere

Principle 3: The physical conditions for production and diversity within the ecosphere must not systematically be deteriorated

Principle 4: The use of resources must be efficient and just with respect to meeting human needs

These four principles are the basis of several indicators for each. These indicators, given by Azar et al as mathematical formulas, can be used to calculate criteria for most technologies including building technologies. For each principle, then, the indicators can be used to assess the sustainability of buildings' impacts on the "ecosphere." Table 12 lists each of the "socioecological" indicators for the four socio-ecological principles.

Many of the criteria from Table 12 can generally be applied to decisions affecting indoor air quality alone or to the composite environmental impacts of a whole building or collection of buildings. The indicators for principles 1 and 2 can be converted more or less directly into indicators useful for the indoor environment.

\section{Sustainable IAQ Practice}

Space limitations do not permit a full exploration of all these IAQ "best practices" persented above. However, we will examine some exemplary ones in order to discover some principles that may demonstrate the application of a systematic evaluation and assessment of building environmental performance based on sustainability criteria.

Table 12. Socio-ecological indicators based on socio-ecological principles (34)

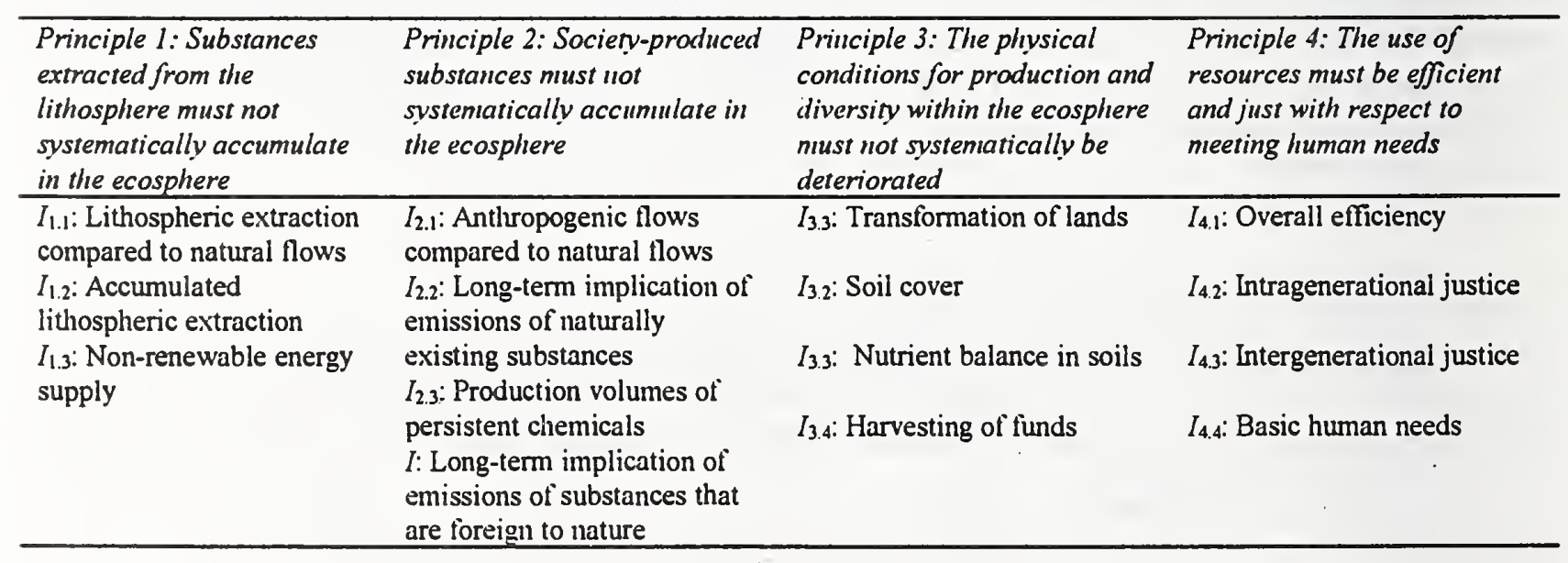




\section{Deciding What's Important In Design}

A simple illustration of the application of criteria that might be developed for healthy material selection considering the indoor air quality, indoor environment, and the general environment is shown in Table 13. The importance of each factor for each environment is indicated by the number of marks in the matrix. This exercise shows that there is considerable overlap among the criteria for different environmental compartments.

\section{"Sustainable Design" Guidance}

Following is preliminary design guidance that attempts to integrate both indoor and general environmental considerations.

Resource conservation. Selecting building materials and products that are extremely durable and can be expected to perform well over an extended useful life will generally result in a better environmental choice than one that must be replaced twice or even ten times during the same time period. This is evident from the approximately ten-fold greater relative additional resource extraction/consumption, manufacturing, transport, installation, and disposal. A roof used in many European applications may last between one and three hundred years while in the United States typical roofs last ten to thirty years. It is obvious that the environmental impacts of U.S. roofs are roughly ten times that of the European roofs regarding the extraction and disposal of materials. Long-lived products are an inherently preferred solution for resource conservation and environmental protection.

Re-using materials and products that have reached the end of their useful lives is the next most effective way to avoid withdrawal of additional resources and creation of environmental pollution associated with the extraction, transport, processing, manufacturing, installation, and disposal. A longer-lasting material is inherently more desirable from an overall environmental perspective(37).

Table 13. Sample Matrix of Criteria for Healthy Materials Selection

\begin{tabular}{|llll|}
\hline Material Selection Criteria & IAQ & $\begin{array}{l}\text { Indoor } \\
\text { Env't }\end{array}$ & $\begin{array}{l}\text { General } \\
\text { Env't }\end{array}$ \\
$\begin{array}{l}\text { Resource conservation } \\
\text { Durability }\end{array}$ & $\mathrm{X}$ & $\mathrm{X}$ & $\mathrm{XXX}$ \\
Low emissions/pollution production & $\mathrm{XX}$ & & $\mathrm{XXX}$ \\
Low emissions/pollution finished & $\mathrm{XXX}$ & $\mathrm{XXX}$ \\
Maintenance chemical requirements & $\mathrm{XXX}$ & $\mathrm{X}$ & $\mathrm{XX}$ \\
Replacement frequency & $\mathrm{XX}$ & $\mathrm{X}$ & $\mathrm{XX}$ \\
Hard surface (IAQ vs. acoustics) & $\mathrm{XX}$ & $\mathrm{XXX}$ & $\mathrm{XXX}$ \\
Smooth surface & $\mathrm{XXX}$ & $\mathrm{XX}$ & $\mathrm{X}$ \\
Energy consumption & $\mathrm{X}$ & $\mathrm{XX}$ & $\mathrm{XXX}$ \\
\hline
\end{tabular}


Durable materials tend to have low emissions. Therefore, they tend to be better for indoor air quality than less durable ones. They may also require less frequent application of maintenance and surface renewal chemicals and use of less harmful chemicals. There is a sort of multiplier effect from the use of durable materials..

Designs that assume frequent changes in interior partitions should provide for re-mounting durable ones rather than demolition/disposal and new construction.

Pollutant source control. Controlling pollution at the source is generally four times as cost effective as removing pollution from air, water, or soil. This applies both to indoor air as well as ambient air. It also applies to both surface and groundwater water. It is widely accepted that the most effective strategies for indoor air quality involve reducing indoor air pollutant sources and their source strengths or toxicities by one of the following measures: elimination, reduction, substitution, or source isolation. Important considerations for material selection and indoor environmental quality include functional requirements, surface characteristics, total mass, chemical composition and emissions, durability - longevity, and cleaning, maintenance and renovation requirements. Selecting low-emitting materials, especially for those products that will be present in large quantities by mass or exposed surface area, is also important to reduce emissions to the general environment. Typically, low-emitting products will have resulted from production processes involving lower exposures of the manufacturing workers as well.

Design for effective moisture protection is important to prevent intrusion of water from outdoors through cracks, openings, or semi-permeable membranes and eliminate potential for standing water or condensate inside the building from chilled water systems. This will prevent the growth of microorganisms and, therefore, result in better indoor air quality. This will also prolong the life of the building and its components resulting in resource conservation.

Energy conservation. The first step toward reducing energy consumption is conservation. This includes effective building envelope insulation, tightly-sealed openings, and control of air movement and thermal transport mechanisms between the building and the outside and, in some cases, between spaces within the building. This does not mean minimal ventilation; it means reducing the requirements for conditioning ventilation air by avoiding unintentional thermal losses. Energy conservation will produce more comfortable indoor environments. Energy conservation is extremely important in reducing potential emissions of greenhouse gases at power plants, and acid-forming gases that cause acid deposition. This will also reduce the need for refrigeration involving ozone-depleting compounds.

Energy efficiency. Where energy-consuming devices are required (such as fans, pumps, motors, appliances, etc.) it is essential to select efficient appliances. The ratio between the best and worst in a class of products may easily be 2-to-1 or even 3-to-1, so it does make a great deal of difference which product is selected.

Ventilation. Ensure adequate ventilation to control pollutants that reach the indoor air by reducing and removing them through dilution, exhaust (local, general), filtration, and air cleaning. Occupant-controlled ventilation can produce energy savings while reducing occupant stress and 
building sickness symptoms. Individual occupant desk top air supply that is turned off automatically when a desk is unoccupied can save energy as well efficiently deliver air when and where it is needed. Reduction in overall air supply volumes reduces ductwork materials consumption, air handler capacity, and operating energy. The cost savings achievable with such an approach can easily pay for the additional costs of the individual desktop supply and control.

Overall design. Design for the whole person: The human body and mind integrate all the factors in the physical, chemical, biological, and psychosocial environment. Full integration of environmental considerations in design will include not only indoor air quality but also thermal comfort, lighting, acoustics, and spatial relationships. Such designs will be inherently healthier. A building that meets the needs of its users (occupants, operators, others) will endure longer and not require demolition, replacement, or other resource- and pollution-intensive actions. The more satisfied building users are, the longer the building will remain in service, avoiding the need for additional construction.

Building design and indoor environmental quality issues must be considered throughout the process of planning, design, construction, use, and disposal/re-use/recycling buildings. The major design phases include site selection, project feasibility, budgeting, building configuration, building envelope, environmental control scheme, energy considerations, and environmental impact analysis.

\section{DISCUSSION and CONCLUSION}

This paper has emphasized a "building ecology" view of buildings as dynamic, interdependent systems (25). This view suggests the importance of planning during the design phase for varying cycles of building performance and use or requirements during the building's lifetime. The more specific the analysis, the more relevant its application to any given building design. Generic analyses are helpful but suffer from the potential to miss important characteristics of a particular situation.

It is apparent that in many instances, the design alternative best for indoor environmental quality is also best for general environmental quality. For example, durable materials will be less likely to emit contaminants into the indoor air, will require lower quantities and less toxic chemicals for the maintenance and refurbishing, and, by definition, will be longer lasting. Service life is an extremely important determinant of overall impact on the general environment since each replacement cycle requires the use of additional resources with the concomitant pollutant emissions.

Designers must be aware of the impacts of the building on the larger environment. These will include impacts on biodiversity, global warming, ozone depletion, on the soil, air, and water, on resource depletion, on waste generation, and on energy consumption,. Some of these will ultimately, although perhaps imperceptibly, affect the building itself and its users. Therefore, each building must be planned and designed as though it were being replicated a million times over so that we take seriously the consequences of its impacts on the global environment and, in a very real sense, its own environment. 


\section{ACKNOWLEDGMENTS}

The preparation of this paper was based in part on work prepared by Atze C. Boerstra, Shela Ray, and Eugena Bendy.

\section{REFERENCES}

1. Pearce, David W. 1993, Economic values and the Natural World. Cambridge, Massachusetts; MIT Press. 129 pp.

2. Fanney, A.H., K. M. Whitter, and T. B. Cohn, Eds., 1995. Second International Green Building Conference and Exposition - 1995. NIST Special Publication 888.

3. Levin, H. 1987. Protocols to improve indoor environmental quality in new construction, in Proceedings of IAQ '87. American Society of Heating, Refrigerating, and Airconditioning Engineers, Inc., Atlanta.

4. Levin, H. 1989a. Building materials and indoor air quality, in, Hodgson, M. and Cone, J., (eds.), State of the Art Reviews in Occupational Medicine, Vol. 4, No. 4.

5. Levin, H. 1989b. Edifice complex, anatomy of sick building syndrome and exploration of causation hypotheses. Proceedings of IAQ '89. American Society of Heating, Refrigerating, and Air-conditioning Engineers, Inc., Atlanta.

6. Levin, H. 1991. Critical building design factors for indoor air quality and climate: current status and predicted trends. Indoor Air $1,79-92$.

7. Levin, H. 1992. "Controlling sources of indoor air pollution" in H. Knöppel and P. Wolkoff (Eds.) Chenical, Microhiological, Health and Comfort Aspects of Indoor Air Quality -- State of the Art in SBS. Kluwer Academic Publishers. 321-342.

8. Levin, H., 1994. "Building Design and Material Selection." Keynote lecture in Proceedings of Indoor Air; An Integrated Approach. (Symposium held in Queensland, Australia, November 1994). in press.

9. Levin, H. 1995. "Emissions Testing Data and Indoor Air Quality." in, Haghighat, F. (ed.), Indoor Air Quality, Ventilation, and Energy Conservation in Buildings, Proceedings of the Second International Conference, Volume 1, 465-482.

10. Skov P, Valbjørn O, and the Danish Indoor Study Group: 1987. The sick-building syndrome in the office environment: the Danish Town Hall Study. Environ Internat 13:339-349.

11. Stenberg, B 1994. Office illness; The worker, the work and the workplace. Umea University Medical Dissertations, New Series No 399. Umeå, Sweden.

12. Sundell, J. 1994. On the association between building ventilation characteristics, some indoor environmental exposures, some allergic manifestations and subjective symptom reports. Indoor Air, Supplement No. 2/94.

13. Mendell, M..J. 1993. Non-specific symptoms in office workers: A review and summary of the epidemiologic literature. Indoor Air $\underline{3}, 227-236$.

14. Lindvall, T. 1992, The sick building syndrome - overview and frontiers. in H. Knöppel, and P. Wolkoff, (eds.) Chemical, Microbiological, Health and Comfort Aspects of Indoor Air Quality - State of the Art in SBS. Kluwer Academic Publishers, Dordecht. 
15. Norbäck, D. 1990. Environmental exposures and personal factors related to sick building syndrome, Thesis, Uppsala University, Uppsala, Sweden.

16. Levin, H., A. Boerstra, and S. Ray, 1995, "Scoping U.S. Buildings Inventory Flows and Environmental Impacts in Life Cycle Assessment" Presented at Society for Environmental Toxicology and Chemistry (SETAC), Impacts assessment work group meeting, Alexandria, VA, April 19.

17. Roodman Malin, David, Nicholas Lenssen, 1995. "A Building Revolution: How Ecology and Health Concerns are Transforming Construction" March, World Watch Institute, Washington, DC.

18. Lippiatt, Barbara C., and Gregory A. Norris, 1995. Selecting Environmentally and Economically Balanced Building Materials, in, Fanney, A.H., K. M. Whitter, and T. B. Cohn, Eds., Second International Green Building Conference and Exposition - 1995. NIST Special Publication 888. pp. 37-46.

19. BRE, 1993. "Building Research Establishment Environmental Assessment Method (BREEAM): New Offices, Version 1/93, An environmental assessment for new office designs." Building Research Establishment, Garston, UK.

20. BSRIA, 1994. Environmental Code of Practice for Buildings and Their Services. Bracknell, Berkshire, UK: The Building Services Research and Information Association. 130 pp.

21. BEPAC, 1993. Building Environmental Performance Assessment Criteria; Version 1, Office Buildings, British Columbia. Vancouver: University of British Columbia School of Architecture. .

22. Heijungs, R., J.B. Guinée, G. Huppes, R.M. Lankreijer, H.A. Udo de Haes, A. Wegener Sleeswijk, 1992. Environmental Life Cycle Assessment of Prodicts, 2 volumes. National Institute of Public Health and Environmental Protection, The Netherlands.

23. Weterings, R.A.P.M., J.B. Opschoor, 1992. "The Ecocapacity as a Challenge to Technological Development." Rijswijk, the Netherlands: Advisory Council for Research on Nature and Environment (RMNO).

24. Goedkoop, Mark, 1995. "The Eco-indicator 95: Weighting method for environmental effects that damage ecosystems or human health on a European scale; Final Report." NOH Report 9523. National Reuse of Waste Research Programme (NOH), available from PRé Consultants, Bergstraat 6, 3811 NH Amersfoort, the Netherlands, Tel +31 334611046 , Fax+31334652853, email: pre@sara.nl.

25. Goedkoop, Mark, 1995. "The Eco-indicator 95: Weighting method for environmental effects that damage ecosystems or human health on a European scale; Manual for Designers." NOH Report 9524. National Reuse of Waste Research Programme (NOH), available from PRé Consultants, Bergstraat 6, $3811 \mathrm{NH}$ Amersfoort, the Netherlands, Tel +31334611046, Fax+31334652853, email: pre@sara.nl.

26. Levin, H. 1981. Building ecology. Progressive Architecture. Vol. 62, No. 4, (April) 173175.

27. Consoli, Frank et al / Society of Environmental Toxicology and Chemistry (SETAC) 1993. A Conceptral Framework for Life-Cycle Impact Assessment. Pensacola, Florida: Society of Environmental Toxicology and Chemistry (SETAC).

28. Consoli, Frank et al (eds) 1993. Guideline for Life-Cycle Assessment: $A$ 'Code of Practice.' Society of Environmental Toxicology and Chemistry (SETAC), Pensacola, FL. 
29. EPA Science Advisory Board, 1990. "Reducing risks: Setting priorities and strategies for environmental protection". Report SAB-EC-90-021 and 021a. Washington DC: United States Environmental Protection Agency.

30. Graedel, Thomas, and Allenby, B. R. 1995. Industrial Ecology. Englewood Cliffs, New Jersey: Prentice Hall. 412 pp.

31. Keoleian, Gregory A., Jonathan E. Koch, and Dan Menerey, 1995. Life Cycle Design Framework and Demonstration Projects: Profiles of AT\&T and Allied Signal. EPA/600/R95/107, Office of Research and Development, Washington, DC.

32. Norberg-Bohm, Vicki, William C. Clark, Bhavik Bakshi, JoAnne Berkenkamp, Sherry A. Bishko, Mark D. Koehler, Jennifer A. Marrs, Chris P. Nielsen, Ambuj Sagar, 1992. "International Comparisons of Environmental Hazards: Development and evaluation of a method for linking environmental data with the strategic debate management priorities for risk management." Center for Science and International Affairs, Publications, Cambridge, MA.

33. Weitz, Keith, and John L. Warren, 1994. "Life Cycle Impact Assessment: A Conceptual Framework, Key Issues, and Summary of Existing Methods." RTI Project Number 94U5810-49 FR. Research Triangle Institute, Research Triangle Park, NC 27709.

34. Azar, Christian, John Holmberg, and Kristian Lindgren, 1996. Socio-ecological indicators of sustainability. Ecological Economics, 18: 89-112.

35. Holdren, John. P., Gretchen C. Daily, and Paul R. Ehrlich, 1995. "The Meaning of Sustainability: Biogeophysical Aspects," in Munasinghe, Mohan, and Walter Shearer (Eds.) Defining and Measuring Sustainability: The Biogeophysical Foundations. Distributed by the United Nations University for the World Bank, Washington, D.C., 1818 H Street N.W., Washington, DC 20433.

36. Nash, James A. 1994. "Risk decisions and moral values". Symposium on Values, Perceptions, and Ethics in Environmental Division, American Chemical Society, August 24, 1994.

37. Goldbeck, Nikki and Goldbeck, David, 1995. Choose to Reuse. Woodstock, New York: Ceres Press. 452 pp. 
Appendix A.: Sustainable versus expected level of environmental impact for selected indicators (Reference 22, p. 25)

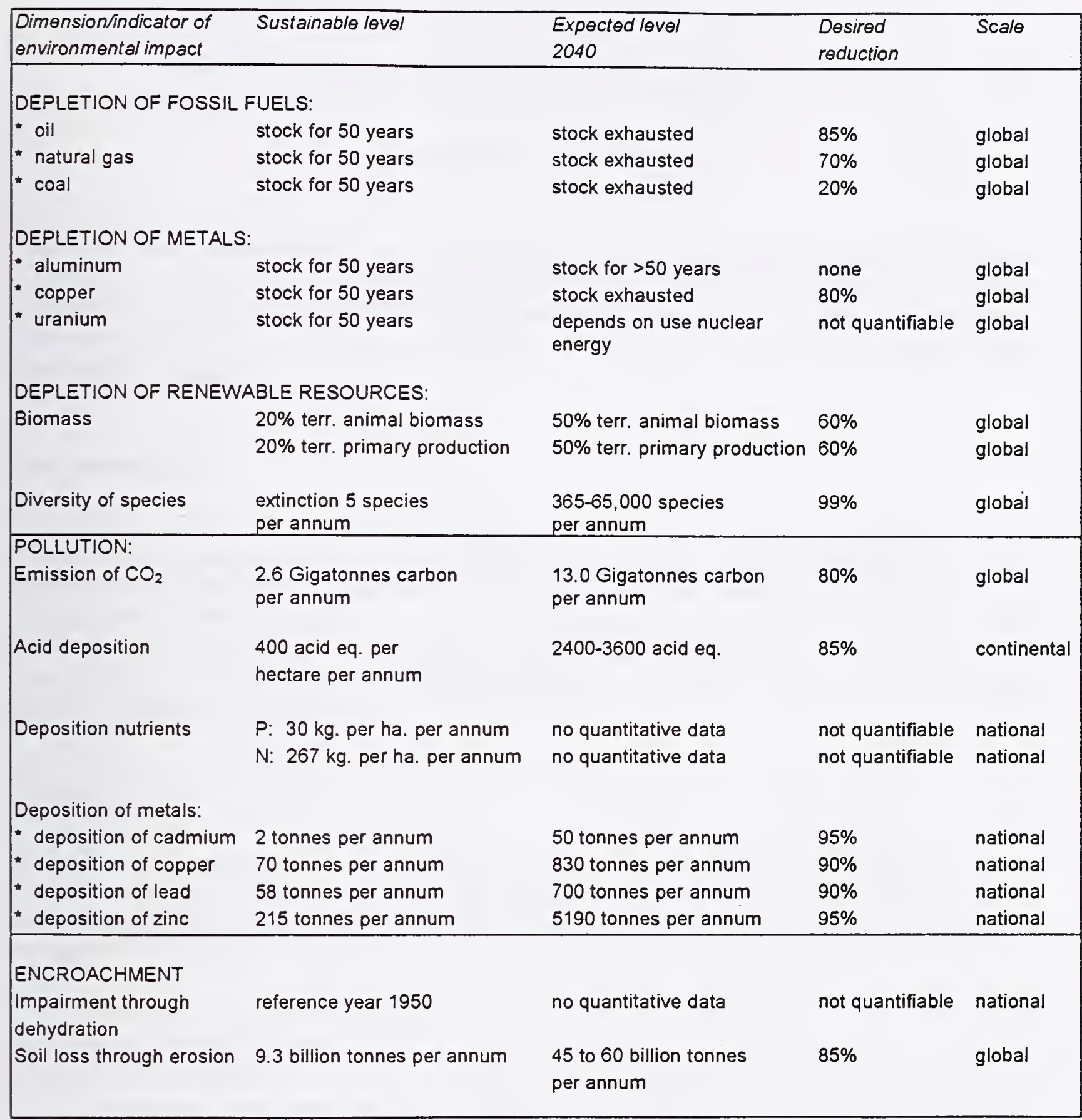





\title{
IMPROVING INDOOR AIR QUALITY IN RESIDENCES - A SYSTEMS APPROACH
}

\author{
Subrato Chandra, David Beal and Andrew Downing \\ Florida Solar Energy Center (FSEC) \\ (A Research Institute of the University of Central Florida, UCF) \\ 1679 Clearlake Road, Cocoa, FL 32922
}

Ph. 407-638-1000 / Fax. 407-638-1010

Abstract. The importance of common residential allergens and irritants (tobacco smoke, dust mites, pollens, pet danders, molds, cockroaches, VOC's, odors, fine dust and radon) is reviewed. Strategies to eliminate them through advanced energy efficient building construction techniques, equipment and material choices are discussed using recently constructed demonstration Health Houses $囚$ as examples.

\section{Acknowledgement}

This work was sponsored by the U.S. Department of Energy, Office of Building Systems, Mr. George James, program manager whose support and goodwill is very much appreciated. The authors are grateful to the American Lung Association of Minneapolis, the American Lung Association of Central Florida, the American Lung Association of Florida, the American Lung Association of Huntsville, the American Lung Association of Alabama, the American Lung Association of New Orleans and Mr. Rick Mickler of New Orleans. Without their cooperation, this work would not be possible.

\section{Introduction}

In order to improve the indoor air quality in residences it is essential to be aware of the various indoor allergens and irritants and their importance. In the authors view they are listed in the order of probable decreasing importance at levels commonly found in indoor environments for the general population:

- Environmental Tobacco Smoke

- Dust Mite Allergens

- Pollen Allergens

- Pet Dander Allergens from cats and dogs

- Molds

- Cockroach allergens

- Volatile Organic Compounds and Odors(VOC's)

- Fine Dust

- Radon

Of course exceptions prove the rule. For the chemically hypersensitive a certain VOC might be 
lethal. Poorly maintained water systems can harbor deadly bacteria such as legionella. Excessive rodents, pesticides and malfunctioning combustion devices can be extremely hazardous. Recent studies point to the increasing importance of cockroach allergens to asthma in inner city housing causing asthma in up to $8.6 \%$ of the children (1), almost twice the national rate. Because of genetic factors, Native Americans have a low incidence of asthma and smoking related lung disease (2). To them tobacco smoking may be a lesser concern.

The following paragraphs contain remarks about each of the allergens and irritants.

Environmental Tobacco Smoke (ETS). About $25 \%$ of North American adults smoke today. In countries such as Japan and Poland, above $50 \%$ of the adult males smoke. The sidestream and exhaled smoke (i.e. ETS) is a major cause of respirable particles indoors as well as various carcinogens, odors and other toxic compounds (3). Some air filtering and purifying devices are reported to clear up ETS somewhat. High levels of localized ventilation may also help. However, the most practical solution seems to be banishing the smokers to the outside of the house. Building science is probably of limited help in alleviating ETS.

Dust Mite Allergens. About $20 \%$ of the general population suffer from allergies. About $5 \%$ suffer from asthma. Among children the percentages appear to be higher. The increasingly large percentage of people suffering from allergy and asthma appears to be a worldwide phenomena. In humid climates, dust mites appear to be a leading cause of asthma (4). In the hot, humid central Florida climate, approximately $60 \%$ of the patients complaining of respiratory problems tested positive to dust mite skin prick tests (5), rates two to three times greater than any other aero-allergen. In a study of North Carolina school children, $30 \%$ tested positive to house dust mites (6).

There are several dust mite species. Dust mites feed on human skin flakes and are translucent creatures invisible to the naked eye and are about $300 \mu \mathrm{m}$ (micrometers or microns) in size (see figure 1). Dust mites themselves also generate type II allergens from their body parts. The dust mite fecal particles contain large amounts of the most common type I dust mite allergens, Der $p I$ and $\operatorname{Der} f I$. The fecal particles are about $10 \mu \mathrm{m}$ in size and heavier than air. When airborne, they settle out in about five minutes. Dust mites live and breed on carpets, sofas, beds and other soft and fluffy furnishings. When a person lies down on a bed, they will release puffs of dust containing dust mite fecal particles. These are likely to be breathed in by the person before they get a chance to be filtered out by a room or a whole house air filter.

Washing clothes in hot $(>130 \mathrm{~F}$ ) water, frequent vacuuming with a good dust filter (pore size $<1$ micron) and covering mattresses and pillows with impermeable covers can reduce exposure to dust mite allergens. However, those measures do not kill the mites. One way to dehydrate and kill dust mites is through humidity control. Laboratory experiments (7) have shown that limiting relative humidity $(\mathrm{RH})$ to about $50 \%$ kills the two most common species of dust mites. A systems approach to controlling RH in homes is a promising approach to controlling dust mite allergens in houses and will be discussed further in this paper.

Pollen Allergens. Pollens from grasses, weeds and local trees are another frequent cause of allergy. In a study of North Carolina school children, $29 \%$ tested positive to grasses and weeds. 
Measurements in the Tucson area (8) indicate that between 10 to $25 \%$ of the outdoor pollen can come indoors. Pollen can come indoors by convective transport through open windows or cracks or can be carried indoors on clothes and footwear. Since most pollen grains are larger than 10 microns, efficient filtration should be effective if the pollen can be trapped before they are breathed in by humans. The practice of removing shoes and outerwear outside the house may be helpful in reducing the pollen inside homes. This could be encouraged by designing such a "mud room" space in the garage just before the garage entry door into the house as most North Americans enter the house through their garages rather than their front doors.

Pet Dander Allergens from cats and dogs. This is another important class of allergens. In the same North Carolina study, $25 \%$ of the school children tested positive to animal danders. Pet dander allergens are really small about 0.3 microns in size and stick to walls after being airborne. Frequent bathing of pets can reduce the allergens. However, like smokers, pets need to be banished to outdoors to eliminate this allergen from the house.

Molds. Mold allergy is also quite common. $20 \%$ of the schoolchildren in the above study tested positive to molds. Molds are ubiquitous in nature and not all molds are harmful. Some molds such as Stachybotrus can be toxic and have been implicated in several sick buildings and in the deaths of children. If the surface relative humidity exceeds $65 \%$ to $70 \%$ on a continuous basis then molds can amplify and create a problem, particularly in the absence of light and airflow. Most molds in buildings arise from water leaks or mist carryover from cooling coils and grow in porous materials. Proper moisture control techniques, biocides and regular cleaning can control molds in housing.

Cockroach allergens. In the North Carolina study only $5 \%$ of the children tested positive to cockroach allergens and that's why we ranked the cockroach problem lower than most others. Recent epidemiological studies (1) point to the increasing importance number of asthmatic children (about $8.5 \%$ ), especially in inner city housing, who have developed asthma because of cockroaches. Proper housecleaning and use of safe pesticides are needed for cockroach control.

Volatile Organic Compounds and Odors(VOC's). Many VOC's and bioeffluents exist in houses, especially during the first several months. While irritating or unpleasant, VOC's are probably not unhealthy in concentrations found generally in houses, except to the hyper sensitive. Proper choice of materials for construction, adhesives, finishes and furnishings can dramatically reduce VOC exposures in houses. Adequate ventilation, such as recommended by ASHRAE (9) should take care of the remaining VOC, odors and bioeffluents.

Fine Dust. Can be generated indoors during remodelling projects or brought in from outdoors. In large quantities, fine dust can trigger bouts of sneezing but is not generally toxic, except to the hypersensitive. Positive pressure ventilation and good air filtration can minimize the dust problem.

Radon. Recent large scale epidemiological studies using 10,000 households in Norway(10) seem to suggest that at levels generally found in houses, Radon is not a significant health risk. If it were, the strategies of positive pressure discussed in this paper should be helpful in mitigating the Radon problem. 


\section{Strategies to Improve the Indoor Air Quality}

From the above discussions it appears that a systems approach to improving residential indoor air quality involves:

1. Designing for water drainage

2. Air tight construction and good air distribution

3. Positive pressure ventilation

4. Whole house dehumidification

5. Excellent filtration

6. Insulation to minimize thermal gradient between floor and air in the house

7. Material selection to minimize VOC emissions

8. Regular cleaning and maintenance

We now discuss the above steps above drawing from recently constructed Health Houses $@$ in humid climates. Please note that energy efficient construction (items 2 . and 6.) are integral parts of the systems approach. Also, this is a work in progress, not all the answers are known yet and considerable challenges lie ahead.

1. Designing for water drainage. It is quite amazing that given the importance of this topic, how often it is overlooked. A partial checklist of things to look for in slab-on-grade houses follows:

- The bottom of the slab or floor should be at least 8 " above the top of the backfilled dirt of the yard which should be graded to drain away from the house.

- Garage floor and driveway should be sloped to drain out.

- The roofs should have at least a 3 in 12 pitch and all roof penetrations properly flashed.

- $\quad$ All windows should be under at least a 2 feet overhang.

- Roof gutters should drain out on splash blocks so water drains away from the house

- The wall system must be designed so that even if there is water penetration, it is allowed to drain out. Figure 2 shows a detail in the Huntsville Health House where a plastic sheeting was installed over the bottom of the studs before the exterior sheathing was applied. The slab perimeter insulation was inserted so that the plastic sheeting covered its top edge. Also note the high level of the floor slab. The wall has a brick finish with an air gap and weep holes for drainage.

- On stuccoed frame walls or block walls a waterproofing sheet with wire mesh must be installed before applying stucco.

- The drain pan of air-conditioners should leave no standing water. 
2. Air tight construction and good air distribution. Air tight construction is needed, because without enclosing the air it impossible to control it. Good air distribution systems assure that the benefits of mechanical ventilation and central dehumidification are distributed evenly throughout the house. Several items need careful attention in this area:

- Air distribution ducts and registers must be constructed to be air tight. Detailed instructions on how to accomplish this may be found in several references (see for example reference 11). See figure 3 for a new metal duct system with o-rings which was used in the Jacksonville Health House. To minimize acoustical problems the runouts were constructed with conventional insulated flex duct in this house. Figure 4 shows the duct system used in the New Orleans Health House. The fiberglass duct has a inner coating with a mildewcide and is fairly rigid. This should prevent loose fibers in the airstream and the hard surface should be easy to clean. The flex duct has a heavy liner to permit future cleaning. The cut lines of the ducts and the joint with flex duct are sealed with a UL listed adhesive and sealant.

- $\quad$ Air tight recessed can lights must be used. Several manufacturers make these now. Figure 3 shows two types used in health houses. These lights should also be rated to allow direct placement of insulation on the lights.

- A good way to airtight frame walls, band joists, garage ceilings and other hard to reach places is to use a combination foam insulation and air sealer. This was used in the Orlando Health House, see figure 6.

- The common practices of using sill sealers, sealing all electrical and plumbing penetrations at the top plate and through the walls, sealing the gap between window frame and wall must not be forgotten.

- Good air distribution is assured by having return or transfer ducts or transfer grills in all bedrooms. This assures good air distribution even if bedroom doors are kept closed.

3. Positive pressure ventilation. In humid climates (e.g. the US south east and the northwest) positive pressure ventilation is recommended. This is only possible if the house is air tight. Positive pressure ventilation requires only one intake and thus permits filtering and dehumidification of the incoming air. Maintaining a positive pressure minimizes infiltration of humidity and dust and improves combustion safety (as opposed to negative pressures which may cause backdrafting). In humid climates mechanical ventilation must be combined with dehumidification. Otherwise the house may experience serious moisture problems in mild and wet months when neither cooling nor heating is required. In the Orlando and Huntsville Health Houses a combination whole house dehumidifier and positive pressure ventilator was used as shown in figure 7.

The kitchen and bathroom exhaust fans should vent to the outside and should be installed for point source exhausts in addition to the central whole house ventilation system. 
4. Whole house dehumidification. Whole house dehumidification in addition to central heating and cooling is recommended to control dust mites. Room dehumidifiers are unlikely to control dust mites throughout the house, although it might benefit a single room. Whole house dehumidifiers, as noted in figure 7, run independently of the central heating and cooling system and control the $\mathrm{RH}$ in homes every month of the year. The authors are currently engaged in research to determine the effectiveness of central dehumidifiers in controlling dust mite allergens by comparing allergen levels in Health Houses and neighboring control homes without central dehumidification and mechanical ventilation.

5. Excellent filtration. Excellent filtration is a key to achieving excellent indoor air quality. For many years studies have shown that allergy sufferers feel more energetic and sometimes require less medication when using room air cleaners or good air filters. Health Houses have used 4" and 7" pleated filters as well as HEPA filters. Disposable filter elements are probably better than washable types. Most electronic air cleaners produce some ozone and if used should be well maintained and regularly cleaned per manufacturer instructions.

A frequent problem noted in many homes is the air bypass around furnace filters. This should be avoided.

6. Insulation to minimize thermal gradient between floor and air in the house. In slab on grade houses the slab is often poorly insulated or not insulated at all because of concern with termites. This creates a RH (as well as temperature) gradient between air in the middle of the room and that at the carpet, where dust mites live and breed. In order to limit the RH to say $50 \%$ at the floor, it may be necessary to set the dehumidifier at $45 \% \mathrm{RH}$ or lower. The effectiveness of slab perimeter insulation is currently being evaluated the authors. A promising new foundation insulation material is now on the market which is termite resistant. Another possibility may be to use insulated aerated concrete blocks as perimeter foundation blocks and then pour the slab inside it. There is a patented termite control system on the market which uses perforated tubes installed under the slab. Then termiticides can be poured regularly at the tube terminating point and spread throughout the soil under the slab. This system was used in the Orlando Health House.

7. Material selection to minimize VOC emissions. Today there are a variety of materials on the market which emit low amounts of VOC's in paints, adhesives, caulks etc. In addition low VOC emitting carpets, pads, hardwood floors, cabinetry can be selected which leads to low VOC levels. One of the difficult areas is material used as subfloor bases in second stories, stair cases and other wooden surfaces which are inside the conditioned space. Choices are available, but not as convenient as using readily available high VOC emitting materials.

In addition there should be no unvented combustion appliances in side the house. Direct vented fireplaces are preferred. In garages and basements combustion appliances should be placed in permanently ventilated spaces which cannot go to a severe negative pressure.

8. Regular cleaning and maintenance. In today's busy lifestyles there appears to be little time or interest in this in many houses. Unfortunately, technology alone will probably not be able to create excellent indoor air quality in a house unless it is regularly cleaned and maintained. 


\section{Conclusions}

Improving indoor air quality in houses requires thought and effort during design, construction and operation of a house. It is an effort well worth making.

\section{References}

1. D.Q. Haney, "Cockroaches are a Factor in Severe Urban Asthma, Researchers Warn", Associated Press, July 14, 1996 as reported in many major newspapers including the LA Times, 1996.

2. A. M. Pope, R. Patterson and H. Burge (editors), Indoor Allergens. National Academy Press, Washington, D. C. p. 67, 1993.

3. Thad Godish, Indoor Air Pollution Control. Lewis Publishers. p. 29, 1989.

4. S. Chandra, R.F. Lockey, L.W. Alidina, D. Beal, R. Codina, and K. Gehring, "Adverse Health Effects and Elimination of Dust Mites in Humid Climate Housing," Proc. 7th International Conference on Indoor Air Quality, Nagoya, Japan, July 21-26, 1996. Vol 3., pp. 433-438, 1996.

5. E. Fernandez-Caldas, R. W. Fox, G. A. Bucholtz, W. L. Trudeau, D. K. Ledford and R. F. Lockey. House dust mite allergy in Florida - Mite survey in households of mite-sensitive individuals in Tampa, Florida. Allergy Proceedings, Vol.11/No.6, pp263-267, 1990.

6. A. M. Pope, R. Patterson and H. Burge (editors), Indoor Allergens. National Academy Press, Washington, D. C. p. 52, 1993.

7. L. G. Arlian, Water balance and humidity requirements of house dust mites. Experimental and Applied Acarology, Vol.16, pp15-25, 1992.

8. M.K. O'Rourke and M.D. Lebowitz. "Environmental Allergens and the Development of Chronic and Allergic Obstructive Lung Diseases," Chapter 13 of Environmental Respiratory Diseases. Eds- Cordasco, Demeter and Zenz. Van Nostrand Reinhold. p.303, 1995.

9. Anon, "Ventilation for Acceptable Indoor Air Quality," ASHRAE standard, public review draft, Ch.9, August 1996.

10. K. Magnus, A. Engeland et al "Residential Radon Exposure and Lung Cancer -- an Epidemiological study of Norwegian Municipalities," Int J Cancer vol. 58, pp.1-7, Jul 1, 1994.

11. J. Lstiburek, "Builder's Field Guide," North Carolina Alternative Energy Corporation, ch.6, 1994. 


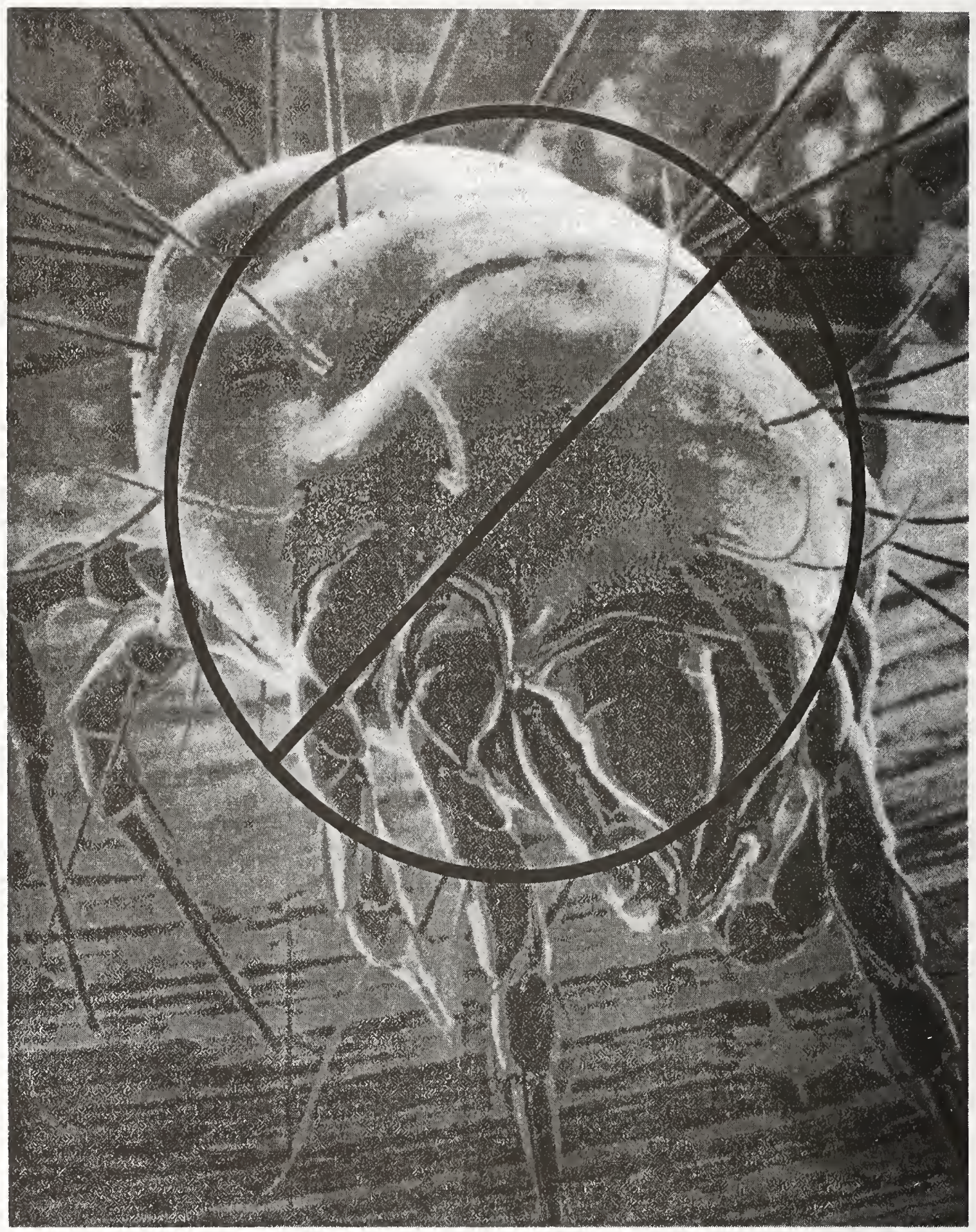

Figure 1: Dust Mite - blomia tropicalis

\section{Photo Courtesy of:}

Dr. Richard F. Lockey, M.D. and Enrique Fernández-Caldas, Ph. D.

College of Medicine, University of South Florida 


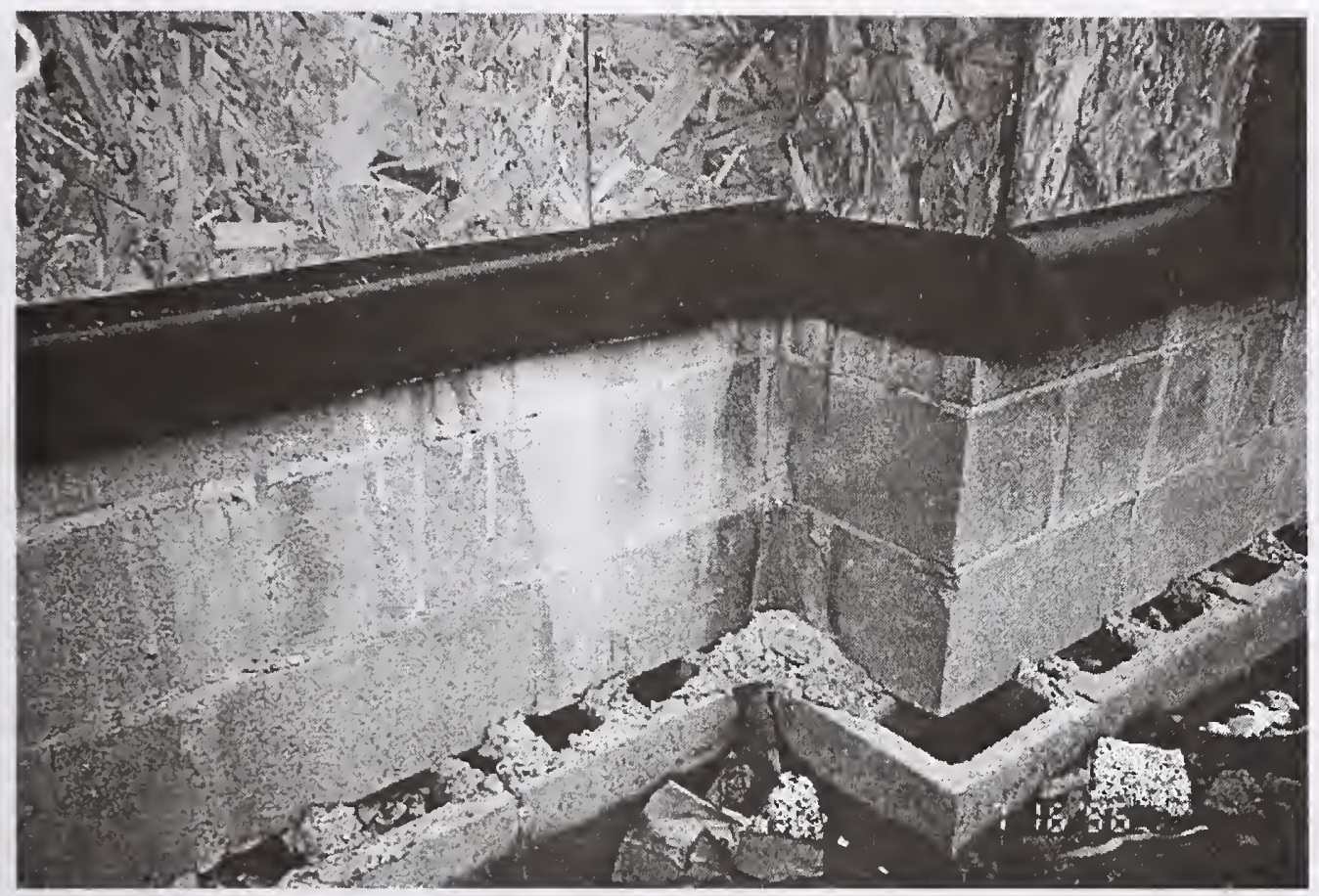

Figure 2: A detail of the Huntsville Health House showing the water drainage sheet.

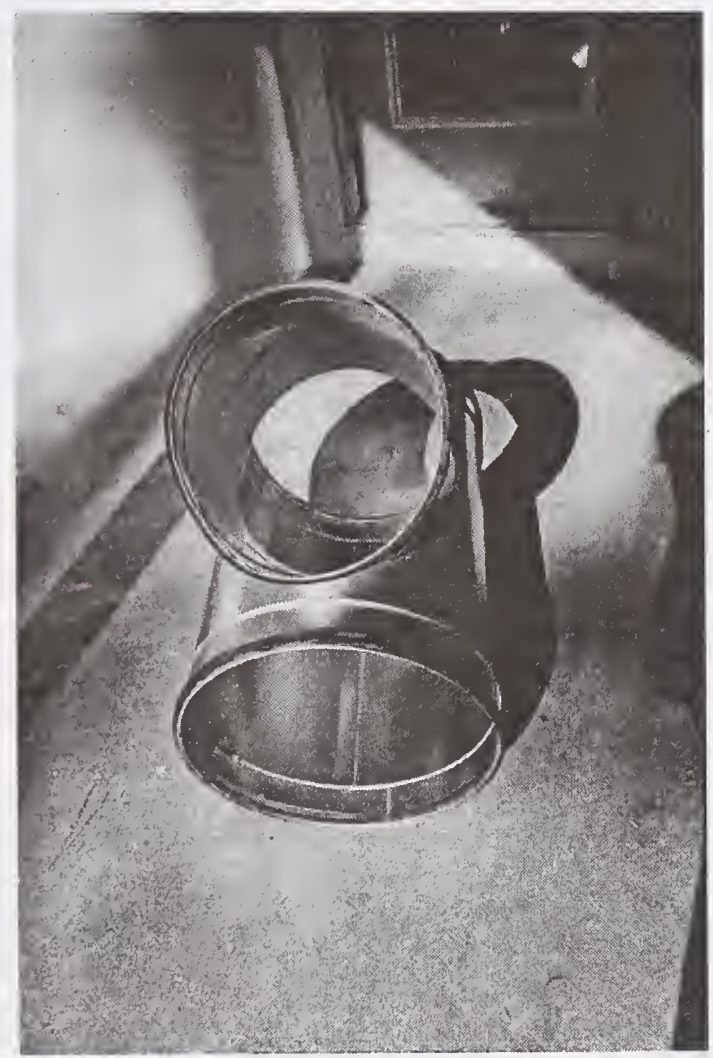

Figure 3: Metal ducts with o-ring seals used in the Jacksonville Health House 


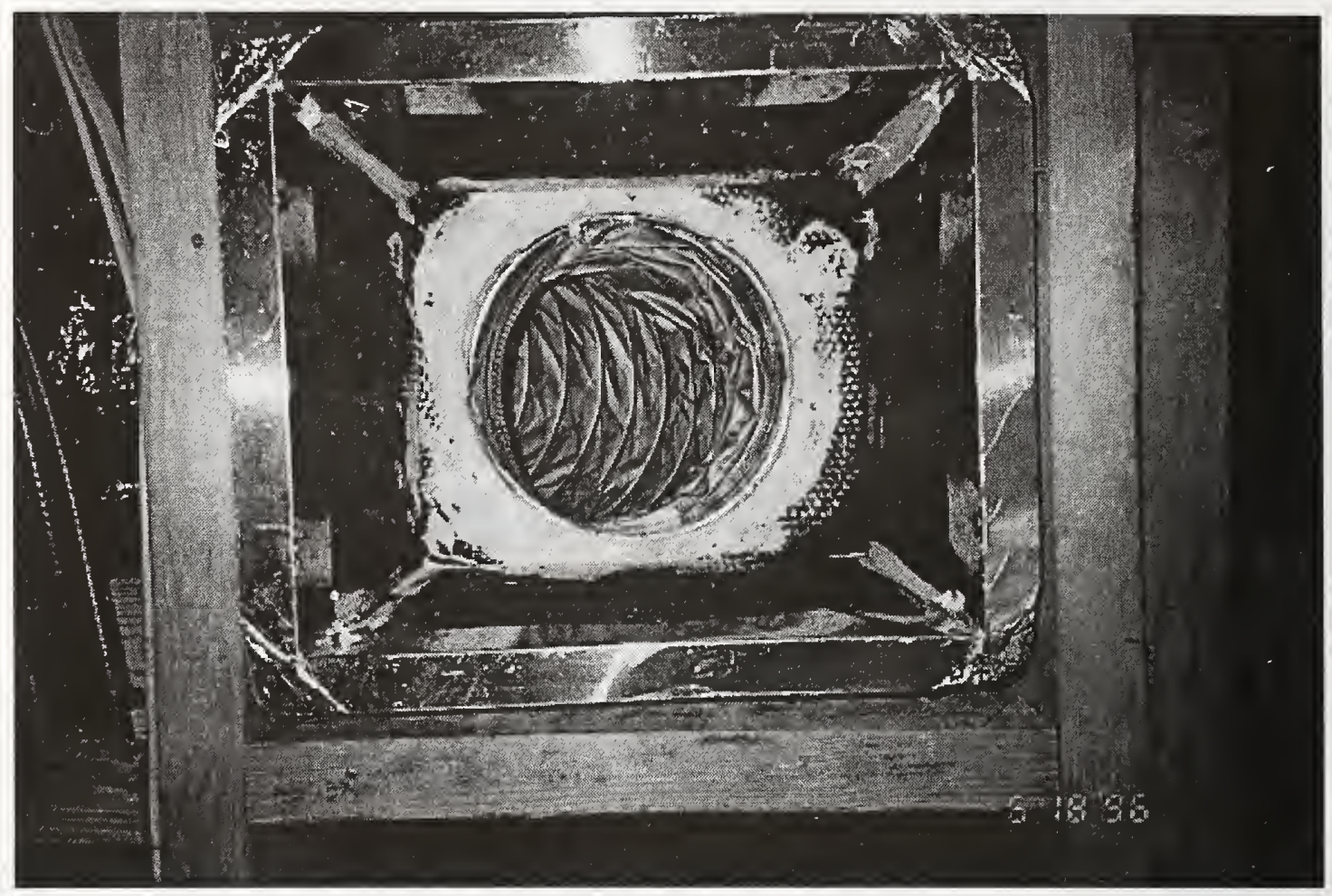

Figure 4: The air duct system in the New Orleans Health House featuring coated ductboard, flex duct with a thick lining, and UL listed inside sealant. 


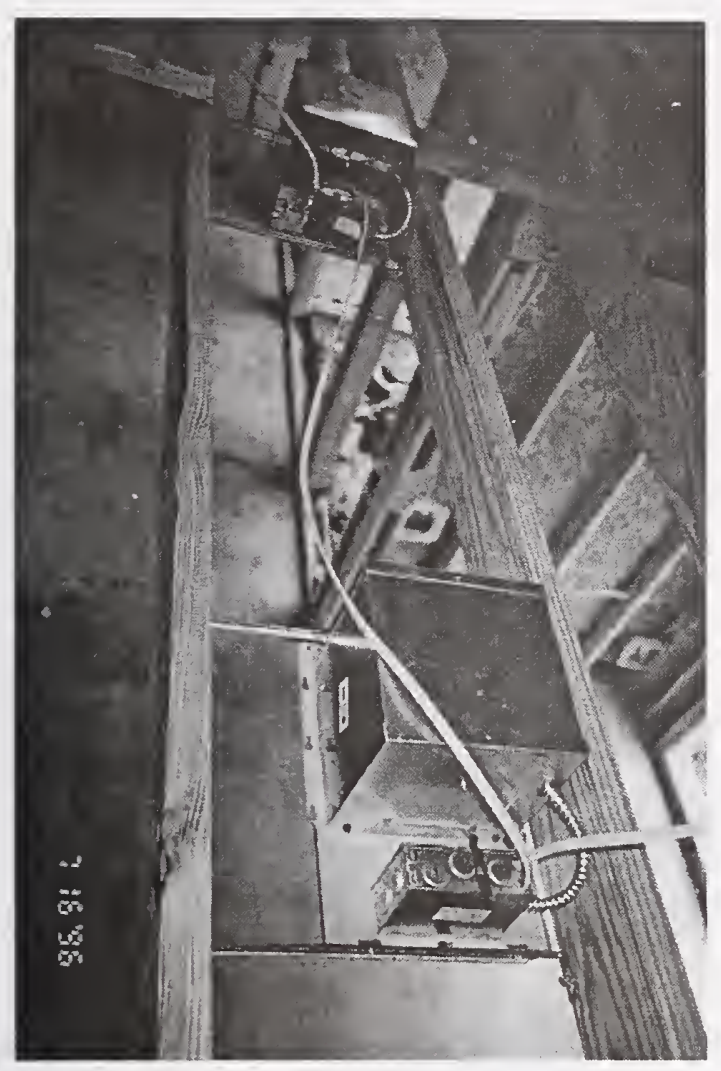

Lights used in the Huntsville Health House.



Lights used in the Jacksonville Health House.

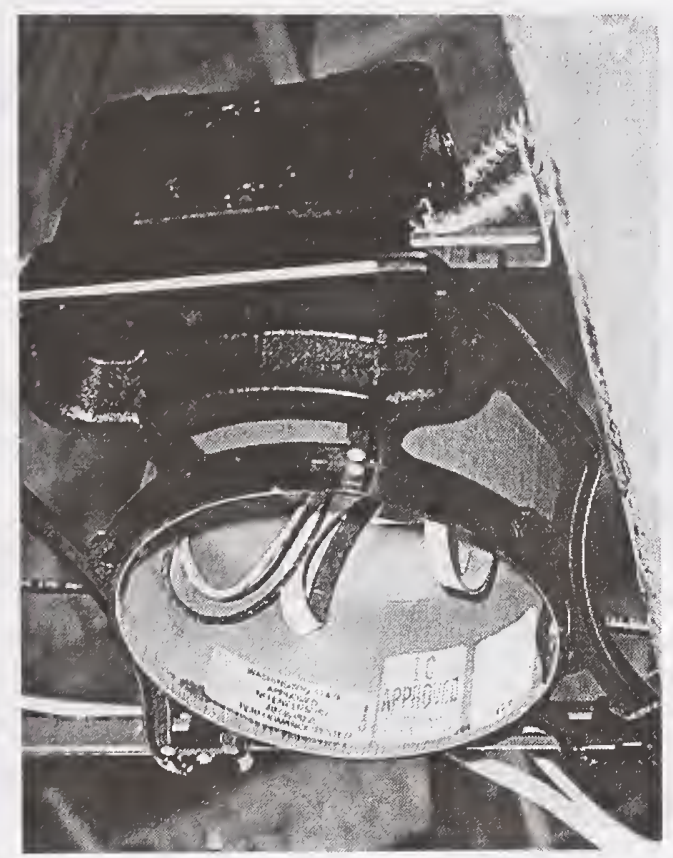

The gasket must be installed to obtain the required air tightness in the light fixture.

Figure 5: Air tight recessed ceiling lights. 




Foam wall insulation being applied.

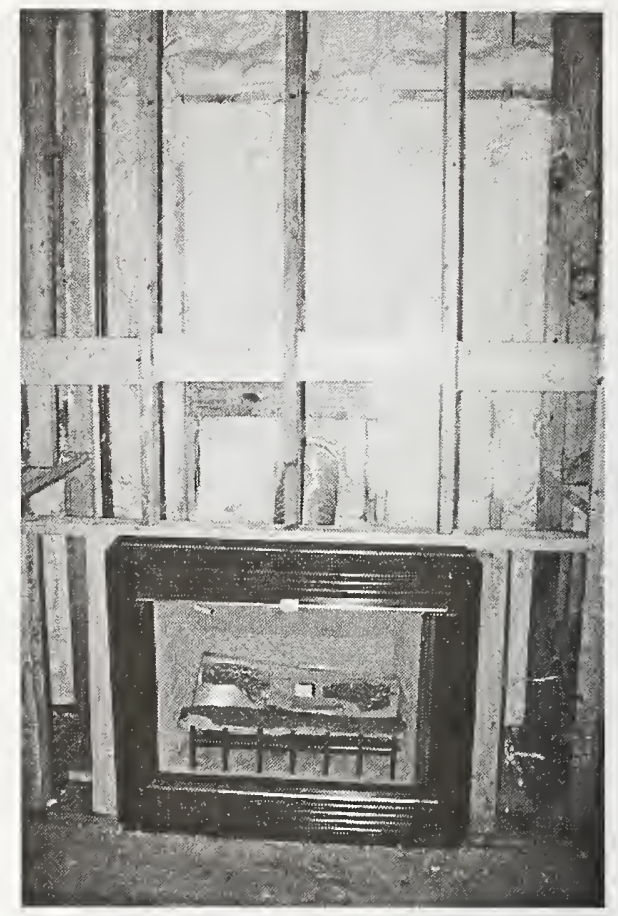

Foam insulation applied around the direct vent propane fireplace.

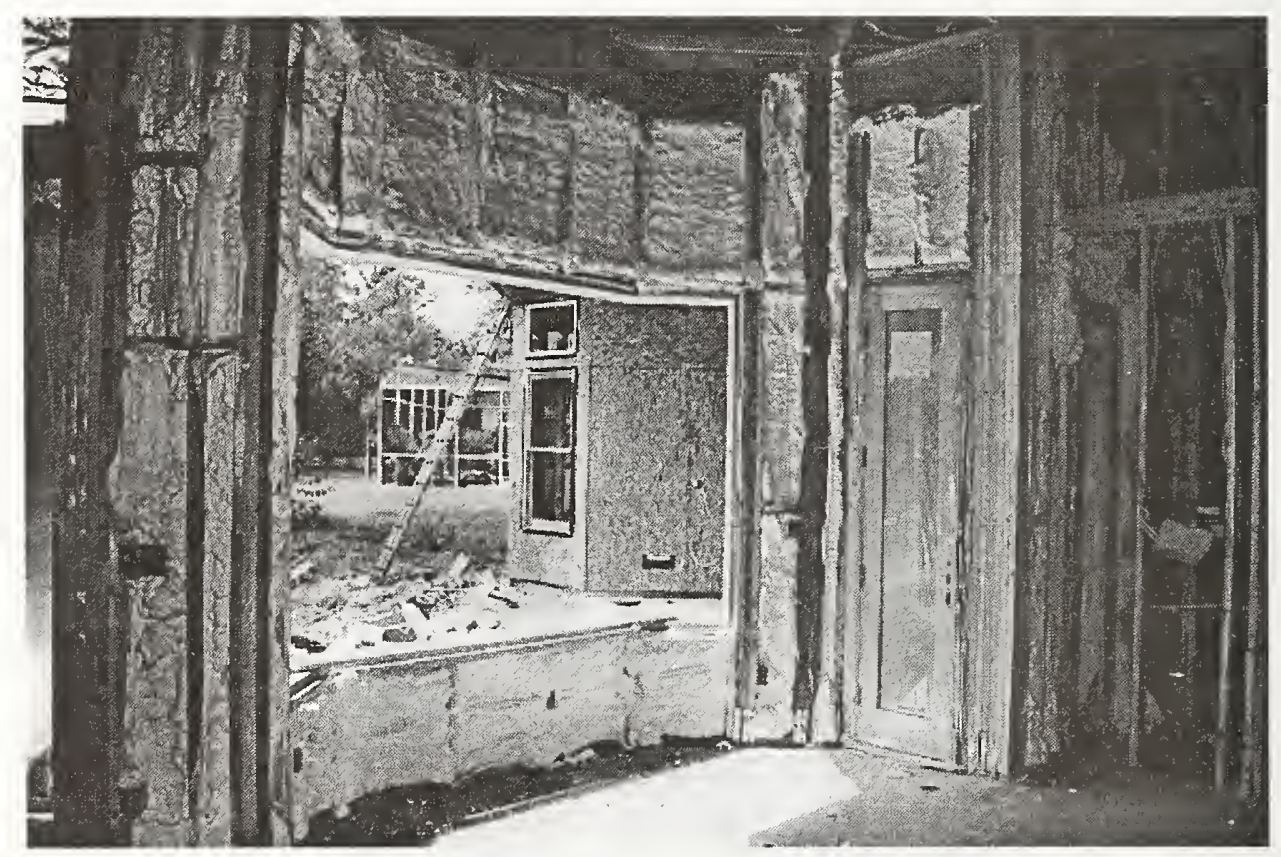

Foam is easy to apply in hard to insulate areas (Wall corners, window headers, etc.)

Figure 6: A foam insulation and air sealing system used in the Orlando Health House. 


\section{Figure 7: Schematic of Whole House Dehumidffier / Ventilator (DV)}

integrated with the Heating and Cooling System.



1. Ventilation timer operates the fresh air vent damper. When open, small fan in DV pulls in fresh air, mixes it with house air, filters it using DV filters, and distributes it to house using the return air ducts.

2. When dehumidistat is not satisilied, compressor and fan in DV turn on and provide dehumidifled wam air to the house.

3. When thermostat calls for heat or cool the heat pump and blower tum on to independantly control temperature. Air from DV unit (if DV is also on) is sucked in and distributed through the supply air ducts. 


\title{
Interoperable, Life-cycle Tools for Assuring Building Performance:
}

An Overview of a New Commercial Building Initiative

\author{
Stephen Selkowitz \\ Building Technologies Program \\ Energy and Environment Division \\ Ernest Orlando Lawrence Berkeley National Laboratory \\ 1 Cyclotron Road \\ Berkeley, CA 94720
}

Abstract. A key impediment to improving the energy efficiency and reducing the environmental impact of buildings is the complexity and cost of managing information over the life cycle of a building. A surprisingly large fraction of the total cost of buildings is embodied in the decision making and information management process due to the nature of the building industry itself, the numerous people and companies involved in the process, the current nature of the building acquisition process, and the long time periods over which buildings operate once design and construction are completed. We suggest that new interoperable software tools could greatly facilitate and rationalize this complex process, thereby reducing time and cost, and greatly improving the habitability and environmental impact of these buildings. We describe a series of projects in which we are building and testing several prototype toolkits as part of a building lifecycle information system that will allow interoperable software tools to function more effectively throughout the design, construction, commissioning, and operations phases.

\section{Background}

Virtually every decision made over the life cycle of a building has environmental consequences of both a short and long term nature. The creation of sustainable buildings requires that thought and care has gone into a wide range of performance issues and impacts on a local, regional, national and even global scale. Many consequences of creating a building are immediate and "visible," but some are more subtle or complex in the way they manifest themselves to designers and owners. Although the occupants, or society at large, may ultimately experience these effects, these groups typically have almost no direct input to the building planning, design, and construction process and often not much more once the building is occupied. Building design and operation is a business in which time and money are important. When the consequences of a decision are "invisible," little extra effort or resources will be spent on fine-tuning that decision.

A central challenge to the task of creating more sustainable buildings is thus to be able to bring all the information needed to assess the consequences of numerous decisions to the attention of the appropriate decision makers in a timely, cost effective, and practical way. This is a challenge that begins when the client first considers constructing or renovating a building to meet a need, and continues over the life cycle of the building. As a prerequisite, it requires that people choose to create a sustainable design, and there are numerous cultural and educational obstacles to overcome in this regard. But assuming this can be done, if we are to have the required impact on a national scale, it must become easier, less risky, and more "practical" to design and create a 
sustainable living and working environment. This will require innovation and advances in both design process and in building technology. As we approach the beginning of the 21 st century, computers and the software infrastructure that supports their operation will almost certainly play a rapidly growing and critical enabling role in meeting these challenges.

Researchers at Lawrence Berkeley National Laboratory have been addressing many of the interrelated issues of sustainable design over the last 20 years, in partnership with industry, government, and professional societies. Since the US Department of Energy has been our primary client, energy use and energy-related impacts have been the focus of our work. Because energy use (extraction, conversion, transmission, and end use) is thought to be the single largest human activity with direct environmental impacts, much of our past and ongoing work has direct relevance to the challenge of creating sustainable buildings. Over the last three years we have made an explicit effort to refocus some of our efforts on the challenge of improving the design and operation of commercial buildings.

Despite significant advances in building technology and the promulgation of tighter building codes, commercial buildings consume about $15 \%$ of all energy used in the US at a cost of $\$ 85$ billion annually, half of which is wasted compared to what is achievable, with associated adverse environmental impacts. Assuring total building performance (which includes health, comfort, and productivity in addition to operating expense such as energy costs) is a priority in an increasingly competitive world. Achieving this goal requires a careful examination of the process by which buildings are designed, built, and operated. A life-cycle perspective on how information is managed in the building sector provides useful new insights and opportunities for achieving performance potentials.

To address these challenges we have launched the "Building Performance Assurance" project. Much of the initial proof-of-concept exploratory effort has been funded by internal R\&D funds at LBNL. Members of the Energy and Environment Division teamed with colleagues in the Information and Computer Sciences Division to pursue this initiative. The immediate goal of the project was to initiate the development and standardization of an interoperable set of tools that enhance building performance by facilitating information transfer throughout the building life cycle. These tools are individually optimized to respond to the specific needs of each phase of the building's life, but are linked by a shared information infrastructure, the Building Life-Cycle Information Systems (BLISS). Our overall project strategy was to develop workable, costeffective prototype solutions to assuring building performance as a springboard for creating building industry interest in these concepts and then developing future private sector partnerships to implement our complete vision.

Our initial effort has focused on the conceptual development of BLISS and the development of a series of prototype tools: a tool for capturing Design Intent, a Chiller Commissioning tool kit to assist in the process of verifying and documenting installed chiller performance, and a Performance Evaluation and Tracking Tool, which incorporates a chiller emulator and data visualization module. In this exploratory project we focused our efforts on chiller system performance, beginning in the design phase and extending through commissioning and operations. We are also using the other tools already under development, such as the Building Design Advisor. In order to ground the proof-of-concept in reality, all of the software models under 
development have been driven by measured data from Soda Hall, a newly occupied building on the U.C. Berkeley campus. As part of this project we have added additional instrumentation to the existing building energy management system and have tapped into these data streams (approx. one gigabyte per month) as needed by our software tools. In addition to the tool development efforts, we have created a computer-based mockup and videotape that demonstrates key elements of our entire BLISS vision and have held a series of meetings with utilities, manufacturers, building owners, and government agencies, all with prospective interests in the successful completion of this effort.

\section{Tool Development Projects}

A brief overview of each of these efforts is given below. More information can be obtained from the references and by contacting the author.

Building Life-Cycle Information Systems, BLISS. The goal of this effort is to create a software infrastructure that can be used for information sharing across disciplines and can be used to link interoperable software tools throughout the building life cycle. The project has three major elements: (1) to specify the distributed software architecture, (2) to build a life-cycle database, and (3) to develop a mechanism to capture and update "design intent" throughout the life cycle (see below). The distributed systems architecture describes how various building software components communicate and the database schema specifies the structure and semantics of the database. An initial version of this software will be built as an extension of the Building Design Advisor data model (see below). In order to be sure that our work is truly interoperable with industry efforts to create a standardized building model, we will make this software consistent with the evolving software specification from the International Alliance for Interoperability (IAI).

International Alliance for Interoperability, IAI. Only a small fraction of buildings are designed using computer-based energy simulation tools, such as DOE-2, in part because of the time and effort needed to enter descriptive and performance data. Much of this needed information already exists in other building design tools (e.g., CAD tools contain the required geometric data) but it is not readily accessible since there is no agreed upon procedure for sharing such information between tools. In the building industry, the goal of "interoperability" means concurrent access to project/building information and information sharing: a single building model that is shared by all participants in a building's design, construction, and use. Interoperability supplants the current sequential data exchange; information is no longer lost in the process. Data compatibility across applications and platforms is no longer an issue. Software users will benefit from enhanced communication among disciplines and across project teams, reduction of inconsistencies from decisions made by different disciplines, and direct links of CAD data to non-CAD applications. The industry will see major cost savings through more efficient information management, tracking of project/building decision-making, and the ability to add to previously made decisions. The benefits of an interoperable future are clear-the challenge is how to get there.

In the fall of 1994 LBNL joined 11 private sector companies, each a major force in the building industry, and formed an alliance whose goal was to bring interoperability to architecture, 
engineering, construction, and facilities management. A 10 month intense development effort culminated in the creation of a demonstration of the potential benefits of software interoperability at the AEC Systems Show in Atlanta in June, 1995. LBNL participated in the demonstration with the Building Design Advisor (BDA), DOE-2, and Radiance, which were simulated in use in a fully interoperable building design environment. After the demonstration, the private alliance of 12 companies was reorganized as the non-profit International Alliance for Interoperability (IAI), which now has 70 US members and 200 additional members in new chapters in Europe and Asia.

IAI's main task is to define, publish, and promote Industry Foundation Classes (IFCs). IFCs comprise a library of commonly defined software "objects" that depict building components, features, and events, and which can be shared by diverse applications throughout a project's/building's life cycle. All IFCs are to be defined by the IAI and are open; i.e., not owned by any vendor. They are to be implemented incrementally, and would continually evolve to meet industry needs. IAI has recently published version 1.0 of IFCs, which contains the reference object model definition (IFCs), IFC conformance criteria, IFC implementation guidelines, and specifications for model exchange requirements. 25 companies have committed to developing software that will be IFC compliant. Prototypes will be demonstrated in the fall of 1996 with initial products available in 1997. If IAI can successfully accomplish its goals and become a de facto new industry standard, it opens the possibility that all energy-related tools will be able to communicate and share information with each other, as well as with the CAD, cost estimation, and facilities management software that is at the heart of the building industry. This has the potential to significantly enhance the impact of energy and environmental tools on building design and operations.

\section{Goal of Industry Foundation Classes (IFC)}

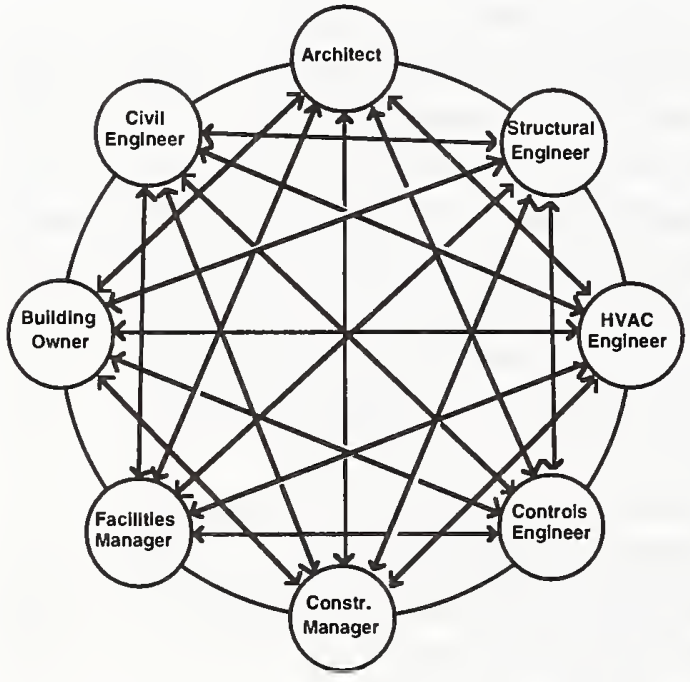

Now

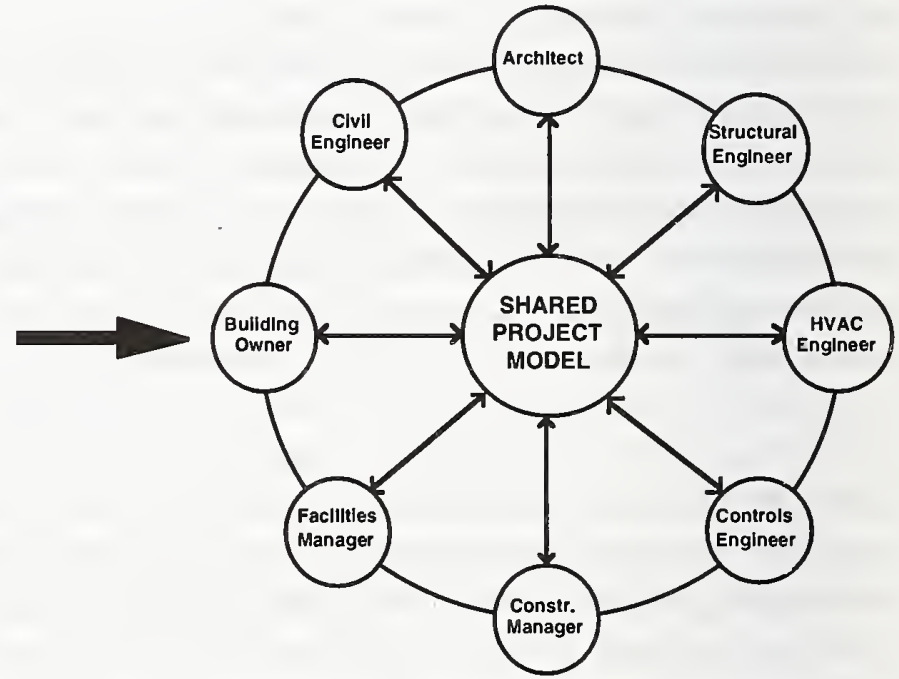

Future

Figure 1. Industry Foundation Classes (IFC) will allow the building profession to share a single project model, thus facilitating the use of interoperable tools. 
ALLIANCE

"PUBLIC"

IFC DEFINITION

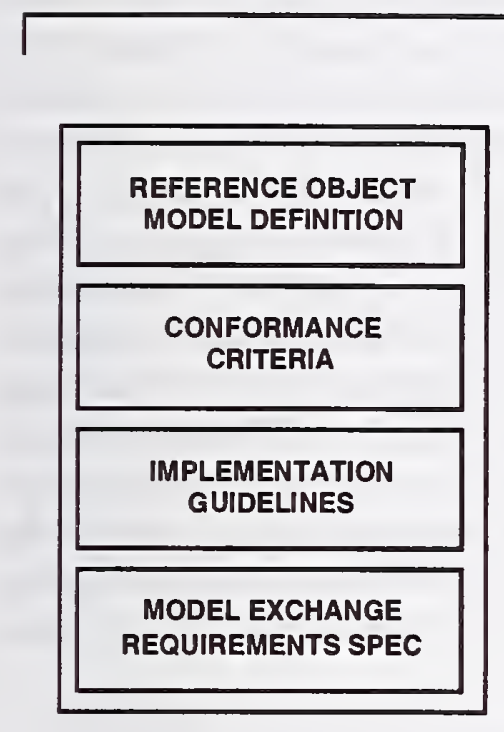

SOFTWARE VENDORS

"PROPRIETARY"

IFC IMPLEMENTATION

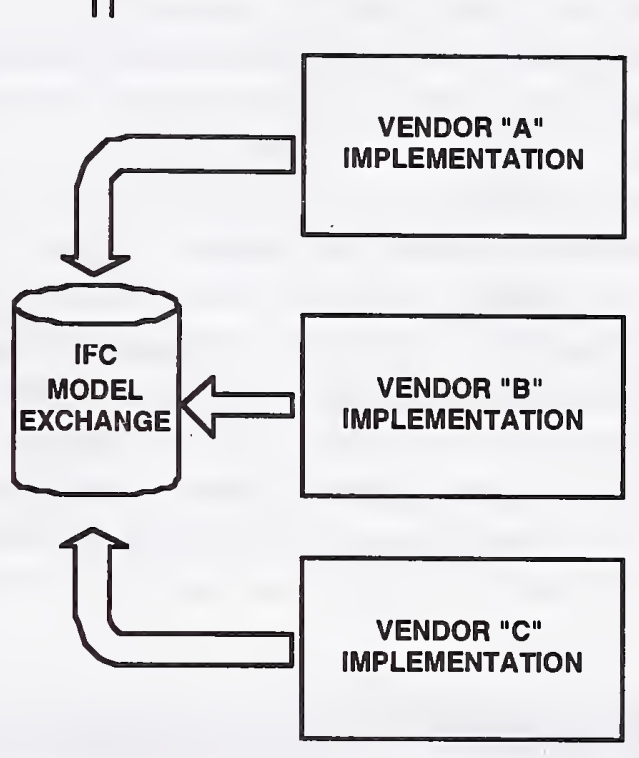

Figure 2. The framework for IFC is being developed by the IAI as a "public" activity. Individual software vendors will then implement IFC in their proprietary software.

Design Intent Tool. This software tool will assist in documenting design intent as expressed in a set of performance objectives that are initially generated during the early phases of design, but then revised and altered in both planned and unplanned ways over the building life cycle. The performance objectives can take the quantitative form of a performance metric with target values or the qualitative form of a text-based descriptive statement. The rationale behind the initial decisions and later alterations, which is typically lost, will be archived by the software for later retrieval as needed.

The design, construction, and operation of a building is a complex undertaking that spans many disciplines over long time durations. Although virtually every element of the building life cycle has become more complex over time, the building information management methods used to support and integrate the wide variety of project participants and their activities have not kept pace. In current practice, the bulk of building design-related information is still documented and communicated in the traditional forms of paper-based specifications and graphical drawings with text annotations. Much valuable information, in particular the intent behind the myriad design decisions made by all project participants, is altered or lost due to inadequate documentation and poor information management. 
We have been examining the issue of documenting design intent from a life-cycle perspective so that this information can be made accessible to all project participants throughout the life cycle to better assure that a building achieves the functional and operational needs of its owners and occupants. We have developed a formal methodology for identifying and documenting the required building-related information. We then developed a prototype of an early vision of a software tool for documenting design intent (1).

The prototype software assists in explicitly identifying and documenting the performance goals (explicit global objectives, EGOs). An individual EGO may take the quantitative form of a performance metric with its target value or the simple qualitative form of a text-based descriptive statement. We also specify Context Parameters which define the operating environment within which the building has been designed to achieve the stated explicit global objectives; e.g., the design day cooling load used to size an HVAC system chiller. A series of Design Rationale Records document the basis for design decisions in which building components, systems, and operation procedures are synthesized to achieve identified objectives under stated operating contexts. A single Building Design Version is thus comprised of a complete set of objectives, context parameters, design records, and other supporting information. The initial Building Design Version then changes over time to reflect life-cycle variations of a building, which can include alternative design solutions, the as-specified design that is sent out for construction bidding, the as-built building, the post-commissioned building, and the building at various stages in its ongoing operation. In the coming year this early prototype will be extended and tested using real building data sources.

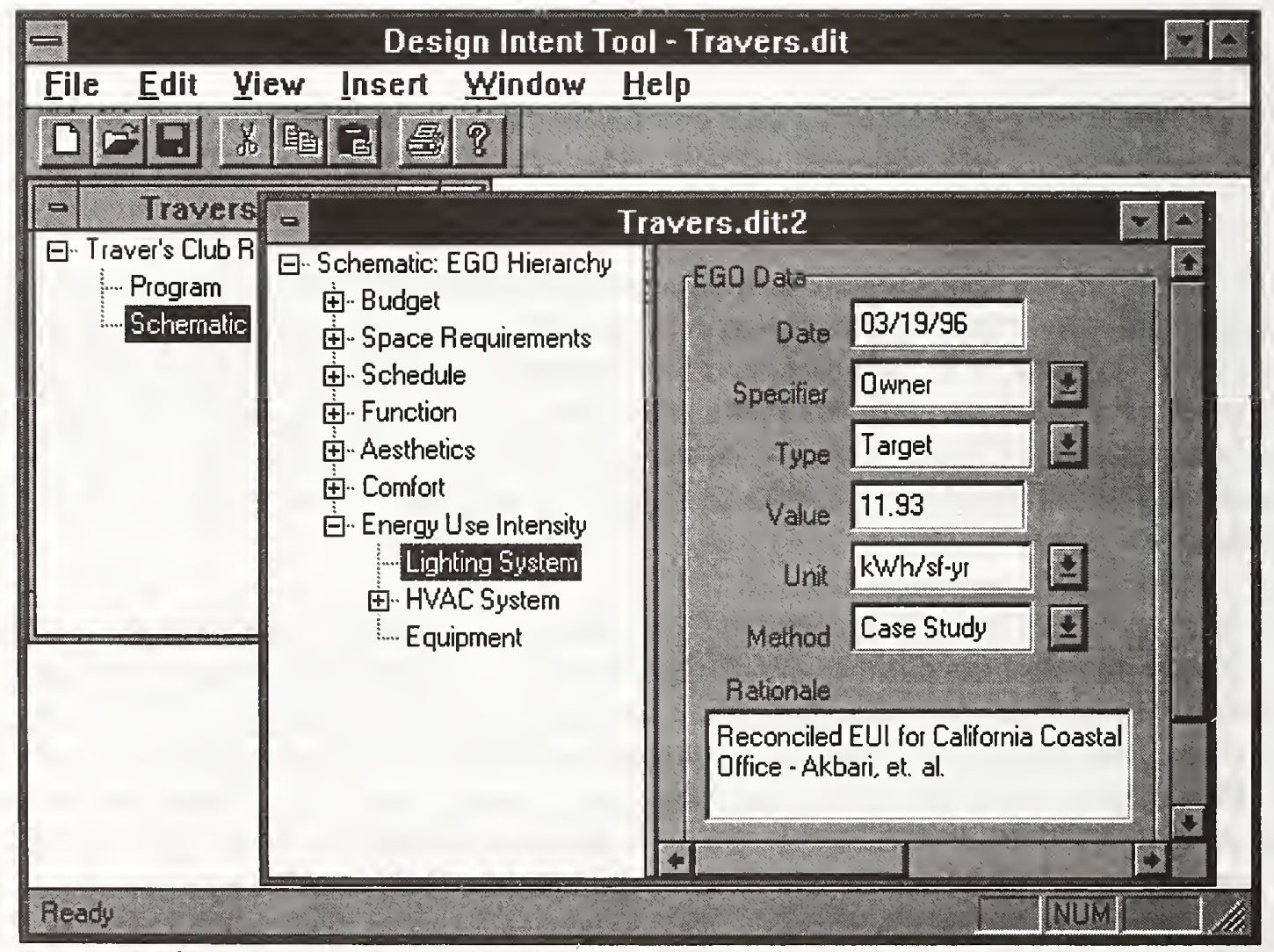

Figure 3. Screen image of Design Intent Tool objectives hierarchy. 
The Building Design Advisor (BDA) is a computer program that allows designers to quickly and effectively use multiple analysis and visualization tools and integrate their output to support informed multicriterion decision-making. The development of BDA started in FY94 with funding from the Pacific Gas \& Electric and Southern California Edison through the California Institute for Energy Efficiency, as well as the US Department of Energy. The objective of the BDA development efforts is to promote energy efficiency and environmental awareness in the design of new buildings, particularly in the schematic design phase, by providing means for decisionmakers to analyze and evaluate the potential performance of their designs. Unless energy and environmental benefits can be accurately predicted, along with other non-energy performance aspects-such as comfort, esthetics, and economics-most building designers will not risk the implementation of new energy efficiency strategies and technologies in their designs.

The currently available tools for accurate prediction of energy and environmental performance are very hard to use because they require preparation of complicated text files to describe the building and its context and provide output in the form of numerical tables that are hard to review and understand. Moreover, such tools use building modeling representations that are incompatible with each other and thus require multiple, specialized descriptions of the building and its context. As a result, such programs are generally used only by experienced consultants for large projects that can justify and support the high associated costs. Our initial goal is to move these decision-making capabilities to the architect's office early in the design process and to make its use cost-effective as viewed by designers.

To facilitate the integrated use of multiple analysis tools-such as DOE-2 for energy simulation, and RADIANCE for lighting analyses and photo-realistic rendering-BDA uses a real-world, object-oriented representation of the building and its context, mapped onto the specialized representations of the analytical models linked to it. In this way, BDA shields building designers from the modeling complexities of the individual analysis and visualization tools, allowing them to concentrate on design decisions. BDA allows the user to quickly specify the basic geometric attributes of spaces, windows, doors, etc. through a CAD-like Schematic Graphic Editor while it automatically assigns default values from a Prototypical Values Database to all non-geometric parameters required for energy and other analyses. The default values are assigned based on location, building type, and space type and can be reviewed and changed at any time using BDA's Browser. Using the Browser, the user can select any number of input and output (computed) parameters for display in BDA's Desktop for decision-making.

In addition to the Prototypical Values Database, BDA is linked to a multimedia Case Studies Database that allows building designers to compare their designs to existing buildings and create an appropriate, realistic context to set performance goals and evaluate performance. The Case Studies Database serves as an electronic magazine and supports the use of images, sound, and video for enhanced coverage of buildings.

The major development effort to create a working prototype of BDA began in 1995 and a beta version was released just after the end of the fiscal year. The release of version 1.0 should occur in late 1996. We have also started with initial development of new modules to extend the functionality of the tool to environmental issues, cost issues, and expect to make BDA compliant with IAI's object specifications. We are exploring the use of BDA as an educational tool, and 
examining how the internet might be used to support BDA development, distribution, and training (2).

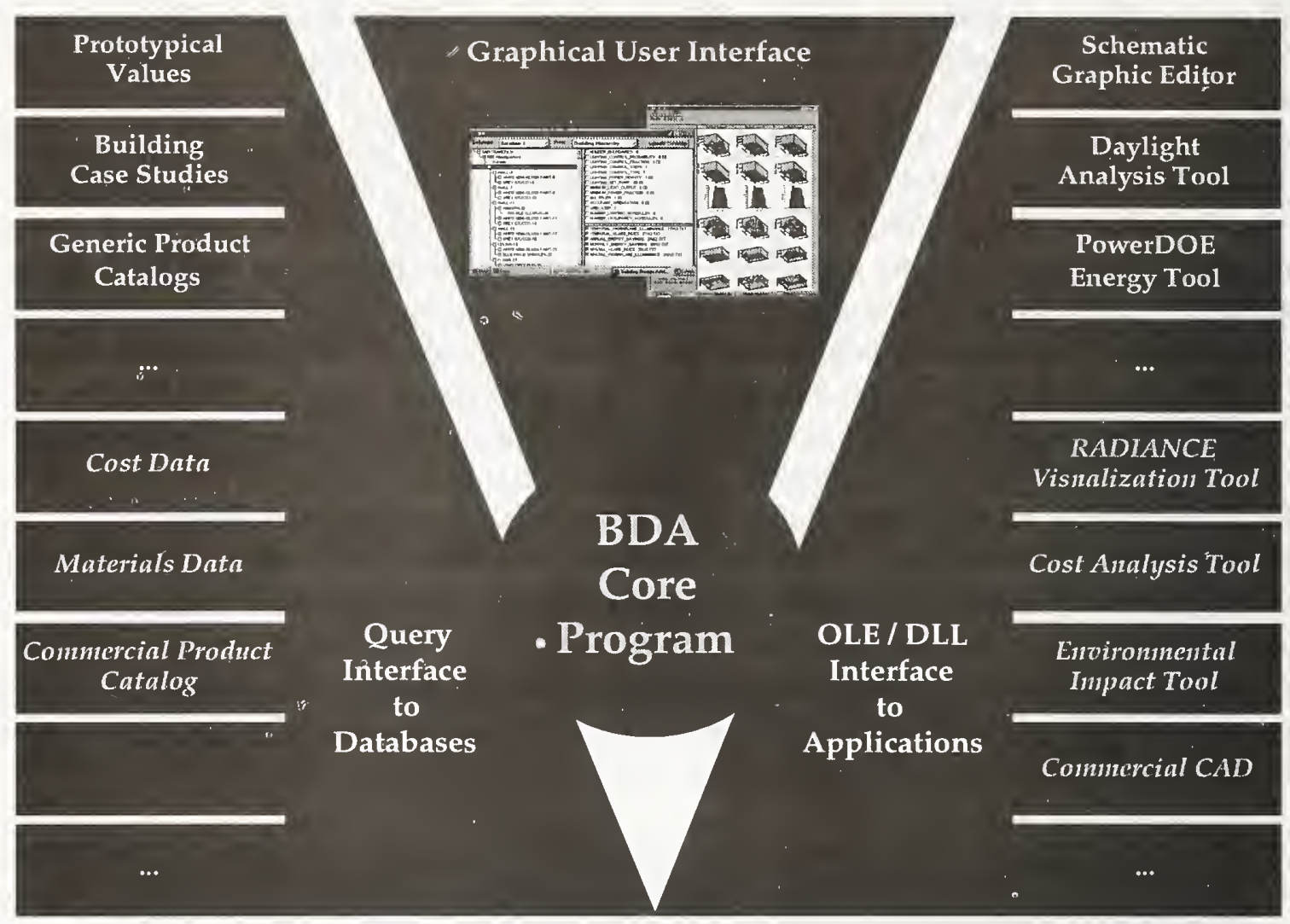

Figure 4. Schematic diagram showing the Building Design Advisor software environment.

Computerized Chiller Commissioning Tools. The focus in this project is to explore the general structure of commissioning tasks and their implementation, plus the development and testing of commissioning procedures for one specific component, chillers, in a new, well-instrumented building. Our prototype commissioning tool kit includes test procedures as well as software to assist in the commissioning of chillers. The software contains a component library and test plans, and it archives results from the commissioning tests.

Commissioning is a set of processes to ensure that building components and systems are installed and operated in an optimal fashion to meet or exceed design intent. Most buildings are not commissioned in a structured manner, resulting in significant problems such as defeated energyefficiency strategies, incomplete control sequences, and poor documentation on as-operated conditions. While recent LBNL analysis of the benefits of commissioning has shown it is often cost-effective on energy savings alone, efforts to reduce costs are needed to encourage more widespread use of commissioning processes and techniques (3).

Computer-based information technology is one approach to address the loss of information that occurs as a building moves from design to operations. We have developed a prototype chiller commissioning tool to assist in the development, customization, execution, and archiving of 
commissioning plans. Our initial efforts have focused on chiller commissioning, since chillers are the largest single energy-using component in buildings with central plants. The first step in applying the software is to describe the characteristics of the chiller components, such as chiller size, type, design efficiency, flow rates, and operating temperatures. The software contains a general description of chiller commissioning activities and a module to record specific test plan methods, customized for a particular building. Laptop computers can be used to track changes to test plans and collect data during plan execution. Test results are recorded and outstanding issues and deficiencies are tracked to ensure that the chiller is fully functional.

The procedures were tested on a 120,000 sq. ft. building on the U.C. campus. At the conclusion of the commissioning procedures we obtain an updated performance model of the as-built performance of the building, a model which is then used as the starting point to track building performance in the operations phase, using the performance tracking tool described below.

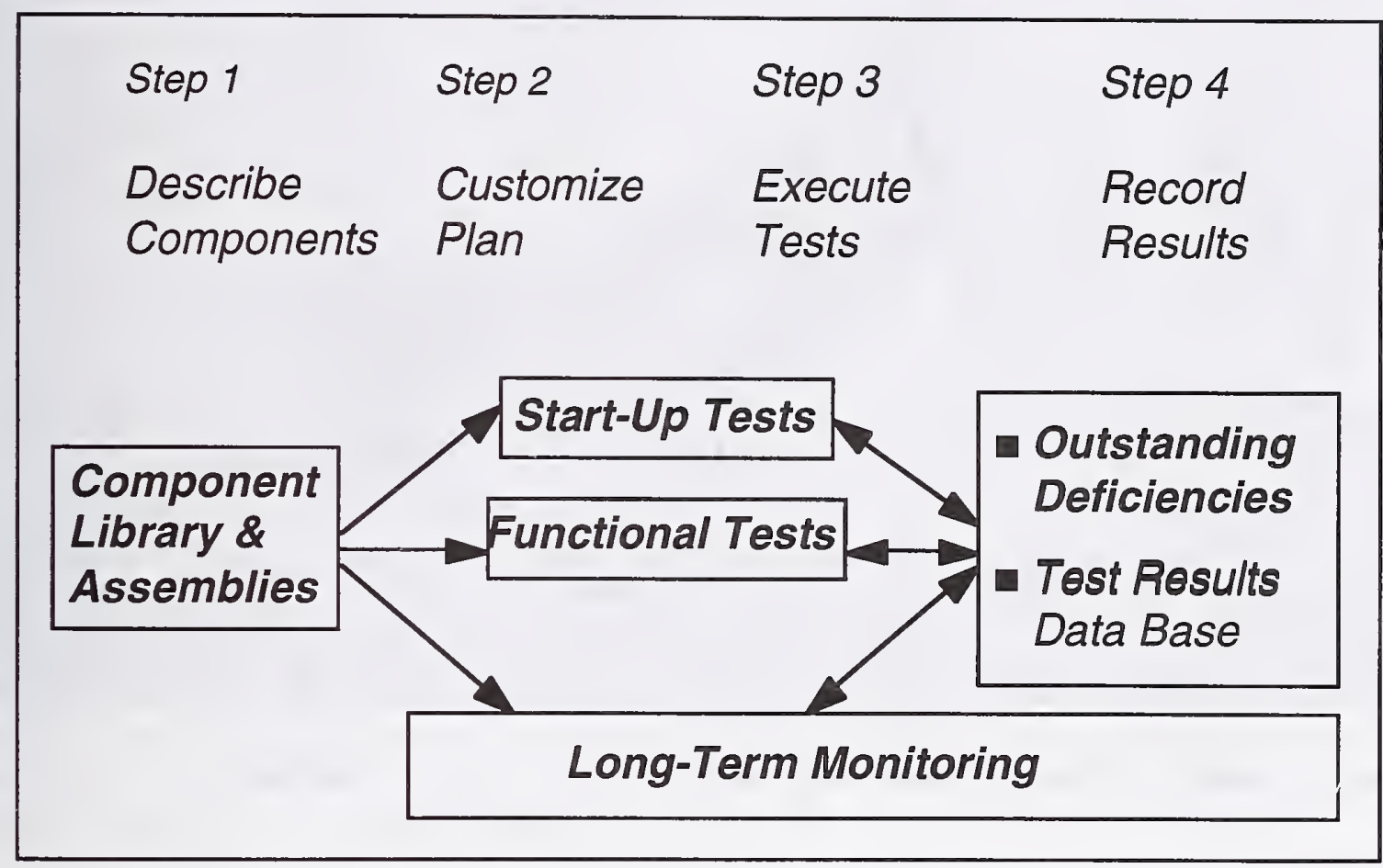

Figure 5. The four steps of commissioning and the use of a computer-based chiller commissioning tool.

Building Performance Evaluation and Tracking Tool, PETT. The focus of this project is the development and testing of performance tracking tools, again focusing on cooling plants. The bulk of the effort was in the development and calibration of a component-based SPARK HVAC simulation model of our case study building to evaluate chiller performance. This model in turn will be the starting point for a controls optimization and retrofit tool.

Measured HVAC time-series data are descriptive of the performance, but only under the strict boundary conditions that the building was exposed to during the monitoring (such as weather 
conditions during monitoring, the control strategies that were applied, etc.). When one wants to estimate performance under other possible conditions, measured time-series data of the past is of limited use. However, a dynamic model of the HVAC systems calibrated to monitored data can facilitate such estimations.

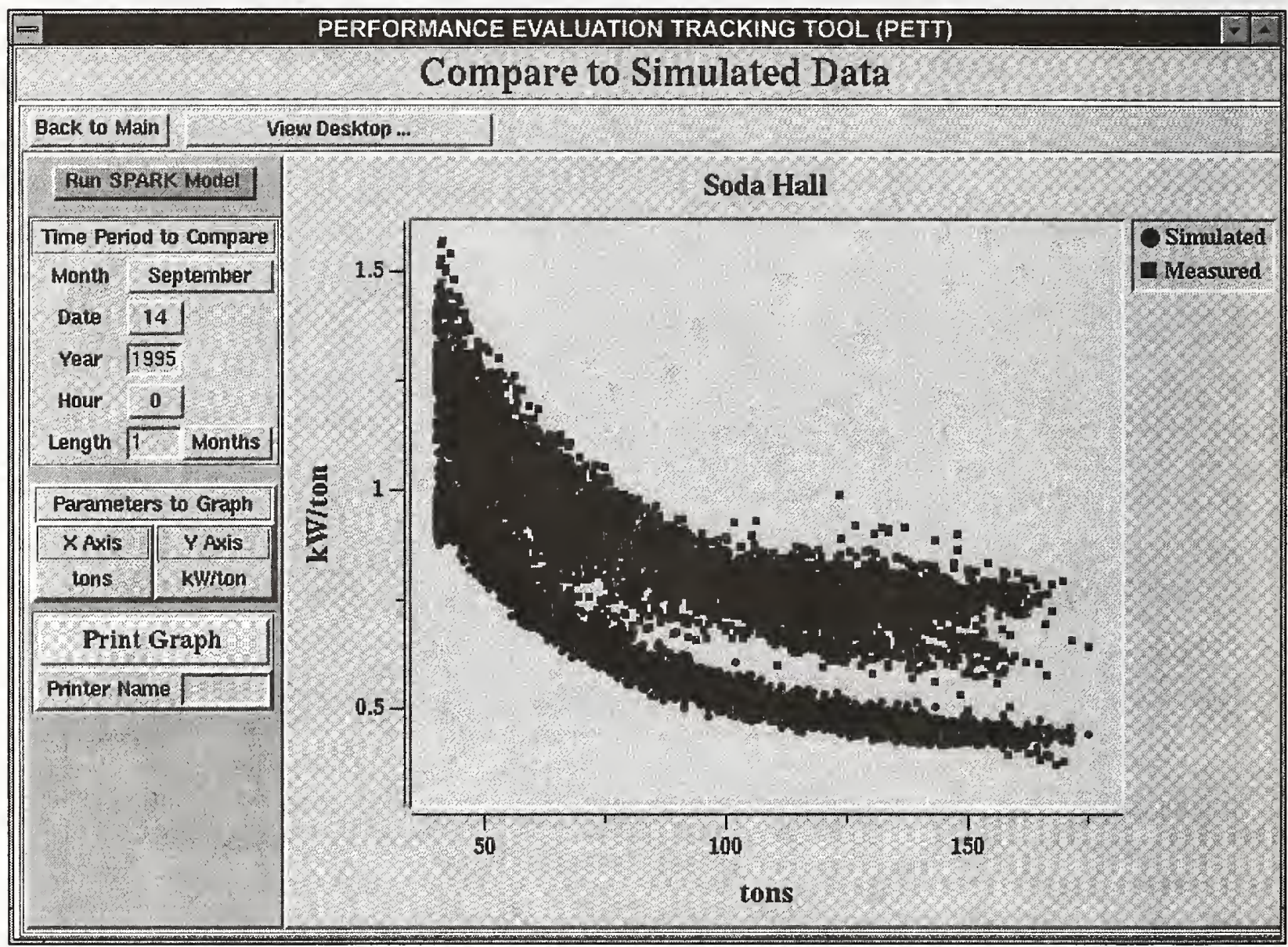

Figure 6. Measured and simulated data for the chillers of a case-study building.

A major objective during this phase of the project was to develop a prototype emulation tool using a dynamic model of the chiller system to track system performance in a testbed building and optimize chiller operations as required. We used the Simulation Problem Analysis Research Kernel (SPARK) to build our emulation model. SPARK is an object-based differential and algebraic equation solver that is well suited for detailed modeling of HVAC systems..

In our methodology, during the design phase, the HVAC model is built using the design documents and manufacturer-supplied data on equipment performance. If the building is still not built at this stage, it is possible to emulate several design options (such as different equipment sizes, efficiencies, etc.), compare the energy performance of these different options, and feed information back to the design process. 
During the commissioning phase, the SPARK model built using the design data is calibrated to represent the dynamic behavior of the system as it actually performs. After the acceptance of the building, time-series data on the HVAC variables are used to revise the SPARK model parameters. At this point, the emulation results and the real data from the building should be very close.

Using the performance tracking options, data from the building can be compared to benchmark data from other similar buildings, to historic data from the same building during other time periods, or most significantly to the emulated data using the SPARK HVAC model. Deviations of the building data from the simulated data may indicate problems in the HVAC system. At this stage, this project is not aimed at pinpointing the source of such problems. While this in not a diagnostics application, other related research projects are addressing those issues.

Options related to control strategy analysis facilitate changes to the control logic that is actually used during the measurement and comparison of the emulated results to the actual measured data. The environmental conditions and the building loads are maintained at the reported levels, but changes are made on the control choices, such as temperature set points or equipment status. Although at this stage, these control strategy analysis options serve as a "what-if" type of analysis facility, capabilities here can be expanded to include optimization. In such an application, the tool would return an optimal set of choices for all of the control options.

\section{Summary}

A series of projects are underway to provide a new set of tools that should make it far easier to create energy efficient, cost effective, sustainable buildings. A set of interoperable tools addresses key decision-making issues in design, commissioning and operations. The development of a Building Life-Cycle Information System, compliant with the emerging IAI specifications for describing buildings, is seen as key to successful linkage of a series of interoperable tools that are needed if sustainable buildings are to become the norm, rather than the exception. The initial tool development has been carried out in parallel with related tests and energy measurements in a near-by building, to validate the initial process and tools.

A number of private and public entities have expressed interest in this approach. We are developing partnerships to cost-share further development of these tool kits. We are interested in learning more about related efforts and exploring how such efforts might be integrated with this project.

Acknowledgment: This work was supported by the Assistant Secretary for Energy Efficiency and Renewable Energy, Office of Building Technology, State and Community Programs, Office of Building Systems of the U.S. Department of Energy under Contract No. DE-AC0376 SF00098. 


\section{References}

A video of the software mockup is available. In addition to the technical reports listed below, check our project web site for more information (http://eande.lbl.gov/BTP/BTP.html.

1. R. J. Hitchcock, "Improving Building Life-Cycle Information Management Through Documentation and Communication of Project Objectives," CIB Proceedings Publication 180, pp. 153-162. 1995. Lawrence Berkeley National Laboratory Report LBL-37602, August 1995.

2. K. Papamichael, F. C. Winkelmann, W. F. Buhl, H. Chauvet, D. Collins, K. L. Ellington, J. LaPorta, J. Sadlier, S. Selkowitz, J. Thorpe, T. Trzcinski, "New Tools for the Analysis and Design of Building Envelopes," Thermal Performance of the Exterior Envelopes of Buildings VI Conference Proceedings, December 4-8, 1995, Clearwater Beach, Florida. Lawrence Berkeley National Laboratory Report LBL-36281, October 1995.

3. M. A. Piette, B. Nordman, and S. Greenberg, "Commissioning of Energy-Efficiency Measures: Costs and Benefits for 16 Buildings," prepared for the Bonneville Power Administration, Lawrence Berkeley National Laboratory Report LBL-36448, November, 1994. 


\title{
DIGITAL PERSPECTIVES IN ARCHITECTURE
}

\author{
Mieczyslaw Boryslawski, Assoc. AIA, President \\ View By View, Inc. \\ San Francisco, California 94109 \\ Associate Member of the American Institute of Architects
}

In this century, the computer has furthered the development of human beings more than any other invention. It has helped the design profession to produce the unimaginable by consolidating insurmountable data available within the global village into tangible visual three dimensional images. The computer, in light of its capacity to produce intelligent $3 \mathrm{D}$ environments, can expand the designer's visual aptitude and ultimately prepare the design community for the next millenium. The explosion of hardware and software technology, combined with increased affordability, has created a new digital information explosion, that of 3D computerbased modeling, rendering and virtual explorations of proposed designs.

\section{Introduction}

More and more, we are beginning to give greater consideration to the ways in wich we do things. We have made some serious mistakes in " world building" and we can't afford any more. Certain things which once seemed so desirable now appear down right dangerous and discomforting. The automobile is one of the best examples. Not long ago more than eighty percent of the population was rural, coming into town to do Saturday shopping. Now eighty percent of the population lives in the city. Streets designed to accommodate the horse and buggy have now become gridlocked and the number of automobiles has increased beyond anyones wildest speculation.

We are now alerted to the fact that our human species is in need of conservation and that in order to save our own place in the world we need to save all others as well. We seem to be the only species whose role consists in defining ourselves. We spend our lives defining and redefining our place in nature

Today's high-tech tools allow ever increasing facility in this learning process. We are achieving a new perspective of existence, a world view perhaps no broader that that of previous cultures, but much more detailed. Our Architecture is being redefined by the tools we use. Objects creation is no longer a barrier. The question "WHY?" is now more important than the question "HOW?". We can now create visions of spaces and places so exact as to appear real. Shadows are cast precisely as they would be from the real object. Colors and textures are taken from the objects themselves, there are even devices which take advantage of the stereoscopic nature of our vision.

What do these new abilities portend? Frank Lloyd wright, in facing the challenges of the industrial age propounded a number of answers which are perhaps even more valid today. He said, "I do not believe any architecture in the time of commercialism, of industrialism and of huge organization can be an architecture true to the spirit of those times unless it includes the use of all these great tools of modern life." 
By substituting the word "machine" with the word "computer" the following statement is quite relevant today.

Mr. Wright went on to say: "In this day and generation we must recognize that this transforming force whose outward sign and symbol is the thing of brass and steel we call a computer, is now grown to the point that the artist must take it up, no longer to protest. Genius must dominate the work of the computer age. We cannot set it aside, although there is involved an adjustment to cherished goals, perplexing and painful in the extreme, and though the fires of longhonored ideals shall go down to ashes, they will reappear Phoenix-like, with new life and purposes."

This would seem to indicate that Mr. Wright foresaw an inevitable step in technology which has not yet taken place and which only computerization can accommodate.

The use of the computer puts us on a new frontier, as we begin to publish rather than draw documents, we also begin to feel the need for a new level of information service, something more akin to API or UPI or RUETERS. Imagine accumulated knowledge and experience at your finger tips the next time you design a building. Perhaps the days of designing a single building irrespective of the environment is at an end. Perhaps hard copy presentation will soon take a backseat to three dimensional simulation. We will no longer be focusing our intelectual energy on the overall design process of the buildings but also on the global environmental impact that such design practice might have.

Digital technology has become the infrastructure of the Internet Revolution which is one of the most important significant technological achievements of this century. I personaly believe that in the short term this technology will have a negative impact on our social fabric but over the long run it will save our already fragile environment and will enrich the lives of all the children on this planet.

Help is now available on the Internet for architects and builders that need information on sustainable architecture and good environmental practice. All it remains is to embrace this technology for the good of this planet. 
Mieczyslaw Boryslawski, Assoc. AIA.

President and Founder of View By View Inc. was born in Poland, educated in Europe, Africa and the US in architecture, film, photography and construction project management.

He holds a degree in construction project management from the school of architecture, University of Cape Town, South Africa, and is a adjunct professor at the California College of Arts and Crafts, School of Architecture, teaching the state of the art in 3D digital architecture. Boryslawski was involved in international architectural competitions on three continents, was a guest speaker on digital architecture at the Smithsonian Institute, Washington DC., Global Engineering Conference, Vancouver, BC. Canada and at the International Outdoor Advertising Conference, Los Angeles as well as other major events.

In 1992, Boryslawski together with the AIAS, initiated an international student design competition and was selected as one of the jurors. This competition was the first digital architectural competition of its kind in the world. Boryslawski was one of the main sponsors of a five day conference focusing on the digital technology in an architectural environment held at the Frank Lloyd Wright Institute's Taliesin West.

His digital work is permanently on display at the Old Executive Building, The White House, Washington D.C. and is being exhibited around the world.

Boryslawski together with CREST produced the "Greening of The White House" CD-ROM, a environmental project funded by the department of Energy.

Currently he is working on a virtual tour CD-ROM that will represent the entire architectural history of the White House.

Boryslawski received an Award of Excellence in the International Competition and Exhibition from The American Society of Architectural Perspectivists.

His work has received considerable attention in the international and local press, including TV coverage. 



\title{
THE NARM SUSTAINABILITY MODEL: DYNAMIC AIDS FOR ECOLOGICAL DESIGN AND SUSTAINABLE COMMUNITIES
}

\author{
David A. Tice, President \\ North American Resource Management, Inc. \\ P.O. Box 6777 \\ Charlottesville, VA 22906
}

Abstract. North American Resource Management, Inc. (NARM) has developed sustainability extensions to dynamic input-output models to provide comprehensive tools for local communities and sustainable development projects. These tools enable communities, developers and planners to:

(a) estimate the flow of resources and dollars between interdependent economic sectors and into and out of the region, to assess community self-sufficiency, economic "leaks", development opportunities and other aspects of sustainable development; and

(b) measure the full extent - the direct, indirect and the induced economic as well as environmental impacts of new sustainable development projects or other economic changes in a region.

The NARM Sustainability Model is a set of extensions to IMPLAN to assist planners and designers in several areas of sustainability, industrial ecology and ecological design:

- Tracing the Ecological Footprint - the NARM model allows users to follow the economic and resource flows resulting from the product or service output of an economic sector, to track the total direct, indirect and induced footprints.

- Sustainable Economic Development - the NARM model identifies the portions of a study regions's economic resources that currently leave the region and opportunities to "plug the leaks" to build local economies through energy and other resource conservation and efficiency measures.

- Closing the Loops ("Waste Equals Food") - the NARM extensions to IMPLAN estimate the emissions, wastes and byproducts ocurring from the output of a particular sector, including the direct, indirect and induced effects of the output. This information is critical for evaluating environmental impacts, developing mitigation strategies and planning for industrial ecology approaches such as zero emissions industrial centers.

- Impact of Sustainable Economic Development - closely related to traditional input-output analysis, the NARM model adds features to enable planners to estimate the total economic and environmental impact of the development of sustainable economic outputs. 
- The Missing Link of Sustainable/Ecological Design - the NARM model fills the gaps in most studies of life cycle analysis (LCA), sustainable architecture and ecological design, by enabling planners to evaluate the induced effects, including both economic and environmental parameters.

\section{Sustainability and Industrial Ecology: The Missing Link}

Communities, states and nations, as well as many private businesses, are expressing growing interest in concepts of sustainable development. Sustainable design, though, as it has been typically defined to-date, omits one element of the equation and, consequently, may not give the totally correct answer. Under current definitions, sustainable design, even if carried out to the letter on a specific project, would miss significant ecological influences and impacts. The largest of the omissions comes from failure to consider the economic transactions as they are distributed by a project, including households. These effects, as integrally wedded to the project as the building materials and energy demands directly attributable to the project, will vary, but can typically range in extent from $50 \%$ to $300 \%$ as great as the direct and indirect effects themselves.

To examine the nature of this missing link, one should start by considering the recent definitions of sustainable architecture. Ken Yeang (1), for example, establishes a framework for ecological design that includes the designed system, its environment and the interactions between the two. He finds that "the designed system requires continuous inputs of energy and materials, and makes outputs of energy and materials into its environment."

The American Institute of Architects (2) workshop on "Sustainable Development and Public Sector Architecture" defined that:

A sustainable architecture must be usable by all people and appropriate in terms of scale, use, cost, materials, and technologies. There should be no depletion of renewable resources caused by the choice, provision, and use of materials.... Sustainable buildings should be healthy, require little energy and maintenance, and not add significantly to existing or future waste streams.

The Green Building Council (3) concerns itself with improving environmental and energy efficiency of the "whole building environment", defined as "site development, the things that go into planning for buildings, wastewater treatment, water use, construction design, planning and operation of the building, and the use of building materials."

Embodied in these definitions is the related emerging field of industrial ecology. According to Hardin Tibbs (4), industrial ecology "involves designing industrial infrastructures as if they were a series of interlocking man-made ecosystems interfacing with the natural global ecosystem." Robert Ayres (5), a key advocate of industrial metabolism, limits its definition to "material flows in a modern economy."

Most sustainable design projects, however, fail to take into account the total flows and processes, 
particularly the induced economic effects: the impacts created by the distribution of financial transactions attributable to the project as they move through the economy, locally, nationally and globally. Yet, there are now valuable tools for estimating induced impacts - tools that can identify cost-saving opportunities to achieve sustainability goals.

\section{Moving beyond thinking in terms of two-dimensional circular systems}

Sustainable design correctly moves the discussion of processes from the linear (acquire-use-waste) system to a two-dimensional circular system, where waste becomes food for the same or other processes. Much of the effort has focused on life cycle analysis, reduction of embodied energy, the sustainable management of raw materials such as forest resources and related techniques. This effort is a major advancement in the development of sustainable systems.

Ecological systems are more than two-dimensional circular systems. If we are truly going to model our built environment and our industrial processes on sustainable ecosystem principles, we need to look at the project ecology in three dimensions.

The third dimension requires encapsulating the circular process flows to include all of the indirect and induced flows of materials, services, and payments that are attributable to the direct activities of the project. Input-output $(\mathrm{I} / \mathrm{O})$ analysis offers a framework by which these impacts can begin to be understood, including identification of opportunities for developing a sustainable program.

Key to this analysis is the recognition that a given project triggers, in both the construction and operation stages, significant household expenditures for both products and services, which, in turn, have environmental impact. Omission of consideration of sustainability issues surrounding household purchases of products and services can be a substantial gap in achieving full sustainability for a project. The broader implication is that the financial flows, perhaps best examined in an I/O analysis, are as critical to a sustainability program as the product flows. If one only looks, for example, at the issue of obtaining lumber from a site in which sustainable forestry is practiced and by which embodied energy and related demands are minimized, an enormous part of the puzzle is overlooked:

A. The indirect flows of materials required in the extraction, manufacturing, transportation, construction, operation and disposal of the lumber;

B. The financial flows through the various economic sectors as the expenditure for lumber triggers a watershed of financial transactions for other goods and services, each of which has its own environmental impact and sustainability concerns;

C. As the original transaction for lumber translates into personal income among dozens, hundreds, or thousands of households, the manner in which that income is subsequently spent on goods and services is as much a part of the environmental impact of the proposed project as the cutting of the trees that directly yield the lumber. 
Picture a new project. It can of any type, but, for the sake of example, let's say that it is a retail store. The store owner comes to an architect and requests a design based on the principles of sustainability. The architect assembles a team which follows the definitions stated above perfectly, so perfectly in fact that they have succeeded in being able to take the store off the grid - it will actually be a net exporter of electricity which it can sell to the local power company, offsetting the embodied energy and indirect energy demands that were calculated by the design team for the building materials and construction processes. Consequently, by their calculations, there will be no net increase in energy demands as a result of the project.

Similarly, the site plan relies on infiltration devices and constructed wetlands for stormwater management. The store even has a cistern to capture rainwater from the roofs and re-use the water for irrigating the native species landscaping around the building. The stormwater system is designed so that the runoff from the site will mimic the natural hydrologic regime for the area, with no increase in peak flows or deterioration of water quality. By tracking the extraction and processing of building materials, the team has also been able to assure the owners that no significant water quality deterioration will occur from the construction phase of the project.

State-of-the-art water flow equipment is used within the store so that potable water demand will only be a fraction of what would occur from conventional store design. And so on, for all of the important potential environmental impacts of the store - the team has developed a plan to minimize the adverse direct and indirect impacts, creating cyclical systems which eliminate waste, achieving zero emissions for nearly all environmental parameters.

The store opens. One year later, the owner reconvenes the design team. Seated at the table with the design team are representatives of the power company, environmental agencies and scientists who have been monitoring the environmental parameters in the region around the store. In this fictional story, the opening of this store is the only thing that has changed in this region in the past year. Yet, when the scientists present their findings, instead of there being no net effect on power demands, there has been a significant increase in energy usage. The water plant operator reports that water usage is higher than the design team forecast. The state division of soil and water conservation reports that they identified non-point stormwater runoff to be the source of significantly higher nitrogen and phosphorus loadings in the streamflow than what had been occurring before the store was built. The air quality board reports that emissions from automobiles, despite the implemented plans of the design team, far exceed the team's impact estimates at the time of project approval. "What happened?", the owner demands to know. "All the monitoring systems that we have in place at the store show that the design features are working at least as well as planned. We monitored the indirect impacts; where is the excess coming from?"

\section{Follow the money}

The design team did a perfect job in designing a zero emissions system, but left out one whole part of the equation. They considered the flow of all of the resources in and out of the project, through its life cycle, except one: money. The business employs $\mathrm{x}$ number of people, supporting households 
who, in turn, demand electricity, use water, affect stormwater runoff at their homes, drive automobiles, and use the income they receive from the plant to purchase other goods and services that have respective environmental impacts. The plant itself pays other suppliers which utilize a portion of those funds to pay their employees and support households, with cumulative environmental impacts. The business, as well as all of its employees and suppliers (and their employees and suppliers), transfers significant financial resources to local, state and federal governments in the form of taxes, which are in turn used to support schools and other public facilities with attendant environmental impacts. The cumulative effect of all of these induced impacts as a result of the distribution of funds from the transactions triggered by the plant throughout its life cycle can be enormous, in some cases dwarfing the direct and indirect effects of the plant itself.

\section{Removing an industry}

Another way to look at the significance of the induced effects from the economic activity attributable to a project is to examine what happens to environmental parameters as a result of a plant closing in an area. Let's say that in the town of Designville, the owners of the large bakery decide to close the store. No business of any type has stepped in to replace it. Look at air emissions in the area - add up the drop in air emissions from the bakery (the direct effects), from the reduced production of the bakery's suppliers and from the reduced traffic (the indirect effects) that may result. Add in any other air quality benefits that can be determined using the sustainable design, industrial ecology and life cycle analysis definitions commonly reported today. They-still fall short of the actual drop in emissions because they fail to take into account the induced economic effects of the plant closing - the reductions attributable to reduced household incomes and expenditures due to the loss of economic activity by the bakery.

Water usage has similarly fallen more than what can be directly or indirectly attributed to the plant. Energy use experiences far greater drop in demand. And so on. The answer, of course, is that the induced economic effects of the plant's closing are responsible. The plant no longer supports as many households and other entities financially. Thus, the households and entities cut their own consumption of resources and modify environmental impacts far greater than what can be accounted for by the direct and indirect effects alone. Of course, one can argue, correctly, that oftentimes such a reduction in income may force households or individuals to engage in more environmentallydestructive behavior rather than less, but that ignores the point of this example.

\section{Drawing from one's own effects}

One can easily see the impact of this from his or her own personal experience. My household is either partially or wholly supported by my employer. The net environmental impact of the activity of the employer, then, must take into account the respective environmental impact of my household, because, absent the employer, either my household would not be here and there would not be that impact or I would be working for a different employer for whom my impact would be attributable. 
Seen in a slightly different way, if my services were replaced by a machine, it is easy to see how the life cycle effects of that machine are a part of the environmental impact of the plant. But, if the plant elects to spend its financial resources on my human services rather than a machine, the impact of my activities on the environment are just as much a real impact attributable to the plant as that of the machine. As Gregg Easterbrook (6) might put it, nature doesn't care whether the molecules modifying the environment come from a machine or from me - it's still an impact. Yet current sustainable design projects generally ignore these induced economic effects.

To the three dimensions we should add a fourth, to incorporate the dynamics of change brought by time. The sustainability concerns of the initial projects have largely treated the earth's resources as they exist at a static point in time. It is dangerous to base sustainable design for projects that may have dozens or hundreds or indefinite years of lifespan, based on a static interpretation of the natural system that we have at this instant. Without even considering anthropogenic impacts on future natural systems, those systems are so dynamic that it is virtually guaranteed that the environmental influences of a particular project built today will be significantly different when it is $20,40,60$ and more years of age. Consequently, the processes that we develop for assuring the sustainability of a project itself must be dynamic, to adjust to changes in the natural systems, changes in the inputoutput elements of the economy of which the project is a part, changes in our understanding of both the natural and economic systems, as well as changes in technology.

\section{The NARM Sustainability Model}

While the dynamic economic flows rippling through the region and the globe may appear too complicated to evaluate, they are real nonetheless, and any exercise in sustainable design which ignores it will fail to achieve true sustainability. One cannot leave out such a large element of an equation and expect to find the right answer.

Fortunately, there are some emerging tools to simplify the process of including induced effects in sustainability considerations. The NARM sustainability model, being developed by North American Resource Management, utilizes economic input-output modeling to examine the direct, indirect and induced effects of a project through hundreds of economic sectors, locally as well as globally. The model consists of "sustainability extensions" to the IMPLAN input-output database, providing resolution at a county or city-level or any larger region. As briefly described by Clark, et al (7), this system is being developed as part of the Haymount project, a new sustainable community along the Rappahannock River in Virginia.

\section{The IMPLAN Model}

The complexity of the web of economic activity created by even a simple change in final demand is often beyond the perceptual capacity of individuals - multiply this simple change by the thousands of transactions involved in an industrial design or sustainable community and the task seems overwhelming indeed. Fortunately, systematic analytical techniques are available to make meaningful assessment of the multiplier effects within the region of study, as well as between the 
region and the rest of the country and between the region and the rest of the world.

One of the most rigorous methods of determining the multiplier effect is by I-O analysis, originally conceived by Wassily Leontief in the 1940's, for which he received a Nobel Prize in 1973. Leontief devised I-O analysis as "a practical extension of the classical theory of general interdependence which views the whole economy ... as a single system and sets out to interpret all of its functions in terms of the specific measurable properties of its structure." Leontief's input-output analysis has become a standard tool in economic accounting around the world.

Input-output analysis was developed to analyze the distribution of materials and transactions among the industries and other sectors of an economy. It is one of the best methods for capturing the secondary and induced effects of a change upon a regional economy.

The IMPLAN (Impact Analysis for Planning) model was originally developed by the USDA Forest Service to estimate the regional economic impacts of National Forest management plans. Further developed by the University of Minnesota and, more recently, private firms, IMPLAN has evolved into a powerful comprehensive input-output model for analysis of nearly any form of economic change or interaction between industrial sectors. The model is based upon a national matrix describing the interrelationships between 528 economic sectors in any particular economy. IMPLAN uses county specific data to produce input-output models on a regional or local scale as small as one county or any aggregation of counties within the U.S.

Input-output tables offer numerous mechanisms to view the interlocking connections between economic sectors in a region and related measures that can be useful in analyzing the sustainability of a region or in developing a program to foster development shaped by ecology.

IMPLAN can provide a holistic estimate of the total benefit of local sustainable development efforts, including the direct and induced changes to income and employment in up to 528 economic sectors. It is, thus, a more comprehensive measure of the economic impact of sustainability projects than reliance on direct impacts alone.

The analytical component of input-output models involves algebraic processing of data organized in the form of matrices. Each matrix contains entries that represent the amount input or output by one economic sector to another. In the "Use" matrix, for example, the rows of the matrix define commodities and the columns define the industries or economic sectors of a region. The data cells of the "Use" matrix, then, represent the amount of that row's commodity that is "used" (input) by that column's industry or economic sector. Similarly, the "Make" matrix contains datacells that represent the amount of that commodity "made" (output) by that industry. Other matrices define the byproducts, the interdependent transactions between the economic sectors and other measures of the structure of the regional economy. For example, the Transactions Table, the heart of an input-output analysis, estimates the flow of transactions, representing the industry-by-industry structure of a local economy. The regional transactions table defines the expenditures that each industry or economic sector makes when purchasing materials and other inputs from each of the other industries or economic sectors. 
In IMPLAN, households are included as an economic sector, to allow measurement of the induced effects. Household data is derived from estimates of Personal Consumption Expenditures, collected by the U.S. Department of Commerce.

Besides the regional data, IMPLAN also provides estimates of the imports and exports flowing through the region, also for each of the 528 commodity groups and 528 economic sectors. Exports are estimated in two categories - to the rest of the U.S. and to the rest of the world.

\section{Economic - Ecologic Integration}

The integration of economic I-O models with ecological models has been conceptualized in numerous papers, such as Isard (8), Daly (9), Duchin (10), Forsund (11), Ayres (12), de Oliveira (13), Breuil (14), Lave et al (15), and Cobas et al (16). These attempts generally embraced the direct and indirect effects of the economic process - the NARM Sustainability Model attempts to add the "missing link" by including the induced effects and allowing analysis at the county or project scale.

Datacells of economic matrices generally define the data in terms of dollars or other monetary value. Combination economic-ecological I-O models, like the NARM Sustainability Model, include both economic data (expressed in dollars) as well as natural resource or environmental data (expressed in tons, BTU's, and other units). The environmental data is constructed from large databases of the resource and energy use and pollutant emissions of each economic sectors. Most, though, not all of these databases are from U.S. sources, including the massive Toxic Release Inventory of the U.S. Environmental Protection Agency (200,000 reporting industry sites listed by economic sector and more than 1500 categories of emissions), energy use data collected by the U.S. Census of Manufactures, the World Bank's Industrial Pollution Projection System, and other databases. There are recognized limitations with each of these databases - not the least of which is that they surely do not accurately reflect resource use or emission levels for indirect and induced effects in other countries - but continued evolution and improvement of the databases are planned.

In the IMPLAN model, a study region can have matrices that are 528-by-528 in size (528 commodity groups and 528 industries or economic sectors). While there are survey methodologies for building the databases for these matrices, they would be laborious to construct to that level of resolution - fortunately, that data is already developed and available for these core matrices for the U.S. and for many other countries. With this model of the economy, the full range of inputs can be traced and the environmental impacts assessed - a level of analysis not presently possible in any other life cycle analysis method.

The NARM sustainability model is an evolving system based on years of experience with economic I/O analysis as well as environmental impact assessment. As such, it embraces the most advanced practical applications of both fields. The applications on a particular project can include:

- Improve marketing of sustainability projects by estimating the full (direct, indirect and induced) economic and jobs effects of the proposed projects. Many sustainability projects have not done as well as they could in promoting the full economic benefits that the projects 
would bring to a locality, because they generally report only the direct and, sometimes, indirect effects. In actuality, due to the multiplier effect, a sustainability project will add much more to the income stream and employment of an area, when the full effects are considered.

Identification of the economic flows into all of a region's sectors as a result of a project, providing the opportunity to address sustainability programs with those economic sectors that are affected.

- Determination of resource imports in a local area and identification of opportunities to increase the portion of resources derived from sustainable local production, possibly providing additional jobs and economic stimulus to the project area.

The Direct Requirements Table displays the expenditures required in each sector of the economy for every dollar of output for a particular industry. The table columns thus define an industry's expenditure pattern for a given study area. This table offers powerful advantages for studies of sustainable development. One of the primary uses is to project a sector's expenditures for any level of total output. For example if some factor were to increase demand for $\mathrm{x}$ product or material by $\$ 100,000$, the y sector would have to increase its purchases of $z$ product or service by an amount projected in the model. Further, the table defines the portion of the activity's inputs that are currently being met only by imports from outside the study area. Other input-output tables further define the commodities or services involved in this importation.

Identify local economic renewal opportunities. One of the often-cited goals of sustainability and regional economic development, as in recent community energy and economic development workbooks by the Rocky Mountain Institute (17), is to "plug the leaks", to reduce the export flow of dollars for nonrenewable energy, materials and services for which a region is not self-sufficient. The NARM Sustainability Model estimates, for the direct, indirect and induced effects, what portion of the inputs are currently purchased locally versus the portion that is imported; in other words, what portion of the local economic resources currently "leak" from the region and where those "leaks" occur. This information can then be used (outside of the model) by the community to identify opportunities to capture that money through improving resource efficiency (such as energy conservation measures) or expanding local businesses, making that money available to enhance local sustainability.

By showing the separate direct, indirect and induced effects, aid decisionmakers in finding the most profitable or cost-effective points on which to focus to achieve environmental goals (for example, if the goal is to achieve an X\% reduction in some parameter of water pollution, the model, by showing the water pollution effects from the direct, indirect and induced impacts of the proposal, can help identify the sectors and activities that could achieve the goal at the least cost).

As it evolves, the NARM Sustainability Model provides additional mechanisms to model 
sustainability aspects of architectural and engineering projects. The available input-output components of the system are already providing a wealth of information to improve environmental stewardship and sustainable development.

\section{Literature Cited}

1. K. Yeang, Designing with nature: the ecological basis for architectural design, McGraw-Hill, New York, 1995.

2. American Institute of Architects, "Sustainable development and public-sector architecture: results of a one-day workshop", AIA, Washington, D.C., 1993.

3. M. Italiano, "The U.S. Green Building Council's initiatives to improve the energy and environmental efficiency of the 'whole building environment" in Proceedings, U.S. Green Building Conference - 1994, NIST Spec. Publ. 863, U.S. Dept. Comm., Washington, D.C., 1994.

4. H. Tibbs, "Industrial ecology," Whole Earth Review 77, pp. 4-19, 1992.

5. R. Ayres, "Industrial metabolism: material flows in a modern manufacturing economy" in Proceedings, National Academy of Engineering Workshop on Industrial Ecology/Design For Environment, Woods Hole, MA., 1993.

6. G. Easterbrook, A moment on the earth. Viking, New York, 1995.

7. J. Clark, N. Payton and D. Tice, "Architecture, ethics and the environment, an exploration of nature and the human spirit" in Proceedings. U.S. Green Building Conference - 1994, NIST Spec. Publ. 863, U.S. Dept. Comm., Washington, D.C., 1994.

8. W. Isard, "Some notes on the linkage of the ecologic and economic system," Regional Science Association Papers, Vol. 22, pp. 85-96, 1968.

9. H. Daly, "On economics as life science," Lof Political Economics, Vol. 76, pp. 392-406, 1968.

10. F. Duchin, "Industrial input-output analysis: implications for industrial ecology," Proceedings of the Natl. Academy of Sciences, Vol 89, pp. 851-855, 1992.

11. F. R. Forsund, in Handbook of Natural Resource and Energy Economics, Elsevier: Amsterdam, 1985.

12. R. Ayres, "Industrial metabolism: theory and policy," in The Greening of Industrial Ecosystems, edited by B.R. Allenby and D.J. Richards, Washington: National Academy Press, 1994. 
13. L.F.S. de Oliveira et al, Risk Analysis, Vol. 7, No. 3, pp. 321-328, 1987.

14. J.M. Breuil, "Input-output analysis and pollutants emissions in France," Energy Journal, Energy Economics Educ. Found., Inc., Cleveland, OH., 1992.

15. L.B. Lave, E. Cobas-Flores, C. Hendrickson and F. McMichael, "Using input-output analysis to estimate economy-wide discharges," Env. Sci.\& Tech., Vol. 29, No. 9, pp. 420426, 1995.

16. E. Cobas, C. Hendrickson, L. Lave and F. McMichael, "Economic input/output analysis to aid life cycle assessment of ectronics products," IEEE Intl. Symposium on Electronic and the Environment Proceedings, Orlando, FL., pp. 273-278, 1995

17. M.J. Kinsley, Economic Renewal Guide, Rocky Mountain Institute, Snowmass, CO., 192 p., 1996. 



\section{VERTICAL INTEGRATION \\ - the key to creating optimum real estate environments - \\ Kevork M. Derderian \\ President \& CEO \\ Continental Offices Ltd. \\ MERITT Corporation}

\section{Executive Summary}

Cross-functional team design optimizes the integration of building systems and components. The result of this design process is a vertically integrated building - a building which achieves optimum energyefficiency, operating performance, and inhabitant comfort. Yet, buildings are rarely built using crossfunctional team design or vertical integration despite the enormous long-term costs that inefficient designs impose on building owners and occupants.

The reasons for this widespread market failure have to do with the traditional framework within which buildings are designed, financed, constructed, and operated. The traditional design process is typically linear and fragmented and encourages the application of obsolete rules of thumb rather than those of true engineering. As a result, this traditional process yields designs that are more expensive to build, more energy-reliant than necessary, and less comfortable for the inhabitants.

The ability to design, build, and operate properties that achieve maximum energy savings, facilitate optimum operating levels, and offer healthier, more responsive work environments is becoming increasingly important to remain competitive in the real estate market. Investments in education and incentives that encourage architects, designers, and engineers to 'team design' integrated solutions are critical to alter the traditional design process.

Even with a capable, well-organized design team, coordinating the interactive process required to achieve vertical integration is difficult. In 1994 the MERITT Alliance was initiated to develop a systems approach 
to cross-functional team design and the vertical integration process. A year-long study ensued. Industry leaders General Electric, Carrier Corporation, Herman Miller, and Rocky Mountain Institute collaborated with more than 20 other companies including service providers, manufacturers, project managers, energyefficient technology researchers, land planners, building operators, managers and owners. The result was "the MERITT approach"- a process to achieve vertically integrated, financially feasible real estate solutions resulting in the optimum work environment. 


\title{
VERTICAL INTEGRATION
}

The MERITT Approach to providing optimum real estate environments.

\author{
Kevork M. Derderian \\ President \& CEO \\ MERITT Corporation
}

\section{The MERITT Approach}

Vertical integration is the key to creating work environments that achieve exceptional energy efficiencies and aesthetic comfort. Designing work spaces for the end user-form following function-saves both human and produced energy and increases worker productivity and quality--both of which can dramatically affect the company and property's bottom line.

A vertically integrated approach in commercial office design is the pillar to creating a high-performance environment. The premise of the vertically integrated approach is that the whole is greater than the sum of its parts Vertical integration is the process by which a fully coordinated, multi-disciplinary, crossboundary design team effectively interweaves building components and systems into a durable, yet flexible, environment that ultimately results in optimum building performance, energy-efficiency, and worker comfort and productivity.

The MERITT Approach furthers the process by incorporating "green" design principles that dramatically affect the end users' work environments, as well as building and operating costs. This approach also directly affects real estate costs by improving space utilization 11 to 12 percent through better design. 
The MERITT Study began with each primary construction/building discipline represented. Industry leaders-MERITT Corporation, General Electric, Carrier Corporation, Herman Miller, and Rocky Mountain Institute- - brought the reach and resources to facilitate and support the process. Seven divisions of GE-Supply, Plastics, Motors, Electrical Distribution \& Controls, Capital, Lighting, and Human Resources - contributed their expertise. Carrier Corporation focused on heating, ventilation and air conditioning systems. Herman Miller provided emerging work trend research and intricate knowledge on designing form to function. Rocky Mountain Institute participated as the "energy conscience" to ensure that cross-cutting issues critical to the performance of the system were appropriately addressed. MERITT Corporation coordinated the process.

These primary partners collaborated with more than 20 companies to launch and participate in the MERITT Study. The study ensued with participants representing each primary building disciplinemechanical, electrical, elevator, structural, civil, and HVAC engineers; project managers; motors, glass, and lighting specialists; energy-efficient technology researchers; land planners; operations and maintenance personnel; and building managers and owners-working together to develop a financially feasible, systems approach to deliver the world's most energy-efficient commercial and office work environments.

Areas of concern included energy efficiency, resource conservation such as native landscaping and recyclable building materials, indoor air quality, lighting, building systems, operations and maintenance, furnishings, and worker productivity. Interactive forum/brainstorming session formats facilitated the process with the MERITT Study participants from each primary discipline working across boundaries to develop the MERITT Approach, a fully coordinated, vertically integrated systems strategy. In preparation for the official study launch, participants were given volumes of information on energy-efficient design, environmental principles, and associated processes, as well as the known resulting benefits of energy savings and increased worker productivity. 
These experts learned about the technological changes that had advanced energy-efficient products into mainstream commodities. They began analyzing, evaluating, and incorporating these technologies into their systems and began to discern the effects of their actions and decisions on other systems and components. Participants were encouraged to engage in boundaryless behavior-to step outside their areas of expertise, to ask questions, and to probe for answers. The goals of the study were defined:

1) develop a systems approach to effectively deliver an environmentally principled real estate solution;

2) determine the financial feasibility of such a solution; and,

3) maximize energy-efficiencies by incorporating state-of-the-shelf technologies.

Underlying these study goals was the vision of creating a unified Alliance comprised of diverse disciplines capable of crossing boundaries and letting go of traditional thinking to create a systems approach to deliver the optimum work environment.

\section{Interdependence of Elements}

The process of vertical integration—effectively weaving interrelated elements and building componentsrequires effective cross-disciplinary interaction. To describe the relativity of some of the primary system components, we begin with one of the greatest influences on energy savings and productivity_lighting.

Lighting, one of the most significant components affecting worker productivity and comfort, consumes about 40 percent of the electricity used in commercial office buildings. Natural daylight is the most desirable and economical form of lighting. The type of windows selected can greatly affect the quantity and quality of light that permeates the office space, as well as the amount of supplemental lighting needed. Other, often overlooked features that impact office lighting are furniture, finishes, colors, and reflective surfaces. These affect:

a) the influx of natural light,

b) the effectiveness of the natural light, and 
c) the amount and type of supplemental lighting; i.e., task, overhead, pendant lighting, that will be used to optimize the benefits of a) and b).

With 40 percent of commercial building energy typically consumed by lighting and another 10 percent or more used to cool the heat generated from lighting, complementing natural light with an energy-efficient lighting system offers significant savings opportunities. Energy-efficient lights use less than 50 percent of the energy that typical commercial office lights use. Incorporating reflectors into the light fixtures can reduce the actual number of lamps required by half, further reducing the amount of energy consumed. Energy-efficient lamps and ballasts also last longer and generate less heat. The results of enhancing natural light with energy-efficient lighting are significant energy savings and reduced HVAC requirements.

Under the MERITT concept, the windows selected to maximize the influx of natural daylight are also evaluated for their affects on the HVAC system. Poorly insulated windows are responsible for about 25 percent of all heating and cooling requirements. High-efficiency windows let in visible light, but block infrared radiation (heat) eliminating excessive heat gain and better protect against heat loss. Knowing the interdependence of these components and their affect on the HVAC system allows the system to be "rightsized" based on the lighting heat load, estimated equipment heat load, and the integrity of the windows, and offers an opportunity for significant capital savings as well as long-term energy savings.

A right-sized HVAC system often means smaller duct work which can increase ceiling heights and provide the option of increased windowline. An efficient HVAC system also allows for pumps, fans, and motors to be right-sized so they can run at peak efficiency levels. HVAC system heat pumps, motors, and drives are significant draws on the base building electrical load. The annual cost of electricity for a typical motor is three to four times greater than its capital cost. High-efficiency motors with adjustable speed drives can save about 25 percent of motor energy. Efficient motors also reduce heat load which, in turn, affects the 
HVAC system capacity requirements. A well-designed system not only provides greater energy-efficiency, but allows more precise control of temperature and ventilation, as well as providing a quieter indoor environment.

In addition, a building automation control system (BACS) can reduce costs even more by taking advantage of a building's tendency to store heat and change temperature slowly. For example, in the summer the air conditioning can automatically be shut down in the late afternoon hours allowing the temperature to rise slowly, but not to a level that exceeds the comfort range until well after the building is no longer occupied. The building can also be precooled, taking advantage of lower electrical rates and cooler night air which reduces air conditioning use during the day when rates are at their peak. Preventive maintenance of the systems can also save considerable money and discomfort-avoiding any emergency repairs or downtime during critical business hours.

Typical electrical systems are configured to plate loads specified by equipment manufacturers rather than to the actual loads the equipment requires to run. This approach oversizes the electrical system and the resulting plug loads. Appropriately sizing the electrical system of the building, as well as the plug loads, creates significant savings in initial capital expenditures for both the electrical and HVAC systems.

Weighing the affects of these interrelated components-lighting, windows, furniture, BACS, and HVAC systems - one to the other and to the interactive system as a whole is indicative of the balance and effectiveness wrought by the vertical integration process.

\section{MERITT Study Results}

The synergism of interactive design and the elegant solutions that result are apparent in the daily movement of a building, its systems, and its inhabitants. A good analogy to the process of vertical integration is the weaving of fabric. Properly woven, the fabric has great strength and durability, yet is flexible to adapt and 
change. Planning for flexibility is a better, far more economical option than oversizing equipment and incurring increased operating costs for the long-term.

The results of the MERITT Study conclusively proved that the vertical integration process delivers an economical solution in both retrofit and design-build case studies. Applying the vertical integration process resulted in a more comprehensive retrofit and $\mathbf{8 1}$ percent greater energy savings than conventional methods. Similarly, applying this approach to new construction resulted in significant reduced energy costs-\$ .62 per square foot-with less than a $\$ 1$ variance in initial construction costs. 


\section{Retrofit Case Study}

\section{Cost Comparison \\ MERITT vs. Conventional}

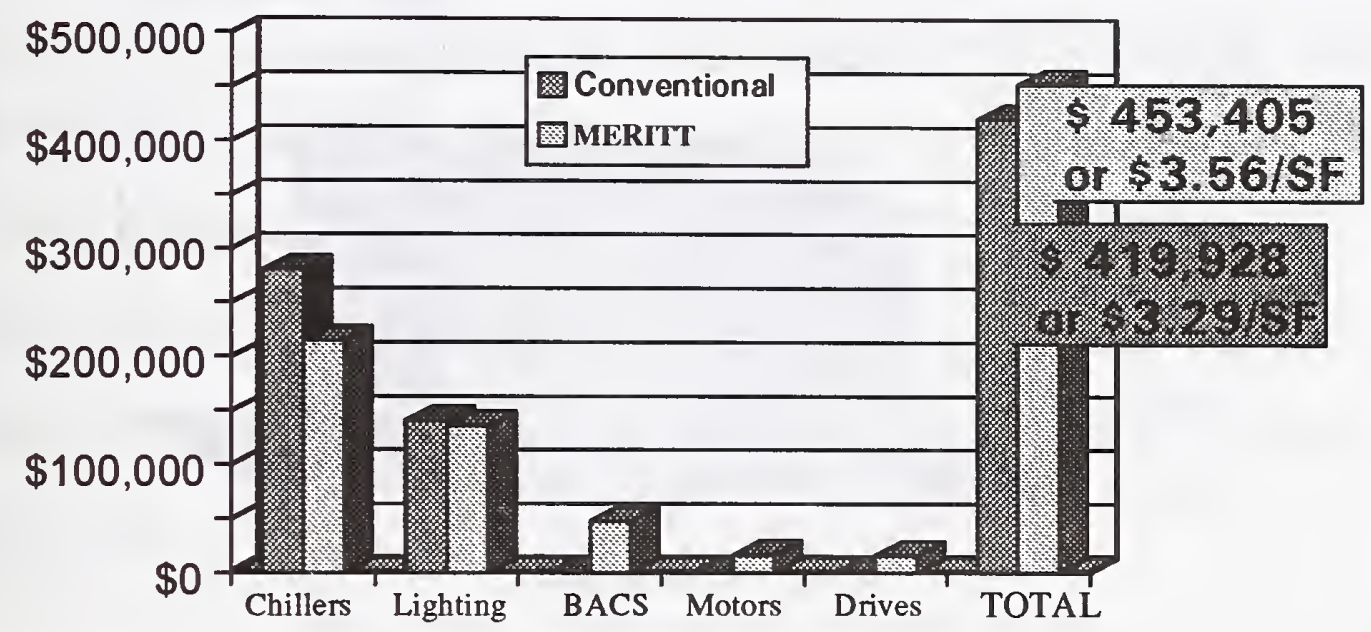

\section{Cost-to-Savings Comparison MERITT vs. Conventional}

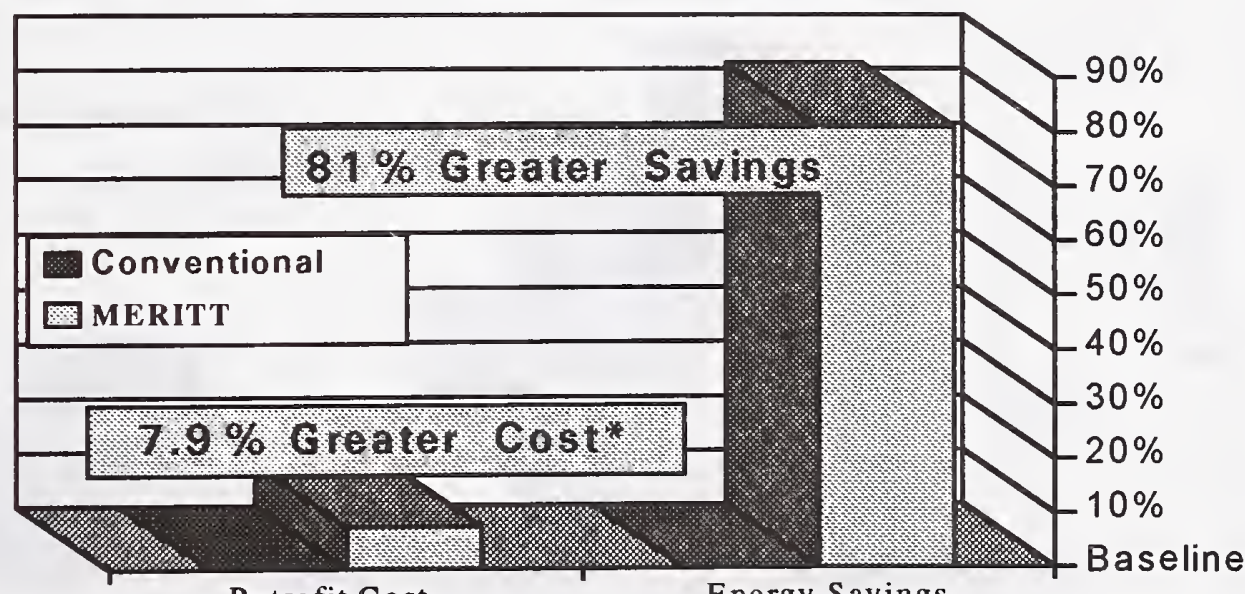

Retrofit Cost Energy Savings

* MERITT additional components : BACS, Drives \& Motors 


\section{New Construction Case Study}
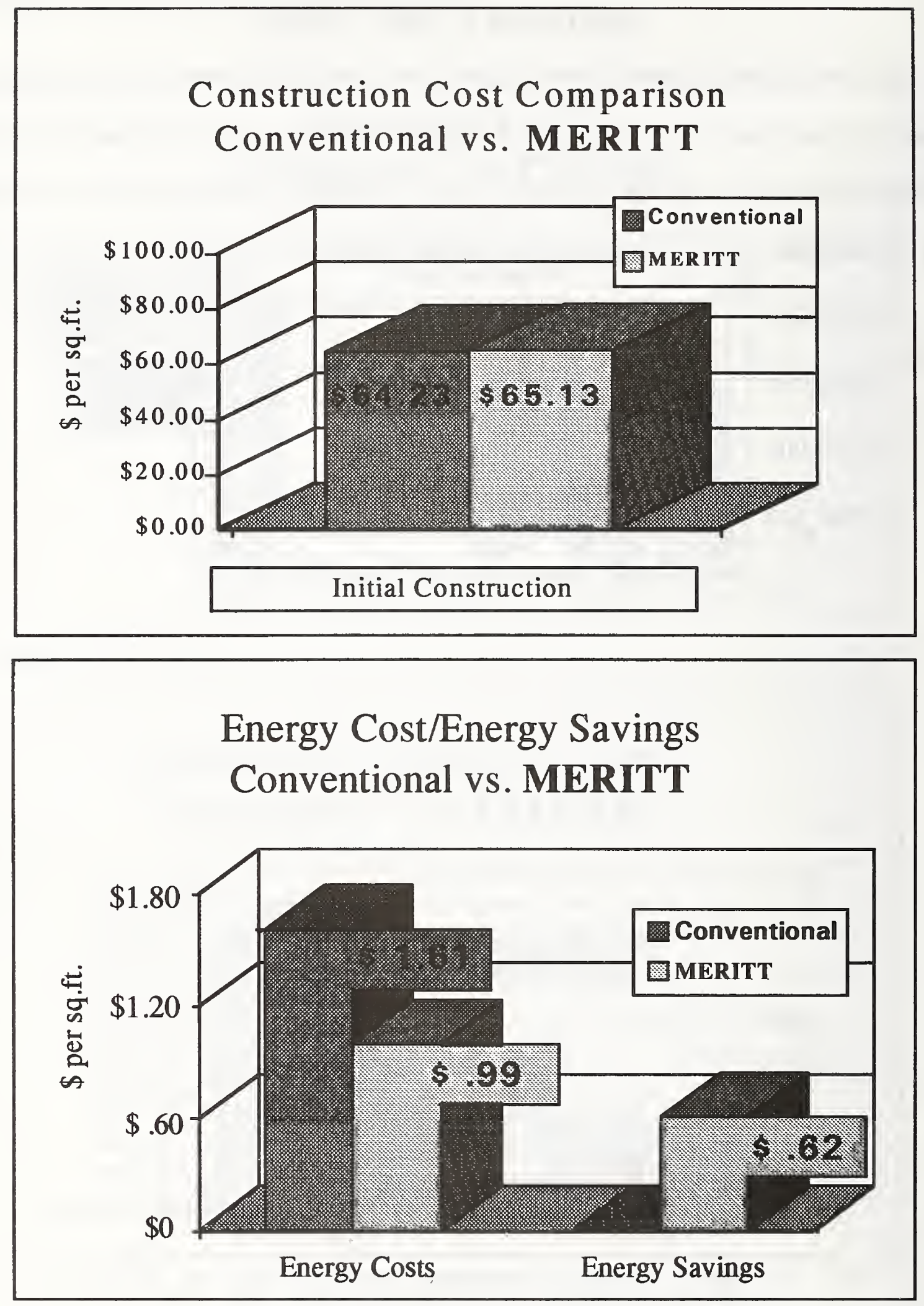


\section{Conclusion}

There are a seemingly infinite number of ways to increase energy-efficiency and incorporate environmental principles to economically and ergonomically benefit commercial/office real estate. A well-integrated and interdisciplinary effort by a design team - vertical integration-is often the key to producing buildings that achieve exceptional energy efficiency and aesthetic comfort. In most cases, even with a well-ordered design team, it is difficult to find anyone coordinating the entire interactive system. The MERITT Alliance, a collaborative effort of industry leaders-MERITT Corporation, General Electric, Herman Miller, Carrier Corporation, and Rocky Mountain Institute/Green Development-provides such services.

The MERITT Alliance coordinates and provides a systematic approach to vertically integrated real estate solutions to maximize the benefits unique to this process - a process that evolves as knowledge and technologies advance. The benefits of the MERITT Approach include: 
- high-performance work environments,

- reduced operating and construction costs,

- healthier work environments,

—improved air quality

- better lighting

- increased productivity,

- reduced maintenance costs,

- increased equipment life span, and

- improved end-user/employee morale.

The MERITT Alliance provides team assembly, project management, process mapping, timeline coordination and management, assembly \& dissemination of operating handbook, and environmental consulting services. In addition, MERITT provides handbooks on equipment and recommended preventive maintenance procedures to optimize the efficiency of the equipment, the life span of the equipment, and to facilitate the productivity of the maintenance staff. Operating manuals for end users are also available to better educate them on more effectively maintaining the comfort of their work environments.

Kevork M. Derderian initiated the MERITT Signature Alliance in an effort to provide turnkey development and retrofit services based on environmentally sound practices to corporations seeking the optimum work environment. Mr. Derderian's 20 years experience in commercial real estate provides a sound basis for implementing such a program. For more than nine years as President and Chief Operating Officer, Mr. Derderian has overseen the business operations including property management, leasing, construction and general contracting, architectural services, and corporate activities of Continental Offices Ltd. In addition to his active involvement in educating commercial real estate executives of the environmental and financial benefits of vertically integrated design and process, Mr. Derderian serves as Chairman of the Municipal and Real Estate Tax Committee and also on the Executive Committee for the Chicago Civic Federation. Mr. Derderian can be reached at 312.663.7242. 


\title{
THE SCIENCE \& ART OF "DAYLIGHTING" BRINGING NATURE'S LIGHT INSIDE
}

\author{
Philippe C. Dordai \\ The Hillier Group
}

ABSTRACT. Daylighting refers to efforts to harness natural light, primarily to increase a building's energy efficiency, but aiso to bring light inside. In the past, architects have had a fairly narrow range of traditional choices in solving the problem of daylighting. Relatively high maintenance solutions have been utilized in Europe, resulting in long, thin (and expensive) buildings. Efforts to control daylighting and increase energy efficiency in this country have focused on providing various types of reflective coatings on glass.

Recent developments in daylighting techniques can be classified as either "passive", which rely upon a particular, fixed configuration of building elements or "active", which involve devices which track and react to the position of the sun. In general, passive solutions, even when costeffective, are less precise. Meanwhile, new technologies such as photo sensitive coatings and micro-laminated coatings on glass promise modified active systems without the costs associated with the moving parts of the present systems. Ultimately, the ideal solution is one which is fully integrated and uses daylighting to supplement artificial light in a dynamic and energy efficient way.

As the advantages of using natural light become more apparent - not only as measured by increased energy efficiency but in terms of improved morale and productivity - daylighting will become a more integral part of building design. At the same time techniques to provide such solutions will become increasingly sophisticated and precise.

\section{Background}

The problem of how to bring daylight into buildings is not new. In the past, architects have had a fairly narrow range of traditional choices in solving this problem, relying on light shelves, skylights, louvers and clerestory glass, etc. (FIGURE 1-2) to selectively admit natural light. The solutions have usually relied upon some manipulation of the depth of the building's exterior wall and have commonly been viewed by owners as high maintenance solutions because of the time required to keep them adjusted and clean.

In Europe, where energy costs are high, daylight control devices have always been a part of exterior wall systems. Deep-set windows, exterior blinds and light shelves are higher maintenance solutions, especially items like blinds, which are either manually adjustable or motorized from the inside of the building (FIGURE 3). European architects have also
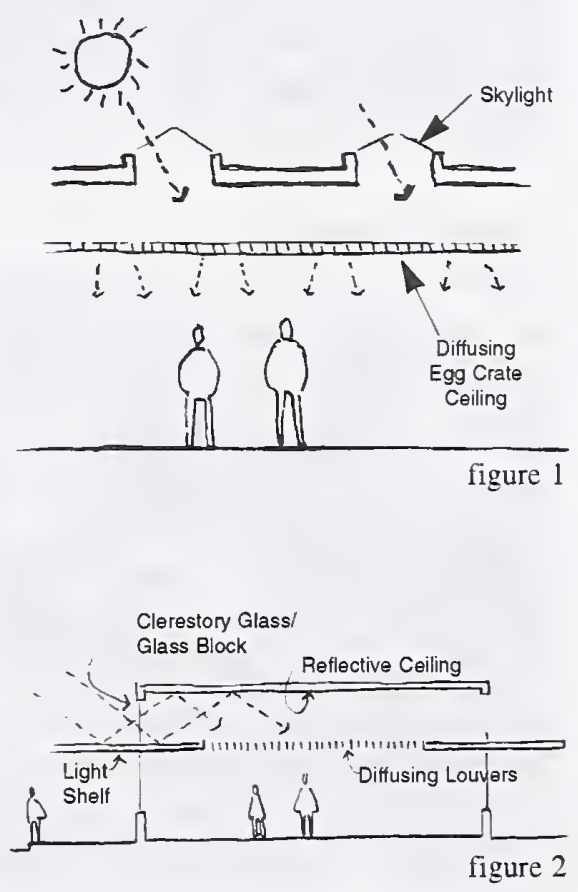
"solved" the daylighting problem by designing longer and thinner (and relatively more expensive) buildings to insure that daylight is available to all. These buildings are more expensive to build because their long thin shape (FIGURE 4A) requires more exterior wall square footage to enclose the same volume of space than in a more conventional rectangular or square building (FIGURE 4B).

In the United States, the control of daylighting and the exterior walls energy performance has focused on either providing various types of reflective coatings on glass to control different parts of the solar spectrum or on adding insulation to the existing envelope to reduce thermal transmission. Early coating methods were rather crude and operated by reflecting most of the light off the mirror glass facade (FIGURE 5). This allowed for much less daylight and produced a sense that one was looking out of the building through dark sunglasses. Subsequent combinations of tinted glass and special coatings have resulted in more sophisticated glass which rejects the infrared band of the spectrum (heat) and permits the visible portion to pass through the glass. These types of low-E glass coatings also work to admit heat into the building during the winter months and reject heat during the summer months.

\section{Recent Developments in Daylighting Techniques}

In general, the recent daylighting solutions we are discussing can be categorized into two groups; "passive" solutions, which rely upon a particular, fixed configuration of building elements to redirect the sun, and "active" solutions, which consist of moving parts which react dynamically to the position of the sun to optimize the daylighting in the building.

\section{Passive Solutions}

A series of recent technological advances has further increased our ability to control the sunlight coming into the building through the use of insulated glass. Almost all commercial glazing (and the majority of new residential glazing) makes use of insulated glass, which consists of two pieces of glass with an airspace in between (FIGURE 6). Using this approach, louvers, prisms and light transmitting fibers are placed inside this airspace with the goal of taking sunlight and the brightness of the sky, and diffusing it or redirecting it upwards to the ceiling surfaces of the building (FIGURES 7 $\& 8)$. Such passive solutions have the advantage of integrating all of the light redirecting surfaces within a protected airspace where maintenance can be virtually eliminated. The
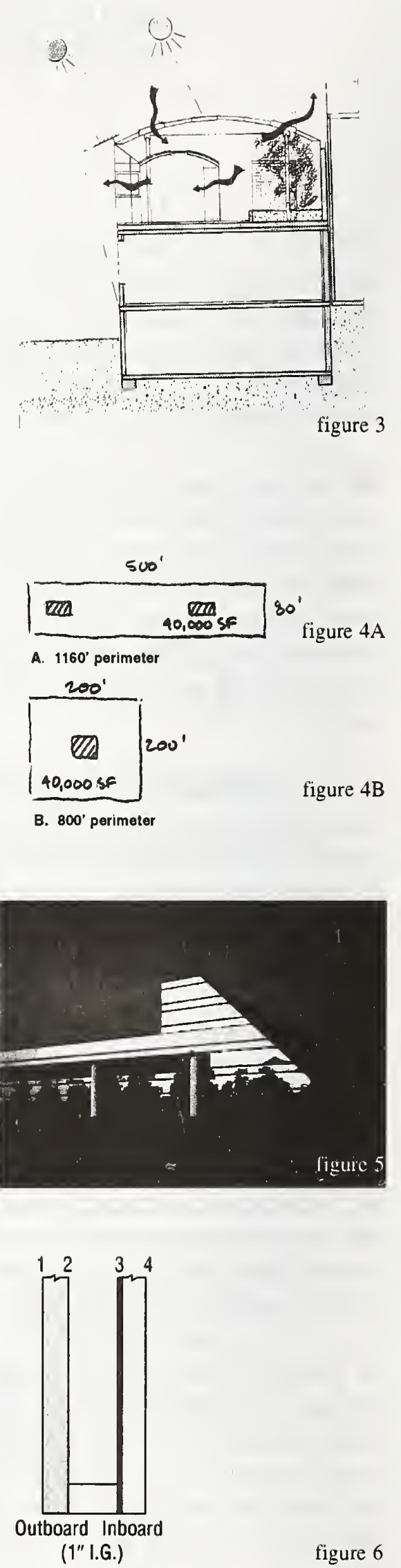
prism or louver must be set at a certain angle which will be determined by the siting of the building and the direction which the glazing faces. Many of these solutions can be adjusted and optimized for their particular orientation for different parts of the world and even for different faces of the building.

While these means of redirecting and controlling daylight are effective and low maintenance, the fact remains that a static solution to a dynamic source (the sun) is not the most optimal solution because any solution involving a static component must work to a hypothetical median condition which cannot take full advantage of the changing position of the sun.

Passive solutions which redirect sunlight within a building, while requiring little or no maintenance, promise to provide substantial energy savings over previous traditional solutions; however, these solutions only provide a part of the overall daylighting solution for a particular project.

\section{Active Solutions}

The challenge of harnessing the sun is one that has fascinated people for centuries. An ideal solution is a device which allows for constant adjustment to the position of the sun as it changes through the day and the seasons. Today such a precise response would require motors, moving parts and a relatively high degree of maintenance. The most elaborate of these devices (heliostats) track the sun continuously using a computer program (FIGURE 9). Such solutions, although extremely precise and efficient, are expensive, and often require a great deal of attention and maintenance. Their payback in terms of life cycle cost is relatively long. However, new technologies, such as photo-sensitive coatings (similar to what is used on sunglasses) and micro-laminated coatings on glass promise modified and more cost-effective active systems.

\section{Daylighting Applications: Case Study}

Any successful daylighting project will be the result of an intensive collaboration between the client, the architect (who will integrate the various components
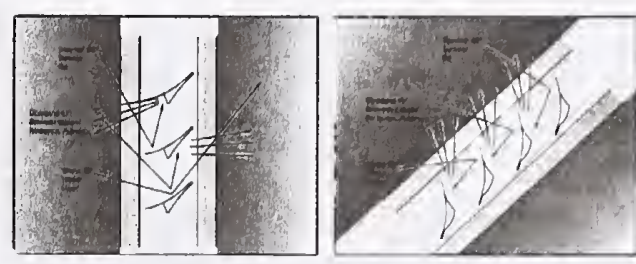

figure 7
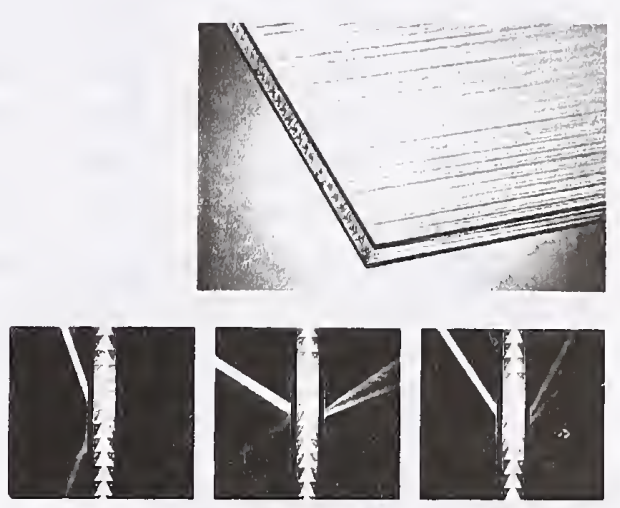

figure 8

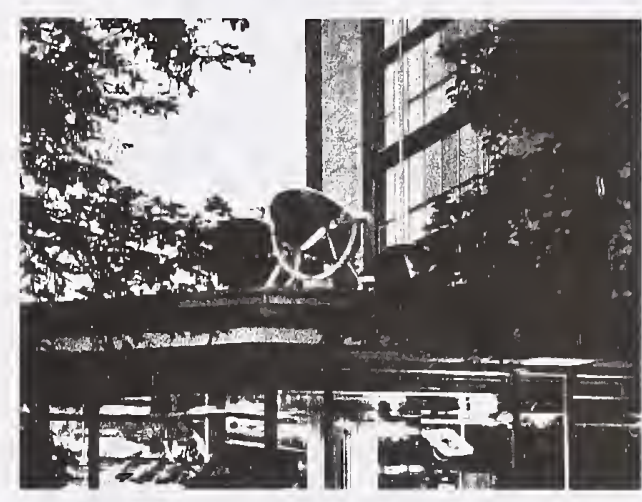

figure 9

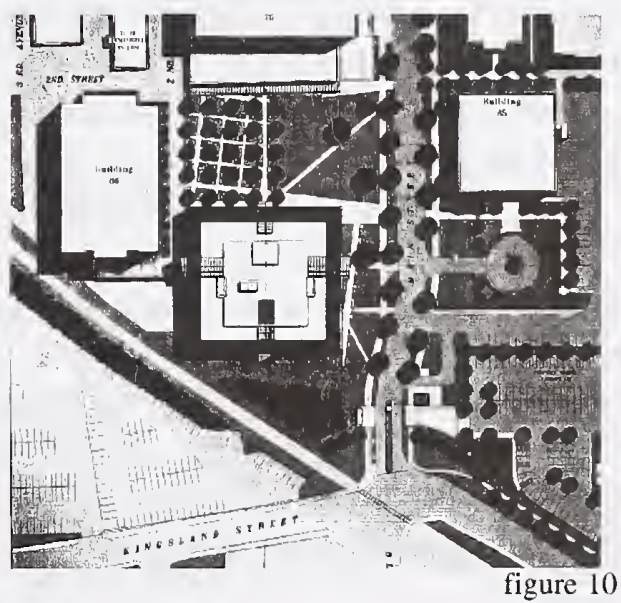


of the solution), the daylighting, lighting, and electrical engineering consultants (who will refine and test the various components of the system), and the manufacturers (who will actually provide the various products which make up the system). Like most architectural systems, daylighting requires a high degree of coordination between different disciplines to realize the energy paybacks potential in the design. This also means that the design of the interior and the exterior of a building must work in concert. Too often, because the work of the architect has been divided between the inside and the outside of the building, the interior concept (lighting, furniture configuration and placement, partitions, colors and finishes) does not recognize and reinforce the daylighting concept, which is part of the exterior building design.

\section{Hoffmann LaRoche}

The challenge at Hoffmann LaRoche's New Building One was defined by the dimensions of the building floor plans required. Given a building of 185 feet by 185 feet (FIGURE 10), how could the structure be designed to maximize available daylight?

The first step was to plan the building with a central core and maximize the available perimeter for daylighting. The core was offset within the square plan to reduce the building depth at the north side where daylight penetrates the least and to accommodate the design of a skylit atrium stair to the south of the core (FIGURE 11) at the location where the plannable space is furthest from the exterior wall.

The next step was to undertake studies, using a computer modeling program, to provide a visual image that allowed the designer to see where the sun would be at various times of the day and year. These "snapshots" (FIGURE 12A \& 12B) of the building's components were taken from the point of the view of the sun and were referenced constantly throughout the design of the daylighting system. These pictures were supplemented with a site analysis that modeled adjacent buildings (FIGURE 13) so that the shading and reflecting effect of adjacent structures on the new building could be evaluated.



figure 11
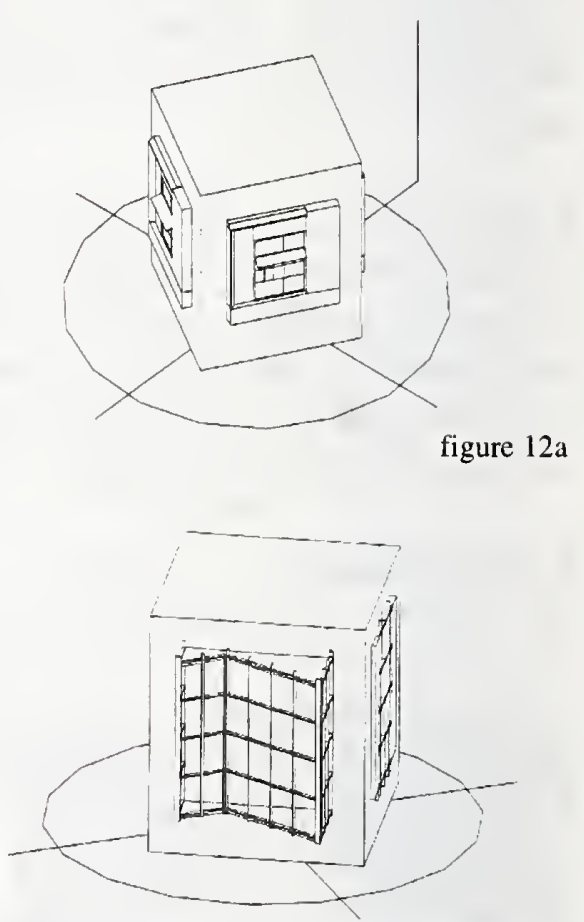

figure $12 b$

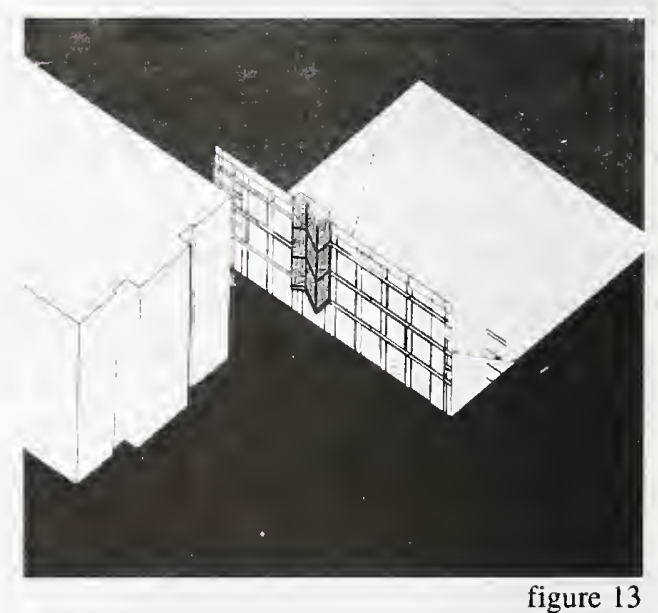

figure 13 
Our initial design concept had proposed two basic approaches to daylighting. The first utilized exterior and interior light shelves (FIGURE 14) to redirect sunlight onto the ceiling; the second utilized large two-story "work studios" (FIGURE 15) which because of their tall glass openings would admit daylight deep into the center of the building (FIGURE 16). These interior spaces were conceived of as functioning like a traditional lightwell - which would normally be enclosed by exterior wall construction. This concept demonstrated the advantages of utilizing interior construction for the boundary wall of the lightwell, a relatively economical alternative to the original exterior lightwell. The ultimate design evolved into a multi-component system in which each part plays a significant role in the overall scheme. The components of the system are as follows:

- A 9'-6" interior ceiling height within a 13'-0" floor-to-floor height to permit the design of an indirect lighting system and maximize the depth of the daylight penetration.

- A ceiling surface and adjacent wall finishes designed to optimize brightness and reduce glare and contrast.

- A series of twelve, two-story high work studios designed as team work rooms and as overall sources of daylight for the adjacent office areas. These rooms are equipped with interior light reflectors and computer-controlled roller shades to again redirect sunlight and skydome light onto the ceiling of these two-story spaces.

- A largely open interior plan with no perimeter offices to maximize the penetration of daylight into the building.

- A well-designed artificial uplighting system which can be dimmed and can handle input from a daylight sensor.

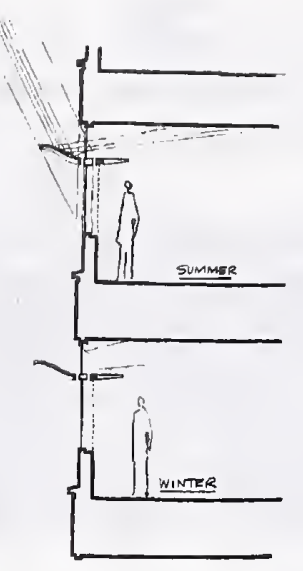

figure 14
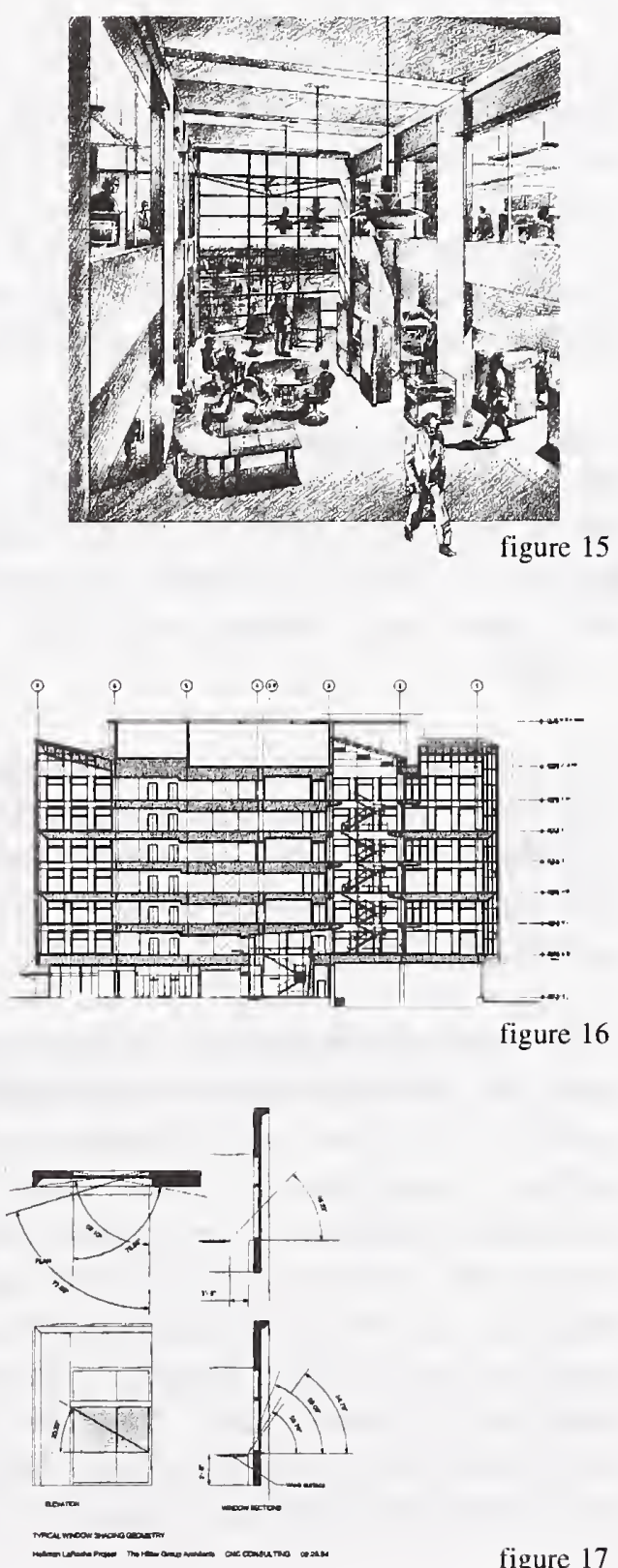

figure 17 
- An exterior wall system which takes advantage of setbacks and projections to shade the vision glass wherever possible (FIGURE 17).

- A light reflector/sunshade which acts to redirect more daylight into the transom glass and hence up onto the ceiling (FIGURE 18).

- A sophisticated transom glass which uses acrylic prisms precisely angled to redirect sunlight and skydome light up onto the ceiling of the space (FIGURE 19).

As each component was developed and fine-tuned, computer analysis played an essential role in providing the engineering back-up to what were originally schematic concepts (FIGURE 20). These tools were also used to keep the client informed about the daylighting solutions and gave the design ideas a quantifiable foundation upon which they could be evaluated.

None of the components alone could have done the job. Together they provide an integrated system in which each piece provides a part of the daylighting design, one which permits the occupants to turn off their lights, save energy, and enjoy higher quality lighting.

And so a fully integrated solution developed out of our analysis of the problem at Hoffman LaRoche (FIGURE 21). It involves a complete system which uses daylighting to supplement artificial light in a dynamic and energy efficient way.

The design, predicated on a compromise between a static solution and a dynamic source (the sun), has an analogy in another, more conventional architectural problem, namely that of rain drainage. Think of how well most pitched roof and gutter systems work to drain roofs. Add a rain barrel at the end of the downspout and you have a relatively good model in terms of a passive system which handles an active and variable source acting upon it (rain). To work properly, all the components must be designed together and be in balance. The pitch of the roofs must be steep enough to

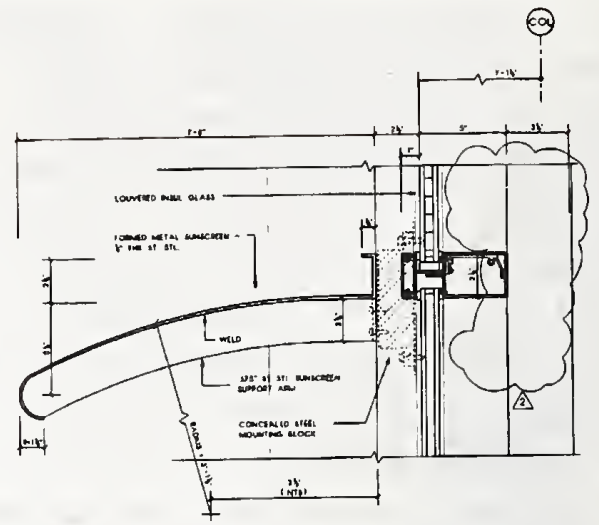

figure 18

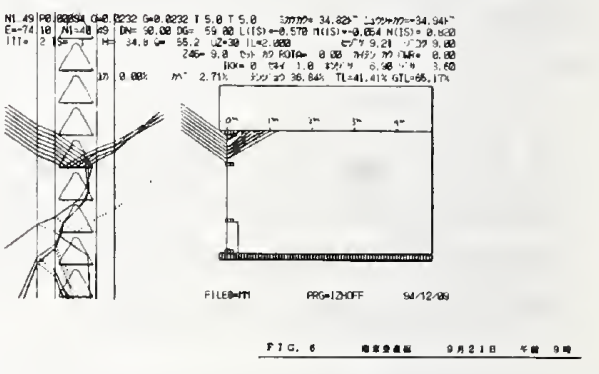

figure 19

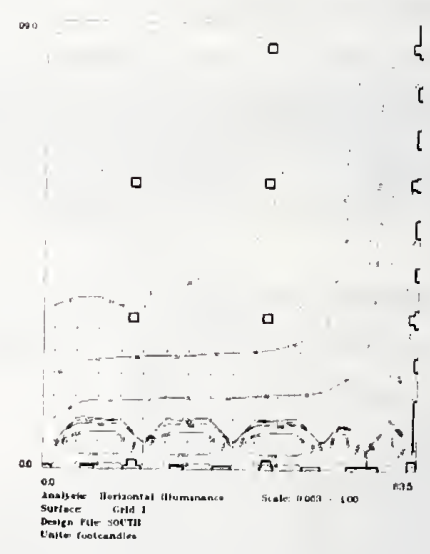

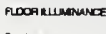


get good drainage but not too steep as to cause the rain to pick up such speed that it overspills the gutter at the eaves. The gutters must be sized to handle a downpour but not so big that they pick up debris and constantly need cleaning out. At the end, the collector must be sized to provide the right size reservoir. Like the rain collection system, the sun collection system must be conceived of as a closed loop, from its source to its end point.

Daylighting has become increasingly important in buildings, in part because it is recognized as relating to the improved morale and productivity of a building's occupants. In Europe, building codes in some countries have required that all office workers in buildings have access to some daylight. While increased productivity is more difficult to measure among white-collar workers, planning specialists are incorporating surveys into their research to attempt to quantify those productivity gains. Coupled with more measurable cost-saving effects of bringing natural light into a building, daylighting should become a more integral part of building design, and techniques to provide such solutions will become increasingly sophisticated and precise.

The author would like to acknowledge the contributions of the manufacturers who participated in the design of Hoffmann-La Roche project, OkaSolar and Figla. Special thanks to Mike Moribayshi and his team of technical experts at Figla for their exhaustive analysis and support in the refinements made to the louvered glass. David Norris of Carpenter Norris Consulting was the daylighting consultant on the Hoffmann-La Roche project and contributed some of the analysis drawings in the article. Finally Don Raney and all of the participants from Hoffmann-La Roche contributed the vision and patience required to implement such innovative solutions to daylighting.

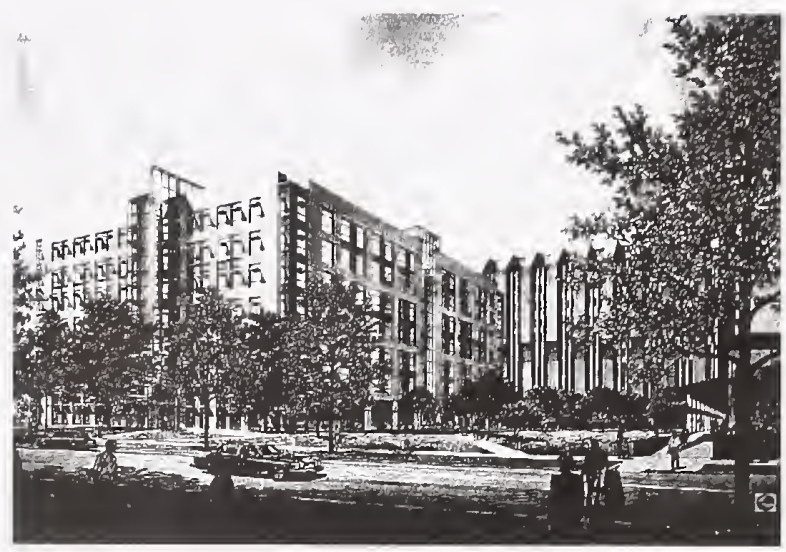

figure 21 



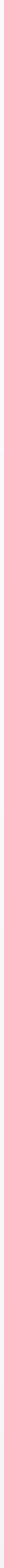





\section{NTSTTechnical Publications}

\section{Periodical}

Journal of Research of the National Institute of Standards and Technology-Reports NIST research and development in those disciplines of the physical and engineering sciences in which the Institute is active. These include physics, chemistry, engineering, mathematics, and computer sciences. Papers cover a broad range of subjects, with major emphasis on measurement methodology and the basic technology underlying standardization. Also included from time to time are survey articles on topics closely related to the Institute's technical and scientific programs. Issued six times a year.

\section{Nonperiodicals}

Monographs-Major contributions to the technical literature on various subjects related to the Institute's scientific and technical activities.

Handbooks - Recommended codes of engineering and industrial practice (including safety codes) developed in cooperation with interested industries, professional organizations, and regulatory bodies.

Special Publications - Include proceedings of conferences sponsored by NIST, NIST annual reports, and other special publications appropriate to this grouping such as wall charts, pocket cards, and bibliographies.

National Standard Reference Data Series-Provides quantitative data on the physical and chemical properties of materials, compiled from the world's literature and critically evaluated. Developed under a worldwide program coordinated by NIST under the authority of the National Standard Data Act (Public Law 90-396). NOTE: The Journal of Physical and Chemical Reference Data (JPCRD) is published bimonthly for NIST by the American Chemical Society (ACS) and the American Institute of Physics (AIP). Subscriptions, reprints, and supplements are available from ACS, 1155 Sixteenth St., NW, Washington, DC 20056.

Building Science Series-Disseminates technical information developed at the Institute on building materials, components, systems, and whole structures. The series presents research results, test methods, and performance criteria related to the structural and environmental functions and the durability and safety characteristics of building elements and systems.

Technical Notes-Studies or reports which are complete in themselves but restrictive in their treatment of a subject. Analogous to monographs but not so comprehensive in scope or definitive in treatment of the subject area. Often serve as a vehicle for final reports of work performed at NIST under the sponsorship of other government agencies.

Voluntary Product Standards-Developed under procedures published by the Department of Commerce in Part 10, Title 15, of the Code of Federal Regulations. The standards establish nationally recognized requirements for products, and provide all concerned interests with a basis for common understanding of the characteristics of the products. NIST administers this program in support of the efforts of private-sector standardizing organizations.

Order the following NIST publications-FIPS and NISTIRs-from the National Technical Information Service, Springfield, VA 22161.

Federal Information Processing Standards Publications (FIPS PUB)-Publications in this series collectively constitute the Federal Information Processing Standards Register. The Register serves as the official source of information in the Federal Government regarding standards issued by NIST pursuant to the Federal Property and Administrative Services Act of 1949 as amended, Public Law 89-306 (79 Stat. 1127), and as implemented by Executive Order 11717 (38 FR 12315, dated May 11, 1973) and Part 6 of Title 15 CFR (Code of Federal Regulations).

NIST Interagency Reports (NISTIR)-A special series of interim or final reports on work performed by NIST for outside sponsors (both government and nongovernment). In general, initial distribution is handled by the sponsor; public distribution is by the National Technical Information Service, Springfield, VA 22161, in paper copy or microfiche form. 


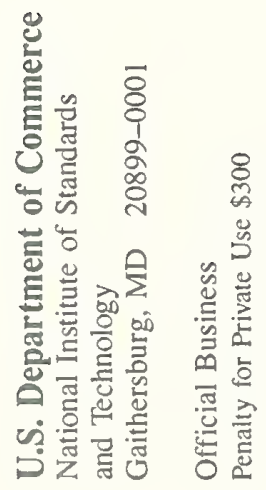

